open 2 access

\title{
collogyium:
newphilologies
}

Special Issue

,Heimat': eine Begriffsanalyse

Edited by Maja Soboleva

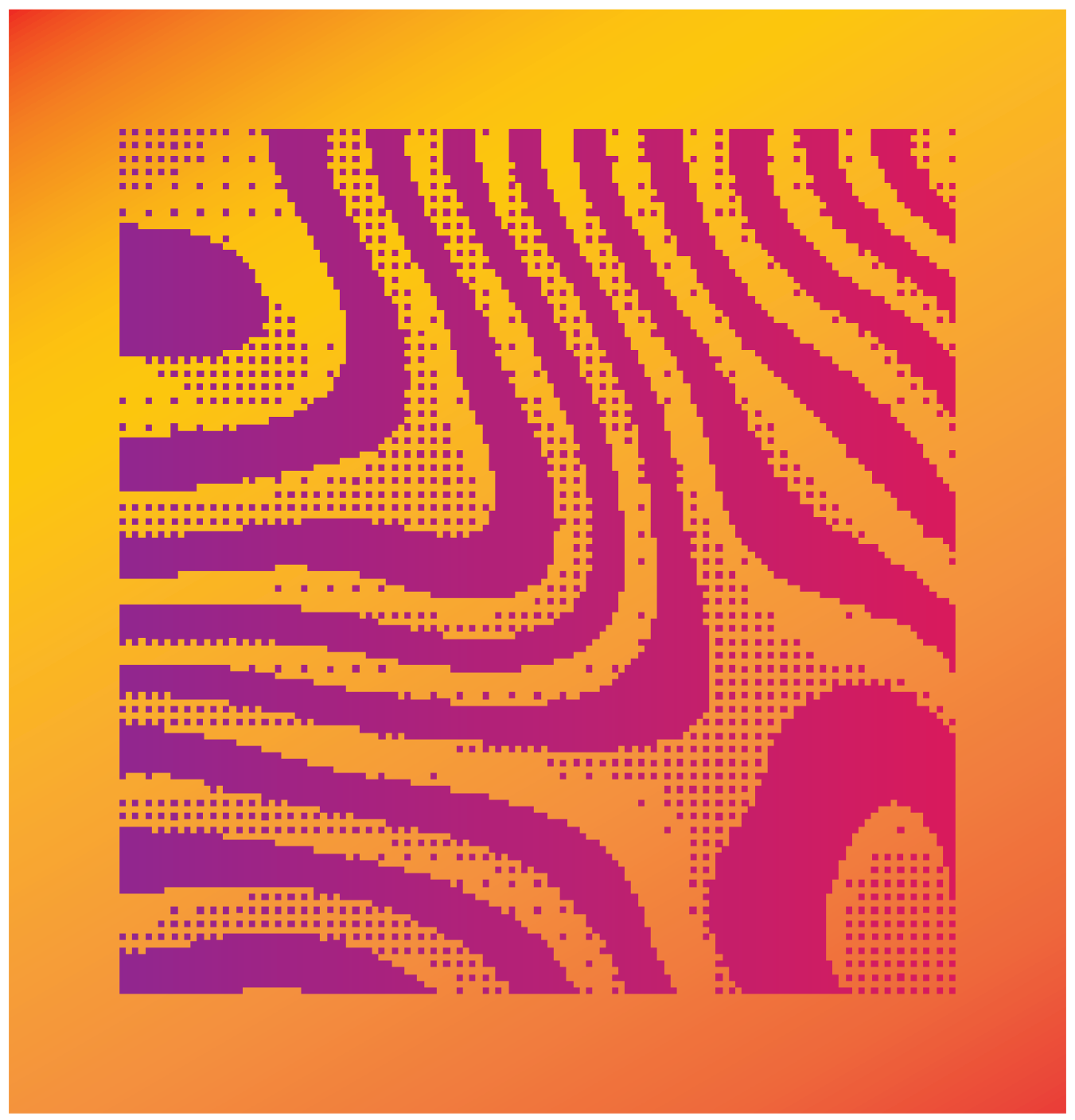


This issue was made possible by financial support from the Faculty of Humanities of the University of Klagenfurt.

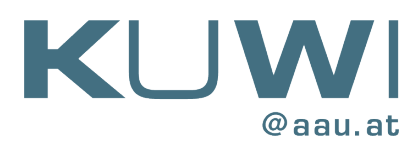

Colloquium: New Philologies is edited by the Alpen-Adria-Universität Klagenfurt.

Chief Editor: Nikola Dobrić

Co-Chief Editor: Cristina Beretta

Section Editors: Cristina Beretta, Marta Degani, Nikola Dobrić, Angela Fabris,

Paul Keckeis, René Reinhold Schallegger, Jürgen Struger, Peter Svetina, Giorgio Ziffer

Technical Editor: Thomas Hainscho

Language Support: Vanessa Erat

World Wide Web

Visit Colloquium online at http://colloquium.aau.at

\section{Legal Information}

Colloquium is an open access, peer-reviewed Academic Journal. It is licensed under a Creative Commons Attribution 4.0 International License (CC BY 4.0).

Colloquium Logo by Gerhard Pilgram; Open Access Logo by Public Library of Science from Wikimedia Commons (CC BY-SA 3.0); Title page image adapted by Thomas Hainscho from "Retroactive" by Roni Kaufman from openprocessing.org (CC BY-SA 3.0).

2021 by Alpen-Adria-Universität Klagenfurt

DOI: $10.23963 / \mathrm{cnp} .2021 .6 .1$

ISSN 2520-3355 


\section{Table of Contents}

Colloquium: New Philologies • Vol 6, No 1 (2021)

Special Issue: ,Heimat‘: eine Begriffsanalyse · Edited by Maja Soboleva

\section{Editorial}

,Heimat': eine Begriffsanalyse

Maja Soboleva

\section{Contributions}

„Worin noch niemand war" - Heimat als Erinnerung und Konstrukt

EMIL ANGEHRN

„Daheim [...] war vielleicht noch Österreich“. Zur Inszenierung und

Demontage des Heimat-Mythos in Joseph Roths Roman Radetzkymarsch 16

Barbara Neymeyr

Von Lübeck zu Kaisersaschern. Die Wandlung in Thomas Manns

Vorstellung von seiner geistigen Heimat

LiIsA STEInby

Fritz Mauthners Heimatbegriff: Zwischen Deutschnationalismus,

jüdischem Selbsthass und Sprachkritik

Thomas Hainscho

Das Wesen der Heimat nach Kurt Stavenhagen

ANDRZEJ GniazDowsKi

Der Mythos ,Heimat' in der politischen Philosophie Iwan Iljins 
Heideggers unheimliche Heimat. Bemerkungen zum Zusammengehören von Denken und Sein

Martin G. Weiss

Topologie der Heimat zwischen Imaginärem, Mythos und begrifflicher Sprache. Paratopos, Utopie-Dystopie-Heterotopie und Transtopisches

Alice Pechriggl

Heimat und Sprache. Überlegungen im Anschluss an Georg Misch

NaEmi Bremecker

At Home, at Mine (chez moi). Return to Oneself

Petar Bojanić 


\title{
,Heimat': eine Begriffsanalyse
}

\author{
Maja Soboleva \\ University of Klagenfurt (Austria)
}

\begin{abstract}
,Heimat' ist ein polyvalentes Wort, das man im öffentlichen Raum in letzter Zeit immer öfter hören kann. Es taucht in verschiedenen Kontexten auf: Landeskunde, Werbung in Zusammenhang mit der Herstellung von idyllischen Stimmungsillusionen, Sozialpolitik, Flüchtlingsproblematik, Integrationsprozesse, Identitätsbildung, etc. Dementsprechend kommen verschiedene Aspekte des Begriffs, Heimat' zum Vorschein.

Einen Grund für die Auseinandersetzung mit diesem Begriff bietet nicht zuletzt das Bedürfnis, sich selbst in seiner Eigenart zu begreifen und von dem Anderen als Fremden abzugrenzen. Im Spiegel der Heimatvorstellungen sich selbst zu erkennen bildet eines der verbreiteten Motive für die Zuwendung zu diesem Thema. Die Heimat-Diskurse scheinen außerdem ein Mittel zu sein, die existenziellen Sorgen, die manche haben, direkter zur Sprache zu bringen: die Angst vor dem Verlust traditioneller Lebensordnungen, vor den Veränderungen, vor der Verschlechterung der Lebensbedingungen usw. In der theoretischen Auseinandersetzung mit dem Thema ,Heimat' zeigt sich eine Doppelstruktur: Sie ist sowohl geschichtsorientierte Vergewisserung eines Vergangenen, eines Schicksals (wenn man will), wie auch Gegenwartsdiagnose. Die Heimatproblematik ruft Interesse auf verschiedenen sozialen Ebenen hervor: Auf der Seite des Individuums bildet Heimat eine alltagsweltliche Bezugsgröße zum direkten Lebens- und sozialen Umfeld, die Bestandteil einer Biografie sind und den Menschen einen gewissen Halt geben. Auf der anderen Seite ist sie ein Thema in der Politik und hier kann man nicht selten beobachten,

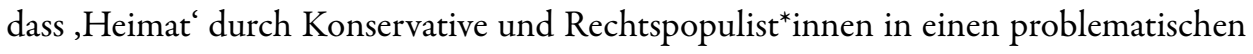
Kontext rückt.
\end{abstract}

Ein oberflächlicher Blick auf gegenwärtige Heimatdiskussionen und Heimatsdiskurse würde bereits genügen, um festzustellen, dass der Heimatbegriff ein ambivalenter ist - ob Heimat als bereits bestehende Herkunfts- oder noch kollektiv zu schaffende Ankunfts-

(c) Maja Soboleva; mayya.soboleva@aau.at

Colloquium: New Philologies, Volume 6, Issue 1 (2021)

doi: 10.23963/cnp.2020.6.1.1

Stable URL: https://colloquium.aau.at/index.php/Colloquium/article/view/145

This work is licensed under a Creative Commons Attribution 4.0 International License (CC BY 4.0). 
heimat verstanden wird. Dieser Ambivalenz scheint die Vorstellung zugrunde zu liegen, dass Heimat grundsätzlich ein Raum - Ort, Territorium, Wohnsitz, Umgebung - ist. Mit dem Raum werden dann verschiedene symbolische Gehalte assoziiert und verschiedene funktionale Bestimmungen verbunden, die das Konzept ,Heimat' bilden.

Vor diesem Hintergrund ist zu fragen, ob es zu der Vorstellung von Heimat als einem räumlichen Objekt mit bestimmten ,sekundären` symbolischen Eigenschaften wie Identitätsgröße, Lebensordnung, Traditionsressource etc. eine Alternative gibt. Vor allem zwei Aspekte sollen dabei ins Zentrum rücken: 1) Wo siedelt sich ,Heimat' ontologisch, das heißt zwischen Realität und Imaginärem an? 2) Inwieweit kann ,Heimat' als Mythos betrachtet werden?

Die ,Realität' oder zumindest,Wirklichkeit' der Heimat kann problematisiert werden, ausgehend beispielsweise von der Annahme, dass das Wort ,Heimat' - sei es retrooder prospektiv betrachtet - unter anderem ein Erlebnisausdruck ist. Als Erinnerung erweist sich Heimat als ein utopischer Lokus der Sehnsucht - ein identitätsstiftender, aber nie real da gewesener. Als zukunftsgerichteter Traum oder Plan ist Heimat eine Projektion des Wunsches nach Geborgenheit. Auch in der Gegenwart ist Heimat nicht auf eine Summe von Gegenständen reduzierbar: ,Heimat' ist und bleibt wesentlich individuelle Wahrnehmung der Gegenstände, die allerdings kollektiv bzw. politisch und vor allem kulturell (Dichtung, Musik, Film etc.) immer neu inszeniert bzw. dekonstruiert und dennoch als eine Art Container unabänderlicher Traditionen beschworen werden.

Bei der Analyse, inwiefern Heimat ein Mythos ist, erstreckt sich die Untersuchung auf die genauere Bestimmung des Mythos, auf die Präsenz der mythischen Denkstrukturen in der alltäglichen Erfahrung sowie auf das Verhältnis zwischen Imaginärem und Mythischem insbesondere in der politischen Kultur. So kann eine Untersuchung des Heimatbegriffs zur weiteren Klärung des Verhältnisses zwischen persönlicher und kollektiver Identität, zwischen politischem Mythos und politischem Imaginärem beitragen. Dahinter steht die Frage, warum mythische Erfahrungsformen für das gegenwärtige Denken überhaupt attraktiv sind: Stellt der Mythos etwa einen anderen Typus von Vernunft als das rationale Denken dar und ermöglicht anderes, dem Massenbewusstsein konformes Begreifen von Wirklichkeit? Zu fragen ist außerdem, ob es alternative Analysewerkzeuge zu den sozial-geographischen und sozial-psychologischen Interpretationen von ,Heimat' gibt. In diesem Zusammenhang kann beispielsweise auf das Spezifische des HeimatNarratives aus einer hermeneutischen Perspektive, die die Begriffe, mytho-poetische' (Giambattista Vico) und ,evozierende‘ (Georg Misch) Rede verwendet, eingegangen werden. Eine reflektierte Auseinandersetzung mit dem Mythos, Heimat' soll im Allgemeinem dazu beitragen, ihn einerseits dank der Aspektanalyse zu verstehen und andererseits seine einseitige Vereinnahmung durch Identitätspolitiken zu problematisieren. 
Dies sind nur einige wenige Fragen, die die Autoren dieses Sonderheftes seit längerem beschäftigen. Das Gespräch erfolgt interdisziplinär. Es ist auf keinen Fall abgeschlossen und lädt zum weiteren Nachdenken ein.

Ganz besonders möchte ich mich bei Frau Bettina Kumpan für die tatkräftige und engagierte Unterstützung bei der Organisation der Tagung und der Vorbereitung dieses Sonderheftes bedanken. 


\title{
„Worin noch niemand war" - Heimat als Erinnerung und Konstrukt
}

\author{
Emil ANGEHRN
}

\begin{abstract}
Home is an ambiguous idea, in terms of spatial and temporal location as well as in terms of reality and valuation. Home(land) can be near or far, encompass small or large spaces, be anchored in an urban area or in the open landscape. It can belong to the oldest past, be irretrievably lost, destroyed, or lie in an unknown future as a utopian place of longing. Homeland can be the real place of origin or where we live at the moment - or the construct of a place where no one has ever been. The deepest ambiva-
\end{abstract} lence that emerges in critical debates about old and new literatures on homelands concerns the oscillation between the anthropological necessity, the human need for home - and its contingency and the will to relinquish it in favor of a free, unbound way of life.

Keywords: memory, nostalgia, homesickness, utopia, exodus, ,Heimatliteratur

(c) Emil Angehrn; emil.angehrn@unibas.ch

Colloquium: New Philologies, Volume 6, Issue 1 (2021)

doi: 10.23963/cnp.2021.6.1.2

Stable URL: https://colloquium.aau.at/index.php/Colloquium/article/view/146

This work is licensed under a Creative Commons Attribution 4.0 International License (CC BY 4.0). 


\section{Heimat als Herkunft}

\section{Dimensionen der Heimat}

Heimat ist Herkunft. Dies scheint die normale, nächstliegende Gedankenverbindung. Die meisten Menschen assoziieren mit dem Wort „Heimat“ Bilder von Orten, Umgebungen, Landschaften, in denen sie - vielleicht schon ihre Familien und Vorfahren - gelebt haben. Solche Bilder sind typischerweise affektiv besetzte Erinnerungen oder Phantasien, die mit Vorstellungen eines Zuhause- und Beisichseins verbunden sind. Sie evozieren nicht allein räumlich-örtliche, sondern ebenso personale, zwischenmenschliche Zusammenhänge, in denen wir uns zuhause, geborgen fühlen. Und sie führen typischerweise zurück in ein Vergangenes, an einen Ort, an dem wir lebten, zu einer Gemeinschaft, deren Teil wir waren, die wir vielleicht verlassen haben, zu denen wir zurückkehren. Heimat, so ein äußeres Minimalgerüst, ist in variierenden Modalitäten räumlich, sozial und zeitlich bestimmt.

Die räumliche Spezifizierung variiert zwischen kleinen und größeren Lebenszonen die enge Familienwohnung, das Haus der Großeltern, in dem wir oft zu Besuch waren, die Straße, in welcher wir mit anderen Kindern aufgewachsen sind, der Kreis der Nachbarn, unter denen wir gelebt haben, das Dorf mit seinem versteckten Ecken und Wegen, die vertraute Landschaft und die umgebende Natur, vielleicht umgrenzt durch den Horizont der Bergketten, aber auch die Industrielandschaft zwischen Fabriken und vielbefahrenen Straßen, schließlich die größeren, teils politisch definierten Räume des Bezirks, der Region, der Nation. Es ist frappierend, wie stark die Verortungen der Heimat - des Heimatgefühls, der Rede von Heimat - mit den verschiedenen Kulturen, kollektiven Identitäten und nationalen Geschichten variieren. Gilt den einen die landschaftliche Umgebung, die dörfliche Gemeinschaft als Brennpunkt des Heimatbezugs, so anderen die politische und historische Zugehörigkeit bis hin zur staatlichen Einheit - die für andere wiederum als fiktive Größe oder äußerlich-entfremdender Zusammenhalt fungiert. Unübersehbar ist schon, dass das (deutsche) Wort ,Heimat' sich nicht ohne Weiteres in andere Idiome übertragen, in anderen Sprachen bedeutungsmäßig explizieren lässt. Offenkundig ist ebenso, dass die Rede von Heimat nur zum Teil eine deskriptiv-feststellende, teils aber ebenso eine zuschreibend-aneignende ist, je nachdem auch eine volitiv-festlegende, eine idealisierend-überhöhende (wenn die Welt als ganze oder das Jenseits zur wahren Heimat erklärt werden) oder auch eine kritische. Wo die Heimat ist, wie ihre Grenzen zu ziehen sind und was alles zu ihr gehört, ist nur zum Teil vorgegeben - doch ebenso wenig in unser Belieben gestellt. Heimat ist Teil unserer konkreten, sozial und geschichtlich geprägten Lebenswelt. 
In alledem interferieren die räumlichen mit den sozialen Bezügen der Heimat, von der engen Mutter-Kind-Beziehung über Familien- und Freundschaftsbande, soziale und regionale Netze bis zu nationalen Gemeinschaften und kosmopolitisch-menschheitlichen Beziehungen. Es hängt nicht nur von individuellen Optionen, sondern von kulturellen und gesellschaftlichen Rahmenbedingungen ab, wie weit sich das soziale Netz unserer heimatlichen Verbundenheit erstreckt. Kennzeichnend ist bei aller Unbestimmtheit und typologischen Vielfalt, dass wir dazu tendieren, als heimatliche Verhältnisse solche zu bezeichnen, die erstens nicht eine rein individuelle Verortung - an einem Herkunftsort, in einer Lieblingslandschaft -, sondern einen in irgendeiner Weise mit anderen geteilten, gemeinsam bewohnten Raum meinen, und die zweitens zu einer konkreten, qualitativ gestalteten Lebenswelt gehören. Lokalisierungen in diffusen Räumen und anonymen Gebilden begründen keine Heimat.

Die räumlich-soziale Bezugnahme ist drittens zumeist zeitlich konnotiert, als Verhältnis zu einem, das einst war, wo wir gewesen sind, was wir erlebt haben. Heimat ist typischerweise Gegenstand der Erinnerung und Rückkehr, ihre Sehnsucht ist dem Vergangenen zugewandt. Wer an die Heimat denkt, seiner Heimat gedenkt, denkt an ein Vergangenes, vielleicht Verlorenes zurück, sei es, dass nur wir es verloren haben, weil wir ausgezogen sind, während die Heimat in der Ferne intakt geblieben ist; sei es, dass diese selbst verloren gegangen ist, wie ein Land, das im Krieg seine Identität verloren hat, ein Dorf, das durch die industrielle Zersiedelung unkenntlich geworden ist. Heimat ist in alledem ein Früheres, dem die Erinnerung, vielleicht die Sehnsucht gilt.

\section{Heimweh und Rückkehr}

Damit sind Konturen eines typischen, nicht des einzig möglichen, doch eines gleichsam idealtypischen Heimatbegriffs umrissen. Sie werden durch Urformen der Rückwendung zur Heimat: Heimweh und Rückkehr, illustriert.

Homers Odyssee ist die Geschichte einer ersehnten, in weiten Irrfahrten und „unnennbaren Leiden“ erkämpften, am Ende glücklich vollendeten Rückkehr (Odyssee I, 4). Odysseus erduldet die Not, um „seine Seele zu retten und seiner Freunde Zurückkunft“ - eine Rückkehr, die ihm selbst vergönnt, seinen Gefährten aber („Toren! Welche die Rinder des hohen Sonnenbeherrschers aßen“) vom Gott verwehrt wird (Odyssee I, 5, 8f.). Der Begriff der Odyssee ist zum Inbegriff einer Irrfahrt geworden, die aber in Homers Epos auf ein klares, einziges Ziel gerichtet ist, die Rückkehr des Helden nach dem Trojanischen Krieg zur heimischen Insel Ithaka, und deren Erzählung mit dem Beschluss der Götter einsetzt, Odysseus die Rückkehr zu erlauben. Der Mythos seiner Fahrt ist zum Inbegriff der Rückkehr und zugleich des Heimwehs (neulat. nostalgia), des Leidens (griech. algos) um die Wiederkehr (griech. nostos), geworden. Getragen ist die lange Reise von der 
Sehnsucht, der Verbundenheit mit dem Zuhause, der von der Gegenseite die Treue der wartenden Gattin Penelope und die Suche des Sohnes Telemachos nach dem vermissten Vater entsprechen.

Die intensive Bindung an den Herkunftsort und Sehnsucht nach der Heimat wird im Topos des morbus helveticus, der, Schweizerkrankheit' anschaulich gegenwärtig. Die 1688 vom Arzt Johannes Hofer beschriebene Krankheit benennt die seelischen und körperlichen Leiden der aus den Schweizer Voralpen stammenden, in fremdländischen Diensten stehenden Söldner, die unter der unerreichbaren Ferne der Heimat litten. Nach einem verbreiteten, auch von Jean-Jacques Rousseau (in seinem Dictionnaire de musique, 1767) tradierten Bericht war es ihnen im französischen Heeresdienst bei Todesstrafe verboten, den ranz des vaches, ein verbreitetes Hirtenlied (,Kuhreihen') zu singen oder zu pfeifen, das in ihnen eine nicht beherrschbare Sehnsucht erweckte und sie zur Desertion verleitete. Es ist das innere Bild der heimatlichen Wiesen, Dörfer und Berge, das den räumlichen und emotionalen Brennpunkt der Heimat verkörpert und dem Heimweh zugrunde liegt. Dieser ursprünglich medizinische, auf die Schweiz beschränkte Fachbegriff des ,Heimwehs' wurde später, in der Romantik, in allgemeinerer Verwendung Gemeingut der deutschsprachigen Länder.

Es ist bemerkenswert, dass der korrelierte Begriff der ,Heimat' zunächst nicht mit den gleichen Konnotationen der affektiven Bindung und Sehnsucht zu versehen ist, sondern bis ins 19. Jahrhundert nüchterner, namentlich in verwaltungsmäßigem Kontext (mit sozialpolitischen oder asylrechtlichen Folgen) zur Bezeichnung des Herkunfts-, Geburtsoder Wohnorts verwendet wird. Dieser Bedeutungshof, der sich zum Teil als solcher erhalten hat (u.a. wiederum in der Schweiz, in ,Heimatschein' und ,Heimatort'), ist dann im Weiteren durch gefühlsmäßige, ideologische und nationale Aspekte zum heutigen facettenreichen, schillernden Syndrom der Heimat angereichert worden.

\section{Vergangenheit und Erinnerung}

Heimat und Heimweh teilen in typischen Ausprägungen den Vergangenheitsbezug. Heimat ist nicht nur der vertraute Ort und nicht nur die bergende Gemeinschaft, in deren Mitte wir leben. Heimat ist auch die eigene Geschichte. Zu uns gehören in einer besonderen, engen Weise die vergangenen Jahre mit ihren Erlebnissen, ihren Freuden und Entbehrungen, in herausgehobenem Sinne unsere Kindheit. Sie bilden den Raum, in dem wir uns zuhause fühlen, der im Innersten in uns ist und zu dem wir gehören, der uns aber auch fremd werden, verloren gehen kann. Im heimatlichen Beisichsein Sicherheit und Geborgenheit zu finden ist eine bestimmte Version der allgemeinen Suche nach dem Ursprung. Das Frühere bietet Halt und Stabilität. In vielfältiger Weise stützen sich individuelle wie soziale Lebensformen auf Vergangenes als Orientierungshilfe, Legitimationsbasis 
oder Ordnungsrahmen ab. Es gibt eine erlebensmäßige Stabilität und kulturelle Autorität des Älteren und schon Dagewesenen, auf die sich die Eingesessenen und etablierten Mächte berufen, und die identitätsstiftende Kraft der Heimat zehrt nicht zuletzt von diesem Privileg der Herkunft.

Dabei steht die Vergangenheit nicht nur für einen Anker der Sicherheit, sondern idealiter auch für einen Raum des Zu-sich-kommens und Mit-sich-Einswerdens. Vielfach werden mit dem Rückblick Erinnerungen an ein ursprüngliches Aufgehobensein, an das unschuldige Glück, die Seligkeit des Kindes verbunden. Kulturen tragen die „Erinnerung des fernsten und ältesten Glücks" als Rückhalt und Fundus in sich (Adorno und Horkheimer 1947, 81). Wie die Kindheit wird auch Heimat in solchen Bezügen zum Ort der Sehnsucht nach dem Ganzsein, der ursprünglichen Erfüllung. Allerdings verbleiben nicht nur im skeptischen Außenblick, sondern auch im eigenen Gedächtnis Ungewissheit und Zweifel, wieweit in solchen Bildern Erinnerung und Wunsch, Realität und Ideal ineinander gehen. Fraglos ist es so, dass typische Imaginationen vom kindlichen Einssein und von der verlorenen Heimat um eines kreisen, das so gar nicht wirklich erlebt worden, nicht real gewesen ist. Vorstellungen vom Kindheitsglück sind nicht notwendig Vergegenwärtigungen real erlebter Erfüllung, sondern auch Erinnerungen an helle Atmosphären, Stimmungen des Geborgenseins. Tiefe Glücksempfindungen, wie sie der Erinnerung an früheste Erlebnisse innewohnen können, müssen nicht auf faktische Ereignisse, sie können ebenso auf Möglichkeiten, auf ein Glücksversprechen, eine Hoffnung gehen. Dabei muss die epistemische Zurücknahme vom Wirklichen ins Mögliche, ins Geahnte und Ersehnte den Gehalt und Status der Erinnerung nicht mindern: Bilder der Kindheit wie Vorstellungen der Heimat verlieren nichts von ihrer Intensität dadurch, dass sie nicht faktisch Eingetretenes, sondern virtuell Angelegtes, Offenes und Bevorstehendes in sich enthalten. Erinnerung gilt in eindringlicher Weise auch dem unabgegoltenen Vergangenen und dem ungelebten Leben. Darauf haben kritische Erinnerungskonzepte den Akzent gelegt, denen es darum ging, im subversiven Potential des Gedächtnisses demjenigen zur Sprache zu verhelfen, was in der Geschichte unterdrückt worden ist und nicht zur Entfaltung, zum Ausdruck kommen konnte. Die emanzipatorische Leidenserinnerung, die das stumme Leiden beredt werden lässt und der unerfüllten Forderung Nachdruck verleiht, hat ihr affirmatives Pendant im Gedenken des frühesten Glücks, das auch dessen gedenkt, was in ihm als Möglichkeit, Verheißung und Erwartung beschlossen lag.

Wir begegnen hier einer Gedankenfigur, die eine ihrer eindringlichsten und schönsten Formulierungen gerade mit Bezug auf die Sehnsucht nach der Heimat gefunden hat. Der Schlusssatz des großen Werks von Ernst Bloch, Das Prinzip Hoffnung (1959), fasst die umfassende Erkundung aller Wunsch- und Hoffnungsbilder der Menschheitsgeschichte im Fluchtpunkt von etwas zusammen, „das allen in die Kindheit scheint und worin 
noch niemand war: Heimat" (Bloch 1959, 1628). Die Sehnsucht nach der Heimat wird als Sehnsucht nach einem Ort evoziert, an dem wir noch nie waren, wie das Heimweh an ein unbekanntes verlorenes Paradies gemahnen kann. ${ }^{1}$ Blochs Formel nimmt den Ausgriff nicht ins Inexistente zurück, sondern steigert ihn auf ein Transzendierendes hin, das alle besonderen Orte und Rückblicke übersteigt, aber dennoch kein abstraktes Ideal ist, sondern seinen Sitz im Leben, im Innersten der Erinnerung hat, allen „in die Kindheit scheint". Solches Scheinen ist kein bloßer Schein, sondern der Glanz, der etwas umgibt, und zugleich sein Aufscheinen im Horizont des Lebens.

Es ist bemerkenswert, dass sich die prägnante Figur eines uneinholbaren, nie real gewesenen Vergangenen auch in neueren Diskussionen der Geschichts- und Kulturtheorie unabhängig von Nostalgie und Heimat - um nicht zu sagen: am Gegenpol zu solchen Vorstellungen - wiederfindet. Mehrere französische Autoren der letzten Jahrzehnte - M. Merleau-Ponty, J. Derrida, P. Ricœur, E. Levinas - haben die Idee eines „Vergangenen, das nie gegenwärtig gewesen ist" (un passé qui n'a jamais étéprésent) zu einem Fokus der Besinnung auf Ursprung und Herkunft gemacht (vgl. Angehrn 2015). Sie markiert einen bestimmten Fluchtpunkt historischer Reminiszenz, von der biographischen Erinnerung, die in die vorbewusste Selbstwerdung zurückweist, über das kollektive oder nationale Gedächtnis, das sich in einer mythischen Urgeschichte verlieren kann, bis zum kosmisch oder menschheitlich „unvordenklichen Vergangenen“ ((Hutter 2001) als dunklem Urgrund aller Dinge; für die Hermeneutik und Dekonstruktion fungiert sie als genereller Eckpunkt in der Prozessualität des Sinns, der aus einem nie zur Gänze aufhellbaren Ursprung kommt und auf eine nie vollendete, immer aufgeschobene Identität vorausweist. Die Figur bietet eine Folie zur Explikation jener Seite der Heimat, nach der uns diese entgleitet, in der erinnernden Rückkehr unbestimmt und diffus bleibt - wobei die kognitive Abschwächung keine Aushöhlung oder Relativierung des Heimatbezugs bedeuten muss, sondern mit dessen Nähe und Intensivierung einhergehen kann. Allerdings ist unübersehbar, dass es sich um einen Bezug spezifischer Art handelt. Der Topos der Heimat als Herkunft, von dem die vorausgehenden Überlegungen ausgegangen sind, ist nach zwei Hinsichten zu kontextualisieren, im Blick auf den Realitätsstatus und auf die Zeitrichtung des Heimatbezugs. Dieser zielt nicht einfach auf eine bestimmte, feste Gegebenheit, und er richtet sich nicht nur auf ein Vergangenes.

1 Charles Taylor schildert das Gefühl, das Chopins Fantaisie-Impromptu in cis-Moll in ihm erweckt, als „ein Gefühl wie Heimweh nach einem verlorenen Paradies, von dessen Existenz ich jedoch nichts wusste, ehe ich diese Musik gehört habe“ (Taylor 2017, 467). 


\section{Die kommende Heimat}

\section{Exodus}

Die Gegenfigur zu Odysseus ist Abraham. Wird jener von der Sehnsucht nach Rückkehr getrieben, so dieser durch den göttlichen Befehl „Gehe hinaus aus deinem Lande und von deiner Freundschaft und aus deines Vaters Haus“ - einen Befehl, den Augustinus als Aufforderung zum inneren Freiwerden versteht, „denn seine Seele hatte sich noch nicht gelöst, solange sie durch Hoffnung zurückzukehren und Heimweh festgehalten wurde“ (Vom Gottesstaat, XVI, 15). Es ist eine grundlegend andere existentielle Grundhaltung, die hier zum Tragen kommt - nicht der Rückkehr ins Eigene, sondern des Hinausgehens ins Fremde, nicht in das bekannte Vergangene, sondern in das unbekannte Neue und Kommende. Die veränderte Haltung ist Teil einer umfassenden Lebenshaltung, die den irdischen Lebensweg als Pilgerschaft auf ein jenseitiges Ziel hin begreift. Ähnliches trifft für das Variationsspektrum des Heimatbegriffs zu, der nicht nur mit der Herkunftsgegend, sondern ebenso mit dem künftigen oder ewigen Leben verknüpft sein kann. Dabei muss die Inversion der Herkunftsausrichtung nicht notwendig auf das Jenseits ausgreifen, sie kann auch auf ein irdisches Anderswo gehen. Auswanderer können eine neue Heimat auf einem fremden Kontinent, in einer anderen Gegend, in einem neuen, ,verheißenen Land suchen; oder sie können, bescheidener, im nächsten Tal, an einem anderen Ort ein neues Zuhause begründen. Es ist naheliegend, dass Menschen, die am Ort ihrer Herkunft Unterdrückung und Katastrophen erlitten haben, einen anderen Lebensort, eine andere, bessere, vielleicht erst wahre Heimat suchen. Heimat muss nicht notwendig in der Herkunft, sie kann auch in der Ankunft liegen. Ihr Ort muss nicht im Hier, er kann in der - bekannten oder unbekannten - Ferne liegen, ihre Zeit muss nicht das Ehemals und längst Vergangene, sie kann das Kommende, das Unerwartete und Nicht-Antizipierbare sein. Es gibt neben dem Heimweh das Fernweh, das jenem nicht notwendig als das Andere entgegengesetzt ist, sondern ihm möglicherweise innerlich verwandt ist und sich nach einem neuen Ankommen und $\mathrm{Zu}$-sich-kommen, einem Daheim im Neuen und Fernen sehnt. Das Anderswo ist nicht nur ein Fremdes, es kann seinerseits Gegenstand der Sehnsucht sein, zur Heimat werden. Im Anderen bei sich sein, Hegels Formel für die Freiheit, ist gleichermaßen eine Chiffre der Heimat.

\section{Abbild und Konstruktion}

So haben wir die Heimat in temporaler und räumlicher Spiegelung in zweifacher Gestalt vor uns. Sie ist die ehemalige, je nachdem die verlassene, verlorene, geraubte Heimat, und sie ist ebenso die künftige, die unbekannte und gesuchte, vielleicht wiedergefundene Heimat. Interessant ist, dass die Spiegelung auch jenen eigentümlichen Status 
des Nicht-Wirklichen tangiert, das einen Fluchtpunkt der Herkunftsbesinnung bildete. Dem je schon Vergangenen, das nie gegenwärtig gewesen ist, korrespondiert auf der Gegenseite das Kommende nicht nur als ein Noch-nicht-Seiendes, sondern in emphatischen Visionen als dasjenige, was jenseits aller bestimmten Antizipation und Ausmalung ist, als eines, das nicht im vermessbaren Raum zu lokalisieren, das ohne Ort (topos), utopisch ist. Nicht umsonst hat Thomas Morus seine Utópia (1516), das titelgebende Urbild der neuzeitlichen Sozialutopien, als Insel in einem fernen Ozean beschrieben. Utopie ist der Nicht-Ort, das Andere zur bekannten Welt, auf welches die individuellen und gesellschaftlichen Wunschvorstellungen ausgreifen, ein Künftiges jenseits des Bestehenden; bemerkenswert ist, dass Ernst Bloch, der das Prinzip Hoffnung ins Bild der Heimat, in der noch keiner war, überführt, eine frühe Hauptschrift dem Geist der Utopie (1918/1923) gewidmet hat. Retrospektiv wie prospektiv ist das Andere und Mögliche jenseits des Wirklichen, das Eigentliche und Wahre jenseits des Realen.

Für die konkrete Beschreibung von Heimat, für das bestimmte Bild, das wir uns von ihr machen, bedeutet dies, dass es nicht einfach Abbild und Explikation eines Bestehenden, sondern immer auch Konstruktion und Projektion ist. Dies ist in gewissem Maße eine Selbstverständlichkeit, wie denn auch schon jede historische Darstellung nicht einen gegenständlichen Faktenverlauf verdoppelnd reproduziert, sondern ihn selektiv vergegenwärtigt und gestaltend zur bestimmten Geschichte macht. Doch geht es hier um mehr und Spezifischeres. Der Konstruktcharakter der Heimat ist nicht nur konstitutives Element der Vergegenwärtigung, sondern wohnt ihrem Gegenstand inne. Das Beisichsein, Ganzsein, Einssein-mit-sich wird im Bild der Heimat als eines gegenwärtig, das nie abgeschlossen, schlicht objektiv seiend da ist, das immer auch Momente des Wunsches, des Unerfüllten und Erhofften in sich birgt - auch wenn es sich mit Erinnerungen an Erlebtes und Geschehenes verbinden kann. Heimat bleibt auch im Rückblick, als Gegenstand des individuellen oder kollektiven Gedächtnisses mit Zügen des Utopischen, des Nicht-Realen versehen. Auch die Erzählung des einstigen Zuhause- und Aufgehobenseins ist, soll sie nicht in Kitsch verfallen, jenseits des platten Realismus. Der uneinholbare Ursprung und die nicht-konstruierbare Vollendung gehen gleichermaßen in ein nicht-reduktives Verständnis von Heimat ein.

\section{Erinnerte und verlorene Heimat}

\section{Heimatbeschreibungen}

Der schillernde Status der (Rede von) Heimat widerspiegelt sich in den Textsorten, die von der Heimat handeln. Im literarischen Schrifttum finden sich eindrucksvolle Zeugnisse, die in einem weiten Sinn zur Heimatliteratur bzw. zum Genre des Heimatromans 
zu zählen sind. Auffallend ist dabei der Tatbestand, dass sie durchaus verschiedenen Typen von Heimatliteratur zugehören. Was ihren Inhalt betrifft, so gelten sie einerseits der Heimat, die durch Traditionen bewahrt, im Erleben gegenwärtig oder im Gedächtnis erinnert ist, andererseits der Heimat, die verlassen wurde, die zerstört worden ist oder verloren gegangen ist. Diese inhaltlich-gegenständliche Dichotomie ist durch eine andere, damit teils korrelierte, teils von ihr unabhängige zu ergänzen: die Zweiteilung zwischen literarisch minderwertigen, ideologisch gebrandmarkten, gesellschaftlich diskreditierten Werken auf der einen Seite und kulturell etablierten, z.T. literarisch hochwertigen, zeitkritisch rehabilitierten Formen von Heimatliteratur auf der anderen. In all diesen Versionen finden wir durchaus prägnante, thematisch aufschlussreiche Formen literarischer Befassung mit der Heimat. In dem einen Grundtypus ist Heimatliteratur der sentimentalen Erinnerung an Orte, Menschen und Lebenskreise gewidmet, die dem Leben jener Zeit Sicherheit und Geborgenheit verliehen haben und die durch die Erinnerung auch für das Hier und Heute lebendig erhalten sind. Es sind Erzählungen vom Dorf- und Bauernleben, die sich als Teil der Volksliteratur im 19. Jahrhundert in Gegenbewegung zur naturalistischen Zentrierung auf das Großstadtleben, auf Industrialisierung und technische Modernisierung herausgebildet haben. Sie haben ihren Niederschlag zum Teil in anerkannten Werken des Literaturbetriebs (Jeremias Gotthelf, Ludwig Ganghofer, Peter Rosegger) gefunden, daneben in Schulbuchtexten, seit Mitte des 20. Jahrhunderts ebenso in Kinofilmen und Fernsehserien (stellvertretend: Heimat - Eine deutsche Chronik, 1981/82, von Edgar Reiz). Zu einem anderen Teil ist dieser Strang der Erinnerungsliteratur in die als Heimatkitsch gebrandmarkte, literarisch zweitklassige Publikation von Heftchenromanen, Erbauungsliteratur und Kriegserinnerungen, in populäre Heimatfilme und das Heimattheater eingegangen, partiell mit ideologischen bis hin zu nationalistischen Konnotationen besetzt.

Dass das Verständnis von Heimatliteratur nicht einfach durch die traditionalistische Optik oder ideologisch-tendenziöse Schlagseiten besetzt wird, verdankt sich dem Gewicht anderer Werke, zu denen neben älteren, der integren oder bewahrten Heimat gewidmeten Romanen auch neuere Schriften zählen, in deren Fokus die verlorene, untergegangene Heimat steht. Fast immer ist ihre Würdigung in den Feuilletons von der Bemerkung begleitet, dass es sich hier um eine andere, untypische Heimatliteratur handle, „weit entfernt von kitschiger Alpenidylle und verbrämter Heimatliteratur" - so die Wiener Zeitung (03.02.2020) mit Bezug auf den jüngst erschienenen Roman Die Bagage (2020) von Monika Helfer. Dörte Hansen, die mit ihren Romanen Altes Land (2015) und Mittagsstunde (2018) Bestseller vorgelegt hat, hat den niederdeutschen Literaturpreis für „Heimatliteratur im besten Sinne“ erhalten (Schlei-Bote 10.11.2019); und zu Peter Kurzeck, der in einer ganzen Reihe von Schriften (mehrere im Romanzyklus Das 
alte Jahrhundert zusammengestellt) von den Menschen, Handwerkern, Kleinbauern und der oberhessischen Gegend, in der er aufgewachsen ist, aus der Nachkriegszeit bis in die Siebziger Jahre berichtet, schreibt die FAZ (07.04.2012), dass es ihm gelungen sei, „,dem verschmähten Genre Heimatliteratur neue Sichtachsen abzutrotzen“.

Das Interessante an diesen stellvertretend genannten Schriften in unserem Kontext ist, dass sie nicht einfach eine Rehabilitierung der Heimatliteratur alter Art betreiben. Sie erzählen vor dem Hintergrund eines geteilten Bewusstseins von der Nicht-Selbstverständlichkeit, der Brüchigkeit des Heimatlichen und des Zuhauseseins. Sie erzählen von eigener Herkunft, teils auch von derjenigen der Familie (so bei Hansen und Helfer), aber sie erzählen von einer Heimat, einem Vertrautsein und Heimischsein, das ein Vergangenes, ein Nicht-mehr-Existierendes, Verlorenes ist. Dieses Verlorene wird über den Zeitabstand hinweg vergegenwärtigt, in Rückblenden (bei Hansen) und obstinaten Spurensuchen (bei Kurzeck), welche verdeutlichen, inwiefern die vergangene Zeit, die hier verhandelt wird, nicht nur ein für uns, für den Autor oder die Autorin Vergangenes, sondern ein an sich Verlorenes, durch die Zeitgeschichte irreversibel Verändertes, Zerstörtes, irreal Gewordenes ist. Das Dorf, die Landschaft sind nicht mehr - oder nur noch in Anzeichen und Spuren - erkennbar, sie sind (optisch, topographisch, sozial) fremd, inexistent geworden. Die zivilisatorische Veränderung, von der die Schriften handeln, ist nicht irgendein qualitatives Anderswerden, der Verlust nicht ein Verlorengehen von diesem und jenem (der alten Webstühle, der Schlittenfahrten), sondern grundlegender ein Verlorengehen der Konkretheit und bunten Farbe der Lebenswelt. Nicht notwendig, aber in signifikanten Fällen geht der Zeitenwandel mit einem Zug ins Anonyme, Abstrakte der Welterfahrung einher.

Dass Heimat etwas Fragiles, Unsicheres, ja, Zwiespältiges ist, hindert nicht, dass ihr auch in solchen Reminiszenzen ein authentisches Interesse, eine existentielle Verbundenheit gilt. Sie trägt, sofern der Heimat als untergegangener und verlorener gedacht wird, den Koeffizienten der Trauer, des Verlusts und der Vergänglichkeit in sich. Solche Trauer fungiert in zwei Modi: als Trauer um die bestimmte, ferne Heimat, den bestimmten Ursprungsort, zu dem zurückzukehren die Sehnsucht treibt - Odysseus' Rückkehr nach Ithaka, die Rückkehr des Arbeitsmigranten ins sizilianische Dorf, die glücklich oder unglücklich ausgehen kann; und als Trauer um die Heimat, die es nicht mehr gibt, deren Heimatlichkeit sich aufgelöst hat - auch wenn jemand in ihr verblieben, vielleicht zu ihr zurückgekehrt ist. Trotz des unwiderruflichen Verlusts indes ist das Gedenken keine bloß kognitive Rekonstruktion, sondern eine vitale Beziehung, ist Heimat weder bloßes Jenseits noch obsolete Chiffre, sondern ein Fokus des Lebens, das sich in der Gegenwart vollzieht, doch nicht im Hier und Jetzt aufgeht. Auch die Sehnsucht nach dem Land, in dem noch keiner war, ist Moment des lebendigen Jetzt. 


\section{Zwischen Heimat und Heimatlosigkeit}

Die unterschiedliche Ausprägung des Topos verdeutlicht die Spannweite der Heimat zwischen höherer Wirklichkeit und Irrealität, Erinnerung und Konstrukt. Sie führt zur grundlegenden Frage nach dem existentiellen Stellenwert des Heimatbezugs zurück. Im Ganzen erscheint Heimat als ein vielgestaltiges, zuweilen schillerndes und uneindeutiges, dennoch nicht kontingentes, sondern lebensweltlich konstitutives Phänomen. Es verändert sich nach verschiedenen Parametern: mit den historischen und sozialen Umständen, den örtlichen und zeitlichen Gegebenheiten, den individuellen Neigungen und Dispositionen, den kulturellen Prägungen. Die Variationsbreite ist erheblich: Es ist nicht generell oder im Voraus auszumachen, wieweit Heimat ein universales oder ein historischkulturell geprägtes Phänomen, der Heimatbezug eine anthropologische Konstante oder eine individuelle Option ist, wobei sich die Spannweite der Differenzen vom einen Extrem ins andere erstrecken kann, zwischen einem substantiellen, intensiven Heimatbezug auf der einen Seite und einem Nicht-Bezug, einem fehlenden oder gleichgültigen Verhältnis zur Heimat auf der anderen. Wieweit das zweite, negative Extrem in seiner Reinform eine tatsächliche Lebensform - oder eher eine behauptete Indifferenz, ein reaktiver Rückzug, eine erzwungene Entwöhnung oder graduelle Zurückdrängung ist und ein basales Heimatverhältnis auch all diesen Negativ- und Schrumpfformen zugrunde liegt, kann offenbleiben. Wichtig ist, das Spannungsverhältnis als solches ernst zu nehmen, das den Heimatbezug in seiner Ambivalenz und Vielschichtigkeit durchzieht. Es gibt die Extreme und ebenso die Mischungen und Überlagerungen zwischen ihnen: den faktischen Heimatverlust, die verzweifelte Heimatliebe in der Fremde, die Trauer um den Verlust und die Distanz in der Verbundenheit (wie sie Thomas Mann im Exil repräsentiert, wie sie aber auch den Quasi-Normalzustand vieler in ihrem gespaltenen Herkunftsbezug definiert).

Am einen Extrem gilt es, die Heimatlosigkeit in ihren unterschiedlichen Formen ernst zu nehmen: nicht nur als erlittenen, schmerzlichen Verlust, sondern ebenso als akzeptierte Heimatlosigkeit, je nachdem auch als willentliche Ablösung, als Heimat-Indifferenz oder gewollte Heimat-Ferne. Es gibt die Möglichkeit eines gelingenden, erfüllten Lebens ohne die substantielle Bindung an einen Ort und eine Lebensform des Zuhause (als erfahrene, ersehnte, vermisste Heimat); es gibt die Möglichkeit der Ablösung von starken Identitäts- und Ganzheitsvorstellungen, wie sie in die Idee von Heimat oder in emphatische Erinnerungen eingehen können. Der negativen Ablösung oder Entbehrung korrespondieren positive Leitvorstellungen der inneren Freiheit und Ungebundenheit, die je nach Veranlagung und Präferenz als angemessene, passende Lebensform hochgehalten werden. Man kann keinem, der auf Heimat verzichtet, der frei von Heimatbindungen lebt oder leben will, die Notwendigkeit eines starken Heimatbezugs andemonstruieren. 
Auf der Gegenseite kann es ebenso wenig darum gehen, die Motive, die in das Verlangen nach Heimat eingehen, theoretisch zurückzudrängen oder wertmäßig zu schmälern. Es sind anthropologisch fundamentale Bedürfnisse, Züge des Menschseins, die nicht nur im Inbegriff der Heimat, sondern in Lebenskonstellationen verschiedenster Art, in der individuellen Lebensführung wie im geschichtlichen Streben und sozialen Kampf zum Tragen kommen. Es sind Bedürfnisse nach Zugehörigkeit und Aufgehobensein, nach Stabilität und Orientierung, aber auch nach Ganzheit und konkreter Gegenwärtigkeit, die in Bildern von - erlebter oder ver-lorener - Heimat aufscheinen. Verwiesen sei auf die unermessliche Fülle von Wunschträumen, Utopien und Glücksvorstellungen, die Ernst Bloch im Leitbild der Heimat zusammenführt. Sie stellen nicht-kontingente Ausprägungen dessen dar, worum es den Menschen in ihrem Leben geht und seit je gegangen ist. In welchen konkreten Formen diese Bedürfnisse und Begehren im Tun und Leben der Menschen verfolgt und verwirklicht werden, hängt, wie gesagt, von eigenen Veranlagungen und Entscheidungen ebenso wie von kulturellen Vorgaben und materiellen Bedingungen ab. Zum Teil mag es in das Ermessen des Einzelnen gestellt sein, ob der Verzicht auf ihre Erfüllung oder ihre Sublimierung in Praktiken des Abstands und der Loslösung sich als lebensfähige Optionen, als authentische Formen von Freiheit und Glück erweisen. Im Grundzug aber scheint unstrittig, dass Heimat zu den Angelpunkten des Menschseins gehört, von denen - in welcher Ausprägung auch immer - ein gelingendes Leben nicht ohne Verlust absehen kann.

\section{Literatur}

Adorno, Theodor W. und Max Horkheimer. 1947. Dialektik der Aufklärung. Amsterdam: Querido.

Angehrn, Emil. 2015. „Das Vergangene, das nie gegenwärtig war: Zwischen Leidenserinnerung und Glücksversprechen." In Das unerledigte Vergangene: Konstellationen der Erinnerung, hrsg. v. Emil Angehrn und Joachim Küchenhoff, 175-205. Weilerswist: Velbrück.

Augustinus. 1978. Vom Gottesstaat (De civitate dei). München: Deutscher Taschenbuch Verlag. Bloch, Ernst. 1959. Das Prinzip Hoffnung. 3. Bd. Frankfurt am Main: Suhrkamp.

Homer. 2001. Odyssee. Übersetzt von Johann Heinrich Voß. Zürich/Stuttgart: Winkler.

Hutter, Axel 2001. „Unvordenkliche, das.“ In Historisches Wörterbuch der Philosophie, Bd. 11, Sp. 339-341. Basel: Schwabe.

Taylor, Charles. 2017. Dassprachbegabte Tier. Grundzüge des menschlichen Sprachvermögens. Frankfurt am Main: Suhrkamp.

Hoferus, Johann. 1688. Dissertatio medica de Nostalgia, oder Heimwehe. Basel. 


\title{
„Daheim [...] war vielleicht noch Österreich“ Zur Inszenierung und Demontage des Heimat-Mythos in Joseph Roths Roman Radetzkymarsch
}

\author{
Barbara NEYMEYR \\ Universität Klagenfurt (Austria)
}

\begin{abstract}
Joseph Roth's Radetzkymarsch opens up a multifaceted historical horizon: By unfolding the fictional story of the Trotta family in the crisis-ridden final period of the Habsburg era, he exemplifies cultural diagnosis through individual fates. Starting with contemporary discourse on Austria, the essay analyses the significance of the $\mathrm{Hei}$ mat myth in Roth's Radetzkymarsch and its mediation alongside the hero myth, and the Kaiser myth. It examines the strategies the novel uses to satirically counteract these mythological configurations.

In the characters' mentality, defeatism, resignation, and anticipations of doom - extending to apocalyptic visions - are combined with regressive nostalgia for fantasies of home, and ironic scepticism. The result is a revealing panorama of heterogeneous sensitivities in a sociopsychological context. The portrait of the hero of Solferino, who once saved the emperor's life and through his portrait remains ever-present in the lives of his descendants, has a leitmotif function: Although the obsession
\end{abstract}

with ancestors in the hero myth offers orientation and support to the hero's son and grandson, it also negatively affects their identity formation. However, it is not only the subject who is affected by the loss of inner stability in the final period of the Austro-Hungarian Dual Monarchy before the First World War. Without illusion, the novel radically shows symptoms of a diffusion of consciousness in the aged Emperor Franz Joseph I himself, rendering him unsuitable as a fatherly authority of reassuring sovereignty and strength - despite all the representative staging.

The essay examines the novel's tense web of motifs by analysing the strategies of ironic dismantling that emerge in the oscillation between myth-making and demythologising. Aspects of rhetorical design are also taken into account, as they significantly contribute to the aesthetics of Roth's epoch novel.

Keywords: Geschichtspanorama, Heimat-Mythos, Joseph Roth, Kulturdiagnose, Mythen-Demontage

(c) Barbara Neymeyr; barbara.neymeyr@aau.at

Colloquium: New Philologies, Volume 6, Issue 1 (2021)

doi: $10.23963 / \mathrm{cnp} .2021 .6 .1 .3$

Stable URL: https://colloquium.aau.at/index.php/Colloquium/article/view/147

This work is licensed under a Creative Commons Attribution 4.0 International License (CC BY 4.0). 


\section{Der Mythos Heimat als Projektionsfeld heterogener Diskurse}

In seinem Roman Radetzkymarsch (1932) reflektiert Joseph Roth die Heimat-Imago als identitätsbildendes Konstrukt, indem er hier unterschiedliche Aspekte des ÖsterreichMythos in der Endphase der Habsburger Donaumonarchie entfaltet. Dabei ergeben sich interessante Spannungsfelder, und zwar durch Inszenierung und Demontage des HeimatMythos, die in unterschiedlichen Figurenperspektiven hervortreten. Sie spiegeln Mentalitäten, die mit dem Heimat-Mythos verbunden sind, im Vorfeld einer Epochenschwelle. Dabei werden individuelle Perspektiven und psychische Befindlichkeiten der Figuren zugleich auf Aspekte der Kulturdiagnose hin transparent. Ratlosigkeit, Angst und Desorientierung sowie regressive Anwandlungen und ironische Subversion erscheinen dabei als zeittypische Reaktionsweisen. Die Einstellungen der Romanfiguren zum HeimatMythos reichen von naiver Identifikation über nostalgisch-regressive Sehnsucht angesichts der nahenden Zeitenwende bis zu skeptischer Infragestellung und ironischer Kritik. Von einem ungebrochen affirmativen Heimat-Kult ist Roths Radetzkymarsch also weit entfernt. Eine wesentliche Rolle spielen hier Strategien kontrastiver Darstellung sowie Wertungen der Erzähler-Instanz, die Figurenperspektiven mitunter auch ironisch hinterfragt. Indem der Roman die Familiengeschichte der Trottas in mehreren Generationen mit der historischen Entwicklung verschränkt, spiegelt er die Décadence der Sippe und den Niedergang der österreichischen Monarchie ineinander.

Ambivalenzen gegenüber dem Mythos Heimat bringt übrigens auch der Autor Joseph Roth selbst zum Ausdruck, etwa im Vorwort zum Vorabdruck seines Romans Radetzkymarsch in der Frankfurter Zeitung im April 1932: Als der Kaiser Franz Joseph I. in der „Kapuzinergruft“ bestattet wurde, „wußten wir alle, seine Soldaten, daß unser letzter Kaiser dahingegangen war und mit ihm unsere Heimat, unsere Jugend und unsere Welt“ (Roth 1990b, 874). - Die Verlusterfahrung evoziert hier einen nostalgisch-wehmütigen Blick auf das Ende der Habsburger-Ära, der aber keineswegs unkritisch ausfällt. So gesteht Joseph Roth in diesem Vorwort:

Ein grausamer Wille der Geschichte hat mein altes Vaterland, die österreichisch-ungarische Monarchie, zertrümmert. Ich habe es geliebt, dieses Vaterland, das mir erlaubte, ein Patriot und ein Weltbürger zugleich zu sein, ein Österreicher und ein Deutscher unter allen österreichischen Völkern. Ich habe die Tugenden und die Vorzüge dieses Vaterlands geliebt, und ich liebe heute, da es verstorben und verloren ist, auch noch seine Fehler und seine Schwächen. Deren hatte es viele. Es hat sie durch seinen Tod gebüßt. Es ist fast unmittelbar aus der Operettenvorstellung in das schaurige Theater des Weltkriegs gegangen. (Ibid., 874) 
Hatte Roth als Journalist zunächst eine kritische Position zur Habsburger Monarchie eingenommen, so neigte er später zu einer skeptisch grundierten Nostalgie - im Gefühl einer traumatischen Entwurzelung durch den Heimatverlust. ${ }^{1}$ Soweit soziale und individuelle Identität an den Mythos Heimat gebunden sind, generiert Heimatlosigkeit durch ein Sinnvakuum Desorientierung und Identitätskrisen.

Ambivalente Brechungen zeigt auch die Perspektive des Satirikers und Kulturkritikers Karl Kraus ${ }^{2}$ : Nach der Ermordung des österreichischen Thronfolgers, des Erzherzogs Franz Ferdinand, im Jahre 1914 spricht Kraus sogar von der „Epoche des allgemeinen Menschenjammers“, der seines Erachtens „in der österreichischen Versuchsstation des Weltuntergangs die Fratze des gemütlichen Siechtums annimmt“" (Kraus 1914, 2) ${ }^{3}$. Und nach dem Untergang der Habsburger Monarchie bekennt er 1920 in seiner Zeitschrift Die Fackel:

Ich habe mich mein Lebtag geschämt, ein Österreicher zu sein, und nie mich dieser Scham geschämt, wissend, daß sie der bessere Patriotismus sei. Nun erst, da das Vaterland kleiner und die nationale Natur klarer geworden ist, erweist sich mir die tiefere Berechtigung dieses Schamgefühls. Ist es nicht die hoffnungsloseste und toteste aller Gewißheiten, unter einer Nation zu leben, die durch Schaden dümmer wird? (Kraus 1920, 2)

Hier erscheinen Affirmation und Kritik, Identifikation und Distanz, Empathie und Satire als komplementäre Faktoren miteinander verbunden und aufeinander bezogen.

Sehr unterschiedliche Perspektiven auf die ,österreichische Idee‘ im Diskurs dieser Epoche zeichnen sich bei Robert Musil und Hugo von Hofmannsthal ab. Musil, der mit seinem Epochenroman Der Mann ohne Eigenschaften (1930/32) auf „das geistig Typische“ (GW II, 939) der Vorkriegszeit zielte, um „Beiträge zur geistigen Bewältigung der

1 Während Joseph Roth in frühen journalistischen Arbeiten zunächst eine kritische Einstellung zur Monarchie erkennen ließ, vollzog er später einen Gesinnungswandel und tendierte fortan dazu, die Habsburger Monarchie zu idealisieren, obwohl ihm Probleme und Defizite des österreichischen Kaiserreichs durchaus bewusst waren. Zur Verklärung der Habsburger Monarchie trugen Roths eigene Erfahrungen von Desorientierung und Heimatverlust wesentlich bei: der frühe Verlust des Vaters ebenso wie das spezifische Lebensgefühl der galizischen Juden.

2 „Keiner hat Wien und Österreich ein Leben lang derart verhöhnt, geschmäht, vernichtend attackiert“, schreibt der Kraus-Biograph Hans Weigel, „denn keiner hat Wien und Österreich tiefer geliebt und darum so sehr an Wien und Österreich gelitten“" (Weigel 1972, 9).

3 Außerdem betont Kraus die fatalen Folgen fehlenden Geschichtsbewusstseins durch eine in politischer Hinsicht verhängnisvolle Amnesie: „Die Welt geht unter, und man wird es nicht wissen. Alles was gestern war, wird man vergessen haben; was heute ist, nicht sehen; was morgen kommt, nicht fürchten. Man wird vergessen haben, daß man den Krieg verloren, vergessen haben, daß man ihn begonnen, vergessen, daß man ihn geführt hat. Darum wird er nicht aufhören“" (Kraus 1957, 659): so das prophetische Fazit in der 49. Szene des Dramas Die letzten Tage der Menschbeit, das Karl Kraus 1922 als Reaktion auf den Ersten Weltkrieg veröffentlichte. 
Welt [zu] geben" (GW II, 942), verbindet das Denkmodell multinationaler Koexistenz im Vielvölkerstaat mit der ,österreichischen Idee', sieht sie aber zugleich auch zur naiven Imago eines von Preußen erlösten ,Weltösterreich pervertieren (vgl. GW II, 939). ${ }^{4} \mathrm{Im}$ Roman Der Mann ohne Eigenschaften schreibt er diese hybride Phantasie dann der satirisch gestalteten Salonidealistin Diotima zu: Mit naivem Enthusiasmus auf ein „Weltösterreich“ (MoE 228) fixiert, schlägt Diotima sogar „ein weltösterreichisches Jahr“"vor, in dem „der europäische Geist in Österreich seine wahre Heimat erblicken könnte!“ (MoE 231). ${ }^{6}$ Und Musil selbst rätselte schon 1912 im Essay Politik in Österreich über die ,österreichische Idee':

Es muß irgendwo in diesem Staat ein Geheimnis stecken, eine Idee. Aber sie ist nicht festzustellen. Es ist nicht die Idee des Staates, nicht die dynastische Idee, nicht die einer kulturellen Symbiose verschiedener Völker (Österreich könnte ein Weltexperiment sein), - wahrscheinlich ist das Ganze wirklich nur Bewegung zufolge Mangels einer treibenden Idee, wie das Torkeln eines Radfahrers, der nicht vorwärtstritt. (GW II, 993)

Im Kontrast zu Musils satirisch pointierter Skepsis ${ }^{7}$ offenbart Hugo von Hofmannsthal in seinem Essay Die österreichische Idee (1917) eine von Optimismus durchdrungene kulturkonservative Mentalität: Zugleich spricht er der ,österreichischen Idee‘ einen avantgardistischen Status zu. Denn sie begreife die „lebensfördernde[n]“ Krisen und ,inneren Spannungen“ als „Vorwegnahme des Tiefsten“ im „europäischen Konflikt“, das „bei uns schon fühlbar“ war, als „das übrige Europa“ noch mutlos in materialistischer „Dumpf-

4 Musil erklärt am 30.4.1926 im Interview mit Oskar Maurus Fontana: „Die Schwarzgelben haben die ,österreichische Idee ‘ [...] aus den Kriegsjahren [...]: Erlösung Österreichs von Preußen - es soll ein Weltösterreich entstehen nach dem Muster des Zusammenlebens der Völker in der Monarchie - der ,Friedenskaiser` an der Spitze“ (GW II, 939).

5 Den Begriff, WWeltösterreich“ verwendete Musil bereits 1926 im besagten Interview (GW II, 939). - Hier ist übrigens irrtümlich vom „35jährige[n]“ Regierungsjubiläum des deutschen Kaisers Wilhelm II. die Rede (ibid.). De facto umfasste die mit dem Dreikaiserjahr 1888 beginnende Zeitspanne seiner Regentschaft (bis 1918) aber nur 30 Jahre.

6 Aufgrund erotischer Affinitäten kommt Diotima sogar auf die bizarre Idee, ausgerechnet den Preußen Arnheim für die Leitung der großen österreichischen ,Parallelaktion` vorzuschlagen. - Ohnehin ist den Lesern des Romans angesichts der europäischen Geschichte bewusst, dass alle aus Anlass des Jubiläums geplanten Festivitäten, die im fiktiven Szenario des Romans fortwährend in sterilen Leerlauf münden, auch realhistorisch ins Vakuum führten: Denn der Zusammenbruch der österreichischen, preußischen und russischen Monarchie machte die geplanten Jubiläumsfeiern schlicht überflüssig. Zu Musils Roman Der Mann ohne Eigenschaften vgl. Neymeyr 2005.

7 Vgl. dazu Neymeyr 1996, 576-607. 
heit“"verharrte, ohne ,seinen größten politischen, das heißt geistigen Problemen ins Auge zu schauen" (Hofmannsthal 1979, 455). ${ }^{8}$

Hofmannsthal „österreichischer Optimismus“ (Hofmannsthal 1979, 456) wird von Musil keineswegs geteilt. Vielmehr geht er in seinem Essay Buridans Österreicher (1919) ${ }^{9}$ mit satirischer Pointierung auf den Heimat-Mythos Österreich ein: So sieht Musil in Österreich „eine zauberhafte Vielfalt" und „wunderbare Kreuzung von Rassen und Nationen, ein märchenschönes Mit- und Ineinander aller Kulturen“ (GW II, 1031). Nach der Inszenierung dieses realitätsfernen Prachtbildes führt Musil den Heimat-Mythos ironisch ad absurdum:

\begin{abstract}
Warum es uns trotzdem immer eigentlich ein wenig schlecht ging, kommt, abgesehen von unserer zu großen Bescheidenheit, nur vom Pech. Wir hätten theoretisch mit unserer Völkerdurchdringung der vorbildliche Staat der Welt sein müssen; mit solcher Sicherheit, daß sich eigentlich gar nicht sagen läßt, warum wir praktisch nicht darüber hinausgekommen sind, ein europäisches Ärgernis zu sein. (GW II, 1031)
\end{abstract}

Hier tritt ein radikaler Kontrast zu Hofmannsthals Ansicht hervor, die ,österreichische Idee' nehme seismographisch europäische Problemkonstellationen vorweg und habe deshalb eine zukunftsweisende Bedeutung für ganz Europa.

\title{
2 Heimat, Held und Kaiser: Mythen und ihre Demontage in Roths Radetzkymarsch
}

Aus der Retrospektive der Zwischenkriegszeit beleuchtet Roths Radetzkymarsch die Endphase der Doppelmonarchie Österreich-Ungarn. Dabei rückt die Epochenwende nach der Habsburger Monarchie mit in den Blick, indem auch die historischen Ereignisse jen-

8 „Das Wesen dieser Idee“ sieht Hofmannsthal in ihrer Selbsterneuerungskraft aufgrund einer „inneren Polarität“, die ihr etwas „Unzerstörbares“ sichere und sie sogar „zu einer sehr hohen Synthese“ befähige (Hofmannsthal 1979, 456).

9 Der Titel erklärt sich aus der ironisch zugespitzten Aporie, in der Musil hier den „gute[n] Österreicher“ sieht: nämlich unentschlossen „zwischen den zwei Heubündeln Buridans, Donauföderation und GroßDeutschland“ (GW II, 1030). Anstelle einer spezifisch „österreichische[n] Kultur“ erblickt Musil bloß „ein begabtes Land, das einen Überschuß an Denkern, Dichtern, Schauspielern, Kellnern und Friseuren erzeugt“ (GW II, 1031). Eine brauchbare Alternative dazu würde laut Musil eine adäquate „Funktionstüchtigkeit“ des Staates voraussetzen (GW II, 1031), weil die Kultur eines Landes nicht von der „Kulturfähigkeit seiner Bewohner" abhängt, sondern von der ,gesellschaftlichen Struktur" und Organisation im Ganzen (GW II, 1042). Statt „Österreich unter dem Namen Donauföderation als europäischen Naturschutzpark für vornehmen Verfall weiterzuhegen“ (GW II, 1032), schlägt Musil deshalb schon 1919 in seinem Essay Der Anschluß an Deutschland den „staatliche[n] Zusammenschluß“ von „DeutschÖsterreich und Deutschland“" vor (GW II, 1036). 
seits der Lebenszeit des historischen Kaisers Franz Joseph I. reflektiert werden, der im November 1916 hochbetagt verstarb. Krisenbewusstsein und Untergangsahnung, EpigonenProblematik und Décadence-Symptome entfaltet der Roman in der Mentalität der Figuren, und zwar durch Desorientierung, Verunsicherung und nostalgische Sinnsuche, aber auch durch Defätismus und Resignation oder durch satirisch grundierte Skepsis. Mitunter können sich die Untergangsphantasien der Figuren sogar bis zu apokalyptischen Visionen steigern (vgl. RM 336, 352). Der kritische Blick auf typische Denkmuster reicht bis zu ironischer Demontage, die allerdings nicht allein dem Heimat-Mythos gilt. Denn Roth verbindet ihn im Roman mit dem Kaiser-Mythos und Helden-Mythos zu einem spannungsreichen Motivgeflecht.

Schon die Anfangspartie gilt einer Heldentat und ihrer fragwürdigen Mythisierung: Dass der Infanterie-Leutnant Joseph Trotta 1859 in der Schlacht von Solferino dem Kaiser geistesgegenwärtig das Leben rettet (RM 139-140) und dadurch ,in die Geschichte seines Regiments" eingeht (RM 140), wird für ihn selbst - entgegen aller Erwartung - zu einer problematischen Lebenszäsur. Von diesem Initialereignis aus entfaltet Roths $R a-$ detzkymarsch die Geschichte der Familie Trotta in der Abfolge dreier Generationen. ${ }^{10}$ Der schwächliche Enkel lebt im Schatten seines Großvaters, des Helden von Solferino, der ihm durch sein ,rätselhaftes Bildnis“ (RM 194), ein erstarrtes Relikt früherer Lebendigkeit, auf unheimliche Weise gegenwärtig bleibt. Im „Herrenzimmer des Bezirkshauptmanns" Franz von Trotta, des Sohnes des Helden von Solferino, hängt dessen Porträt als permanenter Fixpunkt der Erinnerung in fast unerreichbarer Höhe ${ }^{11}$ unter der Decke: „Die Neugier des Enkels kreiste beständig um die erloschene Gestalt und den verschollenen Ruhm des Großvaters“ (RM 168). Zahlreiche Erwähnungen des Gemäldes und seiner düsteren Präsenz im Bewusstsein von Sohn und Enkel interpunktieren leitmotivisch den Roman: „Man lebte im Schatten des Großvaters! Das war es! Man war ein Enkel des

\footnotetext{
${ }^{10}$ Nicht mitgezählt ist dabei der Vater des Helden von Solferino, der im Roman nur kurz zum Thema wird. Roth selbst bezeichnet „die merkwürdige Familie der Trottas“ im Vorwort zum Erstdruck seines Romans Radetzkymarsch (als Fortsetzungsroman in der „Frankfurter Zeitung“) als „die Spartaner unter den Österreichern" (abgedruckt ist dieses Vorwort in: Roth, Werke, Bd. 5, 875). Und über den Sohn des Helden von Solferino heißt es im Radetzkymarsch: Seine „Gesinnung [...] nannte er eine spartanische. [...] Er war ein Spartaner. Aber er war ein Österreicher" (RM 162).

${ }^{11}$ Dieser außergewöhnlichen Höhe entspricht die singuläre Bedeutung des Ahnenporträts. Dass der Heldenmythos bis zum Lebensende des Bezirkshauptmanns weiterwirkt, der zwei Jahre nach dem Tod seines Sohnes ausgerechnet am Begräbnistag des Kaisers stirbt, zeigt die Sterbeszene: Er lässt sich zuerst seinen Kanarienvogel, dann das Porträt des Helden von Solferino ans Sterbebett bringen. Dass er den Vogel zwar noch wahrzunehmen vermag, das Bildnis aber nicht mehr (vgl. RM 454), wird hier als ironische Pointe inszeniert.
} 
Helden von Solferino, der einzige Enkel. Man fühlte den dunklen, rätselhaften Blick des Großvaters im Nacken! Man war der Enkel des Helden von Solferino!" (RM 198). ${ }^{12}$

Diese Obsession durch die Imago des Ahnen zeigt die Unentrinnbarkeit der Memoria: „An dieses Bildnis klammerte sich die Erinnerung Carl Josephs als an das einzige und letzte Zeichen“ seiner „Vorfahren“ (RM 194): Dass er immer wieder „den dunklen Blick des Großvaters im Nacken" fühlt (RM 424), spricht dafür, dass diese Last seine Identitätsbildung behindert, obwohl er selbst das Ahnenporträt wie den Heldenmythos sogar als stabilisierende Kraftreserve empfindet:

Fühlte man nicht ständig im Nacken den dunklen, rätselhaften Blick des Großvaters, wer weiß, wie jämmerlich man durch dieses schwere Leben torkeln müßte. Mutig wurde man nur, wenn man an den Helden von Solferino dachte. Immer mußte man beim Großvater einkehren, um sich ein bißchen zu stärken. (RM 247)

Zum Eindruck einer Identitätsschwäche trägt auch das Indefinitpronomen „man“ bei, weil es das Ich in diffuser Anonymität aufzulösen scheint. Später muss Carl Joseph seinem Vater sogar bekennen: „Ich bin nicht stark genug für dieses Bild“ (RM 296). Und zuvor schon gesteht er dem befreundeten Arzt Demant mit Blick auf das Ahnenporträt: „Ich lebe vom Großvater" (RM 220).

Diese Eindrücke des Enkels geben das epochentypische Syndrom einer Identitätsproblematik zu erkennen, die im Roman essentiell mit dem Phänomen der Epigonalität verbunden ist. Für seinen Vater verflüchtigt sich das Helden-Porträt geradezu ins Pointillistische: „Das Angesicht seines Vaters konnte er nicht deutlich sehen. Das Gemälde zerfiel in hundert kleine, ölige Lichtflecke und Tupfen“ (RM 368-369). Zum optischen Eindruck von Fragmentierung und Aufösung, der an impressionistische Tendenzen in der bildenden Kunst denken lässt, vor allem an den Pointillismus von Georges Seurat und Paul Signac, trägt die außergewöhnliche Platzierung des Bildes wesentlich bei: Auf dem Sessel auf den Zehenspitzen stehend, kann der Bezirkshauptmann am unteren Bildrand nur gerade eben noch die Signatur des Künstlers entziffern (vgl. RM 369). Und auch aus der Perspektive des Helden-Enkels Carl Joseph „zerfiel“ das Bild, ,aus der Nähe“ betrachtet, ,in zahlreiche tiefe Schatten und helle Lichtflecke, in Pinselstriche und Tupfen“ (RM 168), ja es schien ihm zusehends „blasser und jenseitiger zu werden, als stürbe der Held von Solferino noch einmal dahin, als zöge er sein Andenken langsam zu sich hinüber“ (RM 169).

\footnotetext{
${ }^{12}$ Wenn sich später der Bezirkshauptmann, „der früh Gealterte“, an den „Geist der alten Zeit und der alten habsburgischen Monarchie“ erinnert, ist vom „Schatten der Geschichte“ die Rede (RM 399).
} 
Analog zu dieser Perspektive auf das Heldenporträt erlebt Carl Joseph von Trotta, der Enkel des Helden von Solferino, Momente, in denen die Realität für ihn auf ähnliche Weise diffundiert wie das Porträt: „Für ein paar Augenblicke schien es dem Leutnant, daß sein Gast zerfließe und sich aus undeutlichen, grauen Flecken wieder zusammensetze“ (RM 380). - Der Eindruck einer instabilen Wirklichkeit scheint hier mit der Labilität seiner eigenen Identität zu korrespondieren. Markant treten dabei zugleich Affinitäten zu zeitgenössischen Subjekt-Theorien hervor: Ernst Mach zog in seinem epochalen Werk Die Analyse der Empfindungen und das Verhältnis des Physischen zum Psychischen bereits 1886 erkenntnistheoretische Konsequenzen aus der modernen Identitätskrise. Denn er verstand das Ich nicht als ,unveränderliche, bestimmte, scharf begrenzte Einheit“ (Mach 1991, 19), sondern lediglich als einen diffusen „Komplex von Erinnerungen, Stimmungen, Gefühlen“ (Mach 1991, 2), um dann sogar das Fazit zu formulieren: „Das Ich ist unrettbar" (Mach 1991, 20).

Außerhalb des Figurenbewusstseins liegen allerdings die Fakten, die Roths Radetzkymarsch fiktional inszeniert. Denn der Helden-Mythos, der das Bewusstsein des Enkels so nachhaltig prägt, erschien dem Helden selbst eher wie ein Verhängnis. Joseph Trotta, von einfachen slowenischen Bauern abstammend, wurde nach der Rettung des Kaisers mit dem höchsten Orden des Landes ausgezeichnet und in den Adelsstand erhoben (vgl. RM 141), empfand diese Karriere aber als Negativzäsur, weil sie ihn seiner Herkunftswelt entfremdete. Ausgerechnet der Heldenmythos führt insofern zum Heimatverlust. Denn „von der überirdischen Macht des Maria-Theresien-Ordens gesegnet“ (RM 143), ist er den Kameraden fortan entrückt und erscheint seinem Vater „wie ein militärischer Gott“ (RM 143): „Es ist tatsächlich aus! dachte der Hauptmann Trotta. Getrennt von ihm war der Vater durch einen schweren Berg militärischer Grade“ (RM 143-144). Zugleich fühlt er sich selbst dazu ,verurteilt, in fremden Stiefeln auf einem glatten Boden zu wandeln" (RM 141): Nur mühsam vermag er sich mit seinem neuen Rang als Held von Solferino zu arrangieren (RM 144), bis ihn - Jahre später - die patriotische Mythisierung seiner Tat in den Schulbüchern rebellisch reagieren lässt. Denn die Heldenlegende kaschiert nicht nur die historische Niederlage der österreichischen Armee 1859 in der Schlacht von Solferino ${ }^{13}$ durch eine heroische Aura, und zwar gemäß dem mit dem Ra-

${ }^{13}$ Die historische Schlacht von Solferino fand am 24. Juni 1859 statt: Auch strategische Fehler des jungen Kaisers Franz Joseph I. trugen zur Niederlage der Österreicher in dieser Entscheidungsschlacht des Sardinischen Krieges zwischen dem Kaisertum Österreich und dem Königtum Sardinien mit dem verbündeten Frankreich unter Napoléon III. bei. Die historische Folge war, dass Österreich die Lombardei abtreten musste, so dass der Weg zur Einigung Italiens frei wurde: im sogenannten ,Risorgimento ' (bis 1870). - Den historischen Fakten näher als die mit Siegespathos grundierte Geschichtsklitterung, die Roth im Radetzkymarsch durch die wahrheitswidrige Schulbuch-Legende mit satirischem Valeur inszeniert, ist die Darstellung der Schlacht von Solferino im Antikriegsroman Die Waffen nieder! (1889) der Friedensaktivistin Bertha von Suttner. 
detzkymarsch verbundenen Nationalbewusstsein ${ }^{14}$, sondern verfälscht zudem die Fakten so sehr, dass Trotta sein Wahrheitsethos geradezu provoziert sieht: Tatsächlich musste der Infanterieleutnant Trotta den in naivem Leichtsinn durch den Feldstecher schauenden Kaiser in einer Gefechtspause durch Niederreißen vor feindlichen Kugeln der Nachhut bewahren (vgl. RM 140). Der erfundene Mythos jedoch heroisiert den Retter und mit ihm zugleich auch den Monarchen: Auf dem Pferd herbeisprengend, habe Trotta den gegen feindliche Übermacht heldenhaft kämpfenden Kaiser unterstützt, indem er so viele Feinde erschlug, dass ,sich der junge, unerschrockene Monarch leicht der immer schwächer werdenden Angriffe erwehren“ konnte (RM 145).

Angesichts der Schulbuch-Legende fühlt sich der Held von Solferino selbst als Opfer eines Heldenmythos, der mit dem Kaisermythos ${ }^{15}$ amalgamiert und zugleich in den Dienst des Österreich-Mythos gestellt wird: „Vertrieben war er aus dem Paradies der einfachen Gläubigkeit an Kaiser und Tugend, Wahrheit und Recht, und gefesselt in Dulden und Schweigen, mochte er wohl erkennen, daß die Schlauheit den Bestand der Welt sicherte, die Kraft der Gesetze und den Glanz der Majestäten “(RM 149). ${ }^{16}$ Daher versucht Trotta mit offiziellen Interventionen zunächst vergeblich die Löschung der SchulbuchLegende zu erzwingen, quittiert dann desillusioniert den Militärdienst, um fortan anspruchslos wie „ein kleiner slowenischer Bauer“ zu leben (RM 149). Sein Sohn Franz allerdings folgt als Bezirkshauptmann der Maxime: „Das Schicksal hat aus unserm Geschlecht von Grenzbauern Österreicher gemacht. Wir wollen es bleiben“ (RM 256). ${ }^{17}$

Roths Roman bringt die Schlacht von Solferino in ein historisches Spannungsverhältnis zum titelgebenden „Radetzkymarsch“, den Johann Strauß d. Ä. zur Ehrung für den Feldmarschall Radetzky komponiert hatte, und zwar nach dessen Sieg über das Königreich Sardinien-Piemont 1848/49, durch den die Lombardei und Venetien - trotz nationaler Revolutionen - zunächst noch im österreichischen Kaiserreich gehalten werden konnten. In seinem Feuilleton-Text Konzert im Volksgarten bezeichnete Joseph Roth den

\footnotetext{
${ }^{14}$ Klaus-Detlef Müller diagnostiziert die nationale Bedeutung des Radetzkymarschs für Österreich so: „Mit dem Radetzkymarsch wird gewissermaßen die militärische und politische Niederlage bei Solferino verdrängt“" (Müller 1993, 302).

${ }^{15}$ Vgl. auch die betont klischeehafte Inszenierung des jungen Kaisers Wilhelm II. in Heinrich Manns Roman Der Untertan (1918).

${ }^{16}$ Diese Romanpassage legt (wie etliche andere) Skepsis gegenüber Bönings These nahe, der Erzähler in Roths Radetzkymarsch begegne allen Figuren nicht nur mit „Sympathie“, sondern sogar mit „Liebe“; daher werde in diesem Roman „nicht moralisiert, sondern nur liebevoll konstatiert“ (Böning 1968, 32).

${ }^{17}$ Von der permanenten Anstrengung, diese neue Identität aufrechtzuhalten, zeugt sein von nostalgischer „Wehmut" und einer „knöchernen Härte“ bestimmter Habitus (RM 174). - In vielerlei Hinsicht anders gestaltet sich später die Situation seines Sohnes, des Leutnants Carl Joseph von Trotta, der zwischen Österreichertum und Slawentum, zwischen seiner militärischen Lebenswelt und projektiven Phantasien von einer authentischen Existenz in bäuerischer Dorfidylle innerlich changiert.
} 
Radetzkymarsch mit einer paradoxen Pointe als „Marseillaise des Konservatismus“ (Roth 1990d, 923).

Ausgehöhlt wird der habsburgische Mythos ${ }^{18}$ in Roths Roman bezeichnenderweise gerade dort, wo die nationale Identität emphatisch beschworen wird, etwa in der Perspektive des Leutnants Carl Joseph von Trotta, des Enkels des Helden von Solferino: „Daheim, in der mährischen Bezirkshauptstadt W., war vielleicht noch Österreich. Jeden Sonntag spielte die Kapelle [...] den Radetzkymarsch. Einmal in der Woche, am Sonntag, war Österreich. Der Kaiser, der weißbärtige, vergeßliche Greis mit dem blinkenden Tropfen an der Nase, und der alte Herr von Trotta waren Österreich“ (RM 424).

Die machtvolle Inszenierung des Heimat-Mythos in der Österreich-Imago wird hier in mehrfacher Hinsicht konterkariert: Schon die Vorstellung eines vergesslichen alten Kaisers mit Schnupfen durchkreuzt jede charismatische Überhöhung. Und mehr noch: Zwar versucht sich der Helden-Enkel hier in einem stabilen Kontinuum zu beheimaten, indem er sich auf Rituale fixiert, mit denen die Obrigkeit das Nationalgefühl im Volk zu fördern trachtet. Aber diese Mentalität wird zugleich durchbrochen, weil sich diese Memoria auf Diskontinuierliches beschränkt, nämlich auf,Zeitinseln ' im Wochenrhythmus: Denn die Sonntage werden hier als Fixpunkte patriotischer Identifikationsbereitschaft und als imaginative Konzentrate von Heimatgefühlen inszeniert und auf diese Weise mit nationaler Bedeutung überfrachtet. Hinzu kommt der ironische Effekt einer künstlich erzeugten Raum-Zeit-Koinzidenz, wenn allein der in verlässlicher Regelmäßigkeit wiederkehrende Wochentag, der seinen Sonderstatus durch die Aufführung des Radetzkymarschs erhält, durch das auf ihn projizierte Nationalgefühl der Bürger sogar das Staatsgebilde selbst repräsentieren soll: „Einmal in der Woche, am Sonntag, war Österreich“ (RM 424). - Das patriotische Konstrukt wird hier also als fragwürdige Inszenierung kenntlich gemacht und dadurch unterminiert. Sofern sich das Nationalbewusstsein auf sonntägliche ,Zeitinseln' beschränkt, die der Radetzkymarsch adelt, scheint ein stabilisierendes Kontinuum kaum möglich zu sein - zumal ohnehin längst das „Vaterland der Trottas zerfiel und zersplitterte“ (RM 423). Diese Décadence kann auch das inszenierte Nationalbewusstsein nicht rückgängig machen.

\footnotetext{
${ }^{18}$ Laut Magris (1966/2000) ist ,Mythos“ „ein ambivalenter Begriff“, der zwischen Wesenskern, stabilem Wert, Ideenkonstruktion und Ideologie changiert (ibid., 11). Dies gilt auch für den von Magris zwischen „Verzauberung" und „Demolierung" situierten ,habsburgischen Mythos' (ibid., 12): Dieser Mythos ersetze die soziale Wirklichkeit „durch eine fiktive, illusorische Realität“ (ibid., 22), stilisiere Defizite wie den „rückwärtsgewandte[n] Immobilismus“ zu „Vorzügen und Tugenden“ (ibid., 26) und begegne „den zentrifugalen Fermenten“ und der historischen Dynamik mit „Sinn für Ordnung und Hierarchie“ (ibid., 29). Magris benennt drei Hauptaspekte des ,habsburgischen Mythos': „Übernationalität“ sowie „Bürokratentum“ und „Hedonismus“ (ibid., 30). Das Klima „,ornehmen Verfalls“ (ibid., 37) und „melancholiegetränkten Leichtsinns“ sowie das „System akkurater Schlamperei“ hält er für eine „typisch österreichische mediocritas" (ibid., 38).
} 
Wie sehr sich der Heimat-Mythos Österreich bereits zu verflüchtigen droht, zeigt der zeitlich und räumlich reduzierte Geltungsbereich des Patriotismus: „Einmal in der Woche, am Sonntag, war Österreich“ (RM 424). Zudem wird der Realitätsstatus der Österreich-Imago durch das Modalwort ,vielleicht' in die Sphäre des bloß Hypothetischen entrückt und verliert dadurch sein identitätsstiftendes Potential: „Daheim, in der mährischen Bezirkshauptstadt W., war vielleicht noch Österreich“ (RM 424). Von HeimatMythos und Österreich-Leitbild bleiben so nur noch Rudimente erhalten, die zudem in eine spekulative Unverbindlichkeit geraten.

Dass sich die Ära des Habsburger-Reiches schon in der Erzählgegenwart des Romans ihrem Ende näherte, ist den Lesern als Geschichtswissen selbstverständlich präsent und auch mehreren Figuren bereits als Zukunftsahnung gegenwärtig. - Zugleich erscheint diese Österreich-Imago in Roths Roman als ironische Kontrafaktur zu einer Strophe aus Franz Grillparzers patriotischem Gedicht Feldmarschall Radetzky (1848):

Glück auf, mein Feldherr, führe den Streich!

Nicht bloß um des Ruhmes Schimmer,

In Deinem Lager ist Österreich,

Wir andern sind einzelne Trümmer.

(Grillparzer 1963, 318-319)

Für eine intertextuelle Grillparzer-Reverenz spricht schon die syntaktische Strukturanalogie in Roths Inszenierung des Österreich-Topos in Verbindung mit dessen extravaganter Engführung durch lokale Beschränkung: „Daheim [...] war vielleicht noch Österreich“( RM 424).

Übrigens zitiert Roth den relevanten Vers (fünf Jahre nach dem Erscheinen des Romans) auch in seinem Essay Grillparzer. Ein Porträt (1937): „Er hatte die Gabe, in die Ferne zu ahnen, und er tauchte in die Zukunft wie andere in die Vergangenheit", schreibt Roth hier über Grillparzers visionäre Kraft. Sein Diktum „,Von der Humanität durch Nationalität zur Bestialität ““ sei „kein Aperçu, sondern ein Angstschrei angesichts des nahenden Zerfalls der Monarchie, des Endsiegs der erwachenden nationalen Barbarei. Ein Angstschrei, nachzufühlen selbst in dem Siegesruf an Radetzky: ,In deinem Lager ist Österreich!““ (Roth 1991a, 744) - Die tiefreichende Ambivalenz, die Roth dem GrillparzerGedicht aus dem Revolutionsjahr 1848 zuschreibt, gilt umso mehr für die ironische Konterkarierung des Österreich-Mythos in Roths Roman: „Daheim, in der mährischen Bezirkshauptstadt W., war vielleicht noch Österreich“" (RM 424). 


\section{Patriotismus und Kaiserkult: Entmythologisierung im Zeichen der Zeitenwende}

Infantile Regressionsbereitschaft verrät der Kaiserkult: So erfüllt den Bezirkshauptmann Franz von Trotta ein kindliches „Heimweh nach dem Kaiser“ (RM 403), als er ihn in der Residenz aufsuchen will, um die unehrenhafte Entlassung des Sohnes ${ }^{19}$ wegen seiner Schulden durch kaiserliche Gnade abzuwenden. Seine autoritätshörige Unterwürfigkeit reicht dabei bis zur Selbstinfantilisierung: „Nach den einfachen Begriffen Herrn von Trottas war es nicht ein Mißbrauch der kaiserlichen Gnade, wenn der Diener Seiner Majestät vertrauensselig zu Franz Joseph ging wie ein Kind in der Not zu seinem Vater“ (RM 396).

Die Asymmetrie zwischen Monarch und Untertan im Kaisermythos wird hier gemäß traditioneller Familienhierarchie inszeniert. Zugleich klingt der Heimatmythos an, wenn Franz von Trotta vor dem Aufbruch zur Residenz sogar „Heimweh nach dem Kaiser“ verspürt (RM 403). - Diese Untertanen-Mentalität ist seinem Sohn später längst abhandengekommen, so dass ihm auch die selbstverständliche Identitätssicherung im Bewusstsein nationaler Identität fehlt: „Der Leutnant Trotta glich einem Manne, der nicht nur seine Heimat verloren hatte, sondern auch das Heimweh nach dieser Heimat" (RM 353). So vermag er nicht mehr ,als Mitleid mit einem alten Mann“ zu empfinden, als sich ihm „der Kaiser näherte“ (RM 352-353). Die majestätische Aura, die im Rahmen der hierarchischen Ordnung auch persönliche Distanz voraussetzt, verflüchtigt sich hier. Der Heimatverlust führt in ein Sinnvakuum.

Aber die Strategien der Entmythologisierung durch Desillusionierung reichen noch weiter: Denn die Aufösung stabilisierender Fixpunkte der eigenen Identität beschränkt sich nicht auf die Untertanen-Mentalität, sondern greift auch auf die Majestät selbst über. Dass Roths Radetzkymarsch den Kaiser Franz Joseph I. keineswegs ins Numinose entrückt, zeigen charakteristische Innenperspektiven, die das instabile Selbstgefühl und die naive Sichtweise dieser Kaiser-Figur offenbaren. Das Militär scheint er vorrangig im Hinblick auf Repräsentationszwecke und imposante Inszenierung zu schätzen; in dieser Perspektive entgleiten ihm jedoch die eigentlichen Funktionszusammenhänge:

${ }^{19}$ Das Schicksal des Enkels zeigt, wie eine Okkupation durch den Ahnenkult die Entfaltung einer eigenen Identität blockieren kann. Entgegen eigener Neigung ließ sich Carl Joseph von Trotta vom Vater zum Soldatenberuf bestimmen, ohne den Anforderungen wirklich gewachsen zu sein. Zwar erreichte er beim Militär trotz schwacher Leistungen durch Protektion (RM 169, 334) den Rang eines Kavallerie-Leutnants, aber in einem Infanterie-Bataillon nahe der russischen Grenze verfiel er später dem Alkoholismus. Als ihm die unehrenhafte Entlassung wegen erheblicher Schulden drohte, gelang es seinem Vater, die „fatale Angelegenheit“ des Sohnes in der Residenz sogar von „Allerhöchster Stell ““ „begraben“ zu lassen (RM 408) und dadurch die Familienehre zu retten. 
Er hatte Kriege nicht gern (denn er wußte, daß man sie verliert), aber das Militär liebte er, das Kriegsspiel, die Uniform, die Gewehrübungen, die Parade [...]. Und obwohl er wußte, daß Gott selbst ihn auf seinen Thron gesetzt hatte, kränkte es ihn dennoch in mancher schwachen Stunde, daß er nicht Frontoffizier war [...]. (RM 344)

Symptomatisch ist der Hinweis: „Er verstand nichts vom Sinn der Manöver. Er wußte nur, daß die ,Blauen' gegen die ,Roten 'kämpften“ (350). Im Hinblick auf seine Soldaten halten sich „Stolz auf seine Armee“ und „Bedauern über ihren Verlust“ die Waage (RM 352) - in einer apokalyptischen Vision, die bis in kosmische Dimensionen reicht: „Denn er sah sie schon zerschlagen und verstreut, aufgeteilt unter den vielen Völkern seines weiten Reiches. Ihm ging die große goldene Sonne der Habsburger unter, zerschmettert am Urgrund der Welten, zerfiel in mehrere kleine Sonnenkügelchen, die wieder als selbständige Gestirne selbständigen Nationen zu leuchten hatten" (RM 352). ${ }^{20}$

Diese erstaunlich hellsichtige Zukunftsvision des greisen Kaisers verrät eine Art metaphysischer Obdachlosigkeit. Weit entfernt von väterlicher Souveränität und Stärke ist der Kaiser im Roman von Selbstentfremdung, Verunsicherung und Angst durch die drohende Epochenwende umgetrieben. Als Projektionsfläche für infantile Beheimatungsphantasien, die von patriarchalischen Denkmustern zeugen, erscheint er auch durch seine progressive Altersschwäche ungeeignet, die ihn mental so sehr diffundieren lässt, dass er sich nicht einmal mit Sicherheit an sein Lebensalter erinnern kann (vgl. RM 351). Ja, es fällt ihm sogar „schwer, sich selbst für den Kaiser zu halten“, so dass er Selbstvergewisserung durch Nachdenken über ein Buch suchen muss (RM 345). Doch obwohl er sich über seine Identität als „Majestät von Gottes Gnaden“ dann wieder im Klaren ist, kommt sich der Kaiser in dieser Episode, „mager und alt, in einem weißen Nachthemd“ am Fenster stehend, doch „sehr winzig vor im Angesicht der unermeßlichen Nacht“ (RM 345). Und auch sein singulärer Sonderstatus an der Spitze der sozialen Hierarchie kann nicht verhindern, dass der Kaiser sogar patrouillierende Soldaten für „mächtiger“ als sich selbst hält (RM 345). Die kosmische Entgrenzung der Perspektive angesichts „der unermeßlichen Nacht“ (RM 345) und der zerschmetterten ,große[n] goldene[n] Sonne der

${ }^{20}$ Das Gefühl metaphysischer Obdachlosigkeit angesichts der desorientierenden Unendlichkeit lässt an expressive Bilderwelten Nietzsches denken, etwa an die ausdrucksstarke Imagination in seiner Schrift Die fröbliche Wissenschaft: „[...] Was thaten wir, als wir diese Erde von ihrer Sonne losketteten? Wohin bewegt sie sich nun? Wohin bewegen wir uns? Fort von allen Sonnen? Stürzen wir nicht fortwährend? [...] Irren wir nicht wie durch ein unendliches Nichts? Haucht uns nicht der leere Raum an?" (Nietzsche, KSA 3, 481). Vgl. dazu Neymeyr 2016, 336-340. - Nietzsche-Kenntnis verrät Roths Huldigung an den Geist Österreichs, die er mit dem markanten Vers ,weh dem, der keine Heimat hat!" beendet (Roth 1991b, 795), den Schlussvers von Nietzsches Gedicht Abschied (KSA 11,329), das unter dem Titel Vereinsamt bekannt ist. 
Habsburger" (RM 352) erzwingt - trotz des erhabenen Bildes - letztlich eine egalitäre Sicht, die alle sozialen Hierarchien einebnet.

Die Doktrin vom Gottesgnadentum des Kaisers als legitimatorische Basis der Habsburger Monarchie wird kritisch hinterfragt, wenn der Graf Chojnicki erklärt: „Unser Kaiser ist ein weltlicher Bruder des Papstes" (RM 290), und wenn er zugleich betont, dieses monarchische System basiere ,auf dem Glauben, daß Gott die Habsburger erwählt hat, über soundso viel christliche Völker zu regieren“ (RM 290). ${ }^{21}$ - Vollends suspekt wird das elitäre Erwähltheitsphantasma dann nämlich durch eine Verschiebung der Perspektive, die zu dem Fazit führt: Folglich ist „keine andere Majestät in Europa so abhängig von der Gnade Gottes und vom Glauben der Völker“ daran (RM 290). Denn die Imago eines autarken Herrschers, dessen Dynastie durch vermeintlich göttliche Legitimation gesichert ist, schlägt hier dialektisch in eine essentielle Heteronomie um. ${ }^{22}$ Und der Verlust der religiös begründeten Aura des Kaisertums erscheint umso fataler, als ausgerechnet der aufkommende „Nationalismus“ im Zeitalter der Säkularisierung zum Surrogat der vormaligen Selbstlegitimation des Kaisers durch das Gottesgnadentum avanciert. Denn der Nationalismus beginnt nun als „neue Religion“ zu fungieren (RM 290). ${ }^{23} \mathrm{Be}$ kanntlich bildete dieser neue Glaube die Voraussetzung für die Emanzipationsversuche der Völker, die im historischen Prozess dazu führten, dass mit dem übergeordneten Einheitskonzept zugleich auch das Fundament des Staatsgebildes ausgehöhlt wurde, bis die multikulturelle Donaumonarchie am Ende des Ersten Weltkriegs schließlich zerfiel. Im Roman prognostiziert der Graf Chojnicki den drohenden Untergang:

die Monarchie [...] zerfällt bei lebendigem Leibe. Sie zerfällt, sie ist schon verfallen! Ein Greis, dem Tode geweiht, von jedem Schnupfen gefährdet, hält den alten Thron, einfach durch das Wunder, daß er auf ihm noch sitzen

\footnotetext{
${ }^{21}$ Wiederholt inszeniert Roths Roman mit Ironie das Fluidum religiöser Überhöhung, das durch die Sakralisierung des Kaisertums entsteht: So wird „der kaiser- und königliche Gesang der irdischen, aber immerhin Apostolischen Armee-Cherubim“ erwähnt (RM 321).

${ }^{22}$ Eine strukturanaloge Machtinversion kennzeichnet übrigens Kafkas 1917 entstandene und 1919 veröffentlichte Parabel Eine kaiserliche Botschaff, die zu Beginn den Kontrast zwischen einem übermächtigen Kaiser auf dem Sterbebett betont, der dem jämmerlichen Untertanen am Rande des Reiches eine Botschaft zugedacht hat, bis die Schlusspointe das gesamte Szenario von der projektiven Phantasie des adressierten Du abhängig macht. Und auch das Sonnensymbol, das in Roths Roman wiederholt mit der Habsburger-Dynastie verbunden wird, fungiert in Kafkas Parabel als Legitimation des kaiserlichen Boten. Vgl. Neymeyr 2003, 346-352.

${ }^{23}$ In Musils Mann ohne Eigenschaften erscheint der aufkommende Nationalismus ebenfalls als „eine Art Religionsersatz oder ein Ersatz für den guten Kaiser in Wien“ (MoE 529). Und „als Gott Kakanien den Kredit entzog, tat er das Besondere, daß er die Schwierigkeiten der Kultur ganzen Völkern zu verstehen gab“ (ibid.). Dennoch charakterisiert die Erzählinstanz den „berühmten kakanischen Nationalismus“ zunächst ,nicht“ als etwas „besonders Wildes“: „Er war mehr ein geschichtlicher als ein wirklicher Vorgang“ (MoE 529). Dann aber folgt die satirische Pointe: „Die Menschen dort hatten einander recht gern; sie schlugen sich zwar die Köpfe ein [...], aber das taten sie nur aus Rücksichten höherer Kultur“ (ibid.).
} 
kann. Wie lange noch, wie lange noch? Die Zeit will uns nicht mehr! Diese Zeit will sich erst selbständige Nationalstaaten schaffen! Man glaubt nicht mehr an Gott. Die neue Religion ist der Nationalismus. (RM 290)

Vor dem Horizont der Epochen-Dämmerung verbindet Roths Radetzkymarsch die Tendenz des Kaisers zu mentaler Diffusion auch mit dem Eindruck einer universellen Entgrenzung die Mikro- und Makrokosmos korreliert: „Die Grillen zirpten. Ihr Gesang, unendlich wie die Nacht, weckte die gleiche Ehrfurcht im Kaiser wie die Sterne. Zuweilen war es dem Kaiser, als sängen die Sterne selbst. [...] Ihm war, als schwämme er auf dem Meer der Zeit - nicht einem Ziel entgegen, sondern regellos auf der Oberfläche herum, oft zurückgestoßen zu den Klippen“" (RM 346). ${ }^{24}$ - Diese in kosmische Dimensionen expandierende Aufösungsphantasie macht den Monarchen zum Objekt der Naturkräfte und lässt ihn orientierungslos in der unüberschaubaren Weite des Universums vagieren. Der identitätsbildende Mythos Heimat, der räumliche Begrenzung voraussetzt, wird hier durch kosmische Entgrenzung zum Verschwinden gebracht.

In schroffem Kontrast zur physischen Fragilität des Monarchen inszeniert der Roman bereits in einer früheren Passage ein unheimliches Fluidum des Anorganischen: durch die Vorstellung einer kristallinen Unsterblichkeit des Kaisers, die ihn der Sphäre menschlicher Vergänglichkeit vollends entrückt. Denn er scheint „in seiner eisigen und ewigen, silbernen und schrecklichen Greisenhaftigkeit eingeschlossen zu bleiben wie in einem Panzer aus ehrfurchtgebietendem Kristall. Die Jahre wagten sich nicht an ihn heran. Immer blauer und immer härter wurde sein Auge. Seine Gnade selbst, die über der Familie der Trottas ruhte, war eine Last aus scheidendem Eis“ (RM 203) ${ }^{25}$ - so jedenfalls der un-

${ }^{24}$ Diese Vision erinnert an die Agonie der sterbenden Protagonistin am Ende der Monolognovelle Fräulein Else, die Schnitzler mit großer Publikumsresonanz bereits 1924 veröffentlicht hatte - acht Jahre bevor Roths Radetzkymarsch erschien. Elses Bewusstseinsauflösung mündet durch surreale Visionen und narkotische Flugphantasien in eine imaginäre Verschmelzung mit dem Kosmos. Dabei trägt ein musikalisch unterlegter Steigerungszustand zur suggestiven Intensität der ekstatischen Entgrenzung bei. Analog zur archaischen Idee der Sphärenharmonie gestaltet sich die akustische Halluzination von Chor- und Orgelmusik in Fräulein Else: „Alle singen mit. Die Wälder auch und die Berge und die Sterne. Nie habe ich etwas so Schönes gehört. Noch nie habe ich eine so helle Nacht gesehen" (Schnitzler 1972, 381). - Vor allem das Motiv der singenden Sterne lässt in Roths Radetzkymarsch eine intertextuelle Reminiszenz an Schnitzlers Erzählung Fräulein Else vermuten. Die Monolognovelle entfaltet das letale Delirium Elses als ein impressionistisches Vibrieren, das Wirklichkeitssegmente in Gestalt akustischer Eindrücke und Körperempfindungen mit Gedankenfetzen und Traumbildern zu einem synästhetischen Rausch verbindet: im Schwebezustand der Agonie (vgl. Neymeyr 2007, 207.)

${ }^{25}$ Dass im Roman gleichwohl von „,äterlicher Huld“ des Kaisers die Rede ist, bildet dazu keinen Widerspruch, wie der Kontext zeigt: „Das porzellanblaue Auge des Allerhöchsten Kriegsherrn, erkaltet auf so vielen Bildern an so vielen Wänden des Reiches, füllte sich mit neuer, väterlicher Huld und blickte wie ein ganzer blauer Himmel auf den Enkel des Helden von Solferino" (RM 321). Der pathetische Nachdruck dieser hyperbolischen Imago entspringt nämlich allein der personalen Perspektive des Enkels selbst, die von kindlichem Verehrungsbedürfnis und projektiver Sehnsucht zeugt. - Deutlich kühler erscheint schon an früherer Stelle der papierne Blick eines Kaisers-Porträts: Neben der Standuhr „sah der Aller- 
realistische Eindruck des Leutnants Carl Joseph, der den Kaiser momenthaft jenseits der conditio humana situiert. Ebenso weltfremd erscheint die - semantisch genau konträr angelegte - romantische Todeserotik in seinem Wunsch, „für diesen Kaiser in einem wonnigen, warmen und süßen Tod dahinzusterben“ (RM 203). Die spannungsreich pointierte Imago von kristallinem Leben und warmem Tod tendiert zum Oxymoron und schafft insofern durch dialektische Vermittlung Einheit gerade in der Polarität. Durchkreuzt wird die Vorstellung einer „kristallinen Unsterblichkeit“ des Monarchen ohnehin durch die desillusionierende, jede Form auratischer Autorität vollends ad absurdum führende personale Innensicht des Kaisers selbst, den der Roman ungeschönt in körperlicher Fragilität und seniler Schwäche vorführt (vgl. RM 344-352).

\section{Todesästhetik und Epochendämmerung}

Die Entmythologisierung des Kaisermythos, den Roths Roman so inszeniert, dass ihm dadurch die Aura abhandenkommt, hat zugleich Einfluss auf die Bewertung der patriotischen Propaganda. Insofern betrifft sie auch den Heldenmythos und die romantische Phantasmagorie des Heldentodes für den Kaiser. Entfaltet wird sie im Enthusiasmus des Helden-Enkels, der als Kadettenschüler „für diesen Kaiser in einem wonnigen, warmen und süßen Tod dahinzusterben" bereit war: in nostalgischer Reminiszenz an das vermeintliche „Vermächtnis des Großvaters“, „dem Kaiser das Leben zu retten“ (RM 203).

Diese heroische Todesromantik wird in Roths Radetzkymarsch ironisch konterkariert: Dies gilt schon für die kurios anmutende Selbstüberforderung des Helden-Enkels, wenn er sich an die Rettungstat des Großvaters wie an ein schicksalhaftes genealogisches Perpetuum mobile gekettet fühlt: „ohne Unterbrechung rettete man, wenn man ein Trotta war, dem Kaiser das Leben“ (RM 203). Nur wenig später lässt der Roman die Tat des Helden von Solferino dann sogar in epigonaler Schwundstufe mit humoristischer Note wiederkehren: als der Enkel das Porträt des Kaisers aus unwürdigem Ambiente rettet, nämlich aus dem Bordell. Diese Szene repräsentiert Surrogat und epigonale Miniaturform des Heldenmythos zugleich, wie der Helden-Enkel auch selbst erkennt, wenn er relativierend feststellt: „Ich hab’ keine Gelegenheit, ihm das Leben zu retten; leider!“ (RM 209). Als kuriose Überkompensation dieser Einsicht, die allerdings erneut in groteske Überforderung mündet, erscheint es, wenn Carl Joseph an sein Gelübde denkt: ,an seine

höchste Kriegsherr auf seine schweigsamen Offiziere. Es wagte weder jemand, allein fortzugehn, noch den Nächsten mitzunehmen" (RM 227). - Und das Kaiser-Kapitel XV konterkariert vollends jede Erwartung „väterlicher Huld“, wenn von der strategischen Inszenierung „künstlicher Güte“ durch den Kaiser selbst die Rede ist: „Seine Augen füllte er mit künstlicher Güte, mit der wahren Eigenschaft kaiserlicher Augen“ (RM 342), die aber nur sein Desinteresse am Gegenüber verschleiern. Mit auktorialem Nachdruck werden hier die „hellen und harten Augen“ des Kaisers hervorgehoben (RM 342). 
eigene heilige Aufgabe, für den Kaiser zu sterben, jeden Augenblick zu Wasser und zu Lande und auch in der Luft [...]“ (RM 320).

Schon als Kadettenschüler glaubte der Enkel des Helden von Solferino, man sterbe für den geliebten Kaiser „am leichtesten beim Radetzkymarsch“ (RM 160). Ausdrucksstark gestaltet der Roman die Ästhetisierung des Heldentodes aus der Perspektive des Schülers, der sein eigenes Blut ganz harmonisch in den Klangrausch und Farbenteppich eines Militärkonzerts hineinströmen sieht:

Die flinken Kugeln pfiffen im Takt um den Kopf Carl Josephs, sein blanker Säbel blitzte, und Herz und Hirn erfüllt von der holden Hurtigkeit des Marsches, sank er hin in den trommelnden Rausch der Musik, und sein Blut sickerte in einem dunkelroten und schmalen Streifen auf das gleißende Gold der Trompeten, das tiefe Schwarz der Pauken und das siegreiche Silber der Tschinellen. (RM 160)

In kunstvoller rhetorischer Stilisierung entfaltet diese Impression durch Alliterationen und Assonanzen, durch ausdrucksstarke Synästhesien und Metaphern eine Ästhetisierung des Todes. Sie repräsentiert zugleich die Mentalität einer ideologischen Verblendung - als Folge patriotischer Propaganda.

Erheblich nüchterner wird später der tatsächliche Tod des Leutnants geschildert (RM 444-445), der auch keineswegs als heroische Tat erscheint, sondern eher als Folge naiven Leichtsinns und realitätsblinder Tollkühnheit im Gefühl eigener Unverletzlichkeit. Er wird getötet, als er für seine durstigen Soldaten Wasser zu holen versucht - an einem bereits "tödlichen Brunnen“, in dessen Umfeld schon „ein Dutzend Leichen“ liegen: seine eigenen Soldaten, die kurz zuvor durch Feinde ebenfalls aus dem Hinterhalt erschossen wurden (RM 444). Als der Leutnant halluzinatorisch „die ersten trommelnden Takte des Radetzkymarsches“" zu hören glaubt, werden für ihn Jugend-Reminiszenzen wieder lebendig (RM 444). Die geradezu filmische Anschaulichkeit dieser Szene, die von der narrativen Dramatik Kleistscher Prosa inspiriert zu sein scheint, verdankt sich auch ihrer rhetorischen Gestaltung. Zum Rhythmus des Radetzkymarschs passt die stilistische Präsentation der Todesszene. Eine hektische Dynamik erzeugen die schlichten, kurzen Hauptsätze, deren Staccato-Effekt das anaphorische „Jetzt" in emphatischer Position am Satzanfang noch verstärkt: „Jetzt senkte Trotta den zweiten Eimer in den Brunnen. Jetzt schmetterten die Tschinellen. Jetzt hob er den Eimer hoch. [...] Jetzt tat er zwei Schritte. Jetzt ragte gerade noch sein Kopf über den Rand des Abhangs. / Jetzt schlug eine Kugel an seinen Schädel“ (RM 444). An die Stelle von Kleists Ortsdeiktika ${ }^{26}$ lässt Roth hier

${ }^{26}$ Die markante Beschreibung der Naturkatastrophe in Kleists Erzählung Das Erdbeben in Chili (1810) macht die stilistischen Affinitäten evident: „[...] Hier lag ein Haufen Erschlagener, hier ächzte noch eine 
Zeitdeiktika treten; das anaphorisch gestaltete Staccato aber stimmt in beiden Textpartien überein.

Als Tollkühnheit mit Todesfolge eignet sich diese Episode keineswegs „zur Behandlung in Lesebüchern für die kaiser- und königlichen österreichischen Volks- und Bürgerschulen“ (RM 445). Diese Feststellung der auktorialen Erzählinstanz schlägt einen Bogen zum Romanbeginn und zur Geschichtsklitterung im Heldenmythos der SchulbuchLegende (vgl. RM 145-149), gegen die der Held von Solferino rebellierte. Kunstvoll verschränkt Roth den Anfangs- und Schlussteil des Romans: Der tödlichen Risikobereitschaft des Helden-Enkels entspricht der naive Leichtsinn des Kaisers in der zu Beginn geschilderten Schlacht von Solferino.

Dass Roths Radetzkymarsch einen reduzierten Realitätssinn nicht nur als Alterssymptom des Kaisers Franz Joseph I. inszeniert, zeigt bereits die markante Anfangspassage des Romans: Sie lässt den Kaiser zwar persönlich auftreten ${ }^{27}$, macht aber sein Überleben und damit die kurze Zukunft der Habsburger Monarchie ganz von der Geistesgegenwart des Helden von Solferino abhängig. Als der Kaiser damals „einen Feldstecher [...] an die Augen führen“ wollte (RM 139), stand dem Großvater des Leutnants intuitiv sofort die fatale Konsequenz dieser Handlung vor Augen, nämlich ihr Signalcharakter: Die feindliche Nachhut auf dem Schlachtfeld würde dadurch - das ist ihm reflexartig klar zweifelsfrei erkennen, „daß er ein Ziel sei, würdig, getroffen zu werden. Und es war der junge Kaiser. [...] Die Angst vor der unausdenkbaren, der grenzenlosen Katastrophe, die ihn selbst, das Regiment, die Armee, den Staat, die ganze Welt vernichten würde, jagte glühende Fröste durch seinen Körper“ und veranlasste ihn dazu, den „Monarchen“ ohne Rücksicht auf die Etikette abrupt „niederzudrücken“ (RM 140).

Die durch die rhetorischen Stilmittel Oxymoron („glühende Fröste“) und Klimax („Regiment“, „Armee“, „Staat“, „Welt“) bewirkten Steigerungseffekte werden hier zum konsequenten Ausdruck flächenbrandartig expandierender Vernichtungsphantasien. Zugleich spiegeln die eruptiven Ängste des Helden von Solferino seine unreflektierte Untertanengesinnung wider. Unmittelbar nach diesem dramatischen Rettungsakt in letzter Sekunde exponiert sich Kaiser Franz Joseph I. erstaunlicherweise abermals auf unvorsichtige Weise und muss daher erneut niedergerissen werden, um ihn außer Lebensgefahr zu bringen (vgl. RM 140). Schon diese Episode charakterisiert den jungen Kaiser mithin durch ei-

Stimme unter dem Schutte, hier schrien Leute von brennenden Dächern herab, hier kämpften Menschen und Tiere mit den Wellen, hier war ein mutiger Retter bemüht, zu helfen [...]“ (Kleist 1990, 193).

${ }^{27}$ In Musils Epochenroman Der Mann ohne Eigenschaften hingegen tritt der Monarch nicht selbst in Erscheinung, sondern findet lediglich als Vorstellungsinhalt punktuell Erwähnung: Wie eine mythischirreale Figur aus archaischen Zeiten erscheint der Kaiser: als ,,sagenhafter alter Herr“, der nüchterne ,jüngere Menschen“ - trotz seiner öffentlichen Präsenz durch zahlreiche Bilder - sogar zweifeln lässt, „ob es ihn überhaupt gebe“ (MoE 83). 
nen lebensgefährlichen Leichtsinn und damit auch durch ein eingeschränktes Urteilsvermögen, das sich in seinen letzten Lebensjahren in dem Maße weiter reduziert, wie seine Senilität fortschreitet.

Das provokative Roman-Entrée, in dem ausgerechnet der Monarch bei der Schlacht von Solferino zweimal nacheinander zu Fall gebracht und dabei zum bloßen Handlungsobjekt depotenziert wird, kann man auch als ironische Prolepse lesen: So gesehen, antizipiert bereits die Anfangsszene das Ende der Habsburger Monarchie nach dem Ersten Weltkrieg. Dadurch reduziert sich die historische Reichweite der im Roman inszenierten heroischen Tat des Helden von Solferino allerdings beträchtlich, steht sie doch bereits von vornherein unter den Auspizien des Untergangs. Und mehr noch: Über die historische Horizontbildung hinaus wird auch in psychologischer Hinsicht Kontinuität gestiftet: Während der Kaiser in der Anfangspassage vor den lebensgefährlichen Folgen seines Leichtsinns durch Niederdrücken und Umwerfen bewahrt werden muss, verstärkt sich sein - von Anfang an auffallender - Mangel an Geistesgegenwart in späteren Romanpassagen unter den mentalen Rahmenbedingungen der Vergreisung. Wiederholt lässt der Hochbetagte eine senile Gedächtnisschwäche und Bewusstseinsdiffusion erkennen. Sein hilfloses Ringen um Selbstvergewisserung durch Rückbesinnung auf seine Biographie offenbart die Einbuße an Macht und Souveränität (vgl. RM 345). Überraschenderweise gehört zu den letzten Gedanken des Sterbenden der Satz: „Wär' ich nur bei Solferino gefallen!“(RM 453), der zwar eine Brücke zum Romananfang schlägt, aber die Rettungstat des Helden von Solferino und auch das eigene Leben entwertet.

Roths Radetzkymarsch amalgamiert Heimat-Mythos, Helden-Kult und Kaiser-Aura, um sie zugleich einer ironischen Demontage zu unterziehen. Hellsichtig prognostiziert der GrafChojnicki: „Dieses Reich muß untergehn. Sobald unser Kaiser die Augen schließt, zerfallen wir in hundert Stücke“ (RM 265). Auch sonst tritt der Graf durch radikale illusionslose Diagnosen hervor: Bedenkenlos „pflegte Chojnicki zu sagen, der Kaiser sei ein gedankenloser Greis, die Regierung eine Bande von Trotteln, der Reichsrat eine Versammlung gutgläubiger und pathetischer Idioten, die staatlichen Behörden bestechlich, feige und faul“" (RM 265). Patriotische Gesinnung im Zeichen der Monarchie und loyale Untertanen-Gesinnung sähen fürwahr anders aus ...

Die vom Leutnant Carl Joseph von Trotta als aporetisch empfundene Situation, in der er sozialistisch gesonnene Demonstranten niederschlagen soll, evoziert in ihm eine Vorstellung von apokalyptischem Ausmaß: Er sieht „die Zeiten wie zwei Felsen gegeneinanderrollen“ und fühlt sich selbst „zwischen beiden zertrümmert“ (RM 336). Kurz darauf befindet er sich tatsächlich in einer solchen Lage, als seine Truppe „zwischen die zwei Gruppen“ der Aufständischen gerät und er selbst einen Schädelbruch und (wie sein Großvater) eine „Verletzung am Schlüsselbein“ davonträgt (RM 338). - Weniger spek- 
takulär als die apokalyptische Vision gestaltet sich einige Zeit später das Sterben des Helden-Enkels: Nachdem er beim Wasserholen für seine Soldaten der realistischerweise zu erwartenden feindlichen Geschützsalve zum Opfer gefallen ist (vgl. RM 444), sinniert sein Vater vor dem Epilog des Romans mit resignativem Fatalismus: „was ging ihn der Untergang der Welt an [...]? Sein Sohn war tot. Sein Amt war beendet. Seine Welt war untergegangen" (RM 447). So schrumpft der weite geschichtliche Horizont einer Epochen-Dämmerung, die der Roman zuvor bereits wiederholt durch Untergangsmotive inszeniert hat, nachträglich wieder auf die biographischen Dimensionen des Individuums zusammen.

Dementiert wird dabei zugleich die frühere Überzeugung des Bezirkshauptmanns, schlimmer als „die Kunde vom plötzlichen Tod seines einzigen Kindes“ wäre allein schon ein bloßer Verdacht auf „Unehrenhaftigkeit dieses einzigen Kindes“ (RM 392). Als Relikt eines bereits obsolet gewordenen Ehrbegriffs wird diese Assoziation aus auktorialer Retrospektive vom Standpunkt der Zukunft aus kritisch hinterfragt, und zwar auch in mentalitätsgeschichtlicher Hinsicht: „Er war ein alter Mann einer alten Zeit. Die alten Männer aus der Zeit vor dem großen Kriege waren vielleicht törichter als die jungen von heute“, bewahrten aber in schrecklichen Augenblicken „einen heldenhaften Gleichmut. Heutzutage sind die Begriffe von Standesehre und Familienehre und persönlicher Ehre, in denen der Herr von Trotta lebte, Überreste unglaubwürdiger und kindischer Legenden, wie es uns manchmal scheint" (RM 392).

Unangemessen erscheint mithin die dramatisierende Sicht des Bezirkshauptmanns, dem schon die „Erwägung seines Sohnes, die Armee zu verlassen“, zunächst wie die Auflösung „der gesamten kaiser- und königlichen Armee“ selbst vorkommt, ja sogar wie ein universeller Sinnverlust: „Der Untergang der Welt schien angebrochen!“(RM 363). Eine andere Form subversiver Infragestellung liegt in der ironischen Relativierung der Figurenperspektive: etwa mit Bezug auf die pathetisch überhöhte Untergangsphantasie des Bezirkshauptmanns Franz von Trotta, wenn er das bloße Lesen der Dienstpost bereits mit der vergeblichen „heroische[n] Pflicht“ glaubt vergleichen zu können, die etwa „der Telephonist eines sinkenden Schiffes" erfüllt (RM 363).

Diese metaphorische Vorstellung fügt sich als Variante in das facettenreiche Feld der Décadence-Bilder ein, die der Roman wiederholt mit expressiven Bildern inszeniert. Dazu gehört die auktoriale Vorstellung vom „düstern Flügelschlag der Geier“, die schon „über dem Doppeladler der Habsburger kreisten“ (RM 322), und das Naturbild der sin-

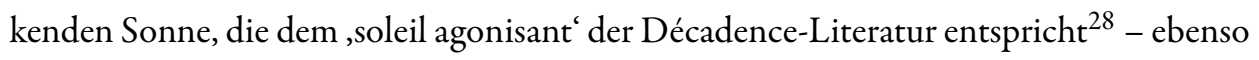

\footnotetext{
${ }^{28}$ Man denke etwa an die mit ironischem Pathos inszenierte Schlusspassage von Thomas Manns Erzählung Tristan (1903), die das Décadence-Motiv der sinkenden Sonne inszeniert.
} 
wie die apokalyptische Imagination des Kaisers, der die ,große goldene Sonne der Habsburger" untergehen und den Vielvölkerstaat zerfallen sieht (RM 352). ${ }^{29}$

Dem fiktionalen Szenario des Romans zufolge hat der Held von Solferino letztlich mit Erfolg seine mentale Selbstauslöschung betrieben, und zwar durch empörte Rebellion gegen die verlogene patriotische Mythenbildung anlässlich seiner Rettungstat. Eine spätere Textpassage zeigt allerdings, dass der Protest des Betroffenen - „Man hat mit mir Mißbrauch getrieben" (RM 146) - nur anfangs erfolglos verhallte, später aber doch zu der gewünschten Konsequenz führte: Betont wird nämlich, dass „der Name des Helden von Solferino in den Geschichtsbüchern oder in den Lesebüchern für österreichische Volksund Bürgerschulen nicht mehr gefunden werden konnte" (RM 402).

Gerade diese Selbstliquidierung des Helden allerdings revidiert Roths Radetzkymarsch in actu, indem er die verlorene Memoria auf authentische Weise zu rekonstruieren vorgibt. Dieser narrative Kunstgriff suggeriert, sogar durch den Bericht über das nachträglich getilgte kulturelle Gedächtnis einer historischen Heldentat selbst werde genuine Erinnerungsarbeit betrieben. Obwohl die fiktionalen Figuren mit ihren erfundenen Lebensschicksalen am Ende einer Ära das Produkt von Roths literarischer Phantasie sind, gelingt es dem Roman Radetzkymarsch im Medium narrativer Inszenierung, ein weit ausgreifendes historisches Panorama zu entfalten: Es ermöglicht aufschlussreiche Einblicke in die Krisenzeit einer Epochen-Dämmerung und in die daraus resultierende Aporie. So erklärt der Bürgermeister am Ende des Romans nach dem Tod des Bezirkshauptmanns, „daß Herr von Trotta den Kaiser nicht überleben konnte“; und der Arzt ergänzt: „ich glaube, sie konnten beide Österreich nicht überleben“ (RM 455). ${ }^{30}$ - Mit dem Kaisermythos verschwindet auch der traditionelle Heimat-Mythos als übergeordneter Sinnhorizont.

\section{Literatur}

Böning, Hansjürgen. 1968. Joseph Roths Radetzkymarsch. Thematik - Struktur - Sprache. München: Wilhelm Fink.

Grillparzer, Franz. 1963. Gedichte - Epigramme - Dramen I, Bd. 1 von Franz Grillparzer: Sämtliche Werke, hrsg. von Peter Frank und Karl Pörnbacher. München: Hanser-Verlag.

\footnotetext{
${ }^{29}$ Vgl. zum Sonnensymbol auch Roths Feuilleton-Text Seine k. und k. apostolische Majestät (Roth 1990c; Erstveröffentlichung: 6.3.1928). Hier betont Roth anlässlich der Beisetzung des Kaisers in der Kapuzinergruft seine Ergriffenheit von der „Zeremonie, mit der die Majestät (und das war Österreich-Ungarn) zu Grabe getragen wurde. Die Sinnlosigkeit seiner letzten Jahre erkannte ich klar, aber nicht zu leugnen war, daß eben diese Sinnlosigkeit ein Stück meiner Kindheit bedeutete. Die kalte Sonne der Habsburger erlosch, aber es war eine Sonne gewesen“ (ibid., 910-911).

${ }^{30}$ Joseph Roth selbst schreibt in seinem „Vorwort zu meinem Roman: ,Der Radetzkymarsch““: Beim Begräbnis des Monarchen in der „Kapuzinergruft [...] wußten wir alle, seine Soldaten, daß unser letzter Kaiser dahingegangen war und mit ihm unsere Heimat, unsere Jugend und unsere Welt" (vgl. den Erstdruck in der Frankfurter Zeitung, 17. April 1932, abgedruckt in Roth, Werke, Bd. 5, 874).
} 
Hofmannsthal, Hugo von. 1979. „Die österreichische Idee“. In Reden und Aufsätze II: 19141924, 454-458, Bd. 9 von Hugo v. Hofmannsthal: Gesammelte Werke in zehn Einzelbänden, hrsg. von Bernd Schoeller in Beratung mit Rudolf Hirsch. Frankfurt am Main: S. Fischer Verlag.

Kleist, Heinrich von. 1990. „Das Erdbeben in Chili“. In Erzählungen, Anekdoten, Gedichte, Schriften, hrsg. von Klaus Müller-Salget, 189-221, Bd. 3 von Heinrich von Kleist: Sämtliche Werke und Briefe in vier Bänden, hrsg. von Ilse-Marie Barth u. a. Frankfurt am Main: Deutscher Klassiker Verlag.

Kraus, Karl. 1914. „Franz Ferdinand und die Talente." Die Fackel, 16, Nr. 400-403 (10. Juli 1914): $1-4$.

Kraus, Karl. 1920. „Klarstellung.“ Die Fackel, 22, Nr. 554-556 (November 1920): 1-5.

Kraus, Karl. 1957. Die letzten Tage der Menschbeit, Bd. 5 von Karl Kraus: Werke, hrsg. von Heinrich Fischer. München: Kösel-Verlag.

Mach, Ernst. 1991. Die Analyse der Empfindungen und das Verhältnis des Physischen zum Psychischen. Mit einem Vorwort zum Neudruck von Gereon Wolters. Nachdruck der 9. Aufl. Jena 1922. [1. Aufl. Leipzig 1886]. Darmstadt. Wissenschaftliche Buchgesellschaft.

Magris, Claudio. 1966/2000. Der habsburgische Mythos in der modernen österreichischen Literatur. Deutsche Übersetzung 1966 (Salzburg: Otto Müller), überarbeitete Neuausgabe 2000, Wien: Hanser-Verlag.

Müller, Klaus-Detlef. 1993. „Joseph Roth: Radetzkymarsch. Ein historischer Roman“. In Interpretationen: Romane des 20. Jahrhunderts, Bd. 1.298-319. Stuttgart: Reclam.

Musil, Robert. 1978a. Der Mann obne Eigenschaften, Bd. 1 von Robert Musil: Gesammelte Werke, hrsg. von Adolf Frisé. Reinbek bei Hamburg: Rowohlt. [= MoE].

Musil, Robert. 1978b. Prosa und Stücke. Kleine Prosa, Aphorismen. Autobiographisches. Essays und Reden. Kritik, Bd. 2 von Robert Musil: Gesammelte Werke, hrsg. von Adolf Frisé. Reinbek bei Hamburg: Rowohlt. [= GW II].

Neymeyr, Barbara. 1996. „Musils skeptischer Fortschrittsoptimismus. Zur Ambivalenz der Gesellschaftskritik in seinen Essays". Zeitschrift für deutsche Philologie 115, 576-607.

Neymeyr, Barbara. 2003. „Eine kaiserliche Botschaft." In Interpretationen. Franz Kafka: Romane und Erzäblungen, hrsg. von Michael Müller. 2., erweiterte Aufl, 346-352. Stuttgart: Reclam.

Neymeyr, Barbara. 2005. Psychologie als Kulturdiagnose. Musils Epochenroman,Der Mann obne Eigenschaften: (Beiträge zur neueren Literaturgeschichte, Bd. 218). Heidelberg: Universitätsverlag Winter.

Neymeyr, Barbara. 2007. „Fräulein Else: Identitätssuche im Spannungsfeld von Konvention und Rebellion“. In Interpretationen. Arthur Schnitzler: Dramen und Erzählungen, hrsg. von Hee-Ju Kim und Günter Saße, 190-208. Stuttgart: Reclam.

Neymeyr, Barbara. 2016. „Sprache als Medium für die verwegensten Kunststücke‘: Nietzsches Experimental-Metaphorik“. In Nietzsche zwischen Philosophie und Literatur. Von der „Fröhlichen Wissenschaft" $z u$ „Also sprach Zarathustra“, hrsg. von Katharina Grätz und Sebastian Kaufmann, 323-353. Heidelberg: Universitätsverlag Winter.

Nietzsche, Friedrich. 1980. Sämtliche Werke. Kritische Studienausgabe in 15 Bänden. [= KSA], hrsg. von Giorgio Colli und Mazzino Montinari. München/Berlin/New York: De Gruyter. 
Roth, Joseph. 1990a. „Radetzkymarsch“. In Romane und Erzählungen 1930-1936, hrsg. und mit einem Nachwort von Fritz Hackert, 137-447, Bd. 5 von Joseph Roth: Werke, hrsg. von Fritz Hackert und Klaus Westermann. Köln: Kiepenheuer \& Witsch. [= RM].

Roth, Joseph. 1990b. „Vorwort zu meinem Roman: ,Der Radetzkymarsch““ (Erstpublikation: Frankfurter Zeitung, 17. April 1932). In Romane und Erzählungen 1930-1936, hrsg. und mit einem Nachwort von Fritz Hackert, 874-875, Bd. 5 von Joseph Roth: Werke, hrsg. von Fritz Hackert und Klaus Westermann. Köln: Kiepenheuer \& Witsch.

Roth, Joseph. 1990c. „Seine K. und K. apostolische Majestät“. Das journalistische Werk 19241928, hrsg. und mit einem Nachwort von Klaus Westermann, 910-915, Bd. 2 von Joseph Roth: Werke, hrsg. von Fritz Hackert und Klaus Westermann. Köln: Kiepenheuer \& Witsch.

Roth, Joseph. 1990d. „Konzert im Volksgarten“. In Das journalistische Werk 1924-1928, hrsg. und mit einem Nachwort von Klaus Westermann, 920-923, Bd. 2 von Joseph Roth: Werke, hrsg. von Fritz Hackert und Klaus Westermann. Köln: Kiepenheuer \& Witsch.

Roth, Joseph. 1990c. „Konzert im Volksgarten“. In Das journalistische Werk 1924-1928, hrsg. und mit einem Nachwort von Klaus Westermann, 920-923, Bd. 2 von Joseph Roth: Werke, hrsg. von Fritz Hackert und Klaus Westermann. Köln: Kiepenheuer \& Witsch.

Roth, Joseph. 1991a. „Grillparzer. Ein Porträt“. In Das journalistische Werk 1929-1939, hrsg. und mit einem Nachwort von Klaus Westermann, 742-751, Bd. 3 von Joseph Roth: Werke, hrsg. von Fritz Hackert und Klaus Westermann. Köln: Kiepenheuer \& Witsch.

Roth, Joseph. 1991b. „Huldigung an den Geist Österreichs“. In Das journalistische Werk 19291939, hrsg. und mit einem Nachwort von Klaus Westermann, 792-795, Bd. 3 von Joseph Roth: Werke, hrsg. von Fritz Hackert und Klaus Westermann. Köln: Kiepenheuer \& Witsch.

Schnitzler, Arthur. 1972. Fräulein Else. In Die Erzählenden Schriften, Bd. 2 von Arthur Schnitzler: Gesammelte Werke, 324-381. Frankfurt am Main: S. Fischer Verlag.

Weigel, Hans. 1972. Karl Kraus oder die Macht der Obnmacht. München: dtv. 


\title{
Von Lübeck zu Kaisersaschern. Die Wandlung in Thomas Manns Vorstellung von seiner geistigen Heimat
}

\author{
Liisa STEINBY \\ Universität Turku (Finland)
}

\begin{abstract}
Thomas Mann did not produce any regional literature, despite his Buddenbrooks being a Lübeck novel. In the essay Bilse und ich (1906), he explains that Lübeck was used only as a material to which he assigned symbolic meaning for creating a work of art. However, in the essay Lübeck als geistige Lebensform (1926) Mann writes that Lübeck is the growing ground of his entire artistic work. Representing an ethical stance on life, it stands for Lebensbürgerlichkeit, i.e. a commitment to the responsibilities of life. This is in accordance with how Mann, in his Betrachtungen eines Unpolitischen (1918), describes the Germans as being positioned in the "middle ground" where the demands of the intellect, or spirit (Geist), and the unconscious urges of life attain a balance. In Joseph und seine Brüder, rooted intellectually in the epoch of the Weimar Republic, the idea of Lebensbürgerlichkeit
\end{abstract}

can be recognized in a biblical setting. However, in Doctor Faustus (1947), which mirrors the epoch of the Third Reich, it is Kaisersaschern, the protagonist's (fictional) school town that represents the Germans' intellectualspiritual stance on life, which Mann now describes as an "antiquatedness of the soul". In this "soul", the irrational forces of life are uncontrollable. In the essay Deutschland und die Deutschen (1945), Mann describes Lübeck by quotations taken from the description of the medieval atmosphere of Kaisersaschern. Lübeck no longer represents the Lebensbürgerlichkeit but has become a representative of what is questionable ("demonic") in the Germans.

Keywords: Thomas Mann, Heimat, mythification

(c) Liisa Steinby; liisa.steinby@utu.fi

Colloquium: New Philologies, Volume 6, Issue 1 (2021)

doi: 10.23963/cnp.2021.6.1.4

Stable URL: https://colloquium.aau.at/index.php/Colloquium/article/view/148

This work is licensed under a Creative Commons Attribution 4.0 International License (CC BY 4.0). 
Thomas Mann hat keine Heimatliteratur hervorgebracht; auch der Lübeck-Roman Buddenbrooks ist das nicht. In seinem Aufsatz Bilse und ich (1906) weist Thomas Mann die Vorwürfe zurück, er habe in Buddenbrooks seine Landsleute karikiert und rücksichtslos dem Hohngelächter aller Welt ausgeliefert. Er beteuert, dass es hier gar nicht um seine Lübecker Bekannten geht, sondern um eine Romanwelt, die von dem Autor selbst erschaffen worden ist. Im Aufsatz Lübeck als geistige Lebensform zwanzig Jahre später weist er aber Lübeck die Rolle der geistigen Landschaft zu, die er nie zurückgelassen hat. Diese ist ein symbolhaftes, mythisches Lübeck - im Thomas-Mann'schen Sinne des Mythos zu der er sich jetzt bekennt. Im Aufsatz Deutschland und die Deutschen von 1945 gibt er Lübeck als geistiger Lebensform jedoch einen neuen Inhalt. Diese Änderungen haben nicht nur mit der Entwicklung von Manns künstlerischem Denken zu tun, sondern auch mit den historischen Veränderungen in Deutschland vom Fin de Siècle des Kaiserreichs über die Weimarer Republik bis hin zum Dritten Reich. Im vorliegenden Aufsatz gilt es, die Grundlinie dieser Entwicklung in Thomas Manns Ansicht von seiner geistigen Heimat, dem symbolisch-mythischen Lübeck, zu skizzieren.

\section{Bilse und ich: Nicht von euch ist die Rede}

„Heimatliteratur“, sowohl eine treue Darstellung des Lebens an einem Ort als auch eine satirische, sah Thomas Mann als minderwertig an (siehe Wysling 1967, 180), ja als Ausgeburt eines künstlerischen Missverständnisses. In der Rede über Lessing (1929) zitiert er zustimmend Lessing, der sich „lustig über den Provinzialismus gewisser Sittenkomödien [macht], deren Verfasser die armseligen Gewohnheiten des Winkels, in dem er geboren worden, für die eigentlichen Sitten des gemeinschaftlichen Vaterlandes halten möchte, während doch niemandem daran liege, ,zu erfahren, wievielmal im Jahre man da oder dort grünen Kohl esse“" (Mann 1990 IX, 213). Genau so, als ob es ihm um die „Gewohnheiten des Winkels“ ginge, lesen ihn aber diejenigen, die den Autor von Buddenbrooks vom „Winkel-Pasquillanten“ Bilse nicht unterscheiden können, meint Mann in Bilse und ich (Mann 1990 X, 12-13). Er will den Lesern klar machen, dass die gegebene Wirklichkeit - das reale Lübeck mit seinen Einwohnern - für ihn bloßes Material war, so wie für Shakespeare die Charaktere und Fabeln aus seiner Bekanntschaft und aus verschiedenen schriftlichen Quellen. Denn am Stoff liegt es in der Kunst gar nicht: „Alle Objektivität, alle Aneignung und Kolportage bezieht sich allein auf das Pittoreske, die Maske, die Geste, die Äußerlichkeit, die sich als Charakteristikum, als sinnliches Symbol darbietet“ (ibid., 16-17). Alles hängt davon ab, was man aus dem Material macht, wie man den Stoff „,beseelt“ (ibid., 15). Im Prozess der „Beseelung“ bewahre die Wirklichkeit ihren Charakter nicht: Beim Verfassen von Buddenbrooks hatte „meine Vaterstadt [...] 
nicht viel Realität für mich [...]. Sie war mir, mit ihren Insassen, nicht wesentlich mehr als ein Traum, skurril und ehrwürdig, geträumt vorzeiten, geträumt von mir und in der eigentümlichsten Weise mein eigen“ (ibid., 15). Thomas Mann schließt mit der Beteuerung ab: „Nicht von euch ist die Rede, gar niemals, seid des nun getröstet, sondern von mir, von mir..." (ibid., 22).

Wenn auch „Realitätspartikel“ in einem Kunstwerk wiederzuerkennen sind, ist Kunst etwas anderes als die Darstellung faktischer Realität. Der Grund für die Wahl einer „Realitätspartikel“ zum Stoff eines Kunstwerks ist, dass der Künstler darin etwas Bedeutendes und Symbolhaftes wahrnimmt, das er für sein Werk ausnutzen kann. Hier erkennt man das Zwei-Schichten-Modell des künstlerischen Denkens Thomas Manns: Die Oberfläche bietet eine Illusion der Realität, aber unter dieser Oberfläche gestaltet sich das Symbolhafte zu bedeutenden Strukturen. ${ }^{1}$ Doch während Thomas Mann in Bilse und ich von diesem Prozess als von der "Beseelung“ des Materials durch den individuellen Künstler spricht, denkt er später, dass das Leben selbst in seiner Gestaltung mythisch-typischen Mustern folgt.

\section{Lübeck als geistige Lebensform: von Lübecker Bürgerlichkeit zu Lebensbürgerlichkeit}

Im Aufsatz Freud und die Zukunft von 1936 verortet Thomas Mann seinen „Schritt vom Bürgerlich-Individuellen zum Mythisch-Typischen“ in der Zeit vor dem Joseph-Roman (Mann 1990 IX, 493). Manfred Dierks stellt aber fest, dass der Begriff des Typus bzw. des Mythos bei Thomas Mann schon vor $1911 \mathrm{im}$ Sinne der Orientierung an einem idealen Gehalt der geschichtlichen Einzelwirklichkeit zu finden ist (Dierks 1972, 39). Dierks zeigt, dass Manns Begriff des Mythisch-Typischen seinen Grund in Schopenhauers Metaphysik hat: Sein mythischer Typus sei „die vollkommene Übersetzung der Schopenhauerschen ,Species““ (ibid., 100). Der Typus sei die Form, die der Wille, der gemeinsame, irrationale Urgrund des Lebens, in der Gestaltung des Individuellen folgt. Das Individuum ist ein Fall, ein Beispiel für den allgemeinen Typus. Thomas Mann bezieht diese auf den Menschen, den er nicht nur als ein Individuum betrachtet, sondern in dem er auch den „ideellen Gehalt“ eines Typus wahrnimmt. Eine mythische Gestalt ist für ihn der Träger einer durch die kulturelle Entwicklung ermöglichten Daseinsform, die von anderen wiederaufgenommen werden kann. Im Lessing-Essay zum Beispiel definiert Thomas Mann das Klassische durch das Mythisch-Typische:

\footnotetext{
1 Zu Thomas Manns „maskenhaftem Realismus“, in dem unter der Oberfläche eine andere, tiefere Bedeutungsstruktur besteht, siehe z.B. Kristiansen 1990.
} 
Denn es ist das Vorgebildete, die anfängliche Gründung einer geistigen Lebensform durch das Lebendig-Individuelle; es ist ein erzväterlich geprägter Urtypus, in dem späteres Leben sich wiedererkennen, in dessen Fußstapfen es wandeln wird - ein Mythus also, denn der Typus ist mythisch, und das Wesen des Mythus ist Wiederkehr, Zeitlosigkeit, Immer-Gegenwart. [...] Klassische Zeit, das ist Patriarchenzeit, mythische Zeit, Zeit anfänglicher Gründung und Prägung des nationalen Lebens. (Mann 1990 IX, 229)

Das Mythische hat für Thomas Mann also nichts mit dem Magisch-Mystischen zu tun. Es ist eine kulturelle Form, die als „uranfänglich“ angesehen wird und die von neuen Individuen immer wieder aufgenommen und als deren Existenzform erlebt wird.

Was bedeutet das Mythisch-Typische aber in Bezug auf Örtlichkeiten? Wie wird ein Ort - hier: die Heimat - mythisch? Das wird ein Ort, wenn er nicht mehr als eine „geschichtliche Einzelwirklichkeit“ wahrgenommen wird, die aus einmaligen „Realitätspartikeln" besteht, sondern von seinem ,,ideellen Gehalt" her. Und dieser Gehalt ist nicht etwas, was der individuelle Autor durch die „Beseelung“ den „Realitätspartikeln“ zuweist, sondern er ist eine geistige Lebensform, die die individuelle Ortschaft exemplarisch vertritt und die als solche denjenigen, der in dieser Lebensform heimisch ist, lebenslang prägt (oder prägen kann). In Lübeck als geistige Lebensform hat Thomas Mann den Schritt von der "geschichtlichen Einzelwirklichkeit" einer Ortschaft, so wie Lübeck in Bilse und ich nur noch als Quelle des Stoffs für künstlerisches Schaffen erschien, zu einer mythischtypischen Auffassung von ihr getan.

Lübeck als geistige Lebensform ist ein Vortrag, gehalten 1926 vor einem Lübecker Publikum. Darin geht es nicht mehr um die Zurückweisung des Vorwurfs einer Verleumdung seiner ehemaligen Mitbürger. Thomas Manns Schaffen umfasste damals schon außer Buddenbrooks auch den Zauberberg, und die im Vortrag beschriebene geistige Landschaft gilt zweifellos auch für den Joseph-Roman, den er am Ende desselben Jahres niederzuschreiben begann (siehe Heftrich 1990, 449). Also nicht allein Buddenbrooks vertritt die „geistige Lebensform“ Lübecks, zu der sich der Autor jetzt bekennt. Statt einer Gegenüberstellung zwischen den Stadtbewohnern und der Freiheit des Autors, der sie als Material für sein Werk verwendet, sieht er nun eine Kontinuität zwischen der geistigen Atmosphäre der Heimatstadt und seinem künstlerischen Schaffen. Er schreibt, dass er „viel mehr ein Apfel vom Baume Lübecks war, als [er] geahnt hatte“ (Mann 1990 XI, 385). Jetzt meint er, dass die Heimatstadt „,von Anfang bis zu Ende in meiner ganzen Schriftstellerei zu finden ist, sie entscheidend bestimmt und beherrscht“ (ibid., 388). Künstlertum ist nichts völlig Ungebundenes, Freischwebendes, sondern es sei „etwas Symbolisches. Es ist die Wiederverwirklichung einer ererbten und blutsüberlieferten [!] Existenzform auf anderer Ebene“ (ibid., 385); „man hört nicht auf, zu sein, was die Väter 
waren, sondern ist ebendieses in anderer, freierer, vergeistigter, symbolisch darstellender Form nur noch einmal“ (ibid., 386). Die Heimatstadt ist nicht mehr der "Traum“ des Künstlers, sondern eine in seiner Tätigkeit auf einer ideellen Ebene fortwirkende, seine Lebenseinstellung wesentlich formende Macht.

Was ist denn das spezifisch Lübeckische in der geistigen Atmosphäre der Stadt? Thomas Mann stimmt Josef Nadler zu, wenn dieser das Lübeckische als „das PatrizistischStändische“ und „das allgemein Hanseatische“ charakterisiert (ibid., 378). ${ }^{2}$ Mann dringt aber tiefer in das Lübeckische ein und definiert es als eine ethische Haltung. Es bedeute „des Lebens ernstes Führen“, das „,mit dem Bürgerlichen in so hohem Grad zusammenfällt"; diese Haltung haben sowohl Thomas als auch sein Bruder Heinrich von ihrem Vater geerbt (ibid., 387). Sie sei in der Tiefe der Psyche des Künstlers, im Unbewussten oder Unterbewussten, bewahrt und bestimme von dort aus sein Schaffen (ibid., 385). Hier überbrückt Thomas Mann die Kluft zwischen Bürgerlichkeit und Künstlertum, dem Kaufmännischen und dem Künstlerischen, die nicht nur in Buddenbrooks, sondern zum Beispiel auch in Tonio Kröger das zentrale Thema ist. Die dem „bürgerlichen“ Ethos entsprechende Literatur lasse sich durch die Stichworte „Norden, Ethik, Musik, Humor“ bezeichnen, im Gegensatz zu „südliche[r] Schönheitsruhmredigkeit“ (ibid., 381).

Der Gegensatz zwischen Süden und Norden soll hier nicht einfach als der zwischen Süden und Norden Deutschlands verstanden werden; es handelt sich vielmehr um eine Charakterisierung der deutschen Literatur im Gegensatz zu einer stereotypisch südeuropäischen. Als ein Beispiel dafür, wie ein Werk von spezifisch norddeutschem Charakter von der ganzen Nation als das Ihrige aufgenommen werden kann, erwähnt Thomas Mann in seinem Lessing-Aufsatz Minna von Barnhelm (Mann 1990 IX, 230). Ähnliches trifft für Thomas Manns Buddenbrooks zu, aber in einem noch weiteren Sinne, denn sein Roman wurde ein internationaler Erfolg. Thomas Mann sagt in Lübeck als geistige Lebensform, dass er nicht geträumt habe, indem er „ein nach Form und Inhalt sehr deutsches Buch gab, zugleich ein überdeutsch-europäisches Buch, ein Stück Seelengeschichte des europäischen Bürgertums überhaupt gegeben haben könnte“ (Mann 1990 XI, 383). Dabei gelte es zu bemerken, dass „wir, indem wir ,Bürgerlichkeit‘ sagen, nichts Klasseninteressenmäßiges, nichts Antisozialistisches etwa im Sinne haben“" (ibid., 397). Vielmehr sei diese Bürgerlichkeit, die den Charakter der deutschen Kultur insgesamt ausmacht, eine „Weltbürgerlichkeit“, eine „Lebensform verbunden mit der Idee der Menschlichkeit, der Humanität und aller menschlichen Bildung“ (ibid., 397). Das Ethische, das den Grundton der Lübeckischen, nördlichen, deutschen „Bürgerlichkeit“ ausmacht, sei „recht eigentlich Lebensbürgerlichkeit, der Sinn für Lebenspflichten, oh-

\footnotetext{
2 Dies bedeutet natürlich nicht, dass er mit Nadler, dem späteren geprägten Antisemiten, im Allgemeinen gleichgesinnt war.
} 
ne den überhaupt der Trieb zur Leistung, zum produktiven Beitrag an das Leben und an die Entwicklung fehlt" (ibid., 387). Die Lebensbürgerlichkeit, die im geschichtlich Einmaligen entdeckt wird, sei nicht nur für Lübeck, sondern für ganz Deutschland typisch und sei eine Lebenshaltung, die sich auch im Rahmen der Menschheitsgeschichte und der Humanität behauptet. Für dieses Zusammenfallen des Partikularen mit dem Typisch-Allgemeinen findet Thomas Mann im Aufsatz Von deutscher Republik ein Vorbild bei Novalis, der schreibt: „Alles Nationale, alles Temporale, Lokale, Individuelle läßt sich universalisieren und so kanonisieren und allgemein machen [...]. Dieses individuelle Kolorit des Universellen ist sein romantisches Element“" (Mann 1990 XI, 815). Solch ein Begriff des Romantischen lässt sich von Manns „,maskenhaftem Realismus“ kaum unterscheiden: Das Konkret-Individuelle ist da, aber es wird nur bedeutend, wenn in ihm das Typisch-Allgemeine wahrgenommen wird.

Ein Beispiel dafür, wie etwas Konkretes als etwas Mythisches und Metaphysisches gedeutet wird, bieten Thomas Manns Überlegungen in Lübeck als geistige Lebensform zur Präsenz der Lübecker Landschaft in seinen Werken. Er beschreibt seine kindliche Faszination vom Meer bei sommerlichen Aufenthalten in Travemünde und kommentiert dazu:

Das Meer ist keine Landschaft, es ist das Erlebnis der Ewigkeit, des Nichts und des Todes, ein metaphysischer Traum, und mit den luftverdünnten Regionen des ewigen Schnees [d.h., der Landschaft im Zauberberg] steht es sehr ähnlich. Meer und Hochgebirge sind nicht ländlich, sie sind elementar im Sinne letzter und wüster, außermenschlicher Großartigkeit. (Mann 1990 IX, 394)

Und der unheldenhafte Held Hans Castorp zeige seine ethische Haltung und „Lebensbürgerlichkeit“, indem er angesichts der elementaren Größe der Gebirgsnatur zwar „Furcht, Ehrfurcht meinetwegen, religiöse Scheu, physisch-metaphysisches Grauen“ empfindet, aber auch „noch etwas mehr: Spott, wirkliche Ironie gegenüber dem übergewaltig Dummen, ein mokantes Achselzucken angesichts gigantischer Mächte, die ihn in ihrer Blindheit zwar physisch vernichten können, denen er aber noch im Tode menschlichen Trotz bieten würde“ (ibid., 395). Wir sind von der konkreten Landschaft des Meeres und des Hochgebirges zu deren metaphysischer und ethischer Bedeutung gekommen: zu der Herausforderung, die das Elementare für den ethisch gesinnten Menschen bedeutet. Auch wenn Thomas Mann sagt, dass ,das Meer, sein Rhythmus, seine musikalische Transzendenz auf irgendeine Weise überall in [s] einen Büchern gegenwärtig“ sei, spricht er vom Meer in einer symbolischen Bedeutung (ibid., 389). Diese Art und Weise, die Landschaft seiner Heimat als „Atmosphäre“ und Grundton seines Werkes zu bewahren, gehöre zu seinem Dasein als Künstler (ibid., 389). 
Die „Lebensbürgerlichkeit“, die in der Kunst in einem vergeistigten und erhöhten Sinn vorkommt, wird von Thomas Mann durch die Idee der Mitte beleuchtet: „Es ist die Idee der Mitte, das ist aber eine deutsche Idee. Das ist die deutsche Idee [...]. Ja, wer Deutschtum sagt, der sagt Mitte: wer aber Mitte sagt, der sagt Bürgerlichkeit“ (ibid., 396). In den Betrachtungen eines Unpolitischen (1918), die als Reaktion auf den Ausbruch des Ersten Weltkriegs entstanden, tritt die Idee der Mitte in der Form von Vermittlung zwischen „Leben“ und „Geist“, d.h. zwischen dem Unbewusst-Triebhaften oder Ursprünglich-Irrationalen und dem Geistig-Intellektuellen im Menschen, in Erscheinung (Mann 1990 XII, z.B. 25, 84, 92-93, 572-73). Die Stellung in dieser Mitte sei für die deutsche Kultur charakteristisch, und Thomas Mann entwickelt weiter den schon geläufigen Gegensatz zwischen deutscher Kultur und französischer „Zivilisation“: Im Kern der ersteren sieht er die aus dem Unbewussten schöpfende Kunst, während in der letzteren die Politik vorherrsche und das Irrationale im Leben nicht genügend berücksichtigt werde (ibid., 31-32). ${ }^{3}$ Wenn dazu noch die russische Kultur als gefühlsbetont und zum Mystizismus neigend hinzugefügt wird, also als eine Kultur, in der das Unbewusst-Triebhafte überwiegt ${ }^{4}$, fällt die geographische Mittellage der Deutschen zwischen „Westen“ und „Osten“ mit der geistigen zusammen. Die Idee vom Mittlertum zwischen „Geist“ und „Leben" wird auch in Manns weiteren Schriften bewahrt, ja sie ist der eigentliche Kern seiner Schopenhauerisch-Nietzsche'schen Metaphysik des Menschen. Schon in seinen Schriften aus den 1920er-Jahren kommt dem Mittlertum aber eine zusätzliche, politische, republikanische und demokratische Bedeutung zu: Jetzt ist es nicht nur die Aufgabe des Künstlers, sondern auch die des Politikers, zwischen den Anforderungen des Geistes und den materiellen Bedürfnissen der Menschen zu vermitteln. ${ }^{5}$

Thomas Manns Ansicht von den Lübeckern und den Deutschen - oder den Franzosen und den Russen - kann als mythologisierend bezeichnet werden. „Es ist wahr“, schreibt er in den Betrachtungen, „die Völker als mythische Individuen anzuschauen ist eine primitiv-volkstümliche Anschauungsweise“; „[e] in Künstler ist [aber] vielleicht nur eben so weit Künstler und Dichter, als er dem Primitiven nicht entfremdet ist“ (Mann 1990 XII, 150-51). Thomas Mann scheint sich hier für das Recht eines Künstlers auszusprechen, mythologisierend zu verfahren. Sein Porträt des geistigen Lübecks ist my-

\footnotetext{
3 Siehe dazu auch Koopmann 1988, 80-85.

4 Siehe Mann 1990 XII, 438-441; die drei werden auf die Formel „der politische Franzose, der menschliche Russe und der wissende Deutsche" zusammengepresst (ibid., 489). Vgl. auch Von deutscher Republik (Mann 1990 XI, 835) und Verhältnis zu Wien, wo die mittlere Position als die der Form und des Lebens zwischen zwei entgegengesetzten „Toden“ dargestellt wird, dem der Aufösung der Formen und dem ihrer Erstarrung (Mann 1990 XI, 401). Zu dieser mittleren Position des Deutschen und zur Rolle des „Russischen“ (als Inbegriff des Ostens) im Zauberberg, siehe Kristiansen 1978.

5 Siehe z.B. Von deutscher Republik (1922) und Rede vor Arbeitern in Wien (1932), Mann 1990 XI.
} 
thisch, insofern als er die „geistige Form“ Lübecks als einheitlich und zeitlos bzw. uralt und anscheinend von jeder historischen Änderung unberührt darstellt: Das „Lübeckische“ fuße auf einer "tausendjährigen“ Tradition (Mann 1990 XI, 398). Diese Tradition wirke in denen, die dort aufgewachsen sind, oft unbewusst fort - aber es sei auch möglich, sich wissentlich von einer solchen Tradition loszulösen. Thomas Mann steht dafür, dass das Tradierte und Eingewurzelte in der Kultur geachtet wird, aber doch nicht so, dass man sich selber dadurch „vom Leben und der Entwicklung“ ausschließt (ibid., 387). Lebensbürgerlichkeit bedeute auch Offenheit dafür, was eine neue historische Situation von einem verlangt.

Wie Hermann Kurzke feststellt, ist Joseph und seine Brüder ein Roman, der geistig in der Epoche der Weimarer Republik verwurzelt ist, auch wenn er erst im Exil verfasst wurde (Kurzke 1983, 225). Hier lässt sich tatsächlich die Idee der Lebensbürgerlichkeit wiedererkennen, trotz des explizit Mythischen in diesem Roman, in dem Thomas Mann nach seinen eigenen Worten die Wende vom Bürgerlich-Individuellen zum MythischTypischen vollzogen hat. Joseph und seine Brüder ist in einem doppelten Sinne ein mythischer Roman: Es wird die mythische Geschichte des biblischen Joseph wiedererzählt, und der Roman handelt von einer Welt, in der die Menschen sich selbst und ihre Welt durch Mythen deuten. Zwischen den Charakteren des Romans gibt es Unterschiede darin, wie sie mit Mythen umgehen: Die Archaischsten unter ihnen machen keinen Unterschied zwischen sich selbst und dem mythischen Vorbild, während es für andere, insbesondere für die Intellektuellen wie Joseph, zwischen dem Individuellen und dem mythischen Typus einen Hiatus gibt, der es dem Individuum ermöglicht, zwischen verschiedenen mythischen Rollen zu wählen und mit ihnen zu spielen.

Das ideelle Zentrum des Romans ist aber die "Gottessorge“ in Abrahams Sippe. Der Gott des Alten Testaments erscheint hier nicht als eine unwandelbare mythische Figur, sondern als eine sich ändernde: Die „Gottessorge“ Abrahams und seiner Nachfolger besteht in der Bemühung, zeitgemäße Änderungen im Bild Gottes wahrzunehmen und bekanntzumachen. Diese Änderungen beziehen sich darauf, was Gott vom Menschen, seinem Ebenbild, verlangt. Die „Gottessorge“ ist somit eine Sorge um den Menschen, um die Bildung der Menschheit. Thomas Mann verfährt anachronistisch, wenn er nicht nur Änderungen im Gottesbild beschreibt, sondern die Patriarchen selbst als sich ihrer Arbeit an der Entwicklung des Gottesbildes bewusst darstellt und ihnen somit die moderne Idee von der Entwicklung der Menschheit zuschreibt. Thomas Mann hat diese „Verfälschung “ aber durchaus geschickt durchgeführt, so dass seinen Lesern der Anachronismus kaum auffällt. Eindeutig spricht Thomas Mann in Joseph und seine Brüder nicht nur für die Weisheit in den uralten Mythen, sondern auch für ihre Vereinbarkeit mit dem modernen, individualisierenden und historischen Denken. 
Ziel der Bildung der Menschheit ist ein Gleichgewicht zwischen den „höheren“ und den „niedrigeren“ Mächten, dem Unbewusst-Triebhaften und dem Intellektuell-Geistigen, im Menschen. Joseph ist derjenige, der von den Mächten des Oben und von denen der Tiefe gesegnet ist, aber auch er muss lernen, seine Gaben für das Wohl anderer einzusetzen: Als Stellvertreter des Pharaos sorgt er für das materielle Wohl des Volks - sowohl des Volks des Pharaos als seines eigenen. Es geht also um die Erlangung einer „Lebensbürgerlichkeit“, die den Joseph-Roman mit der Lübecker Rede, den Betrachtungen und dem Zauberberg verbindet. Das Konkrete, Lokale ist hier ein anderes, und dieses wird ebenso lebhaft und detailreich geschildert wie die Hansestadt in Buddenbrooks oder das Davoser Sanatorium im Zauberberg. In zeitlich und geographisch voneinander entfernten Welten findet Thomas Mann also die im Grunde gleiche Problematik des Lebens und dieselbe ethische Haltung der „Lebensbürgerlichkeit“.

\section{Von Lübeck zu Kaisersaschern: Ummythologisierung des Deutschen}

Stammte Joseph und seine Brüder aus der geistigen Atmosphäre der Weimarer Republik, ist Doktor Faustus (1947) ein Roman der Epoche des Dritten Reichs. Statt Lübeck wird im Doktor Faustus Kaisersaschern als der Inbegriff des Deutschen vorgeführt. Thomas Mann arbeitete am Doktor Faustus im Exil und später auch als amerikanischer Staatsbürger, aber seine geistige Heimat blieb Deutschland; nur hat sich dessen Deutung für ihn geändert. Die neue Ansicht hat er auch im Essay Deutschland und die Deutschen von 1945 zum Ausdruck gebracht.

In Deutschland und die Deutschen ist das Deutsche nicht mehr die glückliche Mitte, die in ihrer Kultur sowohl das Irrational-Triebhafte als auch das Geistige im Menschen berücksichtigt und in Einklang miteinander bringt. Es geht zwar immer noch um das Verhältnis dieser beiden, aber jetzt gelingt die Vermittlung zwischen ihnen nicht. Statt „Lebensbürgerlichkeit“, die solch ein Gleichgewicht enthält und die dafür notwendige Weltoffenheit und Offenheit für historische Änderungen besitzt, findet Thomas Mann jetzt im Wesen der Deutschen eine Kluft. Er spricht von ihrer „Weltfremdheit“, ihrem „Weltungeschick“ und ihrem „spießbürgerliche[n] Universalismus, einem Kosmopolitismus in der Nachtmütze sozusagen“, und fügt hinzu: „Diesem Seelenbild, dieser unweltlichen und provinziellen deutschen Weltbürgerlichkeit hat immer etwas Skurril-Spukhaftes und Heimlich-Unheimliches, etwas von stiller Dämonie angehaftet, das zu empfinden meine persönliche Herkunft mir ausnehmend behilflich gewesen sein mag" (Mann 1990 XI, 1129). 
Der Autor kommt daraufhin vom „alten Lübeck“ zu sprechen, dessen Rathaus in dem Jahr vollendet wurde, ,als Martin Luther seine Thesen anschlug ans Tor der Schloßkirche von Wittenberg“(ibid., 1129-1130):
Aber wie Luther, der Reformator, nach Denkungsweise und Seelenform zum guten Teil ein mittelalterlicher Mensch war und sich zeit seines Lebens mit dem Teufel herumschlug, so wandelte man auch in dem protestanti- schen Lübeck, sogar in dem Lübeck, das ein republikanisches Glied des Bis- marck'schen Reiches geworden war, tief im gotischen Mittelalter [...]. Nein, in der Atmosphäre selbst war etwas hängengeblieben von der Verfassung des Menschengemütes - sagen wir: in den letzten Jahrzehnten des fünf- zehnten Jahrhunderts, Hysterie des ausgehenden Mittelalters, etwas von la- tenter seelischer Epidemie. Sonderbar zu sagen von einer verständig-nüch- ternen modernen Handelsstadt, aber man konnte sich denken, daß plötz- lich hier eine Kinderzug-Bewegung, ein Sankt-Veits-Tanz, eine Kreuzwun- der-Exzitation mit mystischem Herumziehen des Volkes oder dergleichen ausbräche, - kurzum, ein altertümlich-neurotischer Untergrund war spür- bar, eine seelische Geheimdisposition, deren Ausdruck die vielen „Origina- le“waren. (ibid., 1130)

Diese Beschreibung der Atmosphäre Lübecks, in der Kinderzug-Bewegung, Sankt-VeitsTanz und Kreuzwunder-Erscheinungen ihren Platz haben, ist ein Selbstzitat aus der Beschreibung Kaisersascherns, der Schulstadt und geistigen Heimat Adrian Leverkühns in Doktor Faustus (Mann 1990 VI, 52). Das „kaisersaschernisierte“ Lübeck ist nicht mehr die Hansestadt mit ihrer ethischen Haltung und der Atmosphäre einer weltoffenen Bürgerlichkeit; immer noch vertritt Lübeck das Deutsche, aber dieses wird nun wesentlich anders gedeutet. Statt der heilsamen „Mitte“, einer Position der „Lebensbürgerlichkeit“, weist der Autor von Deutschland und die Deutschen den Deutschen eine „Altertümlichkeit der Seele“ zu, „welche sich den chthonischen, irrationalen und dämonischen Kräften des Lebens, das will sagen: den eigentlichen Quellen des Lebens nahe fühlt und einer nur vernünftigen Weltbetrachtung und Weltbehandlung die Widersetzlichkeit tieferen Wissens, tieferer Verbundenheit mit dem Heiligen bietet" (Mann 1990 XI, 1143). Wo der Blick in die „Tiefe“ früher als eine Breite der Ansicht vom Menschen geschätzt wurde, wird jetzt seelische Altertümlichkeit und eine bedenkliche Nähe zum irrationalen Urgrund des Lebens, ja zum Dämonischen, gesehen.

Die Schlüsselfigur dieser Atmosphäre ist Luther, eine „riesenhafte Inkarnation deutschen Wesens" (ibid., 1132), der das Mittelalter samt dessen Dämonologie in der Moderne bewahrt. Thomas Mann gesellt sich zu Nietzsche, wenn er in der Reformation die 
Restauration des Veralteten und in Luther „ein[en] konservative[n] Revolutionär[en]“ sieht: „Er stellte ja nicht nur die Kirche wieder her; er rettete das Christentum. [...] In dem Deutschen Luther nahm das Christentum sich kindlich und bäuerlich tiefernst zu einer Zeit, als es sich anderwärts nicht mehr ernst nahm“ (ibid., 1133). Das Dämonische bei Luther und in der deutschen Kultur wird folgendermaßen geschildert: „Wo der Hochmut des Intellektes sich mit seelischer Altertümlichkeit und Gebundenheit gattet, da ist der Teufel. Und der Teufel, Luthers Teufel, Faustens Teufel, will mir als eine sehr deutsche Figur erscheinen, das Bündnis mit ihm, die Teufelsverschreibung [...] als etwas dem deutschen Wesen eigentümlich Naheliegendes“ (ibid., 1131). Das Zitat zeigt die unmittelbare Nähe von Deutschland und die Deutschen zum Doktor Faustus.

In Adrian Leverkühns geistiger Existenz und künstlerischem Schaffen setzt sich die geistige Lebensform Kaisersascherns fort, genauso wie die Lübecks in Thomas Manns, und beide vertreten dadurch das Deutsche und die deutsche Kultur. ,Wo ich bin, da ist Kaisersaschern“, könnte Leverkühn von sich sagen, ${ }^{6}$ genauso wie Thomas Mann bei seiner Ankunft auf dem Neuen Kontinent „Wo ich bin, da ist Deutschland“, gesagt haben soll. ${ }^{7} \mathrm{Da}$ „Lübeck“ eine Verwandlung durchlaufen hat und sich jetzt von Kaisersaschern als „geistiger Lebensform“ nicht unterscheiden lässt, gilt das, was Thomas Mann in der Gestalt Leverkühns von der deutschen Kultur sagt, auch für ihn selbst. Es handelt sich in Thomas Manns großem Deutschland-Roman also um eine Selbstreflexion, Selbstprüfung und Selbstkritik.

Das fiktive Kaisersaschern ist in der „Luther-Gegend“ von Halle, Wittenberg, Naumburg gelegen, was zur „Luther-Atmosphäre“ des Romans beiträgt. Hans Rudolf Vaget meint aber, dass die Schlüsselfigur im Roman nicht Luther, sondern Kaiser Otto III. sei, der in Kaisersaschern begraben ist (statt Aachen, wo seine Grabstätte eigentlich liegt) und dadurch der Stadt ihren Namen gegeben hat (Vaget 1977). In der Regierungszeit dieses Kaisers, der im Jahre 996 fünfzehnjährig zum Kaiser des Heiligen Deutsch-Römischen Reiches gekrönt wurde und schon mit einundzwanzig verstarb, verlagerte sich der Schwerpunkt der Herrschaft des Kaiserreichs nach Italien. Nach Zeitblom, dem Biographen Leverkühns und dem Erzähler des Romans, nannte der Kaiser sich „Imperator Romanorum und Saxonixus“ und war ein „Musterbeispiel der deutschen Selbst-Antipathie“ (Mann 1990 VI, 51; Vaget 1977, 220). Vaget sieht hier die positive Möglichkeit einer Selbstüberwindung des rein Deutschen und eine Anlage zum Universalismus und argumentiert dafür, dass eher Otto III. als der „mittelalterliche“ Luther die „geistige Lebensform“ Kai-

\footnotetext{
6 Dies ist ein Vorschlag des Teufels, des Alter Egos Leverkühns, im großen „Teufelsgespräch“ in der Mitte des Romans, siehe Mann 1990 VI, 302.

7 „Where I am, there is Germany“; „Mann Finds U.S. Sole Peace Hope“, in: New York Times, 22. Februar 1938, 13. Siehe dazu Koopmann 1981, 104.
} 
sersascherns vertritt, die als Erbe auf Leverkühn übergeht (ibid., 220-221). In Deutschland und die Deutschen spricht Thomas Mann von dem „Deutsche[n] in Reinkultur, $\mathrm{d}[\mathrm{em}]$ Separatistisch-Antirömische[n], „Anti-Europäische[n]“, das ihn an Luther ängstigt (Mann 1990 XI, 1133). Die Überwindung des Luther'schen könnte somit einen Durchbruch zur allgemeinen „Lebensbürgerlichkeit" und zur Position der „Mitte“ bedeuten, die nach Manns früherer Ansicht das Deutsche charakterisiert. In der Gestalt Ottos III. sieht Vaget nun Thomas Manns Stellungnahme zur Debatte deutscher Intellektueller im amerikanischen Exil über die Frage, ob der Nationalsozialismus „aus dem Wesen des Deutschtums hervorgegangen sei“ (die sogenannte Ein-Deutschland-These), oder aber ob zwischen zwei Deutschlands zu unterscheiden sei, einem guten und einem bösen (die Zwei-Deutschlands-These). ${ }^{8}$ Nach Vaget hat Thomas Mann mit der Schlüsselfigur des Kaisers Otto III. Stellung für die Ein-Deutschland-These genommen, aber in einer differenzierten Form, nämlich dass das „böse“ Deutschland das fehlgeschlagene "gute" sei; diese Ansicht wird tatsächlich in Deutschland und die Deutschen (Mann 1990 XI, 1146) vorgelegt. Dies bedeutet nach Vaget aber, dass „Thomas Manns Verständnis der deutschen Geschichte nicht in der Faust-Metapher aufgeht" und dass „[d]as gängige Interpretationsschema, wonach Leverkühn als die Verkörperung derjenigen geistigen und psychologischen Anlagen des Deutschtums aufzufassen sei, die in der Chiffre Luther und Faust gemeint seien, [...] auf einem Mißverständnis [beruht] "(Vaget 1977, 216, 220). Denn sowohl das „gute“ als auch das „böse“ Deutschland seien im Erbe Leverkühns als Möglichkeiten enthalten; er verfehle aber die Chancen, das erstere zu verwirklichen (ibid., 216-229). Vagets Argumentation reicht m. E. aber nicht dazu, das von vielen Forschern entdeckte Unvermeidliche und Schicksalhafte in Leverkühns Faust-Identifikation zu widerlegen. ${ }^{9}$ Selbst die Tatsache, dass jede eventuelle Bemühung Ottos III. zur Überwindung des rein Deutschen durch seinen frühen Tod im Keime erstickt wurde, ließe sich ihn eher als ein Symbol des notwendigen Scheiterns solcher Bemühungen der Deutschen interpretieren.

Schon in Lübeck als geistige Daseinsform wurde Musik als zum Deutschtum gehörig dargestellt. In Deutschland und die Deutschen wird als drittes Glied des Komplexes das Dämonische erwähnt:

Die Musik ist dämonisches Gebiet [...]. Sie ist christliche Kunst mit negativem Vorzeichen. Sie ist [...] die der Wirklichkeit fernste und zugleich die passionierteste der Künste, abstrakt und mystisch. Soll Faust der Repräsen-

\footnotetext{
8 Vaget 1977, 206-7. Siehe auch Vaget 1991, Vaget 2008.

9 „Bis zuletzt sieht Thomas Mann also die deutsche Geschichte, ja Geschichte überhaupt, als einen schicksalhaften Ablauf, den man nicht ändern, sondern dessen Tragik man einzig beklagen kann." (Wißkirchen 1986, 166) Vgl. Straßner $(2010,286)$.
} 
tant der deutschen Seele sein, so müßte er musikalisch sein, denn abstrakt und mystisch, das heißt musikalisch, ist das Verhältnis des Deutschen zur Welt. (Mann 1990 XI, 1131-1132)

Hier ist die Gestalt des genialen Komponisten Adrian Leverkühn vorgezeichnet, der einen Pakt mit dem Teufel eingeht, um seine Kreativität von der Lähmung zu befreien, die sein kritischer Intellekt verursacht hat. Der Teufel vertritt hier die niederen Seelenkräfte des Menschen, vor allem die Sexualität. Der Pakt mit dem Teufel wird durch Leverkühns Beischlaf mit einer Prostituierten geschlossen, bei der er sich mit einer cerebralen Syphilis infiziert. Nach fünfundzwanzig produktiven Jahren fällt er in geistige Umnachtung - im Rahmen seines Faust-Schicksals gedeutet wird er vom Teufel geholt. Die heilbringende Mitte, die Vermittlung zwischen dem Geistigen und dem Leiblich-Triebhaften, ist nicht erreicht.

Der Untergang Leverkühns steht für den Sturz der deutschen Kultur in die Barbarei des Nationalsozialismus. Im Doktor Faustus wird die Erklärung für die deutsche Katastrophe nicht in der politischen Entwicklung oder den historischen Umständen gesucht, sondern sie wird von der unabänderlichen seelischen Verfassung, dem mythischen Wesen der Deutschen abgeleitet. Die Reformation wird nicht als eine historische „Erklärung“ für das Wesen der Deutschen geboten, sondern vielmehr ist sie ein Zeitalter, in dem das Wesen der Deutschen am deutlichsten in Erscheinung tritt. Ebensowenig - oder noch weniger - wird das Deutsche aus der historischen Situation um Jahr 1000, also der Zeit Ottos III., erklärt, sondern dieser Kaiser tritt nur als ein Symbol des Deutschen in Erscheinung.

Ebenso wie Lübeck und Kaisersaschern ist Deutschland für Thomas Mann im Doktor Faustus vor allem eine geistige Größe. Die deutsche Katastrophe wird nicht durch eine historische Analyse der Gründe, sondern aus dem mythischen Charakter der Deutschen heraus erklärt. Die Unüberbrückbarkeit der Kluft zwischen dem mythischen und dem modern-aufgeklärten, historischen Denken wird in der Erzählstruktur des Romans durch die Gegenüberstellung der Perspektiven der beiden Hauptpersonen inszeniert. Leverkühn vertritt das mythische Denken, insofern als er sein Leben als Wiederholung des Lebens von Faust versteht, während Zeitblom, der an einer realistischen Künstlerbiographie schreibt, sich auf die Seite der modernen Rationalität stellt. Adrian identifiziert sich zuerst spielerisch mit Faust, aber die Identifizierung wird immer stärker, bis sie vollkommen ist. Zeitblom ist zu entsetzt und erschrocken von der Faust-Identifikation seines Freundes, um sich ernsthaft mit dieser zu befassen. Die Vorstellungen der beiden Freunde von Leverkühns Leben bleiben voneinander getrennt. Ebenso hilflos wie dem FaustSchicksal seines Freundes steht Zeitblom dem „Bösen“ im gegenwärtigen Deutschland gegenüber. Seine humanistische Idee ist die der „menschlichen Mitte“, die Domestizie- 
rung des Triebhaft-Urgründigen im Menschen durch den Geist. Sie erweist sich aber als seicht, falsch und lächerlich. Im Portrait von Zeitblom gibt Thomas Mann schweren Herzens seine frühere Idee der Humanität als Velleität auf. Eindeutig ist es Leverkühn, der die tiefere Einsicht in das Wesen des Menschen hat. Thomas Mann endet im Doktor Faustus damit, dem urtümlichen Denken in Mythen, vertreten von dem syphilitischen Künstler, rechtzugeben.

Lübeck und Kaisersaschern sind zwei Ortschaften, die Thomas Mann nacheinander als seine geistige Heimat angibt. Mit der Verurteilung der "geistigen Lebensform“ Kaisersascherns, für ihn nun der Inbegriff Deutschlands, als tief bedenklich, ja dem Bösen verfallen, verurteilt Mann auch sich selbst. Dass er als Deutscher des Deutschtums und des deutschen Schicksals unvermeidlich teilhaftig ist, hat er in Deutschland und die Deutschen explizit ausgesprochen (ibid., 1128). In der Entstehung des Doktor Faustus berichtet Thomas Mann von seiner Lungenkrankheit und Operation während der Arbeit an Doktor Faustus, die er im höchsten Maß als zur Sache gehörig ansah: „[D]er schreckliche Roman zusammen mit den deutschen Ärgernissen“ seien an seiner Erkrankung schuld (Mann 1990 XI, 254). Es ist eine Art Inszenierung mythischer Identifikation, wenn er am eigenen Leib den Zusammenbruch Deutschlands mit dem Nationalsozialismus spürt, weil er an diesem das Deutschland wiedererkennt, an dem er teilhat.

\section{Literatur}

Dierks, Manfred. 1972. Studien zu Mythos und Psychologie bei Thomas Mann. An seinem Nachlaß orientierte Untersuchungen zum „Tod in Venedig“, zum „Zauberberg“"und zur „Joseph“-Tetralogie. Thomas-Mann-Studien 2. Bern und München: Francke.

Heftrich, Eckhard. 1990. „Joseph und seine Brüder“. In Thomas-Mann-Handbuch, herausgegeben von Helmut Koopmann, 447-474. Stuttgart: Kröner.

Koopmann, Helmut. 1981. „Das Phänomen der Fremde bei Thomas Mann. Überlegungen zu dem Satz: ,Wo ich bin, ist die deutsche Kultur“". In Leben im Exil. Probleme der Integration deutscher Flüchtlinge im Ausland 1933-1945, herausgegeben von Wolfgang Frühwald und Wolfgang Schieder, 103-114. Hamburg: Hoffmann und Campe.

Koopmann, Helmut. 1988. Der schwierige Deutsche. Studien zum Werk Thomas Manns. Tübingen: Niemeyer.

Kristiansen, Børge. 1978. Unform - Form - Überform. Thomas Manns Zauberberg und Schopenhauers Metaphysik. København: Akademisk Forlag.

Kristiansen, Børge. 1990. „Das Problem des Realismus bei Thomas Mann. Leitmotiv - Zitat - Mythische Wiederholungsstruktur“. In Thomas-Mann-Handbuch, herausgegeben von Helmut Koopmann, 823-835. Stuttgart: Kröner.

Kurzke, Hermann. 1983. „Dichtung und Politik im Werk Thomas Manns von 1914-1955, Teil II“. Literatur in Wissenschaft und Unterricht 16: 225-43. 
Mann, Thomas. 1990. Gesammelte Werke in dreizehn Bänden. Frankfurt am Main: Fischer Taschenbuch Verlag.

Straßner, Frank-Uwe. 2010. Gegenwart und Gegenwelten im Deutschlandbild Thomas Manns. Frankfurt am Main: Peter Lang.

Vaget, Hans Rudolf. 1977. „Kaisersaschern als geistige Lebensform. Zur Konzeption der deutschen Geschichte in Thomas Manns Doktor Faustus." In Der deutsche Roman und seine historischen und politischen Bedingungen, herausgegeben von Wolfgang Paulsen, 200-235. Bern und München: Francke.

Vaget, Hans Rudolf. 1991. „Germany: Jekyll and Hyde. Sebastian Haffners Deutschlandbild und die Genese von Doktor Faustus." In Thomas Mann und seine Quellen. Festschrift für Hans Wysling, herausgegeben von Eckhard Heftrich und Helmut Koopmann, 249-271. Frankfurt am Main: Klostermann.

Vaget, Hans Rudolf. 2008. „Fünfzig Jahre Leiden an Deutschland. Thomas Manns ,Doktor Faustus' im Lichte unserer Erfahrung (2001).“ In Thomas Mann. Neue Wege der Forschung, herausgegeben von Heinrich Detering und Stephan Stachorski, 177-201. Darmstadt: Wissenschaftliche Buchgesellschaft.

Wißkirchen, Hans. 1986. Zeitgeschichte im Roman. Zu Thomas Manns Zauberberg und Doktor Faustus. Thomas-Mann-Studien 6. Bern: Francke.

Wysling, Hans. 1967. „,Geist und Kunst‘. Thomas Manns Notizen zu einem ,Literatur-Essay“' In Quellenkritische Studien zum Werk Thomas Manns, herausgegeben von Paul Scherer und Hans Wysling, 123-227. Thomas-Mann-Studien 1. Bern u. München: Francke. 


\title{
Fritz Mauthners Heimatbegriff: Zwischen Deutsch- nationalismus, jüdischem Selbsthass und Sprachkritik
}

\author{
Thomas HainsCHO \\ Alpen-Adria-Universität Klagenfurt (Austria)
}

\begin{abstract}
This paper investigates the concept of Heimat in the work of philosopher, writer, and journalist Fritz Mauthner (1849-1923). It points out a conflict between Mauthner's language philosophy and his political views. In his philosophical work, he argues that language is an insufficient tool for the acquisition of knowledge. When he writes about his heritage and uses notions such as $\mathrm{Hei}$ mat, Volk, or Vaterland, Mauthner makes claims about the formation of social communities based on a shared language and neglects a critical analysis. It appears as if he ignores the philosophical critique of language when it comes to political concepts. Thus, his political position is usually described without regard to his language
\end{abstract}

philosophy, and Mauthner is conceived as a devoted German nationalist and a typical example of Jewish selfhatred. That reading can be contrasted with parts of his work - especially the late book Muttersprache und Vaterland (1920) - in which he criticizes political concepts from a language-philosophical point of view. I argue that Mauthner, read as a philosopher, cannot be typecast as a naïve nationalist as he is too contradictory. I show that his writings offer both a historical example of German nationalism and a deconstruction of nationalism.

Keywords: Fritz Mauthner, Heimat, Deutschnationalismus, Antisemitismus, Sprachkritik

(c) Thomas Hainscho; thomas.hainscho@aau.at

Colloquium: New Philologies, Volume 6, Issue 1 (2021)

doi: 10.23963/cnp.2021.6.1.5

Stable URL: https://colloquium.aau.at/index.php/Colloquium/article/view/149

This work is licensed under a Creative Commons Attribution 4.0 International License (CC BY 4.0). 


\section{Mauthners Begriff der Heimat}

In der Autobiographie Erinnerungen (1918) führt Mauthner seine böhmische Heimat anhand einer Landschaftsbeschreibung ein: „Unsere Heimat kannten wir freilich, das Hügelland, das sich südlich gegen die Elbe abflacht und nordöstlich mit dem grauen Kamm des Riesengebirges und dem Gipfel der Schneekoppe seinen Abschluß findet" (Mauthner 1918, 6). Der Heimatbegriff kommt bei Mauthner vor allem in autobiographischen Passagen vor, in denen die Frage nach der Heimat eine geographische Angabe fordert: Die Heimat anzugeben, bedeutet, einen Ort zu nennen und Landschaftscharakteristika zu beschreiben. In diesem Sinn ist Heimat beliebig und so schreibt Mauthner in Muttersprache und Vaterland (1920) über den Heimatbegriff auch: ,an Berg und Tal, an Himmel und Fluß, an Blumen und Vogelsang denkt man bei dem Worte Heimat" (Mauthner 1920, 59).

Mauthner bezeichnet Heimat auch als den poetischen Ausdruck für die „Gemeinsamkeit des Wohnsitzes“ (Mauthner 1920, 59). Damit wird Heimat nicht ausschließlich auf die Bedeutung als Geburts- oder Herkunftsort festgelegt, sondern kann ebenso den Wohnort meinen. Auch diese Auslegung findet man in autobiographischen Passagen; so nennt Mauthner rückblickend etwa Berlin, wo er in den Jahren von 1876 bis 1905 gelebt hat, seine „neue Heimat“ (Mauthner 1918, 335).

Es gibt nur wenige Stellen in denen Mauthner in einer Metaposition über den Heimatbegriff schreibt. Aber auch wenn der Heimatbegriff nicht tiefergehend analysiert wird, bildet er eine Voraussetzung für die umfassenderen Überlegungen zum Patriotismus. Die „Gemeinsamkeit des Wohnsitzes“, d.h. die Heimat, bildet die Grundlage für sein Verständnis von Patriotismus: „die Gemeinsamkeit des Wohnsitzes [verleiht] [...] dem Patriotismus alle Stimmungen der tiefsten Zugehörigkeit [...] zu der Umwelt“" (Mauthner 1920, 59).

Patriotismus bezeichnet nach Mauthner ein Gefühl, das aus Liebe zur Heimat hervorgeht. Bezieht sich dieses Gefühl auf einen Nationalstaat, weist Mauthner - zumindest in Muttersprache und Vaterland - darauf hin, dass er Patriotismus nicht in dieser Weise verstehe: Denn die Liebe zum Staat sei ein „künstlich gezüchteter Instinkt“ (Mauthner 1997b, 526), ebenso wie die Liebe zu einem Fürsten, einer Fahne oder einer Farbe (vgl. Mauthner 1920, 29-30). Patriotismus bedeutet für ihn eine Sprache zu lieben und nicht ein Land. Im Jahr 1906 legt Mauthner Patriotismus als Liebe zu Muttersprache und Volk aus: „Patriotismus oder Vaterlandsliebe ist die Liebe zum eigenen Volke, ist die Liebe zur eigenen Muttersprache" (Mauthner 2012, 79). Im Aufsatz Patriotismus im Wörterbuch der Philosophie (1910/11) wird bei der Begriffsauslegung - trotz einer Bezugnahme auf die angeführte Stelle in Mauthner (2012) - nicht mehr auf das Volk verwiesen und Patriotismus ausschließlich als Liebe zur eigenen Muttersprache verstanden (Mauthner 
1997b, 526). Dieses Verständnis behält Mauthner bei und nennt im Jahr 1920 „Liebe zur Muttersprache“ die „alleinige Ursache des Nationalgefühls und des Patriotismus“ (Mauthner 1920, 24).

Heimat stellt somit eine Voraussetzung für den Patriotismus dar, weil die Muttersprache für Mauthner als jene Sprache gilt, die in der Heimat gesprochen wird. Mauthner bezeichnet Muttersprache auch als „Mundart der Heimat“ (1920, 9). Patriotismus besteht also darin, die Heimat zu lieben, was wiederum bedeutet, die Mundart der Heimat zu lieben; das heißt, den Dialekt, der an dem Ort gesprochen wird, den man als Heimat bezeichnet. Wenn Mauthner die Liebe zur Muttersprache thematisiert, schreibt er pathetisch und schwelgerisch, etwa: „Man liebt die Muttersprache sogar stärker als man seine Familie liebt, als man seinen Nächsten lieben kann; man liebt sie wirklich wie sich selbst, wie man nur einen edlen Teil seines Ich lieben kann, wie man sein Auge liebt“" (Mauthner 1920, 52). Diese Liebe sei jedem Menschen mit Muttersprache innewohnend, aber warum sie besteht und auch, was es heißt, eine Sprache zu lieben, bleibt zunächst unklar. Eine Begründung für diese Liebe wird lediglich skizziert. Sie wird psychologisch begründet, auf das Individuum bezogen und besteht deshalb, weil „aller Besitz unseres Innenlebens, was wir als Egoisten und was wir als soziale Wesen unsern Besitz nennen, [...] in unserer Muttersprache gesammelt ist“ (Mauthner 1997b, 526).

Eine territoriale Auslegung als Wohn-, Geburts- oder Herkunftsort ist für das Verständnis von Mauthners Heimatbegriffs somit weniger bedeutsam als eine sprachliche Auslegung. Heimat geht aus der Muttersprache hervor und stellt eine Bedingung dar, sich mithilfe der Sprache zu ermächtigen, sich in der Welt zurechtzufinden. Als diese Bedingung ist Heimat stark positiv konnotiert. Die territoriale Auslegung lässt sich mit dieser Betrachtung nur schwer vereinen, da die Orientierung in der Welt aus der frühkindlichen Erstsprache und dem Spracherwerb hervorgeht und nicht mit einem bestimmten Ort verbunden ist.

Einem ersten Blick nach mag Mauthners Auslegung von Patriotismus als Sprachliebe ungewöhnlich erscheinen. Mit zwei Überlegungen lässt sich dieses Verständnis jedoch kontextualisieren. Die erste Überlegung ist eine begriffsgeschichtliche Betrachtung von Patriotismus. Der Artikel im Historischen Wörterbuch der Philosophie (Busch \& Dierse 1989) zeigt, dass die philosophische Begriffsgeschichte von Patriotismus in Europa seit der frühen Neuzeit in verschiedenen Auslegungen als das Bekenntnis zu einem humanistischen Weltbürger*innentum einerseits und zu einem nationalen Chauvinismus andererseits bestand. Den verschiedenen Auslegungen ist es gemeinsam, als Patriotismus die emotionale Einstellung des einzelnen Menschen zu einem größeren Kollektiv zu verstehen. An diesen gemeinsamen Nenner ist Mauthner anschlussfähig. Das Kollektiv, mit dem sich Patriot ${ }^{*}$ innen verbunden fühlen sollen, ist für ihn durch eine gemeinsame Spra- 
che begründet. In Texten vor dem Jahr 1910 - etwa Mauthner (1899; 2012) - wird dieses Kollektiv auch explizit als Volk eingeführt. Damit zeigt sich ein weiterer Aspekt von Mauthners Begriff der Heimat: Er bezieht sich nicht rein auf Sprache, sondern umfasst auch eine soziale Gemeinschaft, die diese Sprache spricht.

Daran schließt die zweite Überlegung an, die Mauthners Position im Kontext des Nationalismus deutet. Sprache dient im Nationalismus zwar auch als Kommunikationswerkzeug, ästhetische Ausdrucksform, Mittel zur Erkenntnis etc., ihre nationalistische Funktion erfüllt sie vor allem anderen aber als Identifikationsmerkmal (vgl. Hroch 2005, 178-189). Eine nationalistische Position zeichnet sich hinsichtlich Sprache durch die Annahme aus, dass das soziale Kollektiv durch eine gemeinsame Sprache gebildet und zusammengehalten wird. Damit einhergehend sind die Annahme, dass die eigene Sprache anderen Sprachen überlegen sei, sowie die Forderung nach einer kollektiven Einsprachigkeit, das heißt, der Dominanz der eigenen Sprache in verschiedenen Lebensbereichen wie der Schule, dem Theater, der Literatur, als Amts- und Umgangssprache etc. Hroch (2005, 179-180) zeigt mit historischen Beispielen, dass solche Forderungen als Aufruf, die eigene Sprache zu lieben, erhoben worden sind - vom frühen 19. Jahrhundert bis in die Gegenwart und von verschiedenen nationalistischen Bewegungen in ganz Europa: Wer die eigene Muttersprache nicht liebe, könne das Vaterland nicht lieben. Mauthners Behauptungen lassen sich widerspruchslos als weiteres Beispiel dafür anführen. Stellt man die Frage nach Mauthners eigener Muttersprache, sieht man, dass die „Liebe zur Heimat" für ihn sowohl eine soziale Gemeinschaft betrifft, als auch die Identität der Sprecher*innen prägt.

Welche Sprache kann als Mauthners Muttersprache bezeichnet werden? In seiner Autobiographie schreibt er: „Ich war Jude und ich lebte als deutscher Knabe in einem slawischen Land" (Mauthner 1918, 110). Mauthner ist 1849 im Kaisertum Österreich, im böhmischen Horschitz, heute Hořice v Podkrkonoší in der Tschechischen Republik, geboren und in der österreichisch-ungarischen Doppelmonarchie aufgewachsen. Im Jahr 1855, als Mauthner sechs Jahre alt war, übersiedelte seine Familie mit ihm nach Prag, wo er zunächst Privatunterricht erhielt und später die Schule besuchte. Seine Familie war wohlhabend, seine Eltern gehörten der jüdischen Oberschicht und Minderheit ${ }^{1}$ an. Die Mauthners waren deutschsprachig und somit Teil einer weiteren Minderheit, der deutschen Sprachminderheit in Böhmen. ${ }^{2}$ Die k.u.k.-Monarchie hatte sich dem Bohe-

1 In den Jahren 1857 bis 1880 waren 1,7-1,8\% der böhmischen Bevölkerung Jüdinnen bzw. Juden. In absoluten Zahlen für das Jahr 1857 bedeutet das nur rund 1550 Menschen. Im stärker industrialisierten, städtischen Umfeld war dieses Verhältnis anders. Im Gebiet um Prag etwa betrug der Anteil der jüdischen Bevölkerung 10,3\% im Jahr 1880. (vgl. Ullmann 2000, 39)

2 Eine genaue Angabe zum Verhältnis zwischen deutscher Minderheit und tschechischer Mehrheit ist schwierig, da die historischen Statistiken auf Angaben zur genutzten Umgangssprache zurückgreifen, was 
mismus verpflichtet und de jure galten die Bewohner*innen von Böhmen als zweisprachig: deutsch- und tschechischsprachig (vgl. Stachel 2004, 13); so wurde zum Beispiel der Schulunterricht in den beiden Landessprachen abgehalten - auch Mauthner wurde auf Deutsch und Tschechisch unterrichtet - und auch andere Bereiche des öffentlichen Lebens waren zweisprachig organisiert.

Mauthner wuchs mit Deutsch, Tschechisch und Hebräisch auf, sah allerdings keine dieser drei Sprachen als seine Muttersprache an. Tschechisch habe er von der Amme gelernt und er erwähnt, dass er bis zu seinem vierten Lebensjahr Deutsch und Tschechisch gleich gut gesprochen habe; er schreibt aber auch, er habe niemals gelernt, Tschechisch zu schreiben ${ }^{3}$ (vgl. Mauthner 1918, 21). In seinem Umfeld waren Mischformen des Deutschen und Tschechischen geläufig, die er als Kuchelböhmisch bezeichnet, „welches in seinem Grundbau slawisch war, aber eine Unmenge deutscher Worte barbarisch mit slawischen Endungen versah" (Mauthner 1918, 124). Als Böhmisch ist diese Mischsprache weder eindeutig als Deutsch noch als Tschechisch ausgewiesen, die Angabe von Kuchel kennzeichnet aber den sozialen Status ihrer Sprecher*innen: Kuchelböhmisch gilt als Sprache der Bediensteten, die vor allem der tschechischsprachigen Landbevölkerung Böhmens angehörten und in der nicht-tschechischen Kommunikation, etwa mit deutschsprachigen Böhm*innen, auf eine Deutsch-Tschechische-Mischsprache zurückgriffen. Für Mauthner stellt Kuchelböhmisch eine defizitäre Ausdrucksform dar. Diese Bewertung basiert nicht auf dem sozialen Status der Sprecher*innen, sondern auf ihrem Charakter als Mischsprache. Er setzt Kuchelböhmisch in Kontrast zu Reinformen des Tschechischen und des Deutschen; Wörter der einen Sprache mit Endungen der anderen zu versehen, führe zu „einem abscheulichen Mischmasch“ (Mauthner 1920, 5) und wird als „barbarisch“ (Mauthner 1918, 124) bezeichnet.

In einer ähnlichen Weise beschreibt er sein Deutsch als defizitär:

ich besitze in meinem innern Sprachleben nicht die Kraft und die Schönheit einer Mundart. Und wenn jemand mir zuriefe: ohne Mundart sei man nicht im Besitze einer eigentlichen Muttersprache - so könnte ich vielleicht heute noch aufheulen, wie in meiner Jugend, aber ich könnte ihn nicht Lü-

\footnotetext{
in einem zweisprachigen Gebiet nur wenig Aussagekraft besitzt. Einer österreichischen Volkszählung zufolge betrug in Prag im Jahr 1900 der Anteil der deutschen Bevölkerung 8,57\% und der Anteil der tschechischen Bevölkerung 91,35\%. (vgl. Luft 1996, 143-145)

3 Seinem Selbstzeugnis nach waren er und seine deutschsprachigen Mitschüler nach der Schule nicht dazu in der Lage, „einen tschechischen Brief ordentlich schreiben zu können“ (Mauthner 1918, 130), während „die tschechischen Schüler der Zweisprachigkeit sehr nahe kamen“" (Mauthner 1918, 129). Mauthner stellt sich in der Autobiographie als talentiertes und lernwilliges Kind dar und blickt enttäuscht und verärgert auf seine Schulzeit zurück, in der er nur wenig lernen konnte und seine Interessen nicht gefordert worden sind. Er schildert die Schule mitunter als Austragungsort für nationale Konflikte, bei denen deutschsprachige Schüler*innen benachteiligt wurden.
} 
gen strafen. Die dicht beieinander wohnenden Deutschen der böhmischen Grenzgebiete [...] haben ihre lieben und echten Dialekte. Der Deutsche im Innern von Böhmen, umgeben von einer tschechischen Landbevölkerung, spricht keine deutsche Mundart. (Mauthner 1918, 51)

Das Deutsch im Landesinneren von Böhmen - das Deutsch der Mauthners in Prag nennt er „arm“ (Mauthner 1918, 51). Es sei ein „papierenes Deutsch“ (Mauthner 1918, 51) ohne die „Fülle [...] und [...] Melodie der Mundart“ (Mauthner 1918, 51). In der Beschreibung, was eine Mundart ausmache und was seinem Deutsch fehle, greift Mauthner mit dem Ausdruck erdgewachsen auf eine autochthone Blut-und-Boden-Metaphorik zurück. Über das Deutsch der Zentralböhmen schreibt er: „Es mangelt an Fülle des erdgewachsenen Ausdrucks, es mangelt an Fülle der mundartlichen Formen.“'(Mauthner 1918, 51)

Mauthner stellt sich selbst als jemand ohne Mundart dar und somit als jemand ohne eigentliche Muttersprache. Er erkennt damit keine bestimmte Heimat als seine an und attestiert sich Heimatlosigkeit. Diese Heimatlosigkeit resultiert nicht daraus, dass er oder seine Familie von Vertreibung, Flucht oder Exil betroffen gewesen wären, sondern aus seiner Sprachsozialisation. Mauthner verfügt über keine Sprache, zu der er eine positive, heimatliche Bindung hätte entwickeln können. Er beherrscht Tschechisch nur schlecht, sein Deutsch ist für ihn nicht erdgewachsenen, sondern papieren. ${ }^{4}$

Die Kontrastierung zwischen künstlich herbeigeführt einerseits und natürlich entstanden andererseits findet man immer wieder in seinem Werk, wobei natürlich entstanden nicht auf einen idealisierten Naturbegriff verweist, sondern im Sprachgebrauch bedeutet. Ausdrücke, die aus dem Sprachgebrauch hervorgehen und aufErfahrung basieren, akzeptiert Mauthner als wirklich, während er auf die Bedeutungslosigkeit von Ausdrücken hinweist, die künstlich geschaffen wurden und „denen in der Wirklichkeit nichts entspricht“ (Mauthner 1997a, CXXIX). Im Fall des papierenen Deutsch wird diese Unterscheidung jedoch außen vor gelassen. Mauthner akzeptiert nicht, dass ein papierenes Deutsch den Sprachgebrauch des Alltags bildet. Sein Verständnis von Muttersprache verlangt nach

\footnotetext{
${ }^{4}$ Eine Parallele zwischen der Fremd- und Selbsteinschätzung von Mauthners literarischer Ausdrucksfähigkeit deutet darauf hin, dass die sich selbst zugeschriebene Heimatlosigkeit mehr als eine bloße Stilisierung bedeutet: Mauthner schreibt, dass er in seiner Jugend zunächst Dichter werden wollte, sich dazu aber nicht in der Lage sah: „[F]ür die Wortkunst fehlte mir das lebendige Wort einer eigenen Mundart" (Mauthner 1918, 125). Er war später als Autor von Parodien erfolgreich, seine Versuche als Schriftsteller mit literarischem Anspruch blieben aber erfolglos. Die Kritik an seinen literarischen Figuren als „blutleer“ (Kühn 1975, 149) und „blass“ (Kühn 1975, 150) ähnelt der Selbsteinschätzung Mauthners über seine dialektlose Mundart, die er - sofern er sie überhaupt anerkennt - als arm und papieren bezeichnet. Kühns resümierendes Urteil über die Rezeption von Mauthners literarischem Werk - die literarische Sprache erstarre in "geschraubter Künstlichkeit“ (Kühn 1975, 151) - bestätigt Mauthners Behauptung über die Voraussetzungen für lebendige Ausdrucksfähigkeit.
} 
einem Ideal, auf das eine erdgewachsene, das heißt, natürlich entstandene, Mundart zurückgeht. Dieses Ideal kann als Heimat verstanden werden und als ein solches Ideal ist Heimat nicht losgelöst von territorialen Ansprüchen, das heißt, einem Territorium, das den Sprecher*innen einer gemeinsamen Sprache zusteht. So beschreibt Mauthner sich als gegenüber der tschechischsprachigen Bevölkerung benachteiligt; nicht nur, weil er keine Mundart und keine „eigentliche Muttersprache“ besitze, sondern auch, weil ihm ein „natürliches Vaterland“ fehle, und ihm somit dieser Anspruch verwehrt bleibt:

So hatten die Tschechen ein natürliches Vaterland, die Deutschböhmen nur ein künstliches. Man könnte das beinahe grotesk auch so ausdrücken: der Kaiser von Österreich hieß in der heuchlerischen Ausdrucksweise der Schule der Landesvater [...] und wir armen Deutschböhmen erfuhren immer nur von unserem Landesvaterland. Das dem Landesvater untertänige Gebiet, von der Adria bis zum Erzgebirge, hieß uns Vaterland. (Mauthner 1920,7)

Die mit den Ausdrücken erdgewachsen und papieren eingeführte Kontrastierung zwischen künstlich und natürlich wird an dieser Stelle auf das territoriale Vaterland angewandt. Das Königreich Böhmen stelle für die Tschechen ein natürliches Vaterland dar. Das im Zitat erwähnte künstliche Vaterland der Deutschböhmen wird von Mauthner genauso wie das Deutsch der Zentralböhmen als papieren bezeichnet: Für die deutschsprachige Bevölkerung Böhmens sollte „der doppelt papierne, der packpapierne, Begriff Cisleithanien die Bedeutung von Vaterland gewinnen“" (Mauthner 1920, 6-7). Ein Gebiet, das nur am Papier besteht, in dem so wie vom Papier abgelesen gesprochen wird, eignet sich für Mauthner nicht, um heimatliche Zugehörigkeit oder Liebe aufkommen zu lassen.

\section{Deutschnationalismus}

Ein Schlüsselerlebnis in Mauthners Biographie war eine böhmische Schulreform. Ab dem Jahr 1868 sollten böhmische Schüler*innen nur mehr in jener Sprache unterrichtet werden, die sie als ihre Muttersprache angegeben haben (vgl. Jičínská 2021). Für Mauthner war das Deutsch:

Daß wir eine Muttersprache redeten, hörten wir amtlich zum ersten Male im Jahre 1868. Ich saß - nach deutscher Bezeichnung - in Unterprima, als infolge politischer Katzbalgereien eine Verordnung herauskam, nach welcher das Unrecht und der Unfug mit den beiden Landessprachen ein Ende nehmen sollte. Von jetzt ab sollten die Schüler nur noch zum Unterricht in ihrer „Muttersprache“ gezwungen werden; es wurde dem Ermes- 
sen des Einzelnen anheimgestellt, ob er auch an dem Unterrichte in der anderen „Landessprache“ teilnehmen wollte oder nicht. Wir gerieten über diese neue Freiheit in ungeheure Aufregung. Die Lüge, als wären wir zweisprachige Menschen, war von uns genommen worden. Die Regierung hatte anerkannt, daß wir eine Muttersprache besäßen, daß wir Deutsche wären. (Mauthner 1920, 8)

Die Schulreform war eine Folge des Siegs von Preußen über Österreich im Deutschen Krieg 1866. Mauthner schreibt, dass er und seine Mitschüler bereits damals erkannten, dass sie Deutsche seien - „wir waren Deutsche, ohne es zu wissen“ (Mauthner 1918, 79) -, und sie wurden „durch die Erlebnisse des Jahres 1866 aus unserm nationalitätslosen Österreichertum [...] aufgerüttelt; und wenn man uns bald darauf auf unsere politische Gesinnung geprüft hätte, so wäre ungefähr herausgekommen: Deutschlands Einheit und Freiheit" (Mauthner 1918, 80-81). Mauthner schreibt an dieser Stelle nationalitätslos und nicht heimatlos. Mit Blick auf die vorangegangene Interpretation des Heimatbegriffs lässt sich allerdings infrage stellen, ob er hier den passenden Begriff verwendet. Die Habsburgermonarchie lässt sich nur schwer als Nation interpretieren ${ }^{5}$ - nationalistisch motivierte Bewegungen einzelner Volksgruppen und Sprachgemeinschaften, die dem Wunsch nach politischer Unabhängigkeit folgten, gingen mit dem Ende der Monarchie einher -, aber Fragen nach dem nationalen Status der Habsburgermonarchie, der nationalen Identität verschiedener Volksgruppen oder der Staatsbürgerschaft stehen bei Mauthner nicht im Vordergrund. Als Sprecher des von ihm als defizitär angesehenen, künstlichen Papierdeutsch und mit seinen mangelnden Tschechischkenntnissen ist nicht Staatsangehörigkeit sein Problem, sondern die Heimatlosigkeit. Da es keine k.u.k.-Muttersprache gab, die die Bevölkerung der Monarchie zu einer Spracheinheit verbunden hätte, bietet ihm die Habsburgermonarchie keine Heimat.

Mit dem Bekenntnis zu Deutschland kann Mauthner, sich als heimatlos inszenierend, eine Muttersprache für sich beanspruchen und damit auch die Zugehörigkeit zu einer Heimat, nämlich Deutschland als Heimat der Deutschsprachigen. Die Passagen, in denen Mauthner seine Zugehörigkeit zu Deutschland betont - besonders seine im Vorfeld und während des Ersten Weltkriegs veröffentlichten journalistischen Texte -, lassen sich kaum anders als Beispiele für naiven und engstirnigen Nationalismus interpretieren. Aus ihnen geht hervor, dass zwei- oder mehrsprachige Menschen als heimatlos gelten, weil man nur dann von der patriotischen Liebe zur Heimat erfüllt sein kann, wenn man genau eine Muttersprache spricht.

\footnotetext{
5 Mauthner $(1920,53)$ bemerkt dazu: „Die Regenten waren unfähig, [...] eine österreichische Nation zu schaffen."
} 
Auf den historischen Kontext bezogen, ist Mauthners Position kein Einzelfall. Für Max Brod (2016, 61-64) gehört Mauthner einer ganzen Generation von um 1850 geborenen Juden an, die sich fanatisch für ihr Deutschtum einsetzen. Die Zweisprachigkeit Böhmens hatte „keine positive Auswirkung auf die Völkerverständigung“ (Le Rider 2012, 46). Das späte 19. Jahrhundert war in Böhmen geprägt von nationalen Konflikten. Für Stachel (2004) resultiert Mauthners Deutschnationalismus aus der historischen Identitätsproblematik.

Diese Diskurse stehen im Zusammenhang mit Fragen nach nationaler Identität sowie dem Nationalismus im Europa der späten und zerfallenden Habsburgermonarchie. Die Mauthner zugeschriebene Position in diesen Diskursen ist eindeutig: Er sei der Auffassung, ein Volk gehöre aufgrund der gemeinsamen Sprache zusammen und seine Heimat soll mit einem Nationalstaat zusammenfallen, in dem nur diese eine Sprache gesprochen wird.

\section{Jüdischer Selbsthass}

Hebräisch ist die dritte Sprache, von der Mauthner schreibt, dass er mit ihr aufgewachsen ist. Seine Kommentare zum Hebräischen sind verschränkt mit der Betrachtung seines eigenen Judentums. Mauthner interessiert sich weniger für Fragen nach der jüdischen Identität im Allgemeinen, sondern für seine eigene Religionszugehörigkeit. In den autobiographischen Erinnerungen, im Kapitel Ohne Sprache und obne Religion, schreibt er: „Wie ich keine rechte Muttersprache besaß als Jude in einem zweisprachigen Lande, so hatte ich auch keine Mutterreligion, als Sohn einer völlig konfessionslosen Judenfamilie“ (Mauthner 1918, 50-51). Mauthner ist weder jüdischen Gebräuchen nach, noch überhaupt religiös sozialisiert worden. Er bezeichnet seinen Vater als „areligiös“, seine Mutter als ,antireligiös“ (Mauthner 1918, 112; vgl. auch Mauthner 1922, 128) und schreibt, dass er bis zum achten Lebensjahr kaum wusste, was es bedeutet, Jude zu sein (vgl. Mauthner 1918, 109). Vor dem Gymnasium hat Mauthner eine jüdische Klippschule - eine private und gebührenpflichtige Vorbereitungsschule - besucht. In der Klippschule wurde er in Hebräisch unterrichtet und - im Gegensatz zu seinen Eltern - mit dem hebräischen Alphabet vertraut gemacht. Ob ihn der Unterricht aber tatsächlich dazu befähigt hat, Hebräisch zu lesen und zu schreiben, kann infrage gestellt werden (vgl. Mauthner 1918, 114; Weiler 1963, 139-142).

Ähnlich wie schon im Fall von Deutsch und Tschechisch beschreibt Mauthner auch sein Hebräisch als defizitär und damit als Sprache, in der er keine Heimat finden konnte. Wohl auf seine eigene Erfahrung zurückgreifend, schreibt er, dass ein „Jude, der in einer slawischen Gegend Österreichs geboren ist", Deutsch und Tschechisch zu verstehen 
lernt, sowie „ein bißchen Hebräisch als die heilige Sprache des Alten Testaments und als die Grundlage für das Mauscheldeutsch, welches er von Trödeljuden, aber gelegentlich auch von ganz gut gekleideten jüdischen Kaufleuten seines Umgangs oder gar seiner Verwandtschaft sprechen hörte“" (Mauthner 1918, 32).

Beim Mauscheldeutsch handelt es sich wie bei dem Kuchelböhmisch um eine Mischsprache, die in ihrer Wertigkeit aber noch geringer beurteilt wird (vgl. Mauthner 1918, 33). Mauschel gilt als „spottname für einen juden“ (Grimm \& Grimm 1984, 1819) und als Mauscheldeutsch bezeichnet es eine defizitäre Variante des Deutschen. Mit mauscheln bezeichnet Mauthner ein besonderes sprachliches Gebärden (vgl. Mauthner 1999b, 147149), das Sprecher*innen unmissverständlich als Jüdinnen bzw. Juden kennzeichnet. Mauscheln ist ein antisemitisch konnotierter Begriff und war im 19. Jahrhundert auch genauso gebräuchlich. Im Grimm'schen Wörterbuch aus dem Jahr 1885 wird das Verb mauscheln wie folgt erklärt: „wie ein schacherjude verfahren; im handeln: bair. täuscheln und mäuscheln, sich mit heimlichen und unerlaubten geschäftchen abgeben“ (Grimm \& Grimm 1984, 1820).

So wie Mauthner in den Nationalismus-Diskursen eine eindeutige Position einnimmt, so wird ihm auch in der Judaistik eine bestimmte Position zugeordnet, und zwar als ein Beispiel für jüdischen Selbsthass. Der Antisemitismus, aufden Gilman (1993) bei Mauthner hinweist, stellt den Gebrauch des Motivs des Juden dar, der in einer bestimmten Weise jüdisch spricht, sich so als Mitglied einer minderwertigen Kultur ausweist und von als besser bewerteten Kulturen ausgeschlossen bleibt (vgl. Gilman 1993, 131). Für Gilman projiziert Mauthner eigene negative Erfahrungen als Verachtung der Andersartigkeit von Jüdinnen und Juden unter den Deutschsprachigen. Ob diese Analyse zutrifft, ist strittig (vgl. Schapkow 2013, 23). Mauthner hat formal die jüdische Religionszugehörigkeit abgelegt (vgl. Weiler 1963, 138) und sich literarisch gegen antisemitische Diskriminierung engagiert, etwa mit seinem Roman Der neue Ahasver (1882). Kritik am Judentum ist in den atheistischen und philosophischen Text oft exemplarisch, das heißt, er kritisiert Religionen allgemein und entwickelt Argumente am Beispiel einer Religion. Jude zu sein, kann für Mauthner aber nicht davon losgelöst werden, in einer bestimmten, nämlich jüdischen, Art zu sprechen. Es handelt sich erneut um ein Beispiel, bei dem Ausschluss von bzw. Zugehörigkeit zu einer sozialen Gemeinschaft an die Teilnahme einer sprachlichen Praxis gebunden ist und Mauthner sich als davon ausgeschlossen darstellt. 


\section{Muttersprache und Vaterland}

Das vorläufige Fazit wäre, dass Heimat für Mauthner eine Bedingung darstellt, die gegeben sein muss, um einer Gemeinschaft anzugehören. Heimat garantiert diese Zugehörigkeit nicht, aber Heimat stellt die territoriale Bedingung für eine gemeinsame Sprache dar, aus der diese Zugehörigkeit hervorgeht. Sich selbst als heimatlos darstellend, lässt sich Mauthners Wunsch nach Heimat als der Wunsch nach einem Territorium für ein Volk mit einer Sprache verstehen. Die Problematik dieser Auffassung ist bekannt.

Verbunden mit Fragen nach Mauthners Deutschnationalismus und seiner Einstellung zum Judentum wurde seine Position mehrfach aufgearbeitet. Was in diesem Kontext aber bisher weitgehend unbeachtet geblieben ist, ist seine Sprachphilosophie. Zieht man die sprachkritischen Überlegungen heran, ist seine Position keineswegs so eindeutig, wie es bisher nahegelegt wurde.

In der Sprachphilosophie stellt Mauthner Sprache als untaugliches Werkzeug für die Abbildung der Wirklichkeit dar. Mit dem Begriff Zufallssinne, dem Entwurf einer Bildtheorie und der Gleichsetzung von Sprechen und Denken möchte er die Bedingung der Möglichkeit von Erkenntnis untergraben. Seine zentrale sprachphilosophische These lautet, dass Erkenntnis mithilfe von Sprache unmöglich sei. Gottfried Gabriel (2013) hat darauf aufmerksam gemacht, dass Mauthners Sprachkritik Züge der Dekonstruktion trägt und er, gemeinsam mit Nietzsche, als einer ihrer Vorläufer verstanden werden kann. Mit dem Ansatz, Wissenschaft, Denken und Vorstellen als Sprachphänomene zu deuten und Sprache zugleich als erkenntnisuntauglich, aber sozial wirksam zu charakterisieren, ist Mauthners Philosophie dafür angelegt, soziale Phänomene auf Wirkungen von sprachlicher Bedeutung zurückzuführen. Im philosophischen Werk lassen sich mehrere Argumente und Anhaltspunkte finden, die gegen Nationalismus gerichtet sind und zu einer Dekonstruktion des Heimatbegriffs beitragen können.

Anhaltspunkte liefert Mauthner in den Beiträgen zu einer Kritik der Sprache. Eine wiederkehrende These seiner Sprachphilosophie ist eine nominalistische Kritik an der Sprache: Die Sprache wird von Mauthner als unwirklich bezeichnet; wirklich - und damit geeignet, das Wesen der Sprache zu zeigen - seien nur Sprachhandlungen. Sprachregeln, Grammatik und Wörterbücher werden als künstliche Systeme bezeichnet, die innerhalb der Sprachwissenschaft berechtigt sind, aber nur wenig für das Verständnis von sprachlicher Praxis helfen. Er führt den Begriff Individualsprache für den individuellen Sprechhabitus einer Person ein und den Begriff Gemeinsprache für die Sprachspezifika größerer Gruppen (Familien, Berufsstände, Volksgruppen etc.). Gegenseitiges Verstehen ist aufgrund der Abstraktion der Individualsprache zur Gemeinsprache möglich, aber zwei Menschen können einander bestenfalls ungefähr verstehen, da keine zwei Menschen dieselbe Sprache sprechen (vgl. Mauthner 1999a, 3-18). Im Abschnitt Muttersprache Nir- 
gends schreibt Mauthner, dass es sich auch bei der eigenen Muttersprache um eine Individualsprache handelt. Daher gebe es nicht zwei Menschen, die dieselbe Muttersprache sprechen: „Gemeinsam ist die Muttersprache etwa, wie der Horizont gemeinsam ist; es gibt keine zwei Menschen mit gleichem Horizont, jeder ist der Mittelpunkt seines eigenen" (Mauthner 1999a, 19). Aus der gemeinsamen Liebe zur geteilten Sprache kann kein Volk hervorgehen, wenn es keine gemeinsame Sprache mehr gibt. Ob es unter diesem Gesichtspunkt eine Heimat geben kann, ist unklar.

Ein weiterer Anhaltspunkt, der die Liebe zur Muttersprache - die das Ich formt, die Zugehörigkeit zu einem Volk bestimmt und die Grundlage für Mauthners Verständnis des Patriotismus darstellt - untergräbt, ist die Bemerkung, dass es möglich sei, die Muttersprache zu wechseln (vgl. Mauthner 1999a, 195-197). Die Muttersprache kann geändert werden, indem die Sprache des Denkens - eine Konsequenz der Gleichsetzung von Sprechen und Denken ist, dass jeder Gedanken in einer Sprache formuliert ist - von einer anderen Sprache abgelöst wird. Das illustrative Beispiel dafür ist der langjährige Aufenthalt im fremdsprachigen Ausland, der dazu führt, in der Fremdsprache zu denken (vgl. Mauthner 1999a, 196-197). Zwar bildet eine Trennung zwischen Eigenem und Fremden die Voraussetzung für dieses Beispiel, aber die Zugehörigkeit zu Eigenem bzw. Fremden kann beliebig geändert werden.

Abschließend sollen zwei umfassendere Beispiele aus Muttersprache und Vaterland für die Dekonstruktion des Heimatbegriffs besprochen werden: (1) die Kritik an der Vorstellung einer, reinen' Sprache und (2) die kritische Analyse von Herrschaft im Nationalstaat.

(1) Mauthner übt Kritik an den sogenannten Sprachfegermeistern. Damit bezeichnet er sprachpuristische Akteur*innen, die unter dem Schlagwort der Reinigung bestrebt sind, vermeintlich fremde Worte aus der eigenen Nationalsprache zu entfernen. Bei diesen Bestrebungen äußere sich „der Patriotismus in mancher Überspannung des Nationalgefühls“ (Mauthner 1920, 12). Zwar steht Mauthner Bemühungen, die eigene Muttersprache zu bewahren, d.h. sie zu gebrauchen, positiv gegenüber (vgl. Mauthner 1920, 14-15), das Entfernen von Fremd- und Lehnwörtern aus Nationalsprachen lehnt er aber ab. Es sei nicht möglich, etwa nicht-deutsche Ausdrücke aus dem Deutschen zu entfernen, weil auch vermeintlich deutsche Worte von anderen Sprachen abstammen. Jedes Wort lasse sich als Fremdwort verstehen, wenn seine Etymologie offengelegt wird. Eine sogenannte Reinigung ist daher unmöglich. Mauthner liefert damit ein linguistisches Argument, er stellt aber auch eine Analogie zur ,Reinheit der Völker' auf, die er ebenso zurückweist: „Es gibt so wenig eine ungemischte Sprache wie es einen ungemischten Volksstamm gibt“ (Mauthner 1920, 15). ${ }^{6}$ Auch wenn ,Mischsprachen' bei Mauthner negativ konnotiert

\footnotetext{
6 Dieser Satz steht am Anfang einer Passage über Sprachpurismus in anderen Ländern als Deutschland bzw. in anderen Sprachen als Deutsch (Mauthner 1910,15-17) und passt im Text weder zum vorigen Satz als
} 
sind - er spricht von „einem abscheulichen Mischmasch“ (Mauthner 1920, 5) oder einer „häßlichen und ekelhaften Mischsprache“ (Mauthner 1920, 14) -, entspricht die beständige Übernahme von Lehnwörtern aus anderen Sprachen der sprachlichen Praxis. Bei der Beschreibung dieses Vorgangs greift Mauthner wie zuvor bei der Bemerkung, dass sein Deutsch nicht erdgewachsen sei, auf eine Boden-Metaphorik zurück, diesmal aber in einer anderen Wendung:

Die Aneignung fremder Wörter und Begriffe ist in der Geschichte jeder Sprache nachzuweisen. Niemals sind Gedanken und Formen von einem geistig reicheren und älteren Volke zu einem ärmeren und jüngeren gelangt, ohne Wörter mitzuschleppen; stoßweise haben solche Kulturwanderungen ganze Mengen fremder Begriffe dem eigenen Boden zugeführt, schmutzig und ertragreich wie einen gesegneten Nilschlamm. (Mauthner 1920, 16)

Fremdwörter seien schmutzig, weil sie eine Sprache verunreinigen, aber derart, wie Nährschlamm verunreinigend sei. Der schmutzige Nährschlamm ist ertragreich: Ohne ihn ist es nicht möglich, dass etwas im Boden wachsen kann. Mauthner schließt diese Überlegungen ab mit der Behauptung „Sprachreinheit ist ein Ideal wie die Wahrheit“" (Mauthner 1920, 17). Die Aufgabe der Sprachkritik ist es, gegen solche Ideale vorzugehen, indem gezeigt wird, dass sie Scheinbegriffe sind (vgl. Mauthner 1997a, CXXIV-CXXX).

(2) Über längere Passagen hinweg greift Mauthner in Muttersprache und Vaterland auf eine Analogie zwischen Kirche und Nationalstaat zurück (vgl. Mauthner 1920, $24-$ 38; 51-54). Seinem kurzen historischen Abriss zufolge bestand bis ins Mittelalter eine Einheit „des Abendlandes in Religion und Sprache“ (Mauthner 1920, 30). Die katholische Kirche hatte eine Obrigkeitssprache und Kultur verantwortet, durch die sie über die Christ*innen in Form einer Universalmonarchie geherrscht hatte. Die Macht der Kirche wurde schließlich gebrochen, indem sich Sprecher*innen von Nationalsprachen gegen das Kirchenlatein behauptet haben und Nationalstaaten gegründet worden sind:

Die neuen Königreiche hießen, so ungefähr seit der Mitte des 13. Jahrhunderts, Nationalstaaten, weil sie im Gegensatze zu der weltlichen oder geistlichen Universalmonarchie des Mittelalters auf der Einheit einer Nation oder eines Volksstammes beruhten. Diese Einheit sprach sich, nachdem es erst zu einer Staatenbildung gekommen war, bald auch in einer Geschlossenheit wirtschaftlicher Interessen aus; zugrunde lag aber doch nur die Ein-

Anschluss noch zum darauffolgenden. Die Vorstellung eines ,reinen Volkes' lehnt Mauthner aber klar ab: Der Vorstellung eines ,Urvolks‘ wird eine historische Entwicklung von ,Mischsprachen` und ,Mischvölkern' entgegengestellt (vgl. Mauthner 1999b, 653-655); kein Staat habe „ein reines Volkstum als Grundlage“" (Mauthner 1906, 98). Siehe dazu auch Lütkehaus (1997, XXII-XXIII). 
heit der Sprache. Volksgenossen waren die Leute, die einander verstanden, die die gleiche Sprache redeten. Erst der Nationalstaat bot die Möglichkeit, die Begriffe Vaterland und Muttersprache zu schaffen. (Mauthner 1920,

28)

Die historischen Behauptungen sind an dieser Stelle zu allgemein und vage, um überprüft werden zu können. Die angeführte Entstehung des Begriffs Vaterland erklärt Mauthner damit, dass die Zugehörigkeit zu einem Staat, im Gegensatz zur Verbundenheit mit der Muttersprache, kein Gegenstand der Liebe sei. Ein Staat werde nicht geliebt - er sei dem Herrschaftswillen unterworfen und zu häufig „,im Lauf der Geschichte zusammengeschweißt worden“ (Mauthner 1920, 52) -, das Bewältigen von staatlichen Pflichten erfordere aber den größten Einsatz seiner Bürger*innen und sei ohne Liebe nicht möglich. Zur Muttersprache bestehe ein Verhältnis des Herzens, zum Staat könne bestenfalls ein Verhältnis des Verstandes aufgebracht werden (vgl. Mauthner 1920, 57). Daher wurde der künstliche Begriff Vaterland geschaffen, ein Ersatz ,für die Liebe zur Heimat, zur Muttersprache, die dem natürlichen Staate von selbst eigen war" (Mauthner 1920, 53). Vaterland wurde aber nicht als das „Land der Volksgenossen“ (Mauthner 1920, 29) also jener Leute, die einander verstehen können, weil sie die gleiche Sprache reden - verstanden, sondern als Land, das dem „Fürsten der Volksgenossen ,gehörte“ (Mauthner 1920, 29). Im Alltag wurde diese Auslegung von Patriotismus als Liebe zum Vaterland, ein bloßes Schlagwort ohne die emotionale Bindung, die Mauthner der Liebe zur Muttersprache beimisst.

Das Herrschaftsprinzip, das die Kirche als Universalmonarchie über Jahrhunderte aufgebaut hatte - die Liebe zu Gott räumte dem Papst die unumschränkte Alleinherrschaft zu -, wurde als Herrschaftsprinzip in den Nationalstaaten übernommen. Das heißt, die propagierte Liebe zu Gott gilt für Mauthner als Vorbild für die Liebe zu der Machthaberin bzw. dem Machthaber im Nationalstaat. Die Herrschaft der Machthaber*innen über das als Besitz aufgefasste Vaterland ähnelt der Herrschaft der Kirche über die als Besitz aufgefasste Religionsgemeinschaft. So bemerkt Mauthner, dass Machtkriege anstelle von Religionskriegen ausgetragen worden sind. Die Machthaber*innen der Nationalstaaten beschönigten die Teilnahme an diesen Kriegen derart „wie sie vorher immer die gleichen Machtkriege mit der religiösen Verpflichtung beschönigt hatten“" (Mauthner 1920, 29). Die Auslegung von Patriotismus als Liebe zum Staat wird im Zuge dieser Überlegungen zurückgewiesen. Damit wird die Interpretation von Heimat als Liebe zur Muttersprache betont und die Forderung nach einem Vaterland zurückgestellt. 


\section{Resümee}

Dieser Aufsatz soll mit auf den Begriff der Heimat gelegten Fokus zeigen, dass Mauthners Werk keineswegs nur als chauvinistisch-deutschnational zu lesen ist und sich darin auch gegen den Nationalismus gerichtete, sprachkritische Argumente finden lassen. Mauthners sprachpolitische Position ist damit nicht eindeutig, sondern widersprüchlich. Er wünscht sich eine Heimat, die es seiner Sprachphilosophie zufolge nicht geben kann, und hinsichtlich des Heimatbegriffs ist sein Werk gekennzeichnet von der Sehnsucht nach einem Ideal, gegen das er zugleich Argumente entwickelt.

Einige Fragen bleiben dabei offen: Etwa die Frage, warum laut Mauthner die Liebe zur Muttersprache besteht, sowie eine genauere Klärung der Frage, inwiefern ihm jüdischer Selbsthass zugeschrieben werden kann. Die Analyse des Heimatbegriffs hat gezeigt, dass Mauthners Verständnis von sozialer Gruppenzugehörigkeit keineswegs nur auf eine geteilte Sprachpraxis zurückgeht, sondern nationalistisch ausgeprägt ist, und damit auch Ansprüche auf ein Vaterland und Volkszugehörigkeit erhebt. Aus der gegenübergestellten Lektüre von Muttersprache und Vaterland sowie ausgewählter Passagen in den Beiträgen geht die Frage hervor, ob seine sprachpolitischen Ansichten durch seine sprachphilosophischen Überlegungen relativiert werden. Diese Frage wird in dem Aufsatz nicht beantwortet, sondern gestellt.

\section{Literatur}

Busch, Hans Jürgen und Ulrich Dierse. 1989. „Patriotismus.“ In Historisches Wörterbuch der Philosophie, Bd. 7, herausgegeben von Joachim Ritter und Karlfried Gründer, 207-217. Basel: Schwabe.

Brod, Max. 2016. Der Prager Kreis. Göttingen: Wallstein.

Gabriel, Gottfried 2013. „Fritz Mauthner - oder vom linguistic turn zur Dekonstruktion. In An den Grenzen der Sprachkritik. Fritz Mauthners Beiträge zur Sprach-und Kulturtheorie, herausgegeben von Gerald Hartung, 115-130. Würzburg: Königshausen und Neumann.

Gilman, Sander L. 1993. Jüdischer Selbsthaß. Antisemistismus und die verborgene Sprache der Juden. Frankfurt am Main: Jüdischer Verlag.

Grimm, Jacob und Wilhelm Grimm. 1984. Deutsches Wörterbuch von Jacob und Wilhelm Grimm. Bd. 12, L-Mythisch. Nachdruck der Erstausgabe 1885. München: Dtv.

Hroch, Miroslav. 2005. Das Europa der Nationen. Die moderne Nationalitätsbildung im europäischen Vergleich. Göttingen: Vandenhoeck \& Ruprecht.

Jičínská, Veronika. 2021. „Fritz Mauthners Erinnerungen als Kritik am österreichischen Bildungswesen." In Fritz Mauthner (1849-1923). Zwischen Sprachphilosophie und Literatur, herausgegeben von Veronika Jičínská, 197-215. Köln: Böhlau.

Kühn, Joachim. 1975. Gescheiterte Sprachkritik. Fritz Mauthners Leben und Werk. Berlin: de Gruyter. 
Kurzeiter, Martin. 1993. Sprachkritik als Ideologiekritik bei Fritz Mauthner. Frankfurt am Main: Peter Lang.

Le Rider, Jacques. 2012. „Zur kulturhistorischen Situation von Fritz Mauthners Sprachkritik.“ Österreichische Zeitschrift für Geschichtswissenschaften (OeZG) 23 (2): 39-56.

Luft, Robert. 1996. „Zwischen Tschechen und Deutschen in Prag um 1900. Zweisprachige Welten, nationale Interferenzen und Verbindungen über ethnische Grenzen." brücken. Germanistisches Jahrbuch Tschechien - Slowakei, Neue Folge, 4 (1-2): 143-169.

Lütkehaus, Ludger. 1997. „Einleitung." In Wörterbuch der Philosophie. Neue Beiträge zu einer Kritik der Sprache. Fritz Mauthner - Das philosophische Werk, Bd. 1, 1, herausgegeben von Ludger Lütkehaus. Nach der 2. verm. Aufl. von 1923/24, IX-XIX. Wien: Böhlau.

Mauthner, Fritz. 1899. „Muttersprache.“Freie Schlesische Presse, 21.5.1899. Fritz Mauthner Collection (AR 3392) - Archives of the Leo Baeck Institute (LBI), Center for Jewish History, New York. (AR-Z.800, 3764: F. Zeitungen und Zeitschriften; I. Aufsätze von Mauthner; C-F).

Mauthner, Fritz. 1906. Die Sprache. Frankfurt am Main: Rütten \& Loening.

Mauthner, Fritz. 1918. Erinnerungen. Bd. 1. Prager Jugendjahre. München: Georg Müller.

Mauthner, Fritz. 1920. Muttersprache und Vaterland. Leipzig: Dürr und Weber.

Mauthner, Fritz. 1922. „Selbstdarstellung." In Philosophie der Gegenwart in Selbstdarstellungen, herausgegeben von Raymund Schmidt, 121-144. Leipzig: Meiner.

Mauthner, Fritz. 1997a. Wörterbuch der Philosophie. Neue Beiträge zu einer Kritik der Sprache. Fritz Mauthner - Das philosophische Werk, Bd. 1, 1, herausgegeben von Ludger Lütkehaus. Nach der 2. verm. Aufl. von 1923/24. Wien: Böhlau.

Mauthner, Fritz. 1997b. Wörterbuch der Philosophie. Neue Beiträge zu einer Kritik der Sprache. Fritz Mauthner - Das philosophische Werk, Bd. 1, 2, herausgegeben von Ludger Lütkehaus. Nach der 2. verm. Aufl. von 1923/24. Wien: Böhlau.

Mauthner, Fritz. 1999a. Beiträge zu einer Kritik der Sprache. Fritz Mauthner - Das philosophische Werk, Bd. 2, 1: Zur Sprache und zur Psychologie, herausgegeben von Ludger Lütkehaus. Nach der 3., um Zusätze vermehrten Auflage von 1923. Wien: Böhlau.

Mauthner, Fritz. 1999b. Beiträge zu einer Kritik der Sprache. Fritz Mauthner - Das philosophische Werk, Bd. 2, 2: Zur Sprachwissenschaft, herausgegeben von Ludger Lütkehaus. Nach der 3., um Zusätze vermehrten Auflage von 1923. Wien: Böhlau.

Schapkow, Carsten 2013. „Ohne Sprache und ohne Religion?‘ Fritz Mauthners Sprachkritik und die zeitgenössischen Debatten über Deutschtum und Judentum." In An den Grenzen der Sprachkritik. Fritz Mauthners Beiträge zur Sprach-und Kulturtheorie, herausgegeben von Gerald Hartung, 19-49. Würzburg: Königshausen und Neumann.

Stachel, Peter. 2004. „,Die nüchterne Erkenntniskritik hat vorläufig zu schweigen'. Fritz Mauthner und der Erste Weltkrieg oder Die Geburt der Sprachkritik aus dem Geist des Nationalismus." In Aggression und Katharsis. Der Erste Weltkrieg im Diskurs der Moderne, herausgegeben von Petra Ernst, Sabine Haring und Werner Suppanz, 93-134. Wien: Passagen. http://www.kakanienrevisited.at/beitr/fallstudie/PStachel3.pdf

Ullmann, Bettina. 2000. Fritz Mauthners Kunst- und Kulturvorstellungen. Frankfurt am Main: Peter Lang.

Weiler, Gershon. 1963. „Fritz Mauthner: A Study in Jewish Self-Rejection“. Year Book of the Leo Baeck Institute 8 (1): 136-148. 


\title{
Das Wesen der Heimat nach Kurt Stavenhagen
}

\author{
Andrzej GNiazDowsKI \\ Polish Academy of Sciences (Poland)
}

\begin{abstract}
The aim of the paper is to reconstruct the main premises of the notion of "homeland" as analyzed by Kurt Stavenhagen, the significant Latvian-German philosopher of the first half of the twentieth century. The paper points out the differences in Stavenhagen's approach to the notion of homeland between the first and second edition of his study, Heimat als Grundlage menschlicher Existenz (Homeland as the Basis of Human Existence) from 1939 and Heimat als Lebenssinn (Homeland as the Meaning of Life) from 1948. The paper informs about the biographical and political background of Stavenhagen's analysis and argues that his philosophical thought belongs to the so-called phenomenological movement. The thesis of the paper is that Stavenhagen's definition of the homeland as a kind of community presupposes Ferdinand Tönnies' distinction between community and society, which was fundamental for German sociology
\end{abstract}

of that time. The author argues that Stavenhagen follows Max Scheler's ideological misinterpretation of Tönnies' distinction in his "war writings" in that he contrasts two types of sociality: authentic and unauthentic. These types are characteristic for German and Anglo-American social relations, respectively. In this light, Stavenhagen's analysis turns out to be not so much a phenomenology but rather a mythology of the homeland. In reference to Leszek Kołakowski's book The Presence of Myth (1984), the paper presents the need for answering to the "phenomenon of the indifference of the world" as a proper meaning of Stavenhagen's mythology.

Keywords: Phenomenology, Homeland, Community, Society, Mythology, Political Philosophy, Capitalism, Exis-

tence

(c) Andrzej Gniazdowski; agniazdo@ifispan.edu.pl

Colloquium: New Philologies, Volume 6, Issue 1 (2021)

doi: 10.23963/cnp.2021.6.1.6

Stable URL: https://colloquium.aau.at/index.php/Colloquium/article/view/150

This work is licensed under a Creative Commons Attribution 4.0 International License (CC BY 4.0). 
Die philosophische Lyrik vom Philosophen und Hochschullehrer Kurt Stavenhagen (18841951), in welcher er das Wesen der Heimat besingt, klingt in polnischen Ohren mit unbestreitbar vertrauten Tönen aus. Als ein in Riga lebender und aufgrund des MolotovRibbentrop-Paktes aus dem heimatlich Lettland vertriebener baltischer Deutscher (Hiden \& Lane 2003), könnte er vielleicht auch seine emotionale Einstellung zum HeimatPhänomen in der diesbezüglichen polnischen Lyrik wiedererkennen. Das romantische Nationalepos Herr Thaddäus hat sein Verfasser Adam Mickiewicz mit den folgenden Worten inauguriert: „Litauen, du meine Heimat, du bist wie die Gesundheit. Nur wer diese verloren, weiß das Verlorene zu schätzen” (Mickiewicz 1976). Die Frage, ob die Heimat nichts anderes als Mythos ist, hat Mickiewicz mit dieser Invokation offensichtlich genauso negativ wie der heimwehkranke Stavenhagen beantwortet. Ihr Wesen scheint der baltische Pole wie sein deutscher Landsmann darin zu erblicken, dass sie nicht nur - mit Stavenhagen gesprochen - die "Grundlage menschlicher Existenz“ (Stavenhagen 1939), sondern auch der eigentliche „Lebenssinn“ des Menschen ist (Stavenhagen 1948).

Das Problem der Heimat und ihrer Bedeutung für das menschliche Leben hat Stavenhagen in einem Büchlein behandelt, das zweimal unter verschiedenen Titeln veröffentlicht wurde. Seine Vorkriegsauflage von 1939, welche in ihrem Titel die Heimat mit der Grundlage menschlicher Existenz identifizierte, unterscheidet sich von seiner zweiten Auflage, das unter dem Titel Heimat als Lebenssinn erschienen ist, auch inhaltlich. Im Vorwort der Nachkriegsauflage von 1948 hat Stavenhagen die Notwendigkeit dieser Unterschiede durch die „geänderten äußeren Verhältnisse“ erklärt, die einige Abschnitte von seinem Buch nicht mehr „zeitgemäß““ machte (Stavenhagen 1948, 3). Er hat auch darauf hingewiesen, dass er in seinen wissenschaftlichen Einsichten seitdem soweit weitergekommen ist, dass sein ganzes Buch, heute neu geschrieben, im Grunde entsprechend anders aussehen würde. Die Frage, die sich bezüglich beider Auflagen des Heimat-Buches von Stavenhagen von selbst stellt, betrifft einerseits den in ihnen unverändert identifizierten Wesensgehalt jenes Phänomens und andererseits die Motive der nach dem Kriege in seiner Beschreibung getroffenen Streichungen und Ergänzungen. In weiterer Folge betrifft diese Frage auch die eventuellen Korrekturen, welchen diese Wesensbeschreibung aus der Perspektive der gegenwärtigen, noch mehr geänderten äußeren Verhältnisse unterzogen werden sollte. 


\section{Die politische Phänomenologie von Kurt Stavenhagen}

Was die Eigentümlichkeit der Auffassung des Heimat-Phänomens von Stavenhagen besagt, ist in erster Linie der phänomenologische Hintergrund seiner Analysen. Im vergilbten Nekrolog aus einem alten Aktenordner, den der Verfasser des hiesigen Beitrags in einem Buch Stavenhagens gefunden hat, liest man, dass die meisten Untersuchungen des baltischen Deutschen der Phänomenologie der Gemeinschaftsformen galten. Gemäß diesem Nekrolog, der nach seinem Tod im Jahr 1951 vom Rektor der Georg-AugustUniversität zu Göttingen verfasst wurde, ist Stavenhagen, befreundet mit Max Scheler, im Austausch auch mit seinem Landsmann Nicolai Hartmann, philosophisch einen ganz selbständigen Weg gegangen. Das Denken von Stavenhagen, der 1908 in Göttingen mit einer Dissertation aus dem Bereich der Altgriechischen Philologie promovierte, sollte nach seinem Ausgang von den Griechen durch Erfahrung, Kampf und Leid eine Prägung von eigenartiger Kraft und Tiefe erfahren, um in der Reife als seinen Kern die Lehre der Verantwortung des Menschen zu enthüllen.

Als einen selbstständigen, mit den sogenannten Münchener und Göttinger phänomenologischen Kreisen verbundenen Phänomenologen, bezeichnete Stavenhagen auch der Philosophiehistoriker Herbert Spiegelberg. In seiner monumentalen Geschichte der phänomenologischen Bewegung hat Spiegelberg darauf aufmerksam gemacht, dass Stavenhagen erst als Vierzigjähriger begann, seine philosophischen Schriften zu publizieren (Spiegelberg 1965, 219). Inspiriert bei posthum erschienenen Fragmenten der Religionsphilosophie von Adolf Reinach hat Stavenhagen 1925 die ausführliche Studie Absolute Stellungnahmen. Eine ontologische Untersuchung über das Wesen der Religion veröffentlicht. Stavenhagen selbst hat in seinem Buch darauf hingewiesen, dass er sich in den dort enthaltenen Untersuchungen über die „persönlichen Stellungnahmen“ - und zwar nicht nur die absoluten, sondern auch die Stellungnahmen ,in der relativen Sphäre“ - mit den entsprechenden Forschungsergebnissen von Max Scheler, Edmund Husserl und Alexander Pfänder auseinandersetzen musste (Stavenhagen 1925, VII). Der Auseinandersetzung mit der „alten“, von ihren Gründern entwickelten Phänomenologie waren auch seine späten, nach dem Zweiten Weltkrieg entstandenen Studien gewidmet (Stavenhagen 1957). Nachdem er an die Universität Göttingen, seinem Studienort, zurückkehrte, hat Stavenhagen die Methode der nicht-Husserlschen Phänomenologie nach Spiegelberg besonders produktiv in Forschungsfeldern der philosophischen Anthropologie und der Ethik angewandt und seine frühere Untersuchungen über Person und Persönlichkeit in origineller, systematischer Form weiterentwickelt (Spiegelberg 1965, 220).

Neben Max Scheler mit seinen Kriegsschriften (Scheler 1915, Scheler 1916 und Scheler 2017), Edith Stein mit ihren Untersuchungen zur Sozial- und Staatsontologie (Stein 1922 und Stein 1925) sowie Dietrich von Hildebrand mit seinen ethisch-sozialen Schrif- 
ten und seiner antinazistischen, philosophischen Publizistik (Hildebrand 1916, Hildebrand 1922, Hildebrand 1930 und Hildebrand 1994), um nur die wichtigsten Repräsentanten jener Richtung innerhalb der phänomenologischen Bewegung zu nennen, hat Stavenhagen zur Entwicklung der soziologischen und politischen Anwendungsfähigkeit der Phänomenologie wesentlich beigetragen. Anders ausgedrückt: Der phänomenologische Hintergrund seiner theoretischen Zugangsweise zum Problem der Heimat macht es möglich, Stavenhagen als den Vertreter der soziologisch orientierten, „politischen Phänomenologie “ zu bezeichnen. ${ }^{1}$ Wie Spiegelberg bemerkt, konzentrierte sich der Rigaer Phänomenologe in den Dreißigerjahren zunehmend auf solche Probleme der Sozialphilosophie wie zum Beispiel das Wesen der Nation und des Volkes sowie das Phänomen der Heimat und der Solidarität, welche er mit der schöpferischen Anwendung der Studien von Alexander Pfänder und Moritz Geiger untersucht hat (Spiegelberg 1965, 220). Als die wichtigsten Ergebnisse jener Untersuchungen wurden im oben erwähnten Nachruf auf Stavenhagen, der seinerseits selbst als ein Zeitzeugnis betrachtet werden kann, das Buch Das Wesen der Nation von 1934 und eben das uns interessierende Werk Heimat als Lebenssinn genannt. Im ersten dieser Bücher sollte Stavenhagen, mit Rektor der Georgia Augusta gesprochen, „die glänzende Kritik des nationalen Massenwahns“ schreiben und im zweiten „die Bedeutung der echten Heimatbindung für die menschliche Existenz“ zeigen (Trillhaas 2014).

\section{Heimat als politisches Phänomen}

Was die Motive der Untersuchungen Stavenhagens über das Phänomen der Heimat anbelangt, waren sie zweifellos sehr eng mit seiner sozial-politischen Lage als Mitglied der deutschen Minderheit in Lettland verbunden. Es ist schwer, mit Spiegelberg nicht einig zu sein, dass dieselben Motive zum großen Teil auch hinter seiner Hinwendung zur Sozialphilosophie im Allgemeinen standen (Spiegelberg 1965, 220). Von seinen Göttinger Kommilitonen war Stavenhagen als der Heimatvertriebene in Erinnerung behalten, der sein ganzes philosophisches Leben der lettischen Heimat gewidmet hat. In dem bereits erwähnten Nachruf kann man lesen, dass ,er, dem wissenschaftliches Denken Lebenselement war“, nach seiner Promotion 1908 ,um seiner kurländischen Heimat willen“ auf die akademische Laufbahn verzichtet hat (Trillhaas 2014). Er sollte sich „unter das verpflich-

1 Der Darstellung der so von ihm bezeichneten Richtung innerhalb der phänomenologischen Bewegung hat der Verfasser dieses Textes das Buch gewidmet, wo versucht wird, die Weltanschauung der ersten Generation der Phänomenologen (Edmund Husserl, Max Scheler, Edith Stein, Ludwig Ferdinand Clauss, Dietrich Hildebrand) und die sowohl weltanschauliche als auch direkt politische Bedeutung ihrer soziologischen Analysen zu rekonstruieren (Gniazdowski 2015). Der vorliegende Vortrag kann als eine Fortsetzung des diesem Buch zugrundeliegenden Projektes verstanden werden. 
tende Gesetz seiner in der Existenz bedrohter Landmannschaft“ gestellt und ihr „später auch politisch und publizistisch in verantwortlichen Ämtern" gedient haben (Trillhaas 2014).

Einer der politischen Ausdrücke seiner Bereitschaft, der Heimat zu dienen war, dass Stavenhagen, zwölf Jahre nach seiner Heimkehr, im Jahr 1921 die Gründung der Rigaischen Deutschen Hochschule, des Herder-Instituts, in die Wege geleitet hat. Bis 1934 hatte er auch das Amt des Geschäftsführers der Deutschen Fraktion und des Deutschen Ausschusses der Parteien der deutschen Minderheit in Lettland inne, das er erst auf Druck nationalsozialistischer Kreise innerhalb jener Minderheit niederlegen musste (Tilitzki 2001, 806). Zu den publizistischen Beiträgen Stavenhagens zugunsten seiner kurländischen Landsmannschaft sind z.B. die während des Ersten Weltkrieges entstandenen Broschüren wie Stärke und Macht der Deutschen in den baltischen Provinzen (Stavenhagen 1915) sowie Die Kriegsziele des Grossrussentums und der Fremdvölker Russlands (Stavenhagen 1916) einzurechnen. Neben seinen dem Wesen der Nation und der Heimat gewidmeten Schriften hat er zum kulturellen und existenziell-politischen Selbstverständnis der baltischen Deutschen auch mit solchen Studien wie Diekonservativ-liberal-demokratische Staatsauffassungund Mitteleuropa (Stavenhagen 1927), Achtungals Solidaritätsgefühlund Grundlage der Gemeinschaften (Stavenhagen 1931) oder Kritische Gänge in die Volkstheorie (Stavenhagen 1936) beigetragen.

Diese starken politischen, die Untersuchung Stavenhagens über das Heimatphänomen leitenden Interessen kommen insbesondere ausdrücklich in der ersten Auflage seines Heimat-Buches zum Wort. Wie im Falle der anderen baltischen Deutschen ist die Innenpolitik der nach dem Ersten Weltkrieg neu entstandenen, unabhängigen Republik Lettland aufStavenhagens Missbilligung und Widerstand gestoßen (Purs 2012). Im Vorwort zu dieser Studie vom 20. September 1938 definierte Stavenhagen sein Buch als eine Hilfe denen, die „das Bedürfnis haben, sich über ein sie bedrängendes Existenzproblem ernsthaft Rechenschaft abzulegen“" (Stavenhagen 1939, 3). Selbst wenn er sich dort nicht explizit, aus verständlichen Gründen, auf die Bedrohung in der Existenz seiner eigenen lettischen Heimat bezog, lässt sich das Buch Heimat als Grundlage menschlicher Existenz als ein Versuch deuten, auf ihre schwierige, sozial-politische Lage aufmerksam zu machen. Um es zu tun, machte Stavenhagen zum porte parole seiner kurländischen Landsmannschaft, peinlicherweise zehn Tage vor dem Münchener Abkommen und dem Anschluss des Sudetenlandes an Deutschland, den Sudetendeutschen Gottfried Rothaker und sein Roman Dorf an der Grenze (Rothaker 1936). Mit Verweis auf dieses Buch, sowie auf den Roman Der Puchner von Wilhelm Pleyer (Pleyer 1934), machte Stavenhagen in einem nach dem Kriege gestrichenen Fragment der Einleitung darauf aufmerksam, dass das Problem der Heimat insbesondere schwer „auf vielen der unter fremdes Volkstum ver- 
streuten Gruppen“ lastet, die man als „die politisch Minderberechtigten oder gänzlich Enterbten, die nationalen Minderheiten nennt“(Stavenhagen 1939, 14).

In der Einleitung zu seinem Buch definierte Stavenhagen Heimat provisorisch als ein „endgültiges überindividuelles Zuhause“ (ibid.). In düsteren Farben schilderte er auch die politischen Hindernisse, auf welche der Wille einiger nationaler Minderheiten stößt, ein solches Zuhause zu behalten. Wie man dieser Einleitung entnehmen kann, musste er zu jenen direkten, politischen Hindernissen unter anderem die damalige Agrarreform in Lettland rechnen, die in der Enteignung des deutschen baltischen Adels von seinem Grundbesitz bestand (Purs 2012). „Zur seelischen Not der Verlassenheit und der lähmenden Wehrlosigkeit kommt die materielle“ (Stavenhagen 1939, 14). Neben der Ohnmacht des „nervenaufreibenden“, auf die Erhaltung des „täglich kleiner werdenden nationalen Besitzes“ abzielenden, passiven Widerstand, bestand diese Not im „Druck einer heute fast allmächtigen, das Steuer der Wirtschaft lenkenden Staatsmaschinerie“ und in den "gewaltsamen Assimilierungsversuche[n] und [der] Lockung zum Volksverrat" (ibid., 15). Für das Schlimmste angesichts der daraus entspringenden Alternative der Zukunft, ,in der Heimat wirtschaftlich verelenden oder sich aus der Heimat verdrängen lassen“, hielt Stavenhagen den Umstand, „dass die Jugend nicht mehr wurzelfest im Lande steht“ (ibid.). Er fragte: „Was für eine Zukunft hat eine Volksgruppe, wenn sie ihrer Jugend nicht mehr sicher sein kann?“ (ibid.).

\section{Die Heimat als Problem der Existenzphilosophie}

Das Heimat-Buch von Stavenhagen, in allen seinen Varianten, ist als Zeugnis der nicht nur politischen, sondern auch existenziellen Verzweiflung zu lesen. Die Frage, von welcher er persönlich ausgeht, mag zwar direkt politisch sein. Sie mag, als die Frage des Vertreters einer aus ihrer Heimat bald umzusiedelnden, nationalen Minderheit, lauten: „Was hat diese täglich neue Quälerei für einen Sinn? Geben wir wirklich etwas Unersetzliches auf, wenn wir, das Land der Väter verlassend, irgendwo in der Fremde ein menschenwürdiges Dasein suchen?“(Stavenhagen 1939, 15). Von der nicht abstreitbaren, sowohl politischen als auch wirkungsgeschichtlichen Relevanz dieser Frage abgesehen, betrachtete Stavenhagen sie dennoch als ein Beispiel dafür, wie nach der Bedeutung dessen, was menschliches Dasein betrifft, in einem „mehr äußerlichen Sinne“ zu fragen. Indessen erklärte er: „Hier soll die Frage im radikalsten Sinne gemeint sein: es soll nach der Bedeutung von Heimat für die menschliche Existenz gefragt werden. Es soll versucht werden, die Frage, welchen Sinn Heimat vom Standpunkt der Idee des Menschen aus, vom Standpunkt des Eigentlich-Menschlichen im Menschen aus hat, zu beantworten“ (ibid., 16). 
Worauf Stavenhagen fragte, war auf diese Weise nichts anderes als, mit Edmund Husserl aus seiner Krisis-Schrift gesprochen, „Lebensbedeutsamkeit“ (Husserl 1992, 3) von Heimat. Seine Frage war eine Frage aus dem Bereich der Existenzphilosophie, insofern als sie eine radikale Unterscheidung zwischen der eigentlichen und uneigentlichen, der Idee des Menschen nicht entsprechenden Existenz voraussetzte. Wie vor ihm der eingangs erwähnte Adam Mickiewicz hat er diese Unterscheidung mit der zwischen Gesundheit und Krankheit verglichen. In der ersten Auflage seines Buches begründete Stavenhagen die Möglichkeit der philosophischen Bestimmung einer „gesunden“, d.h. im Menschen eigentlich angelegten Existenzform, in Anknüpfung an die entsprechenden Ausführungen von Jaspers und Pfänder (Jaspers 1913; Pfänder 1933). Im Unterschied zu den auch gegenwärtigen Forschern aus dem Bereich der Tatsachenwissenschaften, die ein faktisches Verhältnis zwischen der „Ortsidentität" und „mentalen Gesundheit“ festzustellen versuchen (Lengen 2019, 121-149), war der phänomenologisch geschulte Stavenhagen einer damit verbundenen, „,methodischen Schwierigkeit“ durchaus bewusst. Er hat explizit zugegeben, dass die Frage, was Gesundheit ist, „sich nicht durch induktive Erfahrung feststellen“ lässt (Stavenhagen 1939, 16). Trotzdem wies er darauf hin, dass wir doch ein gewisses, wenn auch nicht genügend klares Bild davon haben, „wie körperliches Leben von Menschen aussteht, wenn es jener in ihm angelegten Vollkommenheitsmöglichkeit entspricht, die wir Gesundheit nennen“" (ibid.). Diesem Bild sollte nach Stavenhagen die „unmittelbare Anschauung“ zugrunde liegen, „die sich durch Wahrnehmung mehr oder weniger vollkommener Exemplaren gewinnen und in systematischer Interpretation verfeinern lässt“ (ibid.). Diese Feststellung hinsichtlich der Möglichkeit einer Bestimmung, was körperliche bzw. mentale Gesundheit ist, ließ sich seines Erachtens auf ein analoges Gebiet der Existenz des Menschen übertragen und die Frage, worin das eigentlichmenschliche Leben bestehen soll, auch als sinnvoll zu bestimmen.

Was nach Stavenhagen ein unklares Bild einer gesunden und dementsprechend kranken Existenz des gegenwärtigen Menschen lieferte, war die Beobachtung der nicht nur politischen, sondern auch ökonomischen und soziologischen Prozesse, welche die Lebensbedeutung der Heimat in Frage stellten. Im Unterschied zum direkten, gegen die tatsächliche Existenz der nationalen Minderheiten gerichteten Druck einer fremden Staatsmaschinerie, sollten diese Prozesse nach seiner Auffassung von allgemeiner und tiefgreifender Bedeutung sein. Den Grund des von ihnen in Gang gesetzten ökonomischen und soziologischen Wandels erblickte Stavenhagen in der durch den modernen Hochkapitalismus bedingten Einwicklung einer ,allumfassenden Arbeitsapparatur“, deren letzte und folgerichtigste Verwirklichung die Großstadt war (ibid., 5). Insofern als die großstädtische, auf ganz anderen als den „heimatlichen“ Prinzipien erbauten Lebensform des Menschen auch die Kleinstädte und das flache Land zunehmend beherrschte, wurde nach 
seiner Auffassung die Heimat selbst als eine eigentliche Art, auf die Welt bezogen zu sein, infolge jener hochkapitalistischen Entwicklung in ihrer grundlegenden, existenziellen Bedeutung gefährdet, wenn nicht überhaupt entwertet.

Aus der Perspektive der von Stavenhagen getroffenen Unterscheidung zwischen eigentlicher und uneigentlicher Existenz sollte großstädtisches Dasein als Dasein, „das nirgendwo hingehört und nirgendshin Bindungen hat" (ibid., 6), der Idee des Menschen radikal widersprechen. In seinem Buch ging Stavenhagen von der heftigen, gegen die großstädtische Lebensform gerichteten Philippika aus, welche die mit ihr zusammenhängende „innerliche Wurzellosigkeit des Menschen“ als den „Kern des Großstadtübels“ darstellte (ibid.). Großstädtisches Dasein sollte nach ihm die menschliche Existenz ihrer Eigentlichkeit berauben, da es als nomadisches Dasein in fortschreitender Weise den Menschen vom Menschen löste. Ein solches (großstädtisches) Wanderleben, dessen Symbol für Stavenhagen amerikanische Trailerstädte mit an Autos angehängte Wohnwägen waren, wie sie unter anderen Werner Herzog in seinem Stroszek porträtierte, sollte den Heimatsinn zerstören und sogar dicht besiedelte Länder in Niemandsländer verwandeln (ibid., 8).

Dem Großstadtleben und der mit ihr zusammenhängenden, entfremdeten Lebensform stellte Stavenhagen die im Miteinanderleben, in einer „persönlichen Umwelt“ bestehenden, eigentliche menschliche Existenz gegenüber. Sie sollte im „Heimatsinn als Verantwortungsgefühl für das Ganze“ gegründet sein, das, wie er betonte, nur „durch innere Bindung von Mensch zu Mensch entsteht" und das nur dann lebendig bleiben kann, wenn die Glieder jenes Ganzen „die Verantwortung auch wirklich tragen“ (ibid., 10). Wo diese zwischenmenschlichen, auf das Ganze gerichteten Bindungen in der „Dimension der Gleichzeitigkeit“ fehlen, bemerkte Stavenhagen, „können auch keine Bindungen von der Vergangenheit her und in die Zukunft da sein“ (ibid., 6). Heimatleben definierte er auf diese Weise als das auf dem Prinzip der Verantwortung gebaute Leben der aus einem eigenständigen Traditionskreis entstandenen, engeren Umweltgemeinschaft. „Menschentum, dem die Verantwortung für seine Stadt oder sein Land abgenommen wird, wird zum verantwortungslosen, Publikum', das sich von sich nur noch um die Achse seiner Privatexistenz dreht, die erforderlichen Pflichtleistungen für das Ganze aber von oben betreiben lässt“" (ibid., 10).

Was das Heimatbuch von Stavenhagen zu einem Zeugnis der nicht nur politischen, sondern auch existenziellen Verzweiflung macht, ist die von ihm gestellte Frage nach der Unausweichlichkeit der von ihm beobachteten „Entwicklung zur Heimatlosigkeit“ (ibid., 12). Nicht nur in der ersten, sondern auch in der zweiten Auflage seiner Studie wies er mit Zufriedenheit auf die damals zu Wort kommenden, in einer „Bewegung für Heimatkultur“ bestehenden Gegentendenzen hin. Neben der „wieder erwachenden Sehn- 
sucht nach Eingliederung in engere persönliche Gebilde, Heimatzentren“" (ibid., 12), betrachtete Stavenhagen als eindeutig positiv unter anderem die Erkenntnis, dass „Grund und Boden kein Spekulationsobjekt für die Börse sein darf“" (ibid.). In einem später gestrichenen Fragment der Vorkriegsauflage begrüßte er in diesem Kontext auch das 1933 erlassene Reichserbhofgesetz, in welchem, wie heute angenommen wird, die nationalsozialistische Blut-und-Boden Ideologie ihren vollen Ausdruck gefunden hat (Grundmann 1979). Die Frage, auf welche Stavenhagen nichtsdestotrotz immer wieder zurückkehrte, lautete: „Ist das berechtigt? Ist Heimat nicht doch eine sentimentale Angelegenheit, die es nicht wert ist, um ihretwillen gegen die angeblich eisernen Wirtschaftsgesetze anzurennen?" (Stavenhagen 1948, 13). 1938 kam das Bedenken hinzu: "Ist die Zustimmung zum Erbhofgesetz nicht das Ergebnis einer Stimmung, die verfliegen wird, wenn man die Härte der ökonomischen Gesetzmäßigkeiten beim Anrennen zu spüren bekommt?“ (Stavenhagen 1939, 14).

\section{Die Phänomenologie der Heimat}

Um diese schwierigen, aber seiner Meinung nach durchaus sinnvollen Fragen zu beantworten, machte Stavenhagen die Heimat ausdrücklich zum Gegenstand einer nach ihrem „Wesen“ suchenden Phänomenologie. Das Problem, worin „der Wert oder die Bedeutung von Heimat“ besteht, ob sie nicht bloß eine „nette Kindererinnerung“ oder, anders ausgedrückt, ein Mythos ist, behandelte er auch als das Problem ihrer Metaphysik und der an Scheler anknüpfenden materiellen Wertethik. Für ihre nicht-mythische Wirklichkeit hat der Rigaer Phänomenologe mit Verweis auf die oben erwähnten, im Menschen angelegten Möglichkeiten der Existenzvollendung argumentiert. Diese unklar geahnten und einer systematischen Interpretation bedürfenden Möglichkeiten sollten sich nach seiner Auffassung auch in einer bloßen Umwelt in „Fragen des Zweifels und der Auflehnung" melden: „Wozu bin ich überhaupt in dieser Umwelt? Warum soll ich eigentlich einem Personenumkreis, dem ich gleichgültig bin und der mir gleichgültig ist, ein Leben des Dienstes opfern? Warum soll ich das Beste, das ich zu geben habe, an Menschen verschleudern, die mir irgendein Zufall in den Weg geworfen hat?" (Stavenhagen 1948, 75).

Der eigentliche Ausgangspunkt der von Stavenhagen entwickelten, von diesen praktischen Fragen motivierten Phänomenologie der Heimat bildete eine anthropologische Feststellung bezüglich des Wesens des Menschen. Im Unterschied zu Helmuth Plessner, der im Rahmen seiner philosophischen Anthropologie von der These über die „exzentrische Positionalität" des menschlichen Lebewesens ausging (Plessner 1975, 288), war für Stavenhagen der Mensch als ein primär seelisches Wesen „in den Mittelpunkt seiner 
selbst gestellt" (Stavenhagen 1939, 17). In Anknüpfung an die Phänomenologin Hedwig Conrad-Martius und ihr Werk Metaphysische Gespräche hat er für sein Unterscheidungsmerkmal eine ,größere Eigenständigkeit" als irgendwelche andere Wesen gehalten (Conrad-Martius 1921, 26). Die Bedingung der Möglichkeit der philosophischen Erörterung des Heimatproblems, d.h. der Beantwortung der Frage nach der Bedeutung von Heimat für die eigentlich menschliche Existenz, hat Stavenhagen in der Anerkennung der metaphysisch-anthropologischen Tatsache erblickt, dass „der Mensch [...] nur in einer von sich aus, von innen nach außen geführten Existenz sich zu eigen gewinnen kann, nicht aber in einem wie ihm immer von außen her aufgedrängten Dasein, das seiner Seele zufällig ist und darum leer bleibt" (Stavenhagen 1939, 17-18).

Ausgehend von dieser anthropologischen Feststellung definierte Stavenhagen Heimat als „eine besondere Art, wie der Mensch auf die Gegenständlichkeiten der Welt bezogen und in ihnen verhaftet ist" (Stavenhagen 1948, 13). Die Besonderheit jener Beziehung sollte nach ihm in einer „Bodenständigkeit“ im Sinne eines "Zuhause-Seins“, d.h. eines solchen - nach Heidegger- „In-der-Welt-Seins“ bestehen, das ein gefühlsmäßiges Haften an den Gegenständlichkeiten einer bestimmten, „, mir nahestehenden und mich innerlich bergenden Umwelt" ist (Stavenhagen 1948, 16). Nach Stavenhagen sollte das Heimatliche keineswegs als Objektivität, sondern eher als eine durch den Wertnebensinn des Nahen und Trauten gekennzeichnete Beziehung bestehen. In anderen Worten: Sie soll nicht in einer räumlichen, sondern soziologischen Einheit bestehen. Deswegen war auch das Wesen der Heimat für ihn nicht etwa in einer Landschaft, sondern eher in einer die Heimat nach der Pascalschen „Logik des Herzens “ konstituierenden Gemeinschaft zu erblicken.

Mit Bezugnahme auf den Begriff der Gemeinschaft hat Stavenhagen seine Heimatlehre in den breiteren, theoretischen Kontext der phänomenologischen Soziologie gestellt. Konstitutiv für diese Zugangsweise zum Problem des Sozialen, zu deren Vertretern u.a. Max Scheler, Edith Stein, Dietrich von Hildebrand und Gerda Walther zu zählen sind, ist primär keineswegs die Intersubjektivitätstheorie Edmund Husserls oder der Satz Heideggers über das Dasein als „wesenhaft Mitsein“ (Heidegger 1993, 120) zu halten. Die phänomenologischen Analysen der sozialen Einheiten haben in erster Linie die von Ferdinand Tönnies vollzogene Unterscheidung zwischen „Gemeinschaft" und „Gesellschaft" bestimmt (Tönnies 2010). Bei den meisten Vertretern der phänomenologischen Bewegung ist diese von Tönnies als wertfrei gedachte Unterscheidung zu einer Gegenüberstellung der echten, „naturhaften und organischen“, und künstlichen, „rationalen und mechanischen “, auf dem Prinzip des Egoismus gegründeten Formen der sozialen Einheit geworden (Stein 2010, 111). Insbesondere während des Ersten Weltkriegs wurde diese Unterscheidung - wie z.B. in den sogenannten Kriegsschriften Schelers - mit der Gegen- 
überstellung von deutschen und englischen Arten der sozialen Beziehung gleichgesetzt, die einerseits von der „positiven Idee einer umfassenden Liebesgemeinschaft aller Geistund Vernunftwesen“ und andererseits vom positivistischen Ideal „einer bloß durch Interessensolidarität und Verträge geeinten Menschenmasse "bestimmt werden sollten (Scheler 1915, 116).

Aufgrund der Bezugnahme auf den Begriff der Gemeinschaft erwies sich die Frage nach dem Wesen der Heimat für Stavenhagen als gleichbedeutend mit der Frage nach der Konstitution der Gemeinschaft der ,in den Mittelpunkt" ihrer selbst gestellten, von „Innen“ nach „Außen“ existierenden Menschen (Stavenhagen 1939, 17-18). Die theoretischen Prämissen seiner Heimatlehre hat er ausführlich im Anhang zu seinem Buch besprochen, den er der analytischen Differenzierung der Aufbauelemente und Urformen sozialer Gebilde gewidmet hat. Obwohl diese Gebilde, nach der Bemerkung Stavenhagens, in ihrer historischen Wirklichkeit immer nur „Mischgebilde“ waren, hat er als ihre Urform die „geistige Gemeinschaft“ bzw. „Traditionskreis“ bezeichnet (Stavenhagen 1948, 117). Diese ursprüngliche Gemeinschaftsart sah er in der Allgemeingültigkeit bestimmter geistiger Inhalte in einer Gruppe von Personen gegründet, wie es z.B. in verschiedenem Maße innerhalb von Ständen, Stämmen, Völkern und Kulturkreisen, aber auch Familien und Vereinigungen der Fall ist (Stavenhagen 1948, 117).

Von den weit verstandenen, geistigen bzw. traditionellen Gemeinschaften, die er für die Grundlage aller anderen sozialen Gebilde hielt und die nach ihm auch selbständig auftreten konnten, unterschied Stavenhagen „Schicksalsgemeinschaften“ und "Gesellschaften“ (Stavenhagen 1948, 118). Innerhalb der ersteren differenzierte er zwischen „seelisch[en]“ und „situationsbedingten“ Schicksalsgemeinschaften, beispielsweise einerseits freundlich gesinnte Standes-, Landes- oder Volksgemeinschaften und andererseits pragmatische Verantwortungsgemeinschaften wie Nachbarschaften oder Polarexpeditionen. Die Grenzen zwischen diesen beiden Formen von Schicksalsgemeinschaften, wie auch jene zwischen Schicksalsgemeinschaften und „Interessen-,Gemeinschaften“" (zum Beispiel die amerikanische „Marktgemeinschaft“, der „Weltmarkt“ oder die „Aktiengesellschaft“), sollten nach Stavenhagen fließend sein (Stavenhagen 1948, 119).

In seinen Untersuchungen über das Wesen der Heimat ging Stavenhagen von der sozialphänomenologischen Unterscheidung zwischen der „Heimatgemeinschaft“ und dem „Heimatphänomen“ aus (Stavenhagen 1948, 21). Während die Heimatgemeinschaft für ihn ein im inneren Miteinandersein bestehendes soziologisches Ganzes war, bezeichnete er das Heimatphänomen als einen im Akt der Heimatliebe intendierten Gegenstand. Stavenhagen polemisierte gegen den üblichen Sprachgebrauch, nach welchem der gegenständliche Heimathintergrund, wie etwa die natürliche und künstliche Landschaft, Häuser, Straßen, Gärten, aber auch Sitte oder Sprechart, als ein konstituierendes Element der 
Heimat angesehen wird. Als das Primäre für die Heimat hat er „inneres Miteinandersein“, „Gemeinschaft“, oder „sogar irgendwie in einem besonders , hohen Grade“ Gemeinschaft" zu sein betrachtet (Stavenhagen 1948, 22). Ohne dieser ursprünglichen gemeinschaftlichen Dimension der individuellen und persönlichen „Beziehungen des Herzens“, so Stavenhagen, „wäre die seelische Wärme, die das Heimatganze ausstrahlt und die von den sie erlebenden Heimatgenossen zurückströmt, völlig unverständlich, denn sie fehlt allen anderen soziologischen Gebilden, z.B. den seit Tönnies sogenannten ,Gesellschaften“" (Stavenhagen 1948, 22).

Die von Kurt Stavenhagen vorgenommene phänomenologische Beschreibung des Heimatwesens ist wegen seiner keineswegs voraussetzungslosen Bezugnahme auf die Tönniesche Unterscheidung offensichtlich von vornherein als eine Art Mythologisierung der Heimat zu bezeichnen. Übrigens legte er über die mythologische Funktion seiner Beschreibung explizit Rechenschaft ab. Die Lebensbedeutsamkeit von Heimat definierte er genauso wie der andere Heimatvertriebene, Leszek Kołakowski, der in seinem Buch Die Gegenwärtigkeit des Mythos als Grund aller Versuche, sich mit den irrationalen, menschlichen Gemeinsamkeiten zu identifizieren, die Flucht vom „Phänomen der Gleichgültigkeit der Welt" interpretierte (Kołakowski 1984, 101). Auch Stavenhagen sah die irreduzible Lebensbedeutsamkeit der Heimat darin, dass sie uns „,vor der Gleichgültigkeit, die an sich zwischen Ich und Welt besteht, vor der seelische Kälte, die die Welt an sich erfüllt, vor dem nirgendwo innerlich hingehören“ bewahrt (Stavenhagen 1948, 85).

Wenn Helmuth Plessner in seinem Buch Grenzen der Gemeinschaft mit Recht feststellt, dass jedes Volk ,seinen Radikalismus“ hat (Plessner 1924, 21), kommt somit in der Phänomenologie der Heimat von Stavenhagen der in diesem Buch identifizierte „deutsche Radikalismus“ in seinem vollen Umfang zum Wort. Während der Radikalismus nach Plessner bei keinem Volk „den Sinn für die Wirklichkeit“ so sehr gefährdet, wie bei den Deutschen (ibid.), hat dennoch über die Radikalität der Frage nach der Heimat bei Stavenhagen sein Versuch entschieden, für ihre existenzielle und ethische Wirklichkeit sine ira et studio zu argumentieren. Stavenhagen wies ausdrücklich darauf hin, dass die Heimat als eine Umwelt- bzw. Schicksalsgemeinschaft „zu den Gegenständlichkeiten gehört, deren Gehalt immer nur bis zu einem gewissen Grade verwirklicht ist“ (Stavenhagen 1948, 17). Indem sie nach seiner Auffassung, wie alles irdische Sein, ,immer etwas Fragmentarisches, Unvollendetes“ war, hat er sie als „zum Teil Wirklichkeit“ und „zum Teil Ideal“, als einen „Grenzbegriff“ bezeichnet (ibid.). Die Frage nach einer „absoluten Gemeinschaft“, d.h. nach einem „schlechthinnigen Geborgensein und letztem Aufgehobensein“, wenn auch gleichfalls sinnvoll, hat Stavenhagen dagegen als die „Zentralfrage der Religionsphilosophie" betrachtet. 


\section{Schlusswort}

Zum Schluss sei darauf hingewiesen, dass damit die Heimat in ihrem phänomenalen Selbst erscheinen kann, eine bestimmte - mit Husserl $(1992,82)$ gesprochen - „Einstellungsänderung“ nötig war. „In der Alltäglichkeit“, schrieb Stavenhagen, ,ist der Heimatwert der Traulich-Bergenden wie verhüllt und im Gewöhnlichen und Banalen untergegangen“" (Stavenhagen 1948, 20). Um den Heimathintergrund aus seiner Stummheit zu erlösen und die Heimat zu schätzen zu wissen, bedarf es in seiner Auffassung „eines gewissen feiertäglichen Aufschwunges der Seele" (Stavenhagen 1948, 20). Nicht anders als Mickiewicz, der in Herr Thaddäus auf die Unumgänglichkeit des Verlustes als auf die Bedingung der Selbstgegebenheit der Heimat verwies, hat Stavenhagen diese Bedingung „in der Heimatliebe und in den Erscheinungsformen dieser Liebe, im Heimweh, in der Wiedersehensfreude und im Abschiedsschmerz" erblickt (Stavenhagen 1948, 21). Die Frage, inwieweit seine Untersuchungen über die Lebensbedeutsamkeit der Heimat unverändert auch heute einen Widerhall finden können, erweist sich im Grunde als dieselbe Frage, wie die nach der Lebensbedeutsamkeit unserer „rationalen“ Strategien - wie Leszek Kołakowski feststellt - die Erfahrung der „Gleichgültigkeit der Welt“ vor uns selbst verheimlichen (Kołakowski 1984, 103).

\section{Literatur}

Conrad-Martius, Hedwig. 1921. Metaphysische Gespräche. Halle: Max Niemeyer Verlag.

Gniazdowski, Andrzej. 2015. Antynomie radykalizmu. Fenomenologia polityczna $w$ Niemczech 1914-1933. Warszawa: Wydawnictwo IFiS PAN.

Grundmann, Friedrich. 1979. Agrarpolitik im Dritten Reich: Anspruch und Wirklichkeit des Reichserbhofgesetzes. Hamburg: Hoffmann und Campe.

Heidegger, Martin. 1993. Sein und Zeit. Tübingen: Max Niemeyer Verlag.

Hiden, John and Lane, Thomas. 2003. The Baltic States and the Outbreak of the Second World War. Cambridge: Cambridge University Press.

Hildebrand, Dietrich von. 1994. Memoiren und Aufsätze gegen den Nationalsozialismus 19331938. Mainz: Matthias-Grünewald-Verlag.

Hildebrand, Dietrich von. 1916. „Die Idee der sittlichen Handlung“. Jahrbuch für Philosophie und phänomenologische Forschung 3: 126-251.

Hildebrand, Dietrich von. 1922. „Sittlichkeit und ethische Werterkenntnis. Eine Untersuchung über ethische Strukturprobleme“. Jahrbuch für Philosophie und phänomenologische Forschung 5: 462-602.

Hildebrand, Dietrich von. 1930. Metaphysik der Gemeinschaft. Augsburg: Haas \& Grabherr. Husserl, Edmund. 1992. Die Krisis der europäischen Wissenschaften und die transzendentale Phänomenologie. Hamburg: Felix Meiner Verlag. 
Jaspers, Karl. 1913. Allgemeine Psychopathologie. Ein Leitfaden für Studierende, Ärzte und Psychologen. Berlin: Springer Verlag.

Kołakowski, Leszek. 1984. Die Gegenwärtigkeit des Mythos. Übersetzt von Peter Lachmann. München/Zürich: R. Piper \& Co.

Lengen, Charis. 2019. „Heimat und mentale Gesundheit: Wie place identity unsere Heimatgefühl und Wohlbefinden beeinflusst." In Heimat. Ein vielfailtiges Konstrukt, edited by Martina Hülz, Olaf Kühne, and Florian Weber, 121-149. Wiesbaden: Springer VS.

Mickiewicz, Adam. 1976. Pan Tadeusz. Versepos. Aus dem Polnischen nachgedichtet von Hermann Buddensieg. Berlin-Weimar: Eidos.

Pfänder, Alexander. 1933. Die Seele des Menschen. Versuch einer verstehenden Psychologie. Tübingen: Max Niemeyer Verlag.

Plessner, Helmuth. 1924. Grenzen der Gemeinschaft. Eine Kritikeinessozialen Radikalismus. Bonn: Friedrich Cohen.

Plessner, Helmuth. 1975. Die Stufen des Organischen und der Mensch. Einleitung in die philosophische Anthropologie. Berlin, New York: Walter de Gruyter.

Pleyer, Wilhelm. 1934. Der Puchner. Ein Grenzlandschicksal. München: Langen/Müller Verlag.

Purs, Aldis. 2012. Baltic Facades. Estonia, Latvia and Lithuania since 1945. London: Reaktion Books.

Rothaker, Gottfried. 1936. Dorf an der Grenze. Roman. München: Langen/Müller Verlag.

Scheler, Max. 1915. Genius des Krieges und der Deutsche Krieg. Leipzig: Verlag der Weißen Bücher.

Scheler, Max. 1916. Krieg und Aufbau. Leipzig: Verlag der Weißen Bücher.

Scheler, Max. 1917. Ursprünge des Deutschenhasses. Eine nationalpädagogische Erörterung. Leipzig: Verlag der Weißen Bücher.

Spiegelberg, Herbert. 1965. The Phenomenological Movement. A Historical Introduction. Volume One. The Hague: Martinus Nijhof.

Stavenhagen, Kurt. 1915. „Stärke und Macht der Deutschen in den baltischen Provinzen“. Grenzboten $74(4): 263-274$.

Stavenhagen, Kurt. 1916. Die Kriegsziele des Grossrussentums und der Fremdvölker Russlands. Charlottenburg: Ostlandverlag.

Stavenhagen, Kurt. 1925. Absolute Stellungnahmen. Eine ontologische Untersuchung über das Wesen der Religion. Erlangen: Verlag der Philosophischen Akademie.

Stavenhagen, Kurt. 1927. „Die konservativ-liberal-demokratische Staatsauffassung und Mitteleuropa“. Ostland 2: 51-62.

Stavenhagen, Kurt. 1931. Achtung als Solidaritätsgefübl und Grundlage von Gemeinschaften. Riga: G. Löffler.

Stavenhagen, Kurt. 1939. Heimat als Grundlage menscblicher Existenz. Göttingen: Vanderhoeck $\&$ Ruprecht.

Stavenhagen, Kurt. 1936. Kritische Gänge in die Volkstheorie. Riga: Plates.

Stavenhagen, Kurt. 1948. Heimat als Lebenssinn. Göttingen: Vanderhoeck \& Ruprecht.

Stavenhagen, Kurt. 1957. Person und Persönlichkeit. Untersuchungen zur Anthropologe und Ethik.

Göttingen: Vanderhoeck \& Ruprecht. 
Stein, Edith. 1922. „Individuum und Gemeinschaft“.Jahrbuch für Philosophie und phänomenologische Forschung 5: 116-283.

Stein, Edith. 1925. „Eine Untersuchung über den Staat“.Jahrbuch für Philosophie und phänomenologische Forschung 7: 1-123.

Tilitzki, Christian. 2001. Die deutsche Universitätsphilosophie in der Weimarer Republik und im Dritten Reich. Bd. 2. Berlin: Akademie Verlag.

Tönnies, Ferdinand. 2010. Gemeinschaft und Gesellschaft. Grundbegriffe der reinen Soziologie. Darmstadt: Wissenschaftliche Buchgesellschaft.

Trillhaas, Wolfgang. 2014. „Nachruf auf Kurt Stavenhagen“. Nachlass Wolfgang Trillhaas. Professor der Theologie 1905-1995. Göttingen: Niedersächsische Staats- und Universitätsbibliothek Göttingen. 


\title{
Der Mythos ,Heimat ${ }^{6}$ in der politischen Philosophie Iwan Iljins*
}

\author{
Maja Soboleva \\ Universität Klagenfurt (Austria)
}

\begin{abstract}
The purpose of this paper is to reconstruct the concept "Heimat" (Rodina) on the basis of Iwan Iljin's works The Way of Spiritual Renewal (1937), Homeland and We (1925), and About Russia - Three Lectures (1934). The paper demonstrates that this concept plays a key role in Iljin's political philosophy. "Heimat" serves as a systematic centre which unites various themes of human life, such as family, community, state, and international affairs. It is also necessary for human self-identification.

Iljin's notion of "Heimat" is not easy to interpret and this is one of the reasons why he is often accused of nationalism and conservatism. However, this is not correct
\end{abstract} since Iljin distinguishes between the instinctive drive to homeland and the spiritual homeland. The spiritual homeland does not require any localization in space or time; it does not designate any material objects and only exists in the imagination. Iljin's homeland seems to be a myth having an educational function. The most important characteristics of the myth "Heimat" are the focus of this paper's analysis.

Keywords: Mythos, Heimat, politische Philosophie, Ideologie, Iljin

(c) Maja Soboleva; mayya.soboleva@aau.at

* Diese Arbeit wurde von dem österreichischen Wissenschaftsfonds (FWF) gefördert (Forschungsprojekt M 2590-G32).

Colloquium: New Philologies, Volume 6, Issue 1 (2021)

doi: 10.23963/cnp.2021.6.1.7

Stable URL: https://colloquium.aau.at/index.php/Colloquium/article/view/151

This work is licensed under a Creative Commons Attribution 4.0 International License (CC BY 4.0). 
Das Thema „Heimat" ist selten Thema einer philosophischen Reflexion. Eine Ausnahme stellt eine Tradition in Deutschland dar, die sich um Heidegger gebildet hat und zu der Adorno, Gadamer und Levinas gehören. Auch in Russland ist der Begriff „Heimat“ (Родина) zwar sehr geläufig und bildet seit der Zeit der Sowjetunion die Grundlage für die patriotische Erziehung der Bevölkerung, aber er hat in die Philosophie kaum Eingang gefunden. Georgij Fedotov (1886-1951) und Iwan Iljin (1883-1954) sind nahezu die einzigen Philosophen, die „Heimat“ zum Gegenstand von systematischen philosophischen Überlegungen gemacht haben. Im Folgenden versuche ich eine Rekonstruktion des Heimatbegriffs bei Iljin zu geben. Diesem möchte ich eine kurze Darstellung der Person Iljins voranstellen, weil er im Westen immer noch relativ wenig bekannt ist.

\section{Zur Person Iljins}

Iwan Iljin wurde am 28. März 1883 in der Familie eines Rechtsanwaltes in Moskau geboren. Er studierte Rechtswissenschaft und später Philosophie bei Pavel Novgorodzev und Eugenij Trubezkoj an der Moskauer Universität. Seine Interessen lagen im Bereich der Rechts- und Sozialphilosophie, der politischen Ethik sowie der Geschichte der Philosophie. Im Zuge der Vorbereitung seiner Doktorarbeit, die ursprünglich Die Krise der rationalistischen Rechtsphilosophie in Deutschland im 19. Jahrbundert heißen sollte, verbrachte er zwei Jahre in Europa, wo er bei Simmel und Münstenberg in Berlin, Husserl in Göttingen, Windelband und Lask in Heidelberg, Cohen und Natorp in Marburg, Stammler in Halle, Bougle und Butroux in Paris studieren sollte. Nach seiner Rückkehr aus dem Ausland hat er 1918 die Dissertation zum Thema Philosophie Hegels als Lehrwerk über das Wesen Gottes und des Menschen vorgelegt. ${ }^{1}$ Es ist hier anzumerken, dass Iljins Studien über Hegel bis heute von einigen Forschern zu den bedeutendsten russischsprachigen Arbeiten über die Untersuchungen des dialektischen Bewusstseins, ausgehend besonders von den rechtsphilosophischen Fragen und den Fragen der politischen Ethik, gerechnet werden. Iljin hatte vor, seine akademische Tätigkeit als Professor an der Moskauer Universität fortzusetzen. Allerdings hat dies die historische Situation in Russland verhindert. Es folgten die Februarrevolution 1917, die Iljin begrüßte, und die Oktoberrevolution, die er kategorisch ablehnte. Im beginnenden Bürgerkrieg hat er sich auf die Seite der konterrevolutionären sogenannten, Weißen Bewegung' gestellt. Er hat gegen die Bolschewiki agiert und die,Weiße Armee' mit Wort und Tat unterstützt, indem er zahlreiche Aufsätze zur gegenwärtigen politischen Situation in Russland geschrieben, an verschiedenen antibolschewistischen Aktionen teilgenommen und Geld für die ,Weiße Armee‘ gesammelt

\footnotetext{
1 Auf Deutsch erschien das Buch unter dem Titel Die Philosophie Hegels als kontemplative Gotteslehre (Bern 1946).
} 
hat. Wegen dieser anti-bolschewistischen Tätigkeit wurde Iljin vom 1918 bis 1922 sechs Mal vom Inlandsicherheitsdienst (ВЧK) verhaftet und sogar zum Tode verurteilt. Das Urteil wurde jedoch nicht vollstreckt. 1922 wurde er auf einem der sogenannten ,Philosophenschiffe zusammen mit anderen missliebigen Intellektuellen aus Sowjetrussland ausgewiesen. Im Berlin der Weimarer Republik begann Iljin seine Tätigkeit als Professor am Russischen Wissenschaftlichen Institut (RWI) in Berlin, wo er bis zur Aufösung dieser Institution 1934 beschäftigt war. ${ }^{2}$ Sein bekanntestes theoretisches Werk aus dieser Periode ist das Buch „О сопротивлении зму симою“ (Über den gewaltsamen Widerstand gegen das Böse) (Berlin 1925), in dem er sich polemisch mit der Lebenslehre Leo Tolstois vom gewaltlosen Widerstand gegen das Böse auseinandersetzt und die „notwendige“ Gewaltanwendung gegen das Böse unter der Bedingung der Anerkennung eigener Ungerechtigkeit und Schuld rechtfertigt. In dieser Zeit widmete er sich hauptsächlich den Themen der gegenwärtigen Politik und wurde zu einem der wichtigsten Ideologen der anti-kommunistischen Opposition in der Emigration. Er verfasste zahlreiche Aufsätze und hielt europaweit Vorträge zu den Problemen des Krieges, des Rechtsbewusstseins des Volkes, der Ursachen der russischen Revolution, des Verhältnisses von Staat und Kirche, zu den Phänomenen des russischen Kommunismus und des deutschen Faschismus, der nationalen Ideologie, etc. Zwischen 1927 und 1930 war er Herausgeber und Redakteur der Zeitschrift „Русский комоко““ (Russische Glocke), die wegen mangelnder Finanzierung eingestellt wurde. 1934 geriet Iljin in Konflikt mit dem Hitlerregime, das er anfangs wie viele andere russische Antikommunisten begrüßte, nachdem er sich geweigert hatte, antisemitische Propaganda zu betreiben. Er wurde zweimal von der Gestapo verhört, konnte aber durch die Vermittlung von Sergei Rachmaninow im Jahr 1938 zusammen mit seiner Frau in die Schweiz fliehen. Dort setzte er, trotz des Verbots jeglicher politischer Tätigkeit, seine publizistische Arbeit und seine anti-sowjetische Tätigkeit bis an sein Lebensende fort. ${ }^{3}$ Felix Philipp Ingold würdigte Iljins Leistungen mit folgendem Verweis:

Unter prekärsten Existenzbedingungen verfasste er ein halbes Hundert Bücher und Broschüren, veröffentlichte überdies - meist an entlegener Stelle - zahllose tagespolitische Artikel und religiöse Traktate, hielt rastlos Vorträge in christlichen Vereinen und städtischen Volkshochschulen, stets bemüht, seine Fundamentalkritik am stalinistischen Totalitarismus zu verbinden mit der Vision einer lichten postsowjetischen Zukunft für Russland. (Ingold 2007)

\footnotetext{
2 Zur Geschichte der russischen Emigration siehe Schlögel (1998 und 1999).

3 Mehr zu Person und Werk Iljins in deutscher Sprache siehe Dahm (1976), Tsygankov (2001), Budde (2013), Offermanns (2018) und Lisitsa (2020).
} 
Im Jahr 1937 erschien Iljins Buch Путь духовного обновления (Der Weg der geistigen Erneuerung) (Belgrad 1937) ${ }^{4}$, das im Fokus der nachfolgenden Analyse stehen wird. Dieses Werk zusammen mit den Reden Die Heimat und wir (Berlin 1925) und Über Russland - Drei Reden (Sofia 1934) bildet den Textkorpus, in dem die Heimatproblematik zentral ist. „Heimat“ wird hier zu einem Schlüsselkonzept, an welchen sich vielfältige, vor allem ethische und politische, Perspektiven eröffnen lassen. Iljin fungiert in diesen Werken als ein Ideologe der, Weißen Bewegung 'im Exil und es geht ihm darum, die geistigen Grundlagen für die Konsolidierung dieser Bewegung zu entwickeln. Sein Heimatbegriff ermöglicht daher einen Brückenschlag zu den zentralen Themen der Organisation - ihren Prinzipien und Zielen - dieser Bewegung und ihres Verhältnisses zu Sowjetrussland.

\section{Heimatbegriff im Werk Die Heimat und wir}

De facto vereinigten sich unter der Bezeichnung, Weiße', einem zeitgenössisch geprägten Begriff, verschiedene Gruppierungen wie Monarchisten, gemäßigte Sozialisten, Republikaner, Nationalisten und andere, so dass die, Weiße Bewegung' ein Sammelbecken für alle Kräfte in der Opposition zur bolschewistischen Revolutionsregierung und gegen jegliches bolschewistisches Gedankengut bildete. Das einzige Bindeglied zwischen diesen unterschiedlich gesinnten, heimatlosen Menschen war die nostalgische Vorstellung vom verlorenen „heiligen“ Russland und der Wunsch, Russland wieder „vereint, mächtig und unteilbar“ zu machen. Wie viele andere teilte Iljin diese Grundauffassung: „Wir erklären heute für Freunde und Feinde: Der Kampf ist nicht zu Ende, er wird fortgesetzt. Er wird beendet nur nach der Befreiung und dem Wiederaufbau Russlands“"(Iljin 1926, 3).5 Allerdings hat er seine eigene, stark idealistische Deutung dieser Vorstellung vorgeschlagen und sie zu einem systematischen Programm zu entwickeln versucht.

Bereits die Schrift Die Heimat und wir kann als ein Manifest, adressiert an die Weiße Exilarmee, interpretiert werden. Seine wichtigste Botschaft ist darin zu sehen, dass in der Erwartung des passenden Momentes für die Rückkehr nach Russland, möglicherweise in Form eines militärischen Einmarschs, die Weiße Armee sich als eine einheitliche Institution erhalten sollte. Dies bedeutete für Iljin vor allem, dass die Weißgardisten ein messianisches Bewusstsein entwickeln und sich als Retter Russlands verstehen müssen. Auf den ersten Blick scheint dies nichts anderes als ein revanchistischer Ansatz zu sein.

\footnotetext{
4 In deutscher Sprache wurde das Buch unter dem Titel Die ewigen Grundlagen des Lebens (Zürich 1943) publiziert.

5 Da die Bücher Iljins in deutscher Sprache unzugänglich sind, werden seine Werke von der Autorin dieses Artikels übersetzt.
} 
Allerdings verschwindet dieser Eindruck bei der genauen Analyse Iljins eigener Begrifflichkeit.

Das stärkste Argument gegen eine geopolitische Deutung von Iljins Ideen kann seine Betonung der geistigen Dimension sowohl der "Weißen Bewegung" als auch des Konzeptes ,Russland' sein. ,Russland' erschließt sich in Iljins Überlegungen als ein geistiges Gebilde. Er schreibt, dass sich Russland als Heimat durch den Ort und gemeinsames Alltagsleben nicht erschöpfe. Vielmehr solle man Russland als eine geistige Heimat, als „ein Schatz der russischen nationalen geistigen Erfahrung" (ibid., 2), begreifen. Russland als Heimat besteht für Iljin aus bedeutsamen historischen, religiösen und kulturellen Ereignissen, die seine geistige kollektive Individualität ausmachen.

Dementsprechend sieht er den Wert der, Weißen Bewegung ' darin, dass diese die geistigen Werte Russlands repräsentieren soll. Der Terminus, Weiße Bewegung ' wurde historisch von den weißen Uniformen der Offiziere (der Kadetten) der zaristischen Armee abgeleitet. Iljin symbolisiert aber diesen Namen: Das Weiße ist für ihn die Metapher für das Ideale, das Gute, Glaube, Wahrheit, Unschuld, Reinheit, Bescheidenheit und Treue. Er ruft die Mitglieder der, Weißen Bewegung ' auf, diese schwierige Zeit fern von der Heimat zu überleben und dabei „den weißen Geist, den Geist der Ehre, des Dienstes und der Treue aufzubewahren“ (ibid., 4). Ohne die Voraussetzung der Geistigkeit ist für ihn die ,Weiße Bewegung' als eine potenzielle Kraft, die Russland nach der Oktoberrevolution, dem Bürgerkrieg und der gesellschaftlichen Katastrophe erneuern kann, nicht denkbar. Unrecht mit Unrecht zu bekämpfen ist für ihn keine annehmbare Option. Russland kann von dem Bolschewismus, der „zwischen Gut und Böse nicht mehr imstande war zu unterscheiden, sich zur Gewalt und zum Ergreifen bekehrte und sich an der Idee des Alleserlaubtseins berauschte“ (Iljin 2001, 66), nur von den moralisch unfehlbaren Trägern der geistigen Werte gerettet werden.

Iljin formuliert in der Rede Die Heimat und wir zehn Forderungen, ja zehn Gebote, an die Weißgardisten, die sich auf die drei Säulen - Ehre, Dienst und Treue - stützen. In Erfüllung dieser Gebote, zu denen materielle Autonomie, geistige Autarkie, religiöser Glaube, konspirative Arbeit gegen das Sowjetrussland und die Vernetzung mit Gleichgesinnten, Treue zur ,weißen Idee', kritisches Begreifen und Evaluieren der russischen Revolution und Vorbereitung der Heimkehr gehören, bestehe die „wichtigste patriotische Aufgabe“ (Iljin 1926, 8). Das Befolgen dieser „patriotischen Imperative“ soll eine geistige Persönlichkeit formen, die die historische Mission der Befreiung Russlands vom Bolschewismus und seine Erneuerung zu erfüllen imstande ist. Das Leben der Emigranten soll also zu einer Aufgabe, Handlung und Heldentat werden.

Iljin schreibt: „Die weiße Idee ist nicht die Idee der Vergeltung, sondern die Idee der Wiedervereinigung und Versöhnung; sie enthält nicht die Restauration (Restauration 
dessen, was es gab), sondern den Wiederaufstieg, nicht die Versklavung, sondern die Befreiung" (ibid., 13). Es ist nicht Russland als ein Territorium mit festen Grenzen und als ein Imperium, wonach er Sehnsucht hat, sondern Russland als eine geistige Heimat, die sich durch die Harmonie zwischen dem Monarchen, den Staat, der Kirche und dem Volk, beruhend auf einer vernünftigen Rechtsordnung, Rechtsbewusstsein und individueller Freiheit, auszeichnet. Nicht das faktische, sondern das ideelle Russland wird von Iljin für die Begründung der ,weißen Idee' genommen. Das bedeutet, dass er den Mythos der Heimat schafft und mit dessen Hilfe die Konsolidierung der, Weißen Bewegung 'im Exil zu erreichen erhofft. Die Mythologisierung der Heimat erfolgt dadurch, dass Heimat als Herkunftsland interpretiert wird, aber die Herkunft symbolisch als die geistige Herkunft gemeint wird. Mythos wird hier als ein Motiv für politische Handlungen verwendet.

\section{Heimatbegriff im Werk Über Russland - Drei Reden}

Die drei Reden Über Russland setzen das Thema der Heimat fort. Heimat stellt sich auch in diesen Texten als symbolische Identifikation, Suchbewegung und Mittel der Diagnose dringlicher Probleme der Gegenwart. Das Problem der Heimat wird im Unterschied zum früheren Text theoretisch gestellt. Iljin fragt nun, ob die Vorstellung von der Heimat und damit verbundener Patriotismus in der modernen dynamischen und zusammenwachsenden Welt überholt und ein Atavismus sei. Die Verbreitung des Internationalismus korrespondiere einerseits mit den christlichen Überzeugungen: „Patriotismus und Nationalismus sind mit dem Geist des Christentums entscheidend unvereinbar. [...] Das Vaterland eines Christen auf der Erde ist das Universum; und ein Christ hat nicht das Recht, darüber hinaus oder zusammen mit diesem eine besondere irdische Heimat zu haben, sie zu lieben, zu bauen und mit Entschlossenheit und Mut dafür zu kämpfen“ (Iljin 2011, 158-159). ${ }^{6}$ Auf der anderen Seite entspreche sie der wachsenden Arbeiterbewegung und ihrer Idee der Solidarität nicht auf der nationalen, sondern auf der sozialen Basis. Diese Idee erfordert, dass der klassenbewusste Proletarier seinem Heimatland die Internationale der Arbeiter bevorzugt. Heißt das, dass die Vorstellung von der Heimat vor dem Hintergrund dieser und ähnlicher Ereignisse obsolet geworden ist? Auf diese Frage geht Iljin in seinen Reden über die Heimat ein.

Den Kern seiner Überlegungen bildet die Unterscheidung zwischen einem ,instinktiven“ und einem „geistigen“ Patriotismus. Der erste begreift Heimat als einen materiellen Gegenstand mit bestimmten Eigenschaften. Für den zweiten ist Heimat ein ideeller Ge-

6 Der Text Über Russland - Drei Reden ist im Buch unter dem Gesamttitel Путь духовного обновления (Der Weg der geistigen Erneuerung) (2011) vollständig abgedruckt. Hier und im Folgenden berufe ich mich auf diese Ausgabe. 
genstand, der außerhalb der räumlich-zeitlichen Bestimmungen steht. Während sich die Heimat im ersten Fall außerhalb des Menschen befindet und einen real existierenden Ort bedeutet, befindet sich die geistige Heimat innerhalb des Menschen und existiert nur in seinen Gedanken, Träumen und Vorstellungen.

Diese zwei Heimat-Konzepte unterscheiden sich nach Iljin in ihrer Herkunft und ihren Funktionen. Die psychologischen Wurzeln der instinktbedingten Heimat seien der Trieb zur Selbsterhaltung begleitet von der Angst vor der Kürze des individuellen Lebens und der Begrenztheit der persönlichen Kräfte und Fähigkeiten. Iljin schreibt: „Not, Gefahr und Angst lehren Menschen, sich mit ihren Mitmenschen zu solidarisieren. Aus dieser Solidarität ergeben sich die ersten Einblicke in Rechtsbewusstsein, ,Ergebenheit‘ und ,patriotische Stimmung'. Und so scheint, Patriotismus' unvermeidlich, zweckmäßig und lebenswichtig zu sein“ (ibid., 161). Iljin nennt die Vorstellung von der Heimat, hervorgerufen von instinktiver Notwendigkeit und empirischer Zweckmäßigkeit, „heteronom“. Seit Kant bedeutet ,Heteronomie` vor allem die Fremdbestimmtheit und die Abhängigkeit von fremden oder äußeren Einflüssen und tritt als Gegenbegriff zur ,Autonomie` im Sinne der Selbstbestimmung auf. Diese Denkfigur liegt dem Nachdenken Iljins über die Heimatproblematik zu Grunde. Er stellt der ,Instinkt-Heimat' die geistige Heimat, die allein das Ergebnis der freien produktiven Tätigkeit des menschlichen Geistes darstellt, entgegen. Der autonome, frei geschaffene Heimatbegriff benötigt keine Lokalisierung im Raum und Zeit, er bezeichnet keine materiellen Objekte und existiert nur als das Imaginäre.

Das Organ der geistigen Heimat sei nicht Instinkt, sondern Liebe. Es gäbe Gegenstände, die dank der Sinne wahrgenommen werden und ebenso gibt es Objekte, die laut Iljin nur durch Liebe wahrgenommen, erlebt und erworben werden können. Allerdings erweist sich Liebe bei ihm als ein komplexes Phänomen: Sie kann sich sowohl als ein blinder und geistig nicht erleuchteter Affekt als auch als eine reflektierte, geistige Tätigkeit zeigen. Die instinktive Heimat-Erfahrung kommt wie von selbst, ohne Suche und Reflexion. Die Menschen gewöhnen sich instinktiv, natürlich und unmerklich an ihre Umwelt, an die Natur, an die Nachbarn, an die Kultur ihres Landes und die Lebensweise ihres Volkes. „Aber genau deshalb, führt Iljin aus, bleibt das geistige Wesen des Patriotismus fast immer jenseits der Schwelle ihres Bewusstseins“ (2011, 161). Die naturwüchsige Heimatliebe nimmt die Form einer Neigung an, die entweder vollständig unmerkbar unter normalen gesellschaftlichen Bedingungen wird oder sich, verursacht von Konflikten und sozialen Krisen, in eine blinde und aggressive Leidenschaft verwandelt. Dann „stellt es sich heraus, dass es nicht die Liebe zur Heimat ist, die im Herzen eines Menschen lebt, sondern eine seltsame und gefährliche Mischung aus militantem Chauvinismus und dummem nationalen Eigendünkel oder einer blinden Sucht nach alltäglichen 
Kleinigkeiten und einem heuchlerischen,Großmacht'-Pathos, hinter dem sich oft individueller oder sozialer Eigennutz versteckt" (ibid., 161). Der Patriotismus in der Form des blinden Herden- oder Masseninstinkts schwankt „wie das eines echten Tieres zwischen steriler Apathie und einem räuberischen Impuls“ (ibid., 162).

Die wahre Liebe hat nach Iljin einen geistigen Charakter und ist untrennbar mit der Reflexion verbunden. Das von Spinoza prominent entwickelte Paradigma ,amor intellectualis Dei“ findet Eingang in die Heimattheorie Iljins. Er versteht, ähnlich wie Spinoza, die „Liebe zu Gott“ als die der Erkenntnis entspringenden Liebe zum Vollkommenen, die in der geistigen Schau das Wahre und das Schöne berührt. Unter dem Begriff der Liebe zum Vollkommenen steht für Iljin die wahre Liebe zur Heimat. Sie ist die Sache „der Freiheit, der inneren Freiheit der menschlichen Selbstbestimmung“(ibid., 167) und hat die Funktion, eine vollkommene Persönlichkeit zu schaffen. Dabei geht es Iljin nicht darum, den Instinkt von dem kulturellen Gefühl zu entkoppeln, vielmehr behauptet er das Zusammenwirken beider, so dass der natürliche Instinkt „aufgeklärt“ und die geistige Liebe in der Leiblichkeit des Menschen verwurzelt wird.

Was bedeutet Heimat als das geistige Phänomen? Iljin behauptet: „Die Idee der Heimat setzt die lebendige Quelle der Geistigkeit im Menschen voraus. Heimat ist etwas vom Geist und für den Geist“ (ibid., 164). Daraus folgt: „Nichts für sich genommen und isoliert vom Geist - sei es Territorium, Klima, geografische Lage, räumliche Nähe der Wohnsitze, nationale Herkunft, gewohnheitsmäßiges Alltagsleben, Wirtschaftsstruktur, Sprache oder formale Staatsangehörigkeit — nichts derartiges macht die Heimat aus, ersetzt sie und wird von der patriotischen Liebe geliebt“ (ibid., 165). Heimat ist also immer mehr als die Summe von Gegenständen und zeichnet sich geradezu dadurch aus, dass sie auf die Faktizität als solche nicht zurückzuführen ist. Iljin setzt fort: „Heimat braucht ein Territorium, aber Territorium ist keine Heimat. Heimat benötigt geografische und klimatische Umgebung, aber ähnliche klimatische und geografische Bedingungen finden sich auch in einem anderen Land usw. Keine dieser Lebensbedingungen allein kann dem Menschen seine Heimat aufzeigen: Denn Heimat ist etwas vom Geist und für den Geist" (ibid., 165). Ein weiteres Argument Iljins, dass Heimat die bloße Faktizität immer überschreitet, besagt, dass man die Vorstellung von Heimat haben kann, sogar wenn keine dieser Bedingungen vorhanden sei. Iljin ist fest davon überzeugt, dass weder die Nationalität noch die Staatsangehörigkeit für die Bildung der Heimatvorstellung relevant sind. So kann „ein Armenier ein russischer Patriot oder vielleicht ein türkischer Patriot sein, er kann aber auch ein armenischer Separatist sein, ein revolutionärer Agitator sowohl in Russland als auch in der Türkei“ (ibid., 166).

Im Unterschied zu den vulgär-soziologischen und empirisch psychologischen Bestimmungen der Heimat stellt Iljin Heimat als den menschlichen Geist dar, der in und durch 
die Faktizität erscheint und diese geschaffen, entwickelt und an ihr seinen Stempel aufgedrückt hat. Er behauptet: „Wer von der Heimat spricht, meint (bewusst oder unbewusst) die geistige Einheit seines Volkes“ (ibid., 185). Heimat bedeutet für ihn den Inbegriff für kollektive geistige Tätigkeit der Menschen und ihren Ertrag in der Welt. Das ist das kulturelle Erbe, womit Russland zu der Weltkultur beigetragen hat. Indem Iljin dies behauptet, interpretiert er Heimat als einen ästhetischen Gegenstand und stellt dabei Folgendes fest: „Ein Objekt namens Heimat ist an sich, objektiv und bedingungslos so schön, dass es für die Seele, die es gefunden und in ihm seine Heimat gefunden hat, unmöglich ist, es nicht zu lieben“ (ibid., 169). Diese Aussage darf jedoch nicht in dem Sinne interpretiert werden, dass die Heimat als ein schöner Gegenstand eine kausale Wirkung auf den Menschen hat und in ihm das Gefühl der Liebe notwendigerweise hervorruft. Iljins ästhetischer Gegenstand ist dem ästhetischen Gegenstand Kants ähnlich. Das Schöne existiert bei Kant nur für die Lebewesen, die dank der besonderen Struktur ihrer Erkenntnisvermögen dafür prinzipiell empfänglich sind. Analog dazu gilt: „Heimat ist eine geistige Realität. Um sie aber zu finden und zu erkennen, muss der Mensch seine eigene persönliche Geistigkeit besitzen“ (ibid., 169). Demnach ist nicht jeder Mensch fähig, eine geistige Heimat zu haben.

Entgegen der verbreiteten Meinung, dass ,Heimat' ein Aspekt der gesamten Beziehung eines Menschen zu seiner physisch-geographischen und soziokulturellen Umwelt sei, von dieser bewirkt beziehungsweise affiziert, kann man an dieser Stelle festhalten, dass ,Heimat' dies nur dann leisten kann, wenn sie bereits ein Teil seiner personalen Identität ausmacht. In den Worten Iljins ausgedrückt: „Heimat ist etwas aus dem Geist Hervorgehendes und für den Geist Existierendes“ (ibid., 164). Daher kann „die Frage nach der Heimat in der Ordnung der Selbsterkenntnis und der freien Wahl entschieden werden“ (ibid., 167).

Diese hier vorgelegte Sicht verbietet es, Heimat als eine anthropologische Konstante zu betrachten. Nur der- oder diejenige hat eine Heimat, der oder die sie sich selbst einbringt und sie sich aktiv aneignet. Daraus, dass die geistige Erfahrung des Menschen komplex und vielfältig strukturiert ist, resultiert die Vielfältigkeit der Heimatvorstellungen: „Einer wird von der Natur oder Kunst seines Heimatlandes angesprochen; ein anderer von dem religiösen Glaube seines Volkes; zum dritten spricht das Reich der nationalen Sittlichkeit; zum vierten - die Größe des Staatsschicksals seines Volkes; zum fünften die Energie seines edlen Willens; zum sechsten - die Freiheit und Tiefe seines Denkens usw." (ibid., 169). Heimat ist und bleibt also eine wesentlich private Vorstellung und ein wesentlich privates Motiv der Handlungen. Wenn man dann gelegentlich über eine gemeinsame Heimat spricht, ist es nur in einem übertragenen Sinn zu verstehen: Gemeint 
wird hier das Heimatland als Herkunft- oder Wohnort. Die wahre Erfahrung der Heimat ist immer individuell und hat einen persönlichen Charakter.

Dies erklärt, warum „das Finden der Heimat von jedem Menschen selbständig und nach seiner eigenen Weise erlebt werden soll. Niemand kann einem anderen Menschen seine Heimat vorschreiben - weder Erzieher und Freunde, noch öffentliche Meinung oder Staatgewalt, weil lieben, sich freuen und schaffen nach der Vorschreibung absolut unmöglich ist“ (ibid., 178). Hiermit bestreitet Iljin nicht, dass das Konzept „Heimat“ ein wesentliches Element sozialer Beziehungen darstellt. Es ist faktisch nachgewiesen, dass durch den gemeinsamen Rekurs auf Heimat und den Patriotismus Gruppenbindungen, Solidarisierungseffekte und Loyalitäten entstehen. Er akzeptiert aber nur denjenigen Patriotismus, der auf „dem Akt der geistigen Selbstbestimmung“ (ibid., 174) basiert.

Zwei Thesen bilden den theoretischen Rahmen dieser Überlegungen Iljins über die Heimat in dem analysierten Text. Es ist erstens die Überzeugung, dass das Wort ,Heimat' nur dann eine sinnvolle Verwendung haben kann, wenn man unter Heimat eine geistige Realität, ein Ideal versteht. Wie Iljin das selbst ausdrückt: „Es ist das geistige Leben, was und wofür man sein Volk lieben, für es kämpfen und für es sterben kann und muss“ (ibid., 176). Zweitens ist es die Überzeugung, dass der Mensch seine geistige Heimat autonom und eigenständig finden muss. Iljin betont mehrfach im Text, dass Heimat in persönlicher geistiger Erfahrung verwurzelt ist und ihren Ort hat. Heimat ist also kein Massenphänomen. Es ist nahliegend, die auf diese Weise interpretierte Heimat als einen lebendigen, tätigen und wirksamen Mythos zu verstehen. Spricht man über den Mythos ,Heimat', so ergeben sich, gerade auch in Bezug auf gesellschaftliche Problemlagen, neue Problemlösungen, Deutungsmöglichkeiten und Zugangsweisen.

\section{Heimatbegriff im Werk Der Weg der geistigen Erneuerung}

Das in Belgrad 1937 erschienene Buch Der Weg der geistigen Erneuerung besteht aus den Essays, die früher unter verschiedenen Umständen und aus verschiedenen Anlässen publiziert wurden. Auch die drei Reden Über Russland wurden von Iljin komplett übernommen und in das neue Buch integriert. Trotz dieser Genese stellt dieses Buch keinen willkürlich zusammengesetzten Sammelband dar, sondern hat den Charakter eines systematisch aufgebauten Werkes.

Iljin beschreibt die zeitgenössische gesellschaftliche Situation als eine „tiefe Krise“ religiöse, geistige und nationale - und stellt sich die Aufgabe, einen Ausweg aus dieser Krise zu finden. Sein Vorschlag ist ein idealistischer, weil er davon überzeugt ist, dass die Lösung der gesellschaftlichen Probleme mit der geistigen Vervollkommnung der Person beginnen soll: „Jeder von uns muss zuerst diesen Ausweg in sich selbst finden, ihn krea- 
tiv gestalten und sich vergewissern, dass er richtig ist“ (Iljin 2011, 19). Erst dann sei es möglich, den Weg aus der Krise den anderen zu zeigen und „den Kampf um die Heimat zu beginnen“ (ibid., 18). Daher geht er in seinem Werk auf „die ersten, fundamentalsten Fragen, Fragen des Seins“ (ibid., 18) ein.

Das Buch ist in zehn große Abschnitte gegliedert: Der Glaube, Die Liebe, Die Freiheit, Das Gewissen, Die Familie, Die Heimat, Der Nationalismus, Das Rechtsbewusstsein, Der Staat und Das Privateigentum. Sie setzen sich aus fortlaufend nummerierten, meist kurzen Paragraphen zusammen. Bei der Lektüre entsteht unmittelbar der Eindruck, dass es sich um eine Anspielung auf Hegels Die Grundlinien der Philosophie des Rechts, insbesondere auf die Kapitel Die Moralität und Die Sittlichkeit, handelt. Die Abschnitte Der Glaube, Die Liebe, Die Freiheit und Das Gewissen fallen unter den Begriff, Moralität; die restlichen Abschnitte - unter den Begriff, Sittlichkeit, dem bei Hegel die Begriffe ,Familie', ,bürgerliche Gesellschaft' und ,Staat' untergeordnet sind. Wie die Philosophie des deutschen Idealismus insgesamt und Hegel im Besonderen versucht auch Iljin, das gesellschaftliche Leben in seiner Differenz und sogar Zerrissenheit als Identität zu denken. Er möchte zeigen, wie sich die Formen menschlichen Zusammenlebens - Familie, bürgerliche Gesellschaft, Staat - in einem aufsteigenden Prozess Stufe für Stufe zu einer natürlichen, organisch gewachsenen, lebendigen Einheit werden können, die es dem Einzelnen ermöglicht, vollkommen darin aufzugehen. Im Unterschied zu Hegel - und darin ist der Einfluss der russischen religiösen Philosophie spürbar - ist das Bindeglied in diesem System und sein Träger das Individuum, das sich zu einem moralischen Subjekt entwickeln und zugleich als Rechtsperson vom Staat anerkannt werden soll.

Die Abschnitte Der Glaube, Die Liebe, Die Freiheit und Das Gewissen bezeichnen die Richtungen, in denen die geistige Vervollkommnung des Individuums und seine Selbsterziehung zur moralischen Person gehen sollen. Eine fundamentale Schicht der menschlichen Existenz bildet der Glaube: Der Glaube „bleibt immer die Hauptkraft des menschlichen Lebens - ganz unabhängig davon, ob die Menschen das verstehen oder nicht" (ibid., 23). Tatsächlich bedeutet ,zu leben` 'zu wählen` und ,zu streben', und es ist entscheidend dabei, welche Werte man wählt, welche Ziele man anstrebt und welcher Glaube die Richtlinien für Handlungen gibt. In der geistigen Liebe sieht Iljin das Mittel, das ideelle Werte zu entdecken vermag: „Man könnte sagen, dass die geistige Liebe nichts anderes als ein Geschmack für Perfektion ist, oder sie ist ein treues geistiges Organ, um göttliche Perfektion sowohl im Himmel als auch auf der Erde wahrzunehmen“ (ibid., 56). Die geistige Liebe „hat die Neigung zur Qualität, Würde und Vollkommenheit“ (ibid., 55) und weil „objektiv Vollkommene das Göttliche [ist]“ (ibid., 56) ist es möglich, dass die geistige Liebe die Einsicht in die tiefste Schicht des Seins eindringen lässt und die höchsten Werte zu erkennen vermag. Den Weg zu den höchsten Wahrheiten soll der Mensch 
selbständig, frei und völlig autonom gehen. Als das Kriterium der Richtigkeit der Wahl wählt Iljin das Gewissen, das er als „,den Zustand der sittlichen Evidenz“ (ibid., 117) charakterisiert.

Die Begriffe ,Glaube', ,Liebe', ,Freiheit' und ,Gewissen` paraphrasieren die Entwicklung des ,subjektiven' Geistes, wo unter dem ,Geist' nun der menschliche Geist verstanden wird, und umschreiben die Dimension der Moralität. Die Begriffe ,Familie', ,Heimat', ,Nationalismus', , Rechtsbewusstsein' und ,Staat' markieren die Stationen des Werdens des ,objektiven', kollektiven Geistes. An der grundsätzlichen Vorordnung der Familie hat sich auch bei Iljin im Vergleich zu Hegel nichts geändert: Die Familie ist die Sphäre, die der Gesellschaft und dem Staat voraus- und zugrunde liegt. Wie für Hegel stellt auch für Iljin die Familie eine der Sphären der Sittlichkeit und zugleich die Quelle des bürgerlichen Bewusstseins dar. In der Familie ist der Einzelne nicht mehr eine Person für sich, sondern geht in der Gemeinschaft auf. Die Mitglieder einer Familie sind durch Liebe, Zutrauen, Gehorsam und Verantwortung fest miteinander verbunden:

Die Familie ist das erste, Wir für das Kind, das aus Liebe und freiwilligem Dienst entstanden ist, wo einer für alle und alle für einen stehen. Sie ist für ihn die Schule der natürlichen Solidarität, wo gegenseitige Liebe Pflicht in Freude verwandelt und die heiligen Tore des Gewissens immer offen hält. Sie ist für ihn eine Schule des gegenseitigen Vertrauens und des gemeinsamen, organisierten Handelns. (Iljin 2019, 139)

Mit dieser Kontinuität ist allerdings das Wesentliche von Iljins Familienmodell nicht erfasst. Die Familie ist - und das ist das Neue im Vergleich zu Hegels Verständnis der Familie - die erste Heimat für das Kind und „das Fundament der Heimat“ überhaupt (ibid., 156). In der Familie findet Heimat ihren natürlichen, unmittelbaren Ausdruck.

Die wichtigste Bedeutung der Herkunftsheimat besteht laut Iljin darin, dass durch die Zugehörigkeit zu ihr Menschen zu Bürgern erzogen werden. Mit anderen Worten ist die Funktion der Herkunftsheimat, Menschen aus dem Familienverband in die bürgerliche Gesellschaft und den Staat zu entlassen. Das Bemerkenswerte liegt nun darin, dass Iljin den Bürger gegen das formalrechtliche liberalistische Modell durch die Fähigkeit, sich mit dem kollektiven Geist zu identifizieren, charakterisiert. Man kann dies in dem Sinne interpretieren, dass der Bürger durch seine Zugehörigkeit zu der organischen Gemeinschaft und nicht zu der formal konzipierten Gesellschaft vornehmlich definiert wird. Das Wesen des so verstandenen ,Bürgers' ist im Nationalismus zu sehen.

Iljins Begriffe ,Nationalismus' und ,Patriotismus' haben allerdings eine eigentümliche Semantik. Ein Nationalist zu sein bedeutet, das „patriotische Selbstbewusstsein“ zu haben (Iljin 2011, 188) und das heißt, „Zwischen sich selbst und seinem Volk Ähnlichkeit, 
Verkehr, Interaktion und Gemeinschaft im Geist herzustellen“ (ibid., 188). Die Identität des geistigen Lebens des Individuums mit dem geistigen Leben seiner Mitmenschen bildet den Kern des Nationalismus, und in der Liebe zu ihrer Kultur besteht der Patriotismus. Derartige Überzeugungen bilden das Wesen des Begriffs, Bürger`. Man kann schlussfolgern, dass der Bürger sich durch kulturelle Identifikation mit seiner geistigen, selbst gewählten Heimat auszeichnet.

Iljin bringt die Begriffe ,Heimat', ,Nation' und ,Patriotismus' in folgender Formel zusammen: „Heimat ist der Geist des Volkes in all seinen Erscheinungsformen und Schöpfungen; Nationalität bezeichnet die wesentliche Eigenart dieses Geistes. Nation ist ein geistig einzigartiges Volk; Patriotismus ist Liebe zu ihm, zu seinem Geist, zu seinen Schöpfungen und zu den irdischen Bedingungen seines Lebens und seiner Blüte" (ibid., 201). Er betont mehrfach, dass die Heimat zu lieben heißt, den Geist ihres nationalen Charakters und gleichzeitig den nationalen Charakter ihres Geistes zu lieben. Dies bedeutet, dass der „wahre Nationalismus“ nicht der auf dem „Instinkt der nationalen Selbsterhaltung“ basierende, sondern der "geistige Nationalismus“ ist (ibid., 203). Dieser Nationalismus zeichnet sich durch seinen offenen, inklusiven, zu den anderen Kulturen affirmativen Charakter aus und bildet eine notwendige Bedingung für den Übergang zu dem Allgemeinmenschlichen, zu dem „supra-nationalen Bewusstsein“. Iljin entwirft eine Dialektik des Nationalen und Supranationalen, in der das Nationale von dem Supranationalen aufgehoben und zugleich in ihm als dessen Teilstück aufbewahrt wird. Als Repräsentant einer Kultur ist man zugleich Repräsentant eines „supranationalen Universums“ (ibid., 205). Auch den Staat definiert Iljin als positiv-rechtliche Erscheinungsform der Heimat: „Recht und Staat entstehen aus der inneren, geistigen Welt der Menschen, werden nur für den Geist und wegen des Geistes geschaffen und realisieren sich mittels des Rechtbewusstseins" (ibid., 228). ${ }^{7}$

Bereits aus dieser knappen Analyse ist ersichtlich, dass das Konzept ,Heimat' einen integralen Bestandteil der politischen Philosophie Iljins darstellt. Es verbindet Individuum, Familie, Gesellschaft, Staat und Welt mittels einer Dialektik, die ihren Ursprung in der inneren, geistigen Erfahrung des Menschen hat und sich nur vollziehen kann, wenn das geistige Individuum bei allen Transformationen und Übergängen erhalten bleibt. Das aus der Familie herkommende Heimatgefühl erfüllt das Individuum und lehrt es, die geistige Erfahrung seiner Mitmenschen zu schätzen, zu respektieren und anzuerkennen. Auf diesem Weg verwandelt sich das Individuum in den ,Bürger'; das ist die Basis für soziale Interaktionen sowohl auf der nationalen als auch auf der internationalen Ebene. Heimat, verstanden als geistige Heimat eines Individuums, fungiert in diesem Schema als Garant

\footnotetext{
7 Ich muss auf die Analyse von Iljins Begriff, Staat` verzichten, weil dies den Rahmen dieses Aufsatzes sprengen würde.
} 
der Geistigkeit und Moralität des Menschen, der auch politisch agiert. Dies klingt volens nolens als ein idealistisches Plädoyer für die Etablierung des Mythos ,Heimat` und die Verwendung dieses Konzepts, um Moral und Politik miteinander zu verbinden.

\section{Abschließende Bemerkung}

Die idealistische Rettung des Mythos ,Heimat' als Form des politischen Bewusstseins führt zu beinah unvermeidlichen Missdeutungen aller von Iljin verwendeten Begriffe. Das brachte ihm im 21. Jahrhundert den Vorwurf ein, er sei der Lieblingsphilosoph Putins. „Wer Russlands neuen Nationalismus verstehen will, schreibt Julia Smirnova, muss den 1954 gestorbenen konservativen Philosophen Iwan Iljin lesen“ (2014). Putin und seine Umgebung greifen tatsächlich öfters auf Iljins Werke zurück und stellen ihn als Gewährsmann für eine autoritäre und nationalistische Gesellschaftsordnung, die auf konservativen religiösen Werten beruht, vor. Doch wenn man sich die Mühe macht und Iljins umfangreiches, komplexes, kontroverses, streckenweise nur schwer verständliches Werk genau liest, erkennt man durchaus die idealistische, ja personalistische, Grundtendenz in seiner Theorie. Bei allen staatsverherrlichenden und russophilen Motiven, die sicher vorhanden sind, stellt sein Werk eine utopische Synthese von Konservatismus und Liberalismus dar, die den heutzutage propagierten ideologischen Stereotypen fremd und als Projektionsfläche der sich im heutigen Russland abspielenden politischen Prozesse nicht geeignet ist.

\section{Literatur}

Budde, Dirk. 2013. „Iwan Iljin - Vom Wesen der Rechtgläubigkeit.“ In Gegen die Krise der Zeit. Konservative Denker im Portrait, herausgegeben von Daniel Führing, 65-80. Graz: Ares-Verlag. Dahm, Helmut. 1976. Grundzüge russischen Denkens. Persönlichkeiten und Zeugnisse des 19. und 20. Jahrbunderts. München: Berchmans.

Iljin, Iwan. 1926. Rodina $i$ my (Die Heimat und wir). Бемград: ГАавное Правление Об-ва Гацмипомийцев.

Iljin, Iwan. 2001. „Der Bolschewismus und die Krise des modernen Rechtsbewußtseins (1925/1926)“” Archiv für Rechts- und Sozialphilosophie / Archives for Philosophy of Law and Social Philosophy 87 (1): 61-71.

Iljin, Iwan. 2011. „Put' duhovnogo obnovlenija“ (Der Weg der geistigen Erneuerung) (1937).“ In Iwan Iljin, Put' duhovnogo obnovlenija, 156-188 Moskva: Institut russkoj civilizacii. Ingold, Felix. 2007. „Machtvertikale.“ FAZ, 27.03.2007.

Lisitsa, Yu. T. 2020. Ivan Ilyin: Singendes Herz. Leben und Karriere und. Liveps. https://liveps. $\mathrm{ru} / \mathrm{de} /$ ivan-ilin-poyushchee-serdce-zhiznennyi-i-tvorcheskii-put-i-a-ilina/ 
Offermanns, Wolfgang. 2018. Mensch, werde wesentlich! Das Lebenswerk des russischen religiösen Denkers Iwan Iljin für die Erneuerung der geistigen Grundlagen der Menschheit. Wachtendonk: Edition Hagia Sophia.

Schlögel, Karl. 1998. Berlin Ostbahnhof Europas: Russen und Deutsche in ibrem Jahrhundert. Berlin: Siedler Verlag.

Schlögel Karl, Kucher, Katharina, Suchy, Bernhard und Gregor Thum 1999. Chronik russischen Lebens in Deutschland 1918-1941. Berlin: Akademie Verlag.

Smirnova, Julia. 2014. „Putin übernimmt Ängste seines Lieblingsphilosophen.“ Welt, 17.12.2014. https://www.welt.de/kultur/article135404575/Putin-uebernimmt-Aengste-seines-Lieblings philosophen.html

Tsygankov, Daniel . 2001. „Beruf, Verbannung, Schicksal: Iwan Iljin und Deutschland“. Archiv für Rechts-und Sozialphilosophie 87 (1): 44-60. 


\title{
Heideggers unheimliche Heimat Bemerkungen zum Zusammengehören von Denken und Sein
}

\author{
Martin G. WEISS \\ Universität Klagenfurt (Austria)
}

\begin{abstract}
Martin Heidegger has been labeled the philosopher of i.e. between "Humanity" and "Being", is not based in "home" (Heimat) and "homelessness" (Heimatlosigkeit). their difference but their identity. Humans, understood But he is also the philosopher of "the uncanny" (das Unas "being-there" (Da-sein), have to cope with the fact beimliche). The present paper first explores the uncanniness provoked by anxiety as Heidegger describes it in Being and Time. It then shows how this uncanniness is based on the relationship between thinking and being, as already described by Parmenides and exemplified by Heidegger in his interpretation of the first chorus in Sothat they have to disclose in their actions - be it thinking, writing poetry or fabricating - the essence of Being, which consists in being the autonomous appearing of beings. Thus, humanity has to accept the uncanniness of not being the independent subject dominating Earth, but a part of evolving nature itself.
\end{abstract} phocles' tragedy Antigone. Heidegger shows that the uncanny in the relationship between thinking and being,

Keywords: Heidegger, Home, the uncanny

(c) Martin G. Weiß; martin.weiss@aau.at

Colloquium: New Philologies, Volume 6, Issue 1 (2021)

doi: 10.23963/cnp.2021.6.1.8

Stable URL: https://colloquium.aau.at/index.php/Colloquium/article/view/152

This work is licensed under a Creative Commons Attribution 4.0 International License (CC BY 4.0). 


\section{Einleitung}

Der Heimatphilosoph aus dem badischen Geniewinkel, lautet die Überschrift einer Rezension des Bandes Martin Heidegger und seine Heimat ${ }^{1}$, der Texte Heideggers zum Thema versammelt (Degenkolbe 2005); ein Aufsatz von Walter Strolz trägt den Titel $\mathrm{Na}$ tur - Sprache - Heimat in Heideggers Denken (Strolz 1986); Axel Beelman hat ein Buch über den jungen Theologiestudenten Heidegger Heimat als Daseinsmetapher (Beelmann 1994) betitelt; Theodor W. Adorno spricht von Heideggers „Heimatkunst“ (Adorno 1964) und von Rainer Marten stammt ein Aufsatz mit dem Titel Heideggers Heimat (Marten 1980), der neben einer Heideggerkritik Grundlinien eines eigenständigen philosophischen Heimatbegriffs entwickelt.

Tatsächlich gibt es, trotz Novalis' Definition des Philosophierens als Heimweh (auf die Heidegger in Die Grundbegriffe der Metaphysik [Heidegger 2004] eigens eingeht), neben Heidegger wohl kaum einen zweiten Philosophen, mit dem der Begriff „Heimat“ so unmittelbar assoziiert wird. Dabei ist Heideggers Bedenken der Heimat höchst umstritten. Helmuth Vetter stellt fest:

Zu den Gründen, Heidegger von vorherein abzulehnen, zählt der Vorwurf seiner angeblichen rückwärtsgewandten Tendenz zur Heimat, zur Bodenständigkeit u. dgl. Er nennt die Heimat den „Ort der Nähe“, spricht vom „Eigentümlichen(n) der Heimat“, von ihr „als (der) Macht der Erde“, aber auch vom „Verfall der Heimat“, bei dem die Erde nur noch die „Stätte bloBer Nutzung und Ausbeutung“ ist, und damit von der „Verwüstung, die über der Heimaterde und ihren ratlosen Menschen lagert". Doch auch vom "Ausblick auf eine neue Bodenständigkeit“ ist die Rede und von der „Bodenlosigkeit des heutigen Bezuges bzw. Unbezuges zur Natur“. (Vetter 2014, 184)

Vetter zufolge lassen sich in den Texten Heideggers zwei Heimatbegriffe unterscheiden: ein eher persönlich „existentieller" und ein „ontologischer" bzw. „seinsgeschichtlicher" (Vetter 2014, 184). Ausdruck des ersteren sind Texte wie Der Feldweg (Heidegger 2002a), Vom Geheimnis des Glockenturms (Heidegger 2002d) und Schöpferische Landschaft. Warum bleiben wir in der Provinz? (Heidegger 2002b).

$\mathrm{Zu}$ letzterem bemerkt Adorno:

Im Reich des Hitler hat Heidegger, was man ihm nachfühlen kann, einen Ruf nach Berlin abgelehnt. Er rechtfertigte das in einem Aufsatz „Warum

1 Büchin \& Denker 2005. 
bleiben wir in der Provinz?“. Mit erfahrener Strategie entkräftet er den Vorwurf des Provinzialismus dadurch, daßer ihn positiv wendet. Das sieht dann so aus: „Wenn in tiefer Winternacht ein wilder Schneesturm mit seinen StöBen um die Hütte rast und alles verhängt und verhüllt, dann ist die hohe Zeit der Philosophie. Ihr Fragen muß dann einfach und wesentlich werden.“ (Adorno 1964, 41)

Zur zweiten Kategorie gehören unter anderem die Auseinandersetzung mit der ,unheimlichen“ Stimmung der Angst in Sein und Zeit (Heidegger 1967) und Heideggers Ausführungen zum „Unheimlichen“ im Rahmen seiner Beschäftigung mit dem ersten Chorlied der Antigone des Sophokles.

Gewissermaßen zwischen diesen zwei Arten der Heideggerschen Heimatliteratur stehen Texte wie der Vortrag Sprache und Heimat (Heidegger 2002c), in dem Heidegger auf einer in Norddeutschland abgehaltenen Tagung der Friedrich Hebbel-Gesellschaft über ein in alemannischem Dialekt verfasstes Gedicht von Johann Peter Hebel spricht, um dessen Unübersetzbarkeit ins Hochdeutsche zu betonen und mit den Sätzen zu schlieBen:

Die Sprache ist kraft ihres dichtenden Wesens, als verborgenste und darum am weitesten auslangende, das inständige schenkende Hervorbringen der Heimat. Damit gewinnt der Titel „Sprache und Heimat“ die ihm gehörige Bestimmtheit. So kann es lauten, wie es lauten muß; nicht obenhin: Sprache und Heimat, sondern Sprache als Heimat. (Heidegger 2002c, 180)

Im Folgenden möchte ich mich auf Heideggers ontologischen Heimatbegriff konzentrieren, den ich ausgehend von Heideggers spätem Text Briefüber den Humanismus (Heidegger 1976a) einführen möchte, um dann nach einer Betrachtung der Stimmung der Angst in Sein und Zeit auf Heideggers Deutung des ersten Chorliedes der Sophokleischen Antigone in seiner Vorlesung Einführung in die Metaphysik (Heidegger 1987) aus dem Jahr 1935 einzugehen, in der Heidegger das Erscheinen des Seienden als „unheimliche" - weil gleichzeitig entbergende und verbergende - Wechselwirkung von Denken und Sein, Mensch und physis, begreift.

\section{Die Heimatlosigkeit des modernen Menschen}

In seinem 1946 veröffentlichten Brief über den Humanismus bezeichnet Heidegger die Heimatlosigkeit des modernen Menschen als ein Weltschicksal und beruft sich für diese Deutung, für viele damalige Leser*innen überraschenderweise, auf Marx: 
Die Heimatlosigkeit wird ein Weltschicksal. Darum ist es nötig, dieses Geschick seinsgeschichtlich zu denken. Was Marx in einem wesentlichen und bedeutenden Sinne von Hegel her als die Entfremdung des Menschen erkannt hat, reicht mit seinen Wurzeln in die Heimatlosigkeit des neuzeitlichen Menschen zurück. [...] Weil Marx, indem er die Entfremdung erfährt, in eine wesentliche Dimension der Geschichte hineinreicht, deshalb ist die marxistische Anschauung von der Geschichte der übrigen Historie überlegen. [...] Das neuzeitlich-metaphysische Wesen der Arbeit ist in Hegels „Phänomenologie des Geistes“ vorgedacht als der sich selbst einrichtende Vorgang der unbedingten Herstellung, das ist Vergegenständlichung des Wirklichen durch den als Subjektivität erfahrenen Menschen. Das Wesen des Materialismus verbirgt sich im Wesen der Technik [...]. Die Technik ist in ihrem Wesen ein seinsgeschichtliches Geschick der in der Vergessenheit ruhenden Wahrheit des Seins. Sie geht nämlich nicht nur im Namen auf die techne der Griechen zurück als einer Weise des aletheuein, das heißt des Offenbarmachens des Seienden. (Heidegger 1976a, 339)

Der Historische Materialismus ist Heidegger zufolge anderen Geschichtskonzeptionen also insofern überlegen, als er einerseits erkannt hat, dass es die Willkür des Subjekts zwar übersteigende, das Weltbild des Menschen aber entscheidend beeinflussende geschichtliche Faktoren gibt und andererseits, weil er vor Augen führt, dass in der Moderne das Seiende, einschließlich des Menschen, zum verfügbaren Bestand einer alleinherrschenden instrumentellen Vernunft geworden ist.

Die daraus resultierende Heimatlosigkeit des modernen Menschen besteht Heidegger zufolge näher hin in einer Reduktion des Seienden auf eine verfügbare Ressource und in der Aufspreizung des Menschen zum verfügenden Subjekt, d.h. zum, „Herrn des Seienden“" (Heidegger 1976a, 342). Ausdruck dieses Subjektivismus, der die Kehrseite der Vergegenständlichung des Seienden darstellt, ist dem Humanismusbrief zufolge auch jede Art von Nationalismus. Heidegger schreibt: „Jeder Nationalismus ist metaphysisch ein Anthropologismus und als solcher Subjektivismus." (ibid., 341) Ähnlich wie bei Adorno schlägt auch bei Heidegger der Subjektivismus in neue Formen der Unfreiheit um, insofern zuletzt auch der Mensch selbst zum jederzeit ersetzbaren „Bestand-stück“ des Produktionsprozesses bzw. zum bloßem Menschmaterial totalitärer Systeme wird.

In Heideggers Geschichtsphilosophie bildet die als Alleinherrschaft der instrumentellen Vernunft verstehbare Heimatlosigkeit des Subjekts das kennzeichnende Merkmal der letzten Epoche der Seinsgeschichte. Für Heidegger gibt sich das Seiende epochal je anders. In der vorsokratischen Antike erscheint das Seiende als das sich von sich selbst her zeigende Natürliche, im christlichen Mittelalter wird das Seiende als Schöpfung Got- 
tes, in der Neuzeit als Gegenstand und im Zeitalter der Technik als verfügbare Ressource verstanden. Dabei bedingt das Seinsverständnis, das eine Epoche jeweils paradigmatisch bestimmt als was das Seiende jeweils erscheint:

[D]as Anwesende [Seiende] kann den Menschen nach verschiedenen Weisen der Anwesenheit angehen. Diese verschiedenen Weisen bestimmen die Epochen der abendländischen Seynsgeschichte. Das Anwesende kann wesen als das von sich aus Hervorkommende, her aus der Verborgenheit, vor in die Unverborgenheit. Dies also Anwesende nennen wir in seinem Anwesen den Herstand [in der Antike]. Das Anwesende kann sich kundgeben als das Geschaffene des Schöpfers, der selbst der ständig und überall Anwesende ist in allem [im Mittelalter]. Das Anwesende kann sich darbieten als das, was im menschlichen Vorstellen für es her und ihm entgegen gestellt wird. [...] Der Gegenstand ist das Objekt für das Subjekt [in der Neuzeit]. Das Anwesende kann aber auch sein als das Beständige im Sinne der Bestandstücke des Bestandes, der als das ständig Bestellbare in demjenigen Stellen gestellt ist, als welches das Ge-Stell [das Wesen der Technik] waltet. [...] Das Beständige besteht in der bestellbaren Ersetzlichkeit durch das bestellte Gleiche [im Zeitalter der Technik]. (Heidegger 2005, 39-40)

In Heideggers Angstanalysen in Sein und Zeit wird zunächst offensichtlich, dass der moderne Mensch von seiner Heimatlosigkeit zumeist nichts weiß. Denn vor der Erfahrung der wesentlichen Unheimlichkeit der Existenz ist der Mensch zumeist immer schon in das „Zuhause der Öffentlichkeit“"geflohen, wie Heidegger formuliert. Der moderne Mensch hat es sich in der Heimatlosigkeit der technisch und medial vermittelten Welt gemütlich gemacht und verliert sich zumeist im zunächst Heimischen des alltäglichen Getriebes dessen, was man tut und tun zu müssen glaubt. In seltenen Augenblicken aber reißt ihn die Stimmung der Angst aus der Verfallenheit an seine gewohnte „Welt“ (Heidegger 1967, 190).

Die Angst wendet den Menschen vom Seienden ab und offenbart ihm „[...] das Nichts, d.h. die Welt als solche [...]“, d.h. die,Welt als Möglichkeitsraum (Heidegger 1967, 190). Deswegen beschreibt Heidegger das Ergebnis der Angst als eine Befreiung aus der Verfallenheit, bzw. als eine Befreiung aus der Uneigentlichkeit, denn insofern im Unbedeutsamwerden des Innerweltlichen im Geschehen der Angst sich die bisherige alltägliche Wirklichkeit als nicht notwendig erweist, eröffnet ihm der Blick auf die Kontingenz des Bestehenden die Perspektive auf Mögliches. Das ,Man' ist an seine, Welt', verstanden als innerweltliches Getriebe, insofern verfallen, als es diese seine, Welt' als die einzig mögliche, d.h. als notwendig ansieht. Das ,Man' ist in seiner, Welt' gefangen, insofern es keine 
mögliche Alternative sieht, ja nicht einmal von der Möglichkeit einer alternativen, Welt ${ }^{\star}$ weiß. Das ,Man' hat keine Möglichkeiten, es weiß nicht, dass es „eigentlich“ immer schon in Möglichkeiten steht und zu wählen hat. In diesem Nichtwissen um seinen eigenen Möglichkeitscharakter besteht die Uneigentlichkeit des ,Man’. In der alltäglichen Verfallenheit an die als Notwendigkeit verstandene, Welt' des ,Man' ist das Dasein fremdbestimmt und seiner selbst entfremdet. Die emanzipatorische Funktion der Angst besteht nun darin, die radikale Fragwürdigkeit und Nicht-Notwendigkeit des Bestehenden aufzuzeigen. In ihrer destabilisierenden Wirkung, die alles scheinbar Heimische plötzlich „unheimlich“" (Heidegger 1967, 188) werden lässt, offenbart sie dem Menschen als Dasein den Möglichkeitscharakter der Welt und damit letztendlich seine eigene Freiheit:

In der Angst versinkt das umweltlich Zuhandene, überhaupt das innerweltlich Seiende. [...] Die Angst benimmt so dem Dasein die Möglichkeit, verfallend sich aus [...] der öffentlichen Ausgelegtheit zu verstehen. [...] Die Angst vereinzelt das Dasein auf sein eigenstes In-der-Welt-sein, das als verstehendes wesenhaft auf Möglichkeiten sich entwirft. (Heidegger 1967, 187188)

Die Angst „stößt“ jede bisherige Gewissheit um und eröffnet dem Dasein so die Welt als Möglichkeitshorizont seiner selbst: „Die Angst [...] holt das Dasein aus seinem verfallenden Aufgehen in der ,Welt' zurück. Die alltägliche Vertrautheit bricht in sich zusammen.“ (Heidegger 1967, 189) In der „unheimlichen“ Erschütterung der Alltäglichkeit wie sie sich in der Angst ereignet, zerbricht jegliche Heimat und zeigt dem Dasein seine bisher scheinbar notwendige Wirklichkeit als bloße Möglichkeit, womit die Eröffnung unzähliger anderer möglicher Welten einhergeht, wobei Heidegger unter diesen sich nun auftuenden Möglichkeiten primär die vom Einzelnen, vom Dasein selbst zu entwerfenden, Möglichkeiten intendiert, insofern er betont, dass in der eigentlichen Angst nicht nur die Welt in Frage steht, sondern vor allem das Dasein selbst als In-der-Welt-sein. Das Dasein begreift sich so als radikales Möglichsein, als Entwurf:

Mit dem Worum des Sichängsten erschließt daher die Angst das Dasein als Möglichsein und zwar als das, das es einzig von ihm selbst her als vereinzeltes in der Vereinzelung sein kann. Die Angst offenbart im Dasein das Sein zum eigensten Seinkönnen, das heißt das Freisein für die Freiheit des Sich-selbstwählens und -ergreifens. Die Angst bringt das Dasein vor sein Freisein für [...] die Eigentlichkeit seines Seins als Möglichkeit, die es immer schon ist. (Heidegger 1967, 187-188)

Allein in der Angst liegt die Möglichkeit eines ausgezeichneten Erschließens, weil sie vereinzelt. Diese Vereinzelung holt das Dasein aus dem Ver- 
fallen zurück und macht ihm Eigentlichkeit und Uneigentlichkeit als Mög-

lichkeit seines Seins offenbar. (Heidegger 1967, 191)

\section{Die Unheimlichkeit des Menschen}

Die Stimmung der Angst, die nicht dem subjektiven Willen des Menschen entspringt, sondern letztlich dem Sein, verstanden als das Geschehen der sich selbst entbergenden physis, verweist so aber zugleich auf das, subjektive' Existential des entwerfenden Verstehens zurück. Dieses den Menschen auszeichnende „Spannungsverhältnis zwischen Verstehen und Befindlichkeit", wie es Helmuth Vetter nennt und in dem es letztlich um das Verhältnis von Sein und Mensch geht, bildet Heidegger zufolge allerdings auch den eigentlichen Inhalt des ersten Chorgesanges der Antigone des Sophokles. Das Chorlied beginnt mit den in Hölderlins Übersetzung berühmt gewordenen Versen: „Ungeheuer ist viel (polla ta deina). Doch nichts / Ungeheuerer (deinoteron) als der Mensch." (Hölderlin $1998,331)^{2}$

Heidegger, der das Chorlied sowohl in seiner Vorlesung Einführung in die Metaphysik als auch in seiner Vorlesung Hölderlins Hymne „Der Ister" (Heidegger 1984) aus dem Jahr 1942 einer ausführlichen Deutung unterzieht, übersetzt: „Vielfältig das Unheimliche (polla ta deina), nicht doch / Über den Menschen hinaus Unheimlicheres (deinoteron) ragend sich regt." (Heidegger 1987, 112) Der Chor zählt dann menschliche Kulturleistungen - Schifffahrt, Ackerbau, Jagen, Fischen, Nutztierhaltung, Sprache, Politik und Wohnungsbau - scheinbar als Beispiele für die Unheimlichkeit des Menschen auf, um ihn schließlich anscheinend ob dieser seiner Gewalttätigkeit, die nur den Tod nicht zu bezwingen vermag, von „Herd“ und „Wissen“ auszuschließen: „Nicht werde dem Herde ein Trauter mir der, / nicht auch teile mit mir sein Wähnen mein Wissen, / der dieses führet ins Werk.“ (Heidegger 1987, 113)

Heidegger zufolge besagt dieser Schluss des Chorliedes allerdings keine Verdammung des „Gewalt-tätigen“ Menschen, sondern lediglich, dass das „Dasein“ des „schaffenden“ Menschen, der in seinem (durchaus problematischen) Tun das Seiende allererst „hervorbringt", d.h. erscheinen lässt, kein Durchschnittsmensch ist (Heidegger 1987, 126).

Tatsächlich begreift Heidegger in der Einführung in die Metaphysik den ersten Chorgesang der Antigone des Sophokles als Darstellung der Beziehung von Denken und Sein bei Parmenides. Parmenides'Satz ,to gar auto noein estin te kai einai“"verweise auf das wesentliche Zusammengehören von Sein und Mensch. Parmenides 'Überlegungen zum Verhältnis von Denken und Sein seien aber noch nicht „Wissenschaft“, sondern ursprüngliches

\footnotetext{
2 Von Hölderlin ist aber auch eine Übersetzungsvariante dieser Stelle überliefert: „Vieles gewaltige giebts. Doch nichts / Ist gewaltiger, als der Mensch“" (Hölderlin 1998, 186).
} 
„dichtendes Denken“. Dieses könne nicht ohne Verlust seiner wesentlichen Inhalte und Aspekte, allen voran seines nichtobjektivierenden Charakters, in „Logik“ oder wissenschaftliche Sprache übersetzt werden. Vielleicht aber könne das „dichtende Denken“ des Parmenides mithilfe des "denkenden Dichtens“, wie es sich in der griechischen Tragödie vollziehe, die immer schon das "griechische Dasein“ "gestiftet" habe, erhellen.

Auf den ersten Blick spricht das erste Chorlied vornehmlich vom Menschen. Dieser ist aber, wenn man Parmenides' These vom Zusammengehören von Mensch und Sein folgt, nicht als neuzeitliches Subjekt zu verstehen, sondern tatsächlich im Sinne von Heideggers „Dasein“, d.h. als „Da“ des Erscheinens von Seiendem, also als „Da“ des „Seins“:

Um sowohl den Bezug des Seins zum Wesen des Menschen als auch das Wesensverhältnis des Menschen zur Offenheit („Da“) des Seins als solchen zugleich und in einem Wort zu treffen, wurde für den Wesensbereich, in dem der Mensch als Mensch steht, der Name „Dasein“ gewählt. Dies geschah, trotzdem die Metaphysik diesen Namen für das gebraucht, was sonst mit existentia, Wirklichkeit, Realität und Objektivität benannt wird, trotzdem sogar die gewöhnliche Redeweise vom „menschlichen Dasein“ in der metaphysischen Bedeutung des Wortes zu sprechen pflegt. Darum wird nun auch jedes Nach-denken verbaut, wenn man sich begnügt festzustellen, in „Sein und Zeit“ werde statt „Bewußtsein“ das Wort „Dasein“ gebraucht. Als ob hier der bloße Gebrauch verschiedener Wörter zur Verhandlung stünde, als ob es sich nicht um das Eine und Einzige handelte, den Bezug des Seins zum Wesen des Menschen und damit, von uns aus gedacht, zunächst eine für das leitende Fragen hinreichende Wesenserfahrung vom Menschen vor das Denken zu bringen. (Heidegger 1976b, 373)

Wie lässt sich das so verstandene Dasein erläutern? Sophokles schreibt: „Vielfältig das Unheimliche, nichts doch / über den Menschen hinaus Unheimlicheres ragend sich regt.“ Der Mensch ist das Unheimlichste inmitten des Unheimlichen, das deinotaton des deinon, das Furchtbarste des Furchtbaren:

Das deinon ist das Furchtbare im Sinne des überwältigenden Waltens, das in gleicher Weise den panischen Schrecken, die wahre Angst erzwingt wie die gesammelte, in sich schwingende, verschwiegene Scheu. Das Gewaltige, das Überwältigende ist der Wesenscharakter des Waltens selbst. Wo dieses hereinbricht, kann es seine überwältigende Macht an sich halten. Aber dadurch wird es nicht harmloser, sondern nur noch furchtbarer und ferner. (Heidegger 1987, 114-115) 
Das deinon, das „Gewaltige“, wie Heidegger nun übersetzt, dem der Mensch gegenübersteht - wir werden sehen, dass Heidegger damit sowohl die "äußere Natur" (das Meer, die Erde, die Tiere) als auch die „innere Natur“ des Menschen (die Stimmungen, das Verstehen, das Dichten, das Denken, die staatsgründende Tat, die Kunst) meint - wird hier als Potenz beschrieben, d.h. als eine Macht, die sich zurückhalten kann. Das so verstandene, an sich halten könnende Gewaltige, das in der Möglichkeit steht, nicht wirklich gewalttätig zu werden, das „Überwältigende“ wie Heidegger auch sagt, steht dem Mensch gegenüber, der gerade dadurch definiert wird, dass er tatsächlich, aktuell, „Gewalt-tätig“ ist, seine Macht also immer schon verwirklicht.

Während das Gewaltige, das Überwältigende, als bloße Potenz an sich halten kann, ist der Mensch bei Sophokles nach Heidegger also wirklich Gewalt-tätig, Gewalt in actu, denn „zum anderen [...] bedeutet deinon das Gewaltige im Sinne dessen, der die Gewalt braucht, nicht nur über Gewalt verfügt, sondern gewalt-tätig ist, insofern ihm das Gewaltbrauchen der Grundzug seines Tuns nicht nur, sondern seines Daseins ist“ (Heidegger 1987, 115). Dieses Gewalt-tätig-sein, dieses Gewalt-ausüben des Menschen, ist Heidegger zufolge aber nicht negativ konnotiert, sondern als techne (zu der Heidegger das [künstlerische] Herstellen, Dichten, Denken die staatgründende Tat, kurz die „Taten“ der „Schaffenden“ zählt) ganz aristotelisch eine Gestalt des Wissens, d.h. eine Form der Entbergung des Seienden:

Das Seiende im Ganzen ist als Walten das Überwältigende, deinon in dem ersten Sinne. Der Mensch aber ist deinon einmal, sofern er in dieses Überwältigende ausgesetzt bleibt, weil er nämlich wesenhaft in das Sein gehört. Der Mensch ist aber zugleich deinon, weil er das Gewalt-tätige in dem gekennzeichneten Sinne ist [Er versammelt das Waltende und läßt es in eine Offenbarkeit ein. $\mathrm{MH}$ ] Der Mensch ist der Gewalt-tätige nicht außer und neben anderem, sondern allein in dem Sinne, daß er auf Grund und in seiner Gewalt-tätigkeit gegen das Über-wältigende Gewalt braucht. Weil in einem ursprünglich einigen Sinne zwiefach deinon, ist er to deinotaton, das Gewaltigste: gewalt-tätig inmitten des Übersättigenden. (Heidegger 1987, 115)

Der Mensch ist deinon einmal, weil er dem Geschehen des Seins, der Kontingenz, der Geworfenheit, passiv ausgesetzt ist und jederzeit (zuletzt auf alle Fälle vom Tod) überwältigt werden kann; andererseits weil er derjenige ist, der das Seiende aktiv ins Sein zwingt, es durch seine Gewalttätigkeit zum Erscheinen bringt, Seiendes, schafft' bzw. ,stiftet': Im Denken, Dichten, der Kunst, der Herstellung, der Politik. Obschon das deinon des Menschen als Gewalttätigkeit dem deinon der Natur einerseits entgegengesetzt ist, insofern 
der Mensch das Seiende zu erscheinen zwingt, ist diese „Her-Stellung“ des Seienden, dieses zum Erscheinen, sprich zum Sein, bringen des Seienden nichts anderes als die eigentliche „Tätigkeit“ der Natur qua physis, d.h. der natura naturans als des von sich selbst her Aufgehenden. Der Mensch vermittelt das Sein, er ,stiftet' das Erscheinen des Seienden. Deshalb kann Heidegger davon reden, das deinon der Natur könne vom Sein des Menschen in der höchsten Steigerung und Verkoppelung gesagt werden (vgl. Heidegger 1987). Das so verstandene deinon der Natur (die potentielle Gewalt) und das deinon des Menschen (die Gewalttätigkeit als Verwirklichung der potentiellen Gewalt der Natur) nennt Heidegger nun aber „das Unheimliche“, bzw. das „Unheimlichste“: „Der Mensch ist to deinotaton, das Unheimlichste des Unheimlichen." (Heidegger 1987, 114)

Tatsächlich ist die Natur das Unheimliche, weil sie das Überwältigende im oben genannten Sinne ist, als dasjenige, was uns jederzeit aus dem gewohnten, heimischen, alltäglichen hinauswerfen kann, und damit in gewisser Weise auch immer schon tut, weil wir um diese Möglichkeit, letztlich im Erahnen unserer Sterblichkeit, immer schon wissen: „Das Un-heimliche verstehen wir als jenes, das aus dem ,Heimlichen', d.h. Heimischen, Gewohnten, Geläufigen, Ungefährdeten hinauswirft. Das Unheimische läßt uns nicht einheimisch sein. Darin liegt das Über-wältigende.“ (Heidegger 1987, 116) Hinter jeder Erfahrung von Heimat liegt Heidegger zufolge zumindest die Ahnung ihrer Zerbrechlichkeit, d.h. ein Wissen um den unheimlichen Boden, auf dem jede „Heimat“ gründet. Er schreibt:

Der Mensch aber ist das Unheimlichste, weil er nicht nur inmitten des so verstandenen Un-heimlichen sein Wesen verbringt, sondern weil er aus seinen zunächst und zumeist gewohnten, heimischen Grenzen heraustritt, ausrückt, weil er als der Gewalt-tätige die Grenze des Heimischen überschreitet und zwar gerade in Richtung auf das Unheimliche im Sinne des Überwältigenden. (Heidegger 1987, 116)

Was hier wie der Verweis auf menschliche hybris klingen könnte - der Mensch maßt sich an, in seiner (technischen) Gewalt-tätigkeit mit dem Überwältigenden der physis zu konkurrieren - ist in Wahrheit etwas anderes. Heidegger will nicht sagen, das Tun des Menschen sei unheimlich, weil es sich mit dem Tun der Natur gleichsetzt, sondern das Unheimliche besteht darin, dass das Da-sein (des Menschen) tatsächlich der Ort des Erscheinens des Seienden ist. Das Unheimliche besteht nicht in der Gegenüberstellung und Trennung von Subjekt und Sein, nicht in der Kleinheit des Menschen vor der Natur des Mönchs am Meer, sondern darin, dass der Mensch nicht vom Sein getrennt ist, dass Denken und Sein wesentlich zusammengehören. Das Unheimliche ist, dass der Mensch dem Sein "gehört" und dieses ihm. Das Unheimliche ist nicht die neuzeitliche SubjektObjekt-Spaltung, sondern die Identität von Denken und Sein. 
Dieses unheimliche Verhältnis zwischen Überwältigender Natur und Gewalt-tätigem Menschen beschreibt Sophokles, Heidegger zufolge, zunächst anhand der Beziehung des Menschen zum (stürmischen) „Meer“, in das der Mensch „aufbricht“, und zur „Erde“, in die der Mensch, sie bestellend, „einbricht“: „In eins geschlungen mit [...] [dem] gewalttätigen Aufbruch in das Überwältigende des Meeres ist der nicht ruhende Einbruch in das unzerstörbare Walten der Erde.“ (Heidegger 1987, 118) Zu diesem Aufbruch ins Meer und zum Einbruch in die Erde gehört auch die Unterwerfung des Lebendigen, das zum Über-wältigenden gehört, das der Mensch gewalt-tätig zu beherrschen sucht: „In dieses in sich rollende Leben [...] dahinein wirft der Mensch seine Schlingen und Netze, dieses reißt er aus seiner Ordnung und sperrt es in seine Gehege und Pferche ein und zwingt es unter die Joche. Dort: Ausbruch und Umbruch, hier Einfang und Niederzwang." (Heidegger 1987, 118) Aber zum Über-wältigenden gehört nicht nur das, was wir unheideggerianisch die ,äußere Natur“ des Menschen genannt haben, sondern auch das, was man als „innere Natur des Menschen“ bezeichnen könnte. Denn es gehören

[...] die Sprache, das Verstehen, die Stimmung, die Leidenschaft und das Bauen nicht minder zum überwältigenden Gewaltigen wie Meer und Erde und Tier. Der Unterschied ist nur der, daß dieses den Menschen umwaltet und trägt, bedrängt und befeuert, während Jenes ihn durchwaltet als solches, was er als das Seiende, das er selbst ist, eigens zu übernehmen hat. Dieses Durchwaltende verliert dadurch nichts von seinem Überwältigenden, daß der Mensch es selbst unmittelbar in seine Gewalt nimmt und diese als solche braucht. Dadurch verbirgt sich nur das Unheimliche der Sprache, der Leidenschaften als jenes, worein der Mensch als geschichtlicher gefügt ist, während es ihm so vorkommt, als sei er es, der darüber verfügt. (Heidegger 1987, 119-120)

Ebenso aber wie die (letztlich zum Scheitern verurteilte) Gewalt-tätigkeit des Menschen Heidegger zufolge das Seiende, das er nicht ist, erst als solches zum Erscheinen bringt, es erschließt, indem er seine innere Natur betätigt, erschließt der Versuch des Menschen, seine (nie zu beherrschende) innere Natur zu gebrauchen, um die äußere Natur zu beherrschen, dem Menschen erst was er selbst ist:

Das „sich selbst“ bedeutet [...] Jenen, der ausbricht und umbricht, einfängt und niederzwingt. Dieses Ausbrechen, Umbrechen, Einfangen und Niederzwingen ist in sich erst die Eröffnung des Seienden als Meer, als Erde, als Tier. Ausbruch und Umbruch geschehen nur, indem die Mächte der Sprache, des Verstehens, der Stimmung und des Bauens selbst in der Gewalttätigkeit bewältigt werden. Die Gewalttätigkeit des dichterischen Sagens, 
des denkerischen Entwurfs, des bauenden Bildens, des staatsschaffenden Handelns ist nicht eine Betätigung von Vermögen, die der Mensch hat, sondern ist ein Bändigen und Fügen der Gewalten, kraft deren das Seiende sich als ein solches erschließt, indem der Mensch in diese einrückt. (Heidegger $1987,120)$

Gerade dieser Versuch, das Seiende, das der Mensch selbst ist, und das Seiende, das er nicht ist, sich auf diese Weise gewalt-tätig zu erschließen, hervorzubringen, macht den Menschen einerseits zum Da des Seins; andererseits entfernt es den Menschen aber zugleich von dem, was er selbst ist und was das Seiende um ihn eigentlich ist, weil die von Heidegger thematisierten, sein-erschließenden' Tätigkeiten des Menschen dieses immer schon auf eine ganz bestimmte Art und Weise erschließen, die bereits auf das neuzeitliche, heimatlose, vergegenständlichende und vergegenständlichte Subjekt vorausweisen. Denn die beschriebene Gewalt-tätigkeit des Menschen wirft ihn immer nur auf seine eigenen Machenschaften zurück und entfremdet ihn sich selbst und dem Seienden, das er nicht ist. Die menschliche Gewalt-tätigkeit, die das Überwältigende bändigen sollte, lässt es erst recht „unheimlich“ werden, diesmal aber nicht im Sinne der Unheimlichkeit der Identität von Denken und Sein, sondern im Sinne des Vergessens dieser Identität im Wahn der vergegenständlichenden Herrschaft über das Seiende und den Menschen.

Unheimlich wird das Seiende, das der Mensch zu beherrschen versucht, nun, weil er sich damit außerhalb des Überwältigenden stellt, weil er sich dem Seienden als Subjekt gegenüberstellt. Das ist es, was Sophokles Heidegger zufolge meint, wenn er sagt, der aufbrechende und einbrechende Mensch sei bereits „erfahrungslos ohne Ausweg“: „Ausweglosigkeit besteht [...] darin, daß er stets auf die von ihm selbst gebahnten Wege zurückgeworfen wird, indem er sich auf seinen Bahnen festfährt, sich im Gebahnten verfängt, sich in dieser Verhängnis den Kreis seiner Welt zieht, sich im Schein verstrickt und sich so vom Sein aussperrt." (Heidegger 1987, 121)

So beschreibt Heidegger den Wechselbezug zwischen Über-wältigender physis und Gewalt-tätigem Menschen, zwischen Natur und Wissen, als das zumindest zweifach Unheimliche: „Der Wechselbezug beider ist das Geschehnis der Unheimlichkeit..'(ibid., 126); „Im Geschehnis der Unheimlichkeit eröffnet sich somit das Seiende im Ganzen. Diese Eröffnung ist das Geschehen der Unverborgenheit. Diese ist nichts anderes als das Geschehnis der Unheimlichkeit.“ (ibid., 127) Er führt fort: „Das Menschsein ist [...]: das Geschehnis jenes Unheimlichsten, in dem durch die Gewalt-tätigkeit das Überwältigende zur Erscheinung kommt und zum Stand gebracht wird.“ (ibid., 131) Während die ersten beiden Zitate die Unheimlichkeit mit der prozessualen Identität von Denken und Sein identifizieren, verweist der Schluss des letzten Zitats auf die Unheimlichkeit der Vergegenständlichung dieser Identität in die Gegenüberstellung von Subjekt und Objekt. 
Letztlich gründet dieser Doppelaspekt der Unheimlichkeit der Beziehung von Denken und Sein darin, dass das Sein, d.h. das Erscheinen des Seienden, „Un-Verborgenheit“ ist, also zugleich gewalt-tätige Entbergung des Seienden (in der menschlichen Tat), und Verbergung des eigentlichen Seins des Seienden, d.h. Verbergung der Überwältigenden physis als das Geschehen des von sich selbst her Aufgehens des Seienden. In dieser nach Heidegger wesentlich gegenläufigen Zusammengehörigkeit von Denken und Sein besteht die Unheimlichkeit der ontologischen Heimat des Menschen, d.h. des Erscheinens des Seienden im Da des Daseins, das sich als Wechselbezug von Denken und Sein vollzieht, to gar auto noein estin te kai einai.

\section{Literatur}

Adorno, Theodor W. 1964. Jargon der Eigentlichkeit. Zur Deutschen Ideologie. Frankfurt am Main: Suhrkamp.

Beelmann, Axel. 1994. Heimat als Daseinsmetapher. Weltanschauliche Elemente im Denken des Theologiestudenten Martin Heidegger. Wien: Passagen.

Büchin, Elsbeth und Alfred Denker, Hrsg. 2005. Martin Heidegger und seine Heimat. Stuttgart: Klett-Cotta.

Degenkolbe, Stefan. 2005. „Der Heimatphilosoph aus dem badischen Geniewinkel. Alfred Denker und Elisabeth Büchin über Heideggers Verhältnis zur Heimat." Literaturkritik.de. 21.09.2005. https://literaturkritik.de/id/8565.

Heidegger, Martin. 1967. Sein und Zeit. Tübingen: Niemeyer.

Heidegger, Martin. 1976a. „Brief über den Humanismus.“ In Wegmarken, herausgegeben von Friedrich-Wilhelm von Herrmann, 313-365, Bd. 9 der Martin Heidegger Gesamtausgabe. Frankfurt am Main: Klostermann.

Heidegger, Martin. 1976b. „Einleitung zu ,Was ist Metaphysik?““ In Wegmarken, herausgegeben von Friedrich-Wilhelm von Herrmann, 365-385, Bd. 9 der Martin Heidegger Gesamtausgabe. Frankfurt am Main: Klostermann.

Heidegger, Martin. 1984. Hölderlins Hymne „Der Ister“. Herausgegeben von Walter Biemel, Bd. 53 der Martin Heidegger Gesamtausgabe. Frankfurt am Main: Klostermann.

Heidegger, Martin. 1987. Einführung in die Metaphysik. Tübingen: Niemeyer.

Heidegger, Martin. 2002a. „Der Feldweg.“ In Aus der Erfahrung des Denkens, herausgegeben von Hermann Heidegger, 87-91, Bd. 13 der Martin Heidegger Gesamtausgabe. Frankfurt am Main: Klostermann.

Heidegger, Martin. 2002b. „Schöpferische Landschaft. Warum bleiben wir in der Provinz?“ In Aus der Erfahrung des Denkens, herausgegeben von Hermann Heidegger, 9-15, Bd. 13 der Martin Heidegger Gesamtausgabe. Frankfurt am Main: Klostermann.

Heidegger, Martin. 2002c. „Sprache und Heimat.“ In Aus der Erfabrung des Denkens, herausgegeben von Hermann Heidegger, 113-117, Bd. 13 der Martin Heidegger Gesamtausgabe. Frankfurt am Main: Klostermann. 
Heidegger, Martin. 2004. Die Grundbegriffe der Metaphysik. Welt - Endlichkeit - Einsamkeit. Herausgegeben von Friedrich-Wilhelm von Herrmann, Bd. 29/30 der Martin Heidegger Gesamtausgabe. Frankfurt am Main: Klostermann.

Heidegger, Martin. 2005. „Das Ge-Stell.“ In Bremer und Freiburger Vorträge, herausgegeben von Petra Jaeger, 24-45, Bd. 79 der Martin Heidegger Gesamtausgabe. Frankfurt am Main: Klostermann.

Hölderlin, Friedrich. 1998. „Antigone.“ In Friedrich Hölderlin: Sämtliche Werke und Briefe, Bd. 2, herausgegeben von Michael Knaup, 317-368. Darmstadt: WBG.

Marten, Rainer. 1980. „Heideggers Heimat. Eine philosophische Herausforderung.“ In Nachdenken über Heidegger: eine Bestandsaufnahme, herausgegeben von Ute Guzzoni, 136-159. Hildesheim: Gerstenberg.

Strolz, Walter. 1986. „Natur - Sprache - Heimat in Heideggers Denken.“ Zeitschrift für Theologie und Kirche, 83 (1): 111-136.

Vetter, Helmuth. 2014. Grundriss Heidegger. Ein Handbuch zu Leben und Werk. Hamburg: Meiner. 


\title{
Topologie der Heimat zwischen Imaginärem, Mythos und begrifflicher Sprache Paratopos, Utopie-Dystopie-Heterotopie und Transtopisches
}

\author{
In Erinnerung an Gerda E. Moser
}

\author{
Alice Pechriggl \\ Universität Klagenfurt (Austria)
}

\begin{abstract}
The article examines Heimat as a multilayered signification and affectively invested phenomenon in the context of the related social imaginary. A topologic perspective elucidating the role of topos in the Heimat imaginary is central to this examination deployed around the idea that Heimat is a paratopos, a place nearby, protecting against the Other/s. Although "Heimat" is a German term which cannot be translated easily, something of the phenomenon seems to exist in cultures other than the Germanophone. It is part of philosophical culture, as will be shown with the help of relevant philosophers. Political imaginaries are also often founded by the "Heimat" phenomenon by way of an origin myth narrating the beginnings of a society or community as homeland or home country, patris, sometimes metropolis, patrie,
\end{abstract}

Heimat etc. After a brief look back into the Ancient Greek imaginary of the patris, the article discusses the gender asymmetry in the topology of "Heimat" and what the author calls the screen imaginary of femininity. This section is followed by a group-psychoanalytic consideration of affective ambivalence and the defense mechanism of splitting at work in the collective imaginary of Heimat and nationalism. Last but not least, the article tries to sketch some "transtopic" ways out of these xenophobic and martial aspects of Heimat as constructed "against" the foreigner as the enemy.

Keywords: Paratopos, self-othering, screen imaginary offemininity, splitting

(c) Alice Pechriggl; alice.pechriggl@aau.at

Colloquium: New Philologies, Volume 6, Issue 1 (2021)

doi: 10.23963/cnp.2021.6.1.9

Stable URL: https://colloquium.aau.at/index.php/Colloquium/article/view/153

This work is licensed under a Creative Commons Attribution 4.0 International License (CC BY 4.0). 


\section{Einleitung}

Heimat ist kein philosophischer Begriff, doch es wird seit langem philosophisch-begrifflich über dieses Wort und das Phänomen, das es bezeichnen soll, nachgedacht. Wenn in diesem Sinn Heimat als ein Ort, der keiner ist, beschrieben werden kann - als eine Zeit, die nie war und auch nicht kommt, dann deshalb, weil die meisten im deutschsprachigen Raum heimischen Menschen etwas damit verbinden; und zwar etwas, das zwischen Existenz und Inexistenz, zwischen Fiktion und Realem angesiedelt ist. Es ist dies eine Wirklichkeit, die Cornelius Castoriadis eine zentrale gesellschaftlich-imaginäre Bedeutung nennen würde. Für den Erfinder des Begriffs des "gesellschaftlichen Imaginären“ verdichten sich in solchen zentralen Bedeutungen Vorstellungen, Wünsche und Affekte zu einem instituierten, vor allem aber zu einem effektiv erlebten Phänomen, das die einfache Gegenüberstellung von fiktiv Imaginärem und real Gegenständlichem durchkreuzt. Ohne Betrachtung der Psyche und ihrer auf kollektiver Ebene relevanten Dimensionen ist es nunmehr schwer, diesem Phänomen gerecht zu werden. Deshalb ist meine Zugangsweise, wie immer in solchen Fällen, eine philosophisch-gruppen/psychoanalytische und eine chiasmatische (von $\chi$ - die Gegensatzpaare über Kreuz legende).

Dass das Imaginäre wirklich ist, gilt in ganz besonderer Weise für den Begriff „Heimat" und das Phänomen, das er zu bezeichnen aufgerufen wird. Damit kann Heimat philosophisch als ein konkret transzendentales Phänomen für die einzelnen Menschen gefasst werden, ähnlich wie "Schicksal“ oder „Muttersprache“, auch wenn Heimat ein deutsches Wort ist und seine Bedeutung keineswegs in allen Kulturen existiert. Doch bleiben wir bei Deutsch: Die Anrufung der „Heimat“, und die meisten germanophonen Menschen fühlen sich zu einer solchen zugehörig, evoziert Affekte, Wünsche aber auch Angst und Abneigung. Es geht dabei um die Angst des „Heimatverlustes“ und um Wünsche als Sehnsucht nach Rückkehr in Form von „Heimweh“, aber auch um heftige Ablehnung, insbesondere, wenn Heimat zum nationalistischen oder gar faschistischen Topos der Kriegspropaganda oder zum politischen Kampfbegriff gegen Asylsuchende, Migrant_innen oder andere nicht Autochthone gemacht wird. Es kann aber auch ganz persönliche Gründe geben, warum jemand gegen (seine) „Heimat“ eine Abneigung hegt oder diesen Begriff für sich ablehnt. Wo ist die Philosophie, wenn es um Heimat geht? Die Philosoph_innen? Ich werde dazu anhand einer kleinen Auswahl einen Streifzug versuchen.

Mit Blick auf die Abwesenheit von „Heimat“ in anderen Sprachen, werde ich auch der Bedeutung der patris oder patria in der Genese von „Heimat“, auf die Geschlechterasymmetrie im gesellschaftlichen Imaginären und in der Praxis der Einsetzung dieser - nicht nur im deutschsprachigen Raum - so zentralen Bedeutung eingehen, bevor ich 
mich zum Schluss wieder der germanophonen und als solcher unübersetzbaren Verfasstheit von Heimat und ihrem Überschreitungspotential zuwende, das ich „transtopisch“ nenne.

\section{Heimat als „Paratopos“ am Beispiel Österreichs und darüber hinaus}

Aus philosophisch-kulturwissenschaftlicher Perspektive ist Heimat jedoch nicht nur kollektiv verbindend und identifikatorisch relevant, sie ist vor allem ein Topos (gr. für Ort, Platz, aber auch weibliches Geschlechtsorgan und im übertragenen Sinn Allgemeinpatz, lieu commun). Ich würde sie zuerst einen Paratopos ${ }^{1}$ nennen, der immer schon im Zeichen der Nachträglichkeit steht, wie alle psychoanalytisch interessanten Phänomene. Ich meine damit einen Topos, der kein realer Ort ist, d.h. kein Ort auf irgendeiner geographischen Karte, an dem gestanden oder an den gegangen werden könnte, oder zumindest nicht nur, denn etwas von der Örtlichkeit und ihrer Verortung bleibt an der Heimat immer haften. Im „Paratopos“ steckt das Gegenstück und der Widersinn, aber auch die Beiläufigkeit des griechischen Suffix para-: Er ist es (Topos im eigentlichen Sinn) und er ist es nicht, ein bei/nahe-Ort also und kein Nicht-Ort wie der A-Topos, das Ungewöhnliche oder die U-topie, die mit dem Griechischen Topos ohnehin nur noch wenig zu tun hat.

Paratopos also, oder „Paraort“ (analog zu Abort). Er verweist auf einen Widersinn der Örtlichkeit, denn die Heimat ist zwar meist territorial verortbar, aber zugleich weit davon entfernt, sich in dieser Verortung zu erschöpfen, ja sie geht in extremis sogar soweit, ohne Boden, ohne chôra, (gr. für Territorium, Land) Bestand zu haben: Dafür steht Athen während der Schlacht von Salamis gegen die Perser ebenso Pate wie das jüdische Volk in der Diaspora. ${ }^{2}$

1 Paratop, engl. paratope, gr. paratopos, bezeichnet in der Genetik jene Stelle eines Antikörpers, an der dieser an ein Antigen bindet, genauer an dessen Epitop. Auch wenn wir in einer Pandemie leben und die Immunologie bzw. Epidemiologie schon seit der Renaissance für die Staatsraison, insbesondere im Zeichen der organologischen Metapher vom Volkskörper, strukturierend war, möchte ich hier keine solchen Verbindungen ziehen.

2 „Die Polis ist ihre Männer, polis gar andres“ und alle, die auf diesen Befehl des Themistokles hin auf die verfügbaren Schiffe evakuiert werden sollen, kurz bevor die Xerxes-Armee die Stadt in Schutt und Asche legt (siehe Thuk., Pelop. Krieg, Jahr 413). Was die Diaspora angeht, so prägt der Auszug aus Ägypten nicht nur die jüdische Religions- und Kulturgemeinschaft, sondern auch die auf ihr aufbauenden abrahamitischen, allerdings nicht in vergleichbar tragischer Weise. Andere, vor allem moderne Phänomene der Migration, die oftmals in einem inflationären Gebrauch des Wortes als Diaspora bezeichnet werden, sind hier nicht automatisch mitgemeint. Besonders entbehrlich und von sozialwissenschaftlich zweifelhaftem Wert sind Listen, zumal auf ihnen stets bestimmte aus ihrer „Heimat“ vertriebene Gruppen nicht aufscheinen (es wird immer irgendeine Gruppe vergessen worden sein ...) Dennoch sind die globalen Vertreibungsphä- 
Dieser Paraort „Heimat“ trägt immer auch schon jenes Gegenstück in sich, über das es sich mit der Nichtheimat, der Fremde verbindet. Das liegt zum einen an der Dialektik des Phänomens, die darin besteht, dass Heimat ohne Fremde überhaupt nicht zur Wirkung kommen könnte, ja vielleicht nicht einmal zu irgendeiner Bedeutung gelangt wäre.

Zum Paraort gehört eine Parazeit, denn die Heimat ist in ihrer mythischen Verfasstheit irgendwie zeitlos und dennoch an den Mythos ihrer zu einem bestimmten Zeitpunkt beginnenden Auto/biographie gebunden. Es ist dies der die Existenz eines Kollektivs begründende Herkunftsmythos, der als immer auch fiktionale Erzählung den weiteren Verlauf der Geschichte dieser oder jener Heimat im kollektiven Imaginären fundiert.

Zumeist steht ein Gründungsereignis an dieser mythischen Stelle, eine Rettung, eine Revolution, ein Friedens- oder ein Staatsvertrag. Letzteres etwa in Hugo Portischs „Zweite Republik“, die wir anlässlich von dessen Tod gerade wieder im Österreichischen Rundfunk zu sehen bekommen und die - ähnlich wie die Geschichtserzählungen der „République Française“ durch Jules Michelet, Pierre Nora und andere seit 1789 - für das Volk und seine Identifikation mit dem Staat als Heimat, als Land und als Regime verfasst und breitenwirksam ausgestrahlt wird. ${ }^{3}$ Da gerade in einem minimal demokratisch verfassten Rechtsstaat diese Art der historiographischen Erzählung einer gewissen Objektivität verpflichtet ist, wird die Geschichte mit einigen Widersprüchen und nicht nur mit ideologischen, im Sinne von Marx die Herrschenden und ihre ausbeuterische Herrschaft legitimierenden, Erbaulichkeiten versehen. Der „Opfermythos“ ist hierin zentral und der durch ihn versäumte Umgang mit dem Anschluss an Deutschland, an Nazideutschland, an Deutschland tout court.

Der Topos des Deutschen, Großdeutschen, Deutschnationalen in Österreich, zu Beginn der Ersten Republik auch „Deutschösterreich“ genannt, ist eine Kernbedeutung des Paraorts Heimat Österreich, bis heute. Das Deutschwerden Österreichs geschah zum einen durch die Niederlage im 1. Weltkrieg und danach auf Betreiben der in der Monarchie unterdrückten slawischsprachigen Bevölkerungen; nach dem Zerfall des Reichs geschah und geschieht es zum anderen auf Kosten der in Österreich verbliebenen „Minderheiten" (Slowen_innen und Kroat_innen werden im Staatsvertrag als solche anerkannt), auf Kosten der Vielsprachigkeit, der Vielfalt und der Aufklärung darüber, was Österreich an seinen Nebenschauplätzen, in seinen düstersten Kellern, Heimaterln, Nebenlagern und

nomene zu allen Zeiten für die Frage nach der Bodenlosigkeit des Paratopos Heimat relevant. (Safran, 1991).

3 Der studierte Historiker und Journalist Portisch, den meine und spätere Generationen von Österreicher_innen als Geschichtsonkel der Nation erlebten, verstarb am 1. April 2021. Michelet gilt in Frankreich bis heute als der Historiker der Revolution, auch wenn sich rund um die 200-Jahr-Feier François Furet und Mona Ozouf an seine Stelle zu setzen suchten. Für sein Monumentalwerk wählte der selbsternannte Auto/biograph der Nation Nora den Titel „Lieux de mémoires“ (Erinnerungsorte, wobei mémoire eher das Gedächtnis und commémoration die Erinnerung bezeichnet). 
Politsümpfen sonst noch alles ist. Auch wenn die Österreicher_innen das mehrheitlich lieber nicht wissen wollen, gilt es in einem Rechtsstaat ein differenziertes Geschichtsverständnis zu vermitteln und ein wenig von der sozialpsychologischen Gewissheit umzusetzen, dass ein Umgang mit diesen düsteren Seiten der Geschichte sich geziemt und für ruhigeren Schlaf in Gegenwart und Zukunft sorgt. Auch da hilft der Paratopos Heimat, der die Ambivalenz aufrecht zu erhalten vermag und zugleich eine abwägende, kritisch sortierende Einschätzung wenn auch nicht verunmöglicht, so doch ganz gut behindert.

Er erlaubt es der Bevölkerung, die im Tourismus schon früh, in den Universitäten erst in jüngerer Zeit vorherrschenden Unterwerfungsgesten gegenüber den oftmals schwadronierend überheblichen, weil reineren und besseren Deutschen unablässig einzuüben; Gesten hin zu diesen zahlenden, und immer öfter auch gut bezahlten „Gästen“, die ja selbst keinen Minderheiten in ihrer heimatlichen Mitte Fremdsprachenrechte einräumen zu müssen meinen (mit dem kolonialistischen Erbe geht es jetzt erst langsam los). Doch statt eine etwas gründlichere Schau in die großdeutsch/österreichischen Keller deutscher Heimattreue vor sowie während der Zweiten Republik zu wagen, wird das gar nicht harmlose Ressentiment gegen die „Piefke“ kultiviert, diese eigentlichen Täter (wäre da nicht der oberste Täter Adolf Hitler und seine zahlenmäßig überrepräsentierten Landsmänner) - ein Ressentiment, das zur österreichischen Heimat gehört wie Hans Krankls Tor zum 3:2 in Cordoba. ${ }^{4}$

Der Paratopos wirkt auch dort, wo der Fremdenhass zum entsublimierten Bruderhass wird und wo dessen Ausagieren und die dazugehörigen Ersatzhandlungen die Wut und Trauer um die verlorenen Sprachen und Menschen immer noch erfolgreich an die Kellerwand spielen. ${ }^{5}$ Dieser paratopische Zug des verinnerlichten und doch abgespaltenen Deutschnationalen im Herzen des zerfallenen aber multilingual nachhinkenden Vielvölkerstaats Österreich ist nur einer der vielen Heimathüte, aber als die Spitze eines grenzüberschreitenden Schneebergs tiefer Ambivalenz, welche „Heimat“ als solche prägt, ist er zentral. Diese Ambivalenz manifestiert sich in der Struktur des Heimatimaginären, aber sie vermag auch unvorhersehbare Neuformationen in ihm hervorzubringen. Der Freudsche Begriff der Abwehr kann beim Verständnis dieser Phänomene als ein Werkzeug fungieren, das ich mit einer philosophischen Chronotopologie der Heimat zu ver-

4 Fußballmatch Österreich gegen Deutschland bei der WM 1978, in dem Deutschland wider Erwarten unterlag. Die Feindseligkeit geht nicht nur auf den Opfermythos oder auf das als arrogant wahrgenommene Benehmen deutscher Schitourist_innen in den 1970er-Jahren zurück, sondern auch auf die Kriege zwischen Österreich und Preußen, die Feindseligkeit zwischen Friedrich II. und Maria Theresia etc.; das österreichische Heimatimaginäre transportiert sie also schon länger, sie wird aber meist nicht bewusst als solche wiederbelebt.

5 Es gilt nicht nur von Wien, die auch als Hauptstadt des Balkans bezeichnet wird, dass fast jede_r dort zumindest einen slawisch- oder ungarischsprachigen Vorfahren hat. Es stimmt wohl auch für Teile Kärntens, des Burgenlandes und der Steiermark. 
knüpfen suche, denn wir haben es hier nicht nur mit Mythos und Imaginärem, sondern mit Mystifizierungen zu tun, die nicht durch aussagenlogische, geschweige denn durch formallogische Analysis allein erhellt werden können.

„Heimat“ als Topos mit der Herkunfts- und Ankunftsfrage zu verknüpfen zieht unverzüglich auch die Frage nach ihrer politischen Wirklich- und Wirksamkeit nach sich. Eine philosophisch- und historisch-anthropologische Perspektive ist im Hinblick auf die Analyse der Affektökonomie gruppen/psychoanalytisch zu wenden, denn im Mittelpunkt stehen dabei die Begriffe des gesellschaftlichen Imaginären und der „-topie“ an der Schnittstelle von Dystopie, Heterotopie und Utopie, was auf die unvermeidliche Frage nach der affektiven Ambivalenz der Heimat als eine imaginäre res extensa verweist, also auf einen imaginären Raum über den eingeengten Topos sensu strictu hinaus.

Als Produkt kollektiver Phantasie ist dieser Raum zugleich in ständiger Veränderung begriffen und wäre damit res extendenda, ein „Ding“, das dazu tendiert, sich auszubreiten, und zwar nicht selten auf Kosten anderer Räume, wie der NS-Begriff des („natürlich“ heimatlichen) „Lebensraums“ am grausamsten verdeutlichte. Überhaupt kippt im konkretistischen Imaginären der Nazis die Heimat am totalsten in die genozidäre Realisierung einer Dystopie. Dagegen waren die humanistisch-kosmopolitischen Heimatideale, für die so manche_r Intellektuelle sein Leben hingab (wie für das revolutionäre Frankreich 1789-1792, die Commune de Paris 1871, für „Griechenland“ 1821 bzw. die „Spanische Republik“ 1936) eher intellektuell sublimierte Utopien, auch wenn sie als solche nicht verwirklicht wurden. Sie glänzen allerdings durch eine eigentümlich europäische Art des Self-Otherings in der Projektion des geistigen und politischen Heimatwunschkonzerts auf eine zu rettende Republik (ich komme weiter unten auf diesen Begriff des Self-Othering zurück).

\section{Philosoph_innen in/aus der Heimat zwischen Mythos und Topos: einige Auserwählte}

Die für das Imaginäre der Heimat konstitutiven Bedeutungen ranken sich um die Polarität des Unheimlichen, des Fremden und Vertrautesten und der heimatbeschwörenden Angstabwehr. Die tiefe Angst vor dem Ausgestoßen-Sein bewohnt zwar jeden Menschen, doch nicht alle haben dagegen und darum herum eine Heimat aufgebaut. Mit dem Heimat-Imaginären bearbeiten die deutschsprachigen Menschen unablässig die affektiven Dispositionen, die mit dieser Polarität einhergehen und zugleich bevölkern sie damit ihre Kultur, auch in der Philosophie, ob die sich nun deutsch-kritisch wie bei Ernst Bloch oder Walter Benjamin, deutsch-fundamentalhinterwäldlerisch wie bei Martin Heidegger, wienerisch-sprachfetischistisch wie bei Ludwig Wittgenstein (Philoso- 
phie aus Wien) und Sigmund Freud (Metapsychologie in und aus Wien) oder kosmopolitisch wie bei Hannah Arendt (aus Deutschland) gibt, um nur die für mich relevantesten in dieser Frage zu nennen.

Während germanophone Dichtung oftmals durch die Zersetzung der Heimat diese - sublimiert - wo/anders (im Reich der literarischen Sprache) wiedererrichtet, versucht die Politik, die Heimat rhetorisch im Phantasma der Nation aufzubauen. Dagegen suchen Philosoph_innen die Funktion der Heimat in der Sprache als einem Labyrinth aus Begriffsgefügen aufzubauen, in denen vielleicht nur jene die Orientierung nicht verlieren, die am Boden der allgemeinen Wirklichkeit immer schon verloren zu sein glauben oder gar wissen (eingedenk ihrer Sterblichkeit). Das ist das spezifisch paratopische Potenzial der Philosophie, einer Welt der Begriffe, die all jenen Heimat gibt, die nicht nur im Wort, sondern auch im systematisch subversiv argumentierenden Sprachspiel zu Hause sind. Und zwar nicht erst seit Wittgenstein oder Derrida, sondern seit Heraklit und Sokrates, Platon und Aristoteles ... Und das sind die sozialen Banden dieser Heimat: Denkverwandtschaftslinien, Schulen, allesamt patrilinear wie die taoistischen Lineages, weshalb Frauen sich darin weniger beheimatet fühlen, ja immer noch eine Art „Ironie des Gemeinwesens" darstellen, um Hegels treffende Formulierung zu bemühen. (Vielleicht liegt aber gerade hierin das kritische Vermächtnis der philosophierenden Frauen, und zwar im Sinne der Philosophie und weniger in jenem des Schulenstreits zur väterlichen Ehrenrettung, wie sie seit Sokrates-Platon immer wieder das Feld beherrscht.)

Eine affektiv derart aufgeladene Bedeutung wie Heimat ist zuerst kein Begriff (Logos oder Genos) sondern ein Mythos, eine Geschichte oder Erzählung, mehr oder weniger erfinderisch gestaltet und ausgeschmückt. Bevor sie philosophisch und/oder durch politische Rhetorik zum Begriff gemacht, also gereinigt, systematisiert und aufpoliert wird, schillert sie in allen Farben folkloristischer Stimmung mit dem obligatorischen Gemeinschaftspathos, den Musik und Gesang so eindringlich verbindend vermitteln. Aus diesen schillernden Vermächtnissen schöpft die begriffliche Arbeit der Philosoph_innen, die sich der Heimat zu bemächtigen versuchen: indem sie sie kritisch beleuchten, destituieren, dekonstruieren, unterminieren, um sie im Himmel der Begriffe immer von Neuem wiederaufzubauen gemäß dem Prinzip des logon didonai (Gründe und Rechenschaft geben, möglichst stringent argumentieren, erhellen, analysieren, begreifen, etc.). Denn auch die Techniken sprachlicher Polemik und eine aus den Gerichtshöfen und den politischen Vollversammlungen in Athen stammende sublimierte Kriegführung gegen das im Volksmund affektiv aufgeladene „Daham“ (daheim) kruder Demagogen, Imperialisten und Genozidäre zielen auf einen Topos ab: den Ort der Sehnsucht (und nicht der Angst), der unerfüllten und der vormals erfüllt geglaubten. 
Ob in Blochs „Noch Nicht“ bzw. in seiner utopischen Rhapsodie Prinzip Hoffnung (Bloch 1984) oder in Benjamins genialen Hauptstadt-Spaziergängen durch die Pariser Passagen (Benjamin, 1982), die kritische Theorie deutscher Nation und jüdischen Backgrounds verweist auf die bereits geschlagenen und tödlich noch bevorstehenden Wunden antisemitischer Ausrottungspolitik im Namen einer reinen, deutsch-arischen Heimat und weist auch schon darüber hinaus. Arendt, die Jüdin im philosophischen Männerclub, oder vielmehr außerhalb desselben, welche den Topos im Aristotelischen Erbe der Theorie-Praxis-Unterscheidung zu verankern sucht, kommt gerade noch aus ihrer zerbrechenden „Heimat“ auf und davon, von ihrem Lehrer und Verführer, dem Nazi Heidegger, aber kaum los. Sie baute mit ihrem Denken weit mehr als Celansche Gräber in den Himmel der Begriffsgefüge: Pariah, Totalitarismus, Natalität, Neues und die Revolution denken „wir" seither in ihrer Nachfolge. Auch Sigmund Freud, der metapsychologisch in den geistigen Untergrund geht, bevor er sich doch noch aus seinem "lieb gewordenen“ Gefängnis Wien befreien und vor den dort bereits einmarschierten Nazis retten lässt, hinterlässt uns eine Begriffswelt, deren Erschließung und Weiterführung erst begonnen hat, obwohl sie noch zu seinen Lebzeiten in der ganzen Welt Anklang gefunden hatte.

Rettung hat in diesem semantischen Feld mit verlorener Heimat und mit Zerstörung (oder mit Katastrophe, wie es die modernen Griechen seit 1918 nennen) zu tun, nicht erst seit Friedrich Hölderlin. Freud baut bis zum letzten Atemzug für ganze Generationen von Psychotherapeut_innen, Philosoph_innen, Kulturwissenschafter_innen und sonstige Laien aus aller Welt nicht nur den Begriff des Unbewussten zu einer schier unermesslichen Un/heimat aus; er weist uns auch noch den Weg, über den wir in ihm, also im Unbewussten - erst mit Hilfe eines therapeutischen Virgil, dann selbst - uns auch heimisch machen können oder zumindest ein wenig vertrauter mit der Fremde in unserer eigenen Mitte. Freie Assoziation heißt die hierzulande längst vor Freud übliche Technik der schlüpfrig-kathartischen Wortspiele und Witze, die nach dem Ende des Naziregimes zugleich mit dem Jazz und dem freien Tanz, der freien Körperkultur und der sexuellen Revolution auch in Wien wieder Einzug hält, sich geradezu paratopisch verankert - gegen die „Ehemaligen“ (Nazis), Antisemiten, Frauenhasser und Homophobe, Klerikalfaschisten, Deutschnationale und Neonazis, die sich jetzt - im euphemistischen Neusprech der frühen Zweiten Republik - „Unabhängige“ nennen. Entgegengesetzte politische Heimaten in einer Stadt, die alles in sich aufnimmt und nicht selten wieder unter sich begräbt.

Und dann sind da noch die beiden Philosophen Ludwig Wittgenstein und Michel Foucault, die ich auch noch kurz vorstellen möchte, weil sie einander in mehr als einer Un/Heimat treffen: Wittgenstein, der Wiener, vermeintliche Gründer der zeitgenössischen amerikanischen und nunmehr Weltsystem-Philosophie, geißelt nicht nur seine Volksschüler, sondern vor allem sich selbst für seine homosexuellen Begierden, und 
verlässt die Heimat Österreich noch rechtzeitig gen Norden. Die Sprache, die in seinen Abhandlungen als aphoristische Paragraphenprosa daherkommt, und nicht nur die philosophische Sprache, wird danach nicht mehr dieselbe sein; die Gewissheit auch nicht und schon gar nicht die Illusion der Klarheit: Mimikri und Analysis der Sprache als unerreichbare Heimat. Doch der Philosoph bleibt „noch ein Gescheiter/ter“. Dagegen tritt Foucault schon selbstbewusster auf, allerdings nur implizit, was die Rechte derer angeht, die wie er anders als „straight" lieben und leben. Heute nennen sie sich im Allgemeinen queer und meinen, in Foucault eine neue Heimat gefunden zu haben. Jedenfalls verdanken wir ihm die Bereicherung der philosophisch-anthropologischen Topologie um den Begriff der Heterotopie (Foucault, 2001). Diese lädt zu einem kleinen Exkurs ein. Sie ist ein Zufluchtsort an der Schnittstelle von Imaginärem und Realem, zwischen mise en scène des Glücks und seiner kurzen mise en acte im Urlaub oder im heimlichen Kinderspiel zu Hause, und erinnert teilweise an Blochs konkrete Utopien (Baumhaus u.a.). Foucault geselle ich den aus der Heimat zweimal vertriebenen hinzu, den ich bereits erwähnte: Castoriadis wird kurz nach seiner Geburt 1922 mit seinen Eltern aus Konstantinopel von den Türken nach Athen vertrieben, von dort durch die politischen Gegner nach Paris. Der Revolutionär und Radikaldemokrat par excellence hinterließ uns nicht nur eine zeitgemäße Ontologie und Theorie des gesellschaftlichen Imaginären (Castoriadis, 1984), sondern auch das Labyrinth (Castoriadis, 1981), aus dem dereinst der kapitalistische Minotaurus verschwunden sein wird, der das Projekt der Autonomie vereitelt und unsere planetarische Lebensgrundlage zerstört. Castoriadis selbst meinte, dass es keinen Minotaurus gäbe im Labyrinth des Dädalus. Ich sehe das anders: Es gibt zahlreiche, und ein Faden wird nicht reichen, um nach deren Überwältigung wieder ins Freie zu kommen. Im Moment wissen wir nicht einmal, ob wir es mit einem Labyrinth oder nicht vielleicht doch mit einem planetaren Gefängnis zu tun haben, wo die Erde doch unser aller „Heimat“ ist: Treibhauseffekt, Pandemie, Artensterben, Atomwaffen und immer mehr Atommüll in lapidaren Umhüllungen, wenn nicht gleich ins offene Meer ...

Mit Jacques Derrida, pied noir juif ${ }^{6}$, teilt Castoriadis lange Zeit nicht nur die Betreuung der Doktoratsstudien für „Philosophie und Gesellschaftswissenschaften“ an der Ecole des Hautes Etudes en Sciences Sociales (EHESS) in Paris, sondern auch das Interesse an der Alterität. Die Destituierung des ererbten Denkens und Handelns, die er anstrebt, ist in manchem analog, obschon politisch expliziter als die begriffliche Dekonstruktion Derridas. Kombiniert vermögen beide die erbaulichen Heimatphantasmen wie kaum etwas

\footnotetext{
6 Derrida ist als Kind jüdischer Franzosen in der damaligen Kolonie Algerien geboren. Die Franzosen aus der Metropole hießen zuerst colons (Kolonisten), später pieds noirs, wörtlich „Schwarzfüße“, vor allem als sie im Zuge des Algerienkrieges nach Frankreich (France métropolitaine) zogen, wo sie noch fremder waren als in Algerien.
} 
auseinanderzulegen, vorausgesetzt ihre Bezüge zu Marx und Freud, weitere Heimatlose und doch wieder Beheimatete, werden mitgedacht.

\section{Antike Griechische Vorläufer: Chôra, Gê, Patris, Metropolis ...}

Doch kommen wir endlich zu den „Anfängen“, d.h. zu den Griechen, auf die Europa sich so gerne beruft. So heimattreu wie falsch der Topos vom "Griechischen Wunder" ist, „wir"verdanken den Griechen die Philosophie und die Demokratie in dieser Explizitheit, ebenso das Theater, so wie wir es in Europa und anderen Teilen der Welt kennen. Ob wir ihnen die Heimat verdanken, ist schwer zu sagen; gewiss geht etwas von ihr auf sie zurück. Die historische Anthropologie am Centre Louis Gernet der EHESS, allen voran Nicole Loraux (Loraux 1998), legte die Strukturen, aber auch das Unstrukturierte der griechischen Herkunfts- und Ursprungsmythen frei, insbesondere das darin kristallisierte Geschlechterimaginäre.

In diesem wird der Weiblichkeit ihr Erdcharakter, der Erde ihre Mütterlich- und Weiblichkeit nachhaltig umgehängt, die Frau wird dafür auf den vom Mann besamten Acker, die Polis auf die Patris reduziert. Mittendrin die Metropolis, wörtlich „Mutterstadt“ und Sehnsuchtsort für jene, die in der Ferne der Kolonie lebten und leben. Athen war also beides, Patris und Metropolis; Athene die Polisgöttin; Gê die Erde und Göttin der Autochthonie. Dem fügt Platon den Begriff der Chôra hinzu, was eigentlich Territorium, Land heißt, das er aber zur Mutter bzw. Amme des Werdens macht, und die er selbst als wundersamen Begriff bezeichnet, unbestimmbar weil in sich widersprüchlich, a-topos oder paratopos, das ist nicht ganz ausgemacht, jedenfalls der Logik spottend, nicht nur der platonischen (Timaios 52c-d).

Von diesem wundersamen Begriffstopos geht es zur Frage nach der geschlechtermetaphorischen und sodann nach der affektiven Seite des Paratopos Heimat, die im bereits erwähnten „Unheimlichen“ mündet.

\section{Geschlecht: Körper, Topos, Projektionsimaginäres der Weiblichkeit}

Um die Heimat in Bezug zur Geschlechtermetaphorik zu betrachten sei kurz auf eine frühere Arbeit verwiesen, die sich mit den Schichtungen des geschlechtsspezifischen Imaginären befasste, insbesondere mit dem, was ich das Projektionsimaginäre der Weiblichkeit nenne (imaginaire-écran de la féminité) (Pechriggl 1998; 1999; 2000). In modernen Staaten wird die Patria oft als weibliche Figur dargestellt, die aber nicht vorschnell als Frau interpretiert werden darf. Vielmehr greifen diese Figuren, ob Marianne für die „Nation 
France", Germania oder andere, weibliche Gottheiten auf, deren geschlechterpolitische Funktion es ist, Frauen im doppelten Sinn in jenen politischen Räumen zu repräsentieren, die Männer damit exklusiv sich selbst als herrschende Geschlechterklasse vorbehalten. Wie die heilige Barbara, die noch heute oft angerufene Schutzpatronin des Untertagbaus, duldet - so der männliche Exklusionsmythos - die verheiligte „Frau“, welche die Nation repräsentiert, keine lebenden Frauen in ihren Stollen bzw. in den Institutionen der Patris, die ausschließlich dem Vater und dessen großen Söhnen gehört, ${ }^{7}$ welche ja das patriotische Imaginäre verwirklichen (und nicht repräsentieren, wie es die allegorisch zugerichteten Pseudofrauen tun).

Ein viel älterer, politischer Frauen-Exklusionsmythos, den wir in Aischylos' Orestie finden, zeigt die Kontinuität in diesem ausschließlich männlichen Heimatimaginären an. Er besagt, dass im Kampf zwischen Poseidon und Athene um die heilige Patronanz über Athen die Göttin den Sieg davontrug, um den Preis - des Frauenwahlrechts ... Die Ver-tretung der Frauen durch eine repräsentative Göttin oder allegorische Frauenfigur wie Marianne erfüllt nun zwei Funktionen gleichzeitig: Sie hält zum einen die Frauen außerhalb der Männerräume, insbesondere in der politischen Sphäre bzw. verdrängt sie wieder aus ihr, sollten sie sich - wie etwa im Zuge der Französischen Revolution oder der Pariser Commune - in sie hineinreklamiert haben (faire écran heißt im Französischen abschirmen); zum anderen fungiert sie als Projektionsfläche (écran bedeutet auch Projektionsschirm oder Kinoleinwand) für Affekte und Vorstellungen. Die Pseudopräsentifizierung des von den patriotischen Männern angebeteten und verteidigten „Weiblichen" ist zentral für deren patriotische Euphorie, die besonders in Zeiten des Krieges erforderlich ist, wenn Männer einberufen werden, und aufgerufen sind, ihr Leben auf dem Schlachtfeld aufs Spiel zu setzen, ja zu lassen. Die Heimat als Patria ist die mütterliche Figur im Namen des Vaters, zu der die kämpfenden Söhne in ein besonders erhebendes Verhältnis treten, und durch das sie ihr Leben gleichsam als Ausgleich zum Todesrisiko der Frauen im Kindbett riskieren sollen. „Wehren und Gebären“, so das Motto der Geschlechterkomplementarität, die in diesem ideologisch-affektiv, ja nachgerade blutig aufgeladenen Heimatsetting wirkt; ein Setting, das sich gegen die Teilnahme der Frauen nicht nur durch ausagierte Frauenfeindlichkeit, sondern vor allem durch das patriotische Projektionsimaginäre der Weiblichkeit abschottet.

\footnotetext{
7 „Land der Berge, Land am Strome / Land der Äcker, Land der Dome, /Land der Hämmer, zukunftsreich! / Heimat bist Du großer Söhne, / Volk, begnadet für das Schöne, / Vielgerühmtes Österreich. / Vielgerühmtes Österreich ...." So lautete die erste Strophe der Österr. Bundeshymne, die seit 2012 inklusiver abgesungen werden muss: „... Heimat großer Töchter und Söhne“. Dagegen begehrten sofort zahlreiche männliche Volkshelden auf, die sich aus ,ästhetischen“ Gründen an der Änderung zu stoßen vorgaben. Intergeschlechtliche Menschen, die nach wie vor ausgeschlossen sind, haben sich aber meines Wissens nicht für „Heimat bist Du großer Kinder“ eingesetzt; ein solcher Vers wäre dann doch zu wahrheitsgemäß und entmystifizierend gewesen.
} 
Dabei wird die Enge und das Unheimliche der paternalistisch-familiären Geborgenheit kultiviert. Die Kleinfamilie ist der paradigmatische Topos der paratopischen Heimat. Eine Zeit lang schien es, als ob für immer in ihrer Mitte, um es mit Foucault zu sagen, die Heterotopie - diese alltäglichste aller verwirklichten Utopien - wohnen würde, ohne je zu einem weltoffenen oder gar inklusiven Gesellschaftsentwurf zu gelangen.

\section{Topologie der Affekte: Ambivalenz und Spaltung im Heimat-Imaginären}

Die Aktualisierung des Heimat-Imaginären verspricht bei jenen, die sie einmal erlebt haben, das Wieder-Aufkommen und den Erhalt kindlicher Gefühle der Geborgenheit im Schutz mütterlicher bzw. elterlicher Liebe und Fürsorge. Aber auch denen, die sie nie erlebten, wird sie gerne vorgegaukelt. Gerade in Momenten, in denen ein Kollektiv großer Angst und den damit verbundenen Ohnmachtsgefühlen ausgesetzt ist, stellt sich der Wunsch nach der heimatlichen Kombination aus Imaginärem und Stimmung als Abwehrschirm gegen die massiven Unlustaffekte ein. Mit dem in Extremsituationen durchaus üblichen Spaltungsmechanismus (Verkennung, Verleugnung, Verneinung, Verwerfung, Verkehrung ins Gegenteil, Ausblendung im Zeichen extremer Dichotomisierung) greift die menschliche Psyche auf frühkindliche Abwehrstrategien zurück, die jedoch im Fall der Chronifizierung zu Realitätsverlust führen und mit einer fabulatorischen Charakterbildung einhergehen. Eine solche Chronifizierung kann sich auch durch dauerhafte Bedrohung und ideologische Berieselung eines Kollektivs in diesem selbst einstellen.

Philosophisch-anthropologisch gesprochen ist der Mensch ein Wesen, das sich ein ,zu Hause", ein geschütztes Lager schafft/e, individuell, in Gruppen, und auch in größeren Kollektiven. ${ }^{8}$ Das können auch Zelte von Nomaden sein, wichtig ist die Schutzfunktion, der Unterschlupf, der auch noch in der Unterwerfung großdeutscher Bewohner_innen Restösterreichs unter den mächtig sich gebärdenden Nachbarn eine Rolle spielte, in dessen „Behemotschen“ Schoß Großdeutsche und später illegale Nazis rasch zu eilen suchten, und in dem sie die eigentliche Heimat sahen, frei von Anderssprachigen, frei von Juden, frei von (jüdischen) Bolschewiken, frei von Sozis.

Damit wäre der Paratopos völkischer Heimat-Rhetorik erreicht, in und durch den die erklärten Feinde im Inneren und Äußeren als „Ab-jekte“ phantasiert, angerufen und entsprechend sonder-behandelt werden. Einschluss, der den Ausschluss immer schon mit sich führt und nach sich zieht. Ein real erlebter und deshalb umso eher wieder befürch-

8 Zur frühen anthropologischen Theorie über die - präpolitische - koinônia, jene die Einzelnen schützende Gemeinschaft, zu welcher Menschen sich sammeln, siehe Aristoteles' Politik; für Ausführungen zu einem menschlichen „Trieb, sich zu betten“, der mit einer schützenden Überdachung einhergeht (Link, 1990). 
teter Verlust dieses Schutzes mobilisiert nicht nur massive Ängste, sondern auch die erwähnten psychischen Abwehren in den Einzelnen und - im Fall von Großgruppenphänomenen - im gesamten betroffenen Kollektiv. Dies führt zur Potenzierung der Affekte und entsprechenden Abwehren, was eine Spirale in Gang setzt: Die Heimat, die alle schützen soll, bedarf ihrerseits des Schutzes und guter Heimatschutz gegen bösen Nestschmutz ist das propagandistische Credo, das in Zeiten der Spaltung zur obersten Priorität gegen die Feinde im Inneren wird, welche ja noch dem realistischen Denken und Sprechen verbunden bleiben, oder um es philosophischer zu sagen: „der Wahrheitssuche“.

Und da der Mensch überhaupt, über die nationalistischen Häupter hinaus, nicht nur ein Wesen ist, das „die Sprache hat“, zoon logon echon, sondern auch ein mit Einbildungskraft begabtes, wird das Heimatphantasma stets in dieser Doppelfunktion von repräsentativer und affektiv besetzter Schutzmacht in Szene gesetzt werden: Die inneren Bilder mobilisieren die an sie gebundene affektive Entspannung und umgekehrt, die heimatlichen Gefühle evozieren die je dazugehörigen inneren Heimeligkeitsbilder, die sich ihrerseits wohlig versichernd anfühlen. Dieser geschlossene Kreislauf zwischen Geborgenheitsmise en scène und affektiver mise en acte, also das unmittelbare Ausagieren, in dem die für Selbstinfragestellung nötige Distanz tendenziell fehlt, lässt die mise en sens (Sinnstiftung durch kritisches Nachdenken) gar nicht oder nur schwer aufkommen. Die affektive mise en acte im Register des Heimatimaginären ist vielmehr das unvermittelte kollektive Ausagieren des Fremdenhasses, bei dem der Fremde immer schon fein säuberlich in den anderen verlegt zu sein scheint. Das hervorzurufen, dazu tendiert die Heimat stets; darin besteht ihre imaginäre wie affektive Verstetigung, so wie die Religion aber auch die herrschaftliche Staatsideologie zum total(itär)en Fanatismus tendiert, weil sie als Glaube an das Ganze alles verneinen muss, was sich ihm nicht fügt. Und im Zeichen der Spaltung stehend dämmert in der Heimat, noch bevor sie als patris/Vaterland zum imaginären und dann realen Kriegsschauplatz aufsteigt, schon das genaue Gegenteil der Heimeligkeit, die sie verspricht: zutiefst Unheimliches. Denn bevor die Spaltung aktiv wird, liegen die Gegensätze miteinander verschränkt am Grund des heilversprechenden Heimatscheins, so wie „die Ambivalenz der Urworte“ am Grund des Unbewussten liegt.

Es soll dort zwar so schön und einhellig sein, wie es - außer in der nachträglich idyllisierenden Erinnerung - nie war, doch das ist nur die eine Seite. Dieses Imaginäre erstrahlt für Bloch als Vorschein bzw. im Nachschein idealer Vergangenheiten, die bei Marx „urkommunistische“ Retroutopien sind. Und so ist die ganze Menschheit in diesen Idyllen zumindest in der Vorstellung heimelig eingebettet zwischen Damals und Morgen. Tendenziell verklärende Heilslehren einer politisch freien und gleichen Heimat im Anschluss auch an antike Gemeinden, die Französische Revolution oder die Pariser Com- 
mune finden sich nicht nur bei Marx, Bloch und Benjamin, sondern auch bei manchen Anarchist_innen und Feministinnen; wir finden sie nicht bei Luxemburg, die zwar auch in der genannten Tradition nach der besten aller Regierungsformen strebte, jedoch „,nach Möglichkeit" und effektiv radikaldemokratisch, weniger in dem messianischen Glauben an etwaige Meisterrepräsentanten, also daran, dass das Paradies auf Erden sich als universelle, ja nachgerade totale Heimat (Blochs „Totum Bonum“) erfüllen würde. Die Erfüllung soll sich da von selbst bzw. dem Gesetz der Geschichte folgend, oder abgeleitet vom „Prinzip Hoffnung" durch die versöhnt-versöhnende Theorie-Praxis einstellen, wenn sie etwa von Bloch mit dem erfüllten Augenblick herbeigeträumt wird, und zwar als heiliger Kairos, nicht als jener realistische und praktische kairos aus Medizin (Hippokrates) und Politik (Aristoteles), den es als nur kurz währende Gelegenheit zu ergreifen gilt.

Die idealisierenden Vorstellungswelten gepaart mit einer psychologisch-anthropologischen Perspektive legen nahe, dass Heimat etwas Universelles sei, zumal wir auch von „politischer Heimat“ sprechen, die sich im Kosmopolitismus Zum ewigen Frieden (übrigens auch Name eines Wirtshauses) auf alle Menschen ausbreiten würde, wenn es nach Kants - durchaus auch ironischer - Geschichtsphilosophie ginge. Die „Neger“ (Kant) waren davon gewiss ausgenommen; hier blieb Kants Weltoffenheit, sein bis heute viel gepriesener Humanismus, regional eingeengt, sprich eurozentrisch-rassistisch und gewiss auch kleinbürgerlich, was sich mit seiner süffisanten Frauenfeindlichkeit gut verbinden ließ. ${ }^{9}$

Wenn nun zwar die Ideen universeller Bürgerschaft paratopisch, bei/nahe und wider die je kulturellen Abschottungstendenzen, alle humanistisch-heimatlich einzuschließen vermögen, so gilt auch hier: Der Ausschluss ist konstitutiv für den Einschluss, und auf die Manifestation der fein säuberlich Ausgeschlossenen folgt ihre Abspaltung, d.h. die Abspaltung der „Anderen“ vom „Eigenen“. Damit verbunden ist aber auch die umgekehrte Peinlichkeit, dass mit dem Wegfall dieses konstitutiven und stets für Verunglimpfungen bereiten „Anderen“ aus dem bewussten Wahrnehmungsraum ein fundamentales Loch im „Eigenen“ entsteht, das sogleich wieder gefüllt werden muss: Ein anderer Anderer muss her, und sei er durch Identifikation illusionär herbeigeschafft. Das geschieht auch durch etwas, das ich als Self-Othering bezeichnen möchte: „Wir sind die eigentlichen Opfer" sagen z.B. die ihres konstitutiven Anderen sich beraubt habenden Täter; oder die Täter_innen, die auf der Betrachtungsebene der Einzelpsyche vielleicht tatsächlich chronisch Opfer waren, identifizieren sich mit den Opfern, indem sie in Ermangelung jeglichen Sinns für Verhältnismäßigkeit etwa die Pflicht, in Zeiten der Pandemie Mas-

9 Das heißt keineswegs, dass wir aufhören könnten, ihn zu lesen, oder seinen Humanismus ernst zu nehmen, wie manche es neuerdings minoritätsidentitär - und keineswegs mehr „dissidentitär“ - fordern. Ich kann aus Platzgründen darauf nicht genauer eingehen. (Pechriggl 2016). 
ken zu tragen mit der Vergasung in einem NS-Vernichtungslager gleichsetzen, was auf eine besonders pikante Kombination von Spaltungsmechanismen verweist.

Diese korreliert mit identitärer Politik im höchst zugespitzten Sinn von Freuds „Narzissmus der kleinen Unterschiede", wenn nicht gar im Sinn kollektiver Paranoia, der auch wieder nur mit humanistisch-internationalistischen Orientierungen zu entkommen ist, welche auf der Erfahrung und dem Begriff der Interdependenz basieren. Alles andere als hilfreich ist dagegen der abstrakte Begriff, gegen dessen Dominanz die Partikularismen ja gerade aufbegehren. Es geht nur durch die möglichst gleichberechtigte Konkretisierung des Allgemeinen, das wusste schon Hegel auszudrücken und das versucht auch das Ringen um gesellschaftliche Bezeichnungen von Diskriminierten wie LGBTIQ*, wobei das * für den nie erfassbaren Rest, die nächsten, noch nicht zu Klassen- bzw. Gruppenbewusstsein gelangten Diskriminierten, Unterdrückten, Ausgebeuteten steht. Dass dagegen der spaltende kollektivpsychische Topos (diesmal im Sinn von Allgemeinplatz) des Self-Othering gerade im Heimat-Imaginären der Dominanzkultur virulent wird, wissen wir aus diversen sozialpsychologischen Analysen der Kriege und ethnischen Konflikte seit Freud (Freud 1927). Er kann aber auch Minderheiten erfassen.

\section{Zeit/Raum: transtopische Überschreitungen}

Wenn wir allerdings die von immer wiederkehrender Ent-täuschung begleiteten Heimatillusionen auf ihre Verbindungen zum Herkunftsmythos hin betrachten, der den imaginierten Beginn von Gesellschaften oder auch Staaten erzählt, dann fällt eines auf: Die Spaltung als psychische Abwehr prägt nicht nur dieses Anfangskapitel der Parazeit Heimat (so wie sie die Form jeder heftigen Auseinandersetzung prägt), sie strukturiert es vielmehr im starken Sinn. Um genauer zu sein, strukturiert sie den Übergang vom ersten Gründungsereignis zum zweiten Moment der ersten Differenzierungen. Man kann derartige Phänomene auch in psychoanalytisch arbeitenden Großgruppen beobachten, wo vor allem zu Beginn die Angst (in) der Gruppe die konstitutiven Anfangsillusionen und -erwartungen massiv bedroht und dadurch zu paranoid wirkenden, fragmentarischspaltenden Wortmeldungen (auch Präsidentengezwitscher) führt. In der Realität staatlich verfasster und militärisch veranlagter Heimaten kann es da schon zum Ausagieren bürgerkriegsartiger Aufspaltung der Bevölkerungen oder kriegerischer Handlungen gegenüber einem Außenfeind kommen, der immer auch den Vorteil hat, eine Zeit lang für innere/n Frieden und Sicherheit zu sorgen, also der sich als Widerstreit zu manifestieren beginnenden Ambivalenz im „Inneren“ Herr zu werden. Das trifft auch auf die gerade noch geeinte Heimatstimmung zu: droht sie im Angesicht größerer Bedrohung einmal ins Alptraumhafte zu kippen, wird geleugnet, verteufelt, bezichtigt. Denen, die in diesem 
Modus vorstellen und denken, erscheint nur noch der für Außenstehende stets kasperlhafte Held in der Lage, das Ungeheuer zur Strecke zu bringen (oder „,wegzukickeln“), das die identitär-utopisch aufgeblähte Heimat bedroht, das er aber immer auch selbst ist, sprich diejenigen, die sich mit ihm identifizieren und durch ihn voll und ganz - total repräsentieren lassen: „einer für alle - alle für einen“.

Weil sie imaginär ist, also zuerst in der Vorstellungswelt existiert, muss Heimat sich in der res extensa materialisieren, realisieren: im Körper, im Raum, im Territorium; aber manche finden ihre Heimat eher in der Sprache, in der Dichtung, der Wissenschaft, der Philosophie; sie wirken zuweilen auf die heimatlich Verankerten, die der ländlichen, familiär-paternalistischen oder nationalen Heimat effektiver verbunden sind, wie Verlorene, bedrohliche Zugvögel inmitten einer Pseudostabilität, Migrant_innen des Geistes oder im Geiste, nomadisch nennen manche es in Anlehnung an die Lebensweisen der Beduinen, Tuaregs, Mongolen u.v.a., die vielleicht auch schon auf Elemente des Kosmopolitismus verweisen.

Wenn wir den Eingangs skizzierten Paratopoi einiger Philosoph_innen die Kosmopolitismus-Mimikri der arisch-deutschen Intelligentsia im NS-Reich gegenüberstellen, dann finden wir, ohne lange suchen zu müssen, das einzige Manifest der „deutschen Professorenschaft“, das zudem in fünf Sprachen an die „Gebildeten der Welt" gerichtet war: das „Bekenntnis der Professoren an den deutschen Universitäten und Hochschulen zu Adolf Hitler und dem Nationalsozialistischen Staat“ (NS-Lehrerbund, 1933).300 - auch einige Dozent_innen und Lehrbeauftragte haben unter diesem Titel unterzeichnet - reihen sich ein hinter die sieben Ansprachen für diesen deutschen Ruf des Professor-Seins, unter deren Autoren der Heimat- und Schollespezialist Heidegger ebenso prominent wie geistlos hervorsticht. ${ }^{10}$

Die durch Heideggers Nazi-Verstrickungen in Verruf geratene Phänomenologie und Existenzphilosophie hat interessanterweise noch während des Zweiten Weltkriegs in Frankreich zu überleben begonnen. Und es mag der Ironie des Ideenschicksals geschuldet sein, dass gerade Emmanuel Lévinas, der gegen Lebensende immer mehr zum Thora-Interpreten wurde, hier eine initiale Rolle spielte. Vor allem der Philosoph der Weiblichkeit als Andersheit und „Bleibe“ (auch eine Heimat?), Jean-Paul Sartre und in gewisser Weise auch Maurice Merleau-Ponty waren es, die Heidegger in Frankreich, Europa und darüber hinaus wieder salonfähig machten. ${ }^{11}$ Heidegger als ambivalent besetzter Star der franzö-

\footnotetext{
${ }^{10}$ Heideggers Kollege Gadamer war „nur“ unter den Unterzeichnern.

${ }^{11}$ Wie Emmanuel de Saint Aubert aufzeigt, wird diese Ambivalenz deutlich bei einer systematischen Analyse von Merleau-Pontys Bezugnahmen auf Heidegger (de Saint Aubert, 2011).
} 
sischen Postmoderne, das hört bis heute nicht auf, mich zu verwundern. ${ }^{12}$ Wenn man den fundamentalnationalistischen Wahlwerbetext von Heidegger für Hitler liest, ${ }^{13}$ besticht die Nähe zur politischen Debilität, die mit Teilen dieser Strömung in den 1980er Jahren einher ging und deren Folge der Aufstieg zunehmender identitärer Faschisierung war.

Vielleicht wird jemand dieses Kapitel französischer und europäischer Geistesgeschichte eines Tages im Lichte des französischen (de Gaules') Antiamerikanismus lesen und uns besser verständlich machen. Es wird jedenfalls nicht abgelöst zu sehen sein von den Entwicklungen der Geopolitik und anderer europäischer „Heimaten“ der Philosophie nach dem Zweiten Weltkrieg.

Doch obwohl es der politischen, gesellschaftlichen und kulturellen Voraussetzungen für Entstehung und Weiterentwicklung der Philosophie bedarf, ist die Heimat der Philosophie als Begriffswelt die Sprache. Das hat sie mit der Dichtung gemein, die sie aber aufgrund ihres Hangs zur Episteme auf Distanz hält. Dass die sprachliche Heimat der Philosophie keine lingua franca sein kann, hat schon Cicero gewusst, der die griechischen Begriffe ins Lateinische übersetzte; und auch Kant, der so viele Begriffe aus dem Lateinischen ins Deutsche übertrug, um erstmals systematisch Philosophie in dieser, seiner Muttersprache schreiben zu können. Was nun aber - philosophisch gesprochen - „Heimat" ist, ob Mythos, Begriff oder Phänomen, und inwiefern alle drei, das kann weiterhin nur an der Schnittstelle von philosophischer und historiographischer, kulturtheoretischer und sozialpsychologischer Betrachtung erhellt werden. Caspar cas und step by step, nicht ohne den ständigen Versuch, wieder alles Mögliche - von Neuem und provisorisch - auf und unter die allgemeineren Begriffe zu bringen, also ohne den Begriff erneut zum

\footnotetext{
${ }^{12}$ So wie sich die Grande Nation über die Verbrechen ihrer Armee in den Kolonien, vor allem während des Algerienkrieges hinwegtäuschte (Vidal-Naquet 2001), so machten sich seine Vorzeigeintellektuellen lange Zeit Illusionen über die Unverfänglichkeit der Heideggerschen Sprache und die Gewalttätigkeit seines politischen Denkens und Tuns. Während Derrida mit den Mitteln der Dekonstruktion auf Französisch kaum imstande ist, dem angemessen beizukommen, schlägt Elfriede Jelineks permanente Heidegger-Parodie gewaltig gegen den Blut- und Bodendünkel des Heimatphilosophen ein; ihre grausame Parodie durch Verarbeitung nicht nur seiner eigentümlichen Philosopheme, sondern auch des privaten und zugleich völkischen Duktus', ist für sprachmusikalische Ohren bei/nahe eine Tortur, bevor sie zum Genuss an der Parodie selbst wird. Vielleicht ist das ja die Hoffnung mancher deutschsprachiger Heidegger-Rezipient_innen: dass das metaphysische Getöns durch beständige Gestaltung zum philosophischen Kunstwerk werde. Ich fürchte, dass das Gelingen eines solchen Unterfangens der Literatur oder dem Theater vorbehalten ist bzw. einer Mischung dieser beiden mit der philosophischen Untersuchung, wie Platon sie so unnachahmlich vorlegte.

13 „Das deutsche Volk ist vom Führer zur Wahl gerufen. Der Führer aber erbittet nichts vom Volke, er gibt vielmehr dem Volke die unmittelbarste Möglichkeit der höchsten freien Entscheidung, ob das ganze Volk sein eigenes Dasein will, oder ob es dieses nicht will. Das Volk wählt morgen nichts Geringeres als seine Zukunft." (Heidegger 1933, 13) Ganz oder gar nicht, Existenz oder Vernichtung, Führerprinzip oder Untergang ... Heidegger ist schon ganz eingestimmt auf die pathetische Denkzwang- und KurzschlussRhetorik Hitlers.
} 
Verbrecher am Besonderen werden zu lassen. Und die Systematik der philosophischen Sprachheimat, die das System hinter sich lässt, wäre ein Begriffsgefüge, das zugleich ein Begriffsmobile ist, dessen sich alle, die möchten, bedienen sollen - ohne Patente, ohne property, öffentlich zugänglich eben, wie diese Zeitschrift mit dem schönen Namen.

\section{Literatur}

Benjamin, Walter. 1982. Das Passagenwerk. Gesammelte Schriften Band 5.1 und 5.2. Frankfurt am Main: Suhrkamp.

Bloch, Ernst. 1984. Das Prinzip Hoffnung. 3 Bände. GW Band 5. Frankfurt am Main: Suhrkamp. Castoriadis, Cornelius. 1981. Durchs Labyrinth. Hamburg: Europäische Verlagsanstalt.

Castoriadis, Cornelius. 1984 (1975). Gesellschaft als imaginäre Institution. Frankfurt am Main: Suhrkamp.

De Saint Aubin, Emmanuel. 2011. „Merleau-Ponty face à Husserl et Heidegger: illusions et rééquilibrages." Revue germanique internationale: illusions et rééquilibrages 13. Aufgerufen am 15. April 2021. http://journals.openedition.org/rgi/1122; DOI: https://doi.org/10.4000/rgi.1122.

Foucault, Michel. 2001 (1984). Schriften. Band 1. 1954-1969. Frankfurt am Main: Suhrkamp.

Freud, Sigmund. 1990 (1927). Zukunft einer Illusion. GW Band XIV, Frankfurt am Main: Fischer, 325-380.

Link, Jürgen. 1990. „Massendynamik und As-Sociation.“ kultuRRevolution 36: 3-12.

Loraux, Nicole. 1998. „Falsche Mimesis - richtige Mütter. Warum die Mütter angeblich die Erde nachahmen“ In Mutterwitz. Das Phänomen Mutter - Eine Gestaltung zwischen Obnmacht und Allmacht, herausgegeben von Gudrun Perko, 29-51. Wien: Milena.

NS-Lehrerbund (Hg.). 1933. Bekenntnis der Professoren an den deutschen Universitäten und Hochschulen zu Adolf Hitler und dem Nationalsozialistischen Staat. Dresden. Abgerufen am 10. April 2021. https://archive.org/details/bekenntnisderpro00natiuoft/page/n3/mode/2up

Pechriggl, Alice. 1998. „Welche Mutter? Überlegungen zur Geschichtung einer ambivalenten Gestalt zwischen Psyche-Soma und Gesellschaft." In Mutterwitz. Das Phänomen Mutter - Eine Gestaltung zwischen Ohnmacht und Allmacht, herausgegeben von Gudrun Perko, 339-377. Wien: Milena.

Pechriggl, Alice. 1999. „Der Körper in den Gestaltungen und Schichtungen des geschlechtsspezifischen Imaginären." In Körper-Konzepte, herausgegeben von Julika Funk und Cornelia Brück, 25-35, Tübingen: Gunter Narr.

Pechriggl, Alice. 2000. Corps transfigurés. Stratifications de l'imaginaire des sexes/genres. 2 Bände. Paris: l'Harmattan.

Pechriggl, Alice. 2016. „Sprachregelung und Verfügung über die Vergangenheit." DERDIEDAS. Akademiezeitung 5: 5-6.

Safran, William. 1991. „Diasporas in Modern Societies: Myths of Homeland and Return.” Diaspora: A Journal of Transnational Studies 1 (1): 83-99.

Vidal-Naquet. Pierre. 2001 (1975). Les crimes de l'armée française. Algérie 1954-1962. Paris: La découverte. 


\title{
Heimat und Sprache Überlegungen im Anschluss an Georg Misch
}

\author{
Naemi BREMECKER \\ Philipps-Universität Marburg (Germany)
}

\begin{abstract}
This text seeks to understand the concept of Heimat. I of knowledge and speech that are tied to the individual argue that it is not so much Heimat itself that needs to be examined but rather the subject area which includes experience of the speaker. This insight sheds new light objects such as Heimat. I develop this concept with the on certain confusions of representational references in the discourses on Heimat.

help of Georg Misch's analytical tools. Heimat as an object shows itself in a specific form of speech - „Evozieren" (to evoke). Objects of evoking speech, like objects Keywords: Heimat, Georg Misch, Hermeneutik, Evozierende Rede, practical knowledge, experience
\end{abstract}

of practical knowledge, are subject to specific conditions

(c) Naemi Bremecker; naemibremecker@gmail.com

Colloquium: New Philologies, Volume 6, Issue 1 (2021)

doi: 10.23963/cnp.2021.6.1.10

Stable URL: https://colloquium.aau.at/index.php/Colloquium/article/view/154

This work is licensed under a Creative Commons Attribution 4.0 International License (CC BY 4.0). 
„Jedermann kennt was man mit [...] Heimat meint. Sobald wir uns jedoch aufmachen, dem nachzudenken,[...] wo und wie Heimat waltet, sind wir schon ins Unbestimmte und Bodenlose geraten“, sagt Martin Heidegger $(1983,155)$ in seinem Aufsatz Sprache und Heimat und illustriert so die Denkschwierigkeit, die sich dieser Aufsatz zur Aufgabe gesetzt hat. In der Suche nach einer Antwort auf dieses Problem, wird zunächst mittels einleitender Beobachtungen in den Gegenstandsbereich eingeführt um anschließend, mithilfe einiger theoretischer Überlegungen Georg Mischs, der Antwort auf die Frage nach der Heimat näher zu kommen.

\section{Einleitende Eingrenzung des Problembereichs}

Andrea Bastian versucht in ihrer Dissertation Der Heimat-Begriff. Eine begriffsgeschichtliche Untersuchung in verschiedenen Funktionsbereichen der deutschen Sprache (1995) ein Verständnis von Heimat zu entwickeln. Sie sammelt und systematisiert die Gebrauchsweisen des Wortes Heimat in der deutschen Sprache und kommt zu einem komplexen Ordnungssystem. Sie unterscheidet die Gebrauchsweisen des Wortes schließlich in räumliche, zeitliche, soziale und emotionale kategoriale Zuordnungen für die Funktionsbereiche des Alltags und der Theorie in Recht, Politik, Literatur- und Naturwissenschaften. Auf der letzten Seite ihres Fazits kommt sie schließlich zu dem ernüchternden Schluss: „Es ist von der Existenz eines Heimatbegriffs auszugehen.“ Sein „inhaltliches Spektrum [ist] sehr breit gefächert [...] und [...] schwer einzugrenzen.“ Andrea Bastian folgert: „Es gibt keine allgemeingültige ,eigentliche“ Bedeutung von ,Heimat ““ (Bastian 1995, 221).

Auch wenn Bastian wichtige Beobachtungen macht, scheint das Problem an der Suche nach Heimat darin zu bestehen, dass Heimat fast alles sein kann. Die Dimensionen schwellen an, die Facetten häufen sich und Bastians Funktionsbereiche decken endlich quasi jeden Bereich des Lebens ab. Das Problem besteht letztlich darin, dass Heimat so zwischen ,traditionell gebraut', ,Dresden', oder ,dem Ort der allen in die Kindheit scheint ${ }^{*}$ alles bedeuten kann. Diese Beobachtung ist auf gewisse Weise ernüchternd. Trotzdem kann man etwas aus dem methodischen Vorgehen Bastians lernen.

Folgende drei Eigenschaften von Heimat lassen sich in einer ersten Beobachtung anführen: Heimat ist kein Begriff, der verschiedene Eigenschaften definitorisch enthält. Man kann nur bedingt, wie Bastian es versucht hat, alle Eigenschaften von Heimat, z.B. in den verschiedenen Gebrauchsweisen des Wortes, aufsuchen und sortieren, um dann - aufleitend - zu einer Definition zu kommen. Dies lässt sich nicht nur an dem in seinem Umfang nicht mehr umgrenzten Heimatbegriff Bastians zeigen, sondern auch dadurch, dass man sich folgende Analogie verdeutlicht. Bestimmt man z.B. die Lebensbedingungen einer Pflanzenart, dann untersucht man zunächst deren natürliches Biotop und entdeckt 
bestimmte Eigenschaften. Beispielsweise könnte eine bestimmte Pflanze viel Licht und einen feucht-sumpfigen Moorboden bevorzugen. Es ist dann möglich, diese Eigenschaften an anderen Orten zu finden oder im Gewächshaus zu reproduzieren, und die Pflanze wird an einem anderen Ort mit selben Eigenschaften ebenso gut wachsen können. Heimat kann zwar geographisch-materiell ebenso lokalisierbar sein und dieser Ort kann in seinen Eigenschaften beschreibbar sein, ist aber durch keinen anderen Ort und kein ähnliches Ding ersetzbar. Die Heimat ist ein Einzelnes und Individuelles, welches nicht in der Beschreibung der Summe seiner Teile aufgeht, weil Heimat nicht als ein Ganzes aus Teilen oder eine Summe von Eigenschaften angemessen modelliert werden kann.

Ebenso wie die vorgestellten Methoden nicht funktionieren können, um zu einem Begriff von Heimat zu kommen, ist die gegensätzliche Richtung zwar durchsetzbar, aber problematisch. Entwirft man ein bestimmtes Bild von Heimat und legt die Eigenschaften derselben verbindlich fest, dann führt jede Grenzziehung zum Ausschluss des Anderen. Wird diese Heimat dann auch noch zu einem politisch erwünschten Ziel erklärt, führt dies in seinen abartigsten Formen dazu, dass Menschen davon sprechen können, ,das Reich' müsse vom demjenigen gesäubert werden, was die Verwirklichung von Heimat bedrohen könnte.

Die zweite Beobachtung besteht darin, dass die Eigenschaften, die Heimat zugeschrieben werden, einander widersprechen können und nicht zwingend sind. So kann Heimat beispielsweise für die Außenseiter der Romantik ein unerreichbarer Sehnsuchtsort sein und zugleich das Aufgehen in einer völkischen Gemeinschaft aufdeutschem Boden. Auch individuelle Heimatbegriffe sind unterschiedlich und nicht zwingend. Wenn Menschen beispielsweise aus derselben Region stammen, kann einer von ihnen stolz erklären, eben diese Region sei seine Heimat, während ein anderer behauptet, seine Heimat in Gottes Liebe gefunden zu haben, und ein dritter spricht davon, seine Heimat in den Steppen Afrikas zu haben. Selbst für das einzelne Individuum muss Heimat nicht konsistent sein und man kann erklären, seine Heimat in den Bergen zu finden, um im Laufe der Zeit festzustellen, dass dies nicht mehr gilt und man sich als heimatlos beschreibt.

Der Titel dieses Aufsatzes lautet: Heimat und Sprache. Schon daran, dass zuvor die Wörter „Erklären“ und „Behaupten“ verwendet wurden, kann erahnt werden, dass Sprache und vor allem das Sprechen eine Rolle spielen könnte. Die dritte Beobachtung formuliert sich so zugleich als These: Heimat ist ein Gegenstand, der sich im Sprechen von Sprache vollzieht. Illustrieren wir diesen Gedanken zunächst mit einer einfachen Beobachtung: Es ist ein Unterschied, ob man sagt: „Ich bin in Hamburg geboren“ oder „Ich bin Hamburger. Meine Heimat ist Hamburg “. Der Referent ,Hamburg bleibt in beiden Sätzen bestehen, aber während die erste Sprechweise eine eher nüchterne Beschreibung einer Tatsache ist, wird im zweiten Satz etwas getan. Das Ich des Sprechers, seine indi- 
viduelle Person, wird an den Geburtsort gebunden. Es ist ja mitnichten nötig, den eigenen Geburtsort zur Heimat zu erklären. Man sagt also quasi: ,Ich bin geworden, der ich bin, eben weil ich von genau dort herkommé. Die Sprecherin stellt eine Verbindung zwischen ihrem gegenwärtigen Ich und dem referentiellen Ort der Rede ,Hamburg' her. Damit ist Hamburg aber nicht mehr ein Ort neben anderen Orten, sondern ,Hamburg wird zu demjenigen Ort, den der Sprecher als Ort der Heimat erlebt hat. Wir haben es hier mit einem performativen Akt zu tun, der einen Ort (oder weiter gefasst ein Ding in der Welt) herausstellt und ihn besondert, indem er als bedeutsam für die Sprecherin in einem Akt sprachlicher Anerkennung erklärt wird. Diese sprachliche Bezugnahme, die eine Verortung, Zuordnung und Verknüpfung des Sprechers darstellt, kann für Einzelne sowie Gruppen gelten. Sie ist nicht zwingend, kann ausbleiben, sich ändern oder sich ähneln - aber, und das ist der springende Punkt, sie muss vollzogen werden.

Modifizieren wir also die eingangs gestellte Frage. Wir fragen uns nun nicht mehr, was Heimat ist, sondern was es für Gegenstände sind, die die oben angedeutete Form haben, und kehren damit die Beobachtungsrichtung gewissermaßen um. Es wird nun nicht das Wissen über Heimat untersucht und systematisiert, sondern es sollen Gegenstände eines bestimmten Typs philosophisch entwickelt werden, um in einem zweiten Schritt zu erfragen, ob Heimat ein solcher Gegenstand sein könnte und welcher Mehrwert sich aus einer solchen Betrachtungsperspektive ergeben könnte.

\section{Überlegungen im Anschluss an Georg Misch}

Ich werde die Frage danach, was Heimat für ein Gegenstand ist, mithilfe der philosophischen Begrifflichkeiten Georg Mischs ausschnittsweise analysieren. Misch ist dem sogenannten Göttinger Kreis der 1920-30er-Jahre zuzurechnen und seine ,logische Hermeneutik' siedelt sich inhaltlich zwischen Diltheys Philosophie des Lebens, der Phänomenologie Husserls und Heideggers Fundamentalontologie an. Auch wenn Misch durchaus präsent im philosophischen Diskurs seiner Zeit positioniert war, wird sein Name heute eher mit seinem 4000 Seiten umfassenden Mammutwerk Die Geschichte der Autobiographie verbunden. Vom Reichsbürgergesetz betroffen und zwangsweise in den Ruhestand versetzt, war der den Nationalsozialisten als jüdisch geltende Misch 1935 seines Amtes als Philosophieprofessor in Göttingen enthoben worden und floh schließlich ins englische Exil, ohne seine Lehrtätigkeit zeitlebens wieder aufnehmen zu können (Becker, Dahms \& Wegeler 1998, 295f.). Sein theoretisches Hauptwerk Der Aufbau der Logik auf dem Boden der Philosophie des Lebens. Göttinger Vorlesungen über Logik und Einleitung in die Theorie des Wissens erscheint erst posthum, 1994, nach langjähriger Editionsarbeit. 
Misch ist auf gewisse Weise, nicht nur aufgrund der Repression seiner Werke, ein unzugänglicher Philosoph. Er entwickelt seine Argumente häufig, indem er zwischen zwei Perspektiven wechselt. Dieses methodische Vorgehen ist der Einsicht geschuldet, dass über gewisse Phänomene zwar gesprochen werden kann, sie aber zugleich im Moment des Sprechens und der denkenden Vergegenständlichung modifiziert sind. Der schichtweise Aufbau seiner Logik ist immer von der Unmöglichkeit des Sprechen-Könnens begleitet, vor der Misch nicht schweigt, sondern - immer eingedenk der Verformung - in reflexiv-methodischer Perspektivität oszillierend hin und her geht. Die Weise über Dinge zu reden, die zwar ansprechbar, aber nicht aussagbar sind, nennt Misch die evozierenden Rede.

Im ersten Teil seiner Logikvorlesungen verfolgt er die Entwicklung von einem elementaren Ausdrucksverstehen zu einem diskursiven Sprechen, das Hervorgehen des begrifflichen Denkens aus dem Untergrund eines elementaren Lebensverständnisses, mit einer „erstmaligen Gründlichkeit und Systematik“, so Friedrich Otto Bollnow (1983, 46). Diese Gründlichkeit mit ihren vielfachen Differenzierungen hat allerdings mitunter den Preis der leichten Zugänglichkeit und bedeutet hier, dass wichtige logische und begriffliche Unterscheidungen zwar benannt und skizziert werden, aber es bei Schlaglichtern bleiben muss.

Lautete die These zuvor: Heimat ist ein Gegenstand, der sich im Sprechen von Sprache vollzieht, so lautet sie nun, übersetzt in das Vokabular Mischs: Heimat ist ein hermeneutischer Gegenstand. Ein Wissen um ihn liegt in der Schicht der erlebnishaften Lebensvollzüge und wird in evozierender Rede zum Ausdruck gebracht. Diese These zu verstehen ist Leitsatz der nun folgenden Ausführungen.

Die wichtigste Unterscheidung, die Misch in seinen philosophischen Betrachtungen entwickelt und die gewissermaßen den Schlussstein eines aufwendigen Argumentationsgerüsts bildet, ist die Unterscheidung zweier gänzlich verschiedener Redeformen. Verschieden sind sie in Bezug auf die gegenständliche Beziehung, ihren Wahrheitswert und die Form, in der sie ausgedrückt werden. Begründet liegt dieser Unterschied aber in grundsätzlich verschiedenen Verhaltensweisen des Menschen, Welt sprachlich bedeutsam werden zu lassen. Um die uns interessierende evozierende Seite der Rede zu verstehen, muss zunächst die gegenüberliegende Seite aus Abgrenzungsgründen eingeführt und verstanden werden.

Auf dieser Seite des Spektrums findet sich nämlich die rein-diskursive Rede; eine Rede die wesentlich dadurch gekennzeichnet ist, dass sie sich in Sätzen ausdrückt, die Gegenstände, die so oder so sind und uns im Vorhandensein gegenüberstehen, anspricht und in einem bestimmten Sinn nimmt, in dem Aussagen über diese Dinge getätigt werden (vgl. Misch 1994, 539f.). Ziel einer solchen Weise zu sprechen ist die Eindeutigkeit. In 
den rein-diskursiven Feststellungen ist der Gedanke in den satzmäßigen Formulierungen zum vollen Ausdruck gekommen und der Sachverhalt, auf den sich die Worte meinend beziehen, ist in der Aussage aufgehoben und kann aus ihr entnommen werden. Sofern das Ziel von Sprechen auch immer Verständigung ist und dieselbe am besten gelingt, je eindeutiger die Sprache ist, ist es nicht verwunderlich, dass die rein-diskursiven Aussagen zum Sprachideal, ja bisweilen zur einzig möglichen Weise, Sprache zu denken, erhoben werden.

Am klarsten ist diese Redeform in den Naturwissenschaften ausgeprägt, wo jeder Begriff als Terminus in Definitionen maximale Eindeutigkeit anstrebt und eben diese definitorische Eindeutigkeit in ihrer Allgemeingültigkeit und Indifferenz zu Äußerungssituation, durch geregelte Einführungs- und Inferenzregeln den Erfolg der Wissenschaften sichert (Vgl. Misch 1994, 573). Die Wahrheit der rein-diskursiven Feststellungen betitelt Misch mit "sachlicher Richtigkeit“ und sie besteht in der Wahrheit einzelner Sätze, die sich ihrerseits in der Übereinstimmung des Urteils mit der Sache zeigt. Es wird also über die Dinge geredet und Richtigkeit liegt in der korrekten Anwendung der Worte im Urteil, sodass die sachliche Beschaffenheit des Gegenstandes erfasst wird.

Aber nicht bei allen Gegenständen menschlicher Rede funktioniert eine solche Vorstellung von Sprach-Welt-Relation. Misch erinnert zum Ende seiner Ausführungen an den platonischen Dialog Laches, der ein solches Problem zu umkreisen scheint. Sokrates fragt in diesem Dialog nach der Tapferkeit und er fragt hierbei nicht unbedingt nach der Bedeutung des Wortes, welches man z.B. ermitteln könnte, indem man wie Andrea Bastian die Verwendungsweisen eines Wortes sammelt und systematisiert. Er will also nicht wissen, was die Intention des Wortes, Tapferkeit' je und je sein kann, sondern er will in essentieller Hinsicht wissen, was Tapferkeit ist. Platon verfährt nun in seinen sokratischen Dialogen häufig so, dass er eine Person, die die gesuchte Eigenschaft verkörpert - also tapfer ist - zum Hauptunterredner macht. Misch stellt fest:

Dies ist kein bloßes künstlerisches Mittel der Verlebendigung, sondern eine methodische Notwendigkeit. Denn der, der die betreffende Tugend besitzt, hat ein Wissen von ihr und muss also sagen können, was sie ist [...]. [V]on dem, was wir besitzen, müssen wir ein Wissen haben, wovon wir aber wissen, davon müssen wir auch sagen können, was es ist. (Misch 1994, 575)

Dieser Ausspruch ähnelt dem Problem, dass das Thema dieses Aufsatzes ist. Heidegger hatte gesagt: „Jedermann kennt, was man mit Heimat meint" und auch die Menschen, die von Heimat sprechen, müssten doch ein Wissen von dem haben, von dem sie doch erzählen? Sobald man aber versucht zu sagen, was man weiß und hat, ist man ins Bodenlose geraten, ebenso wie der tapfere Redner bei der Antwort scheitert und sich verwirrt 
und schließlich ausruft: „[...] ich bin ganz unwillig, wie ich, was ich in Gedanken habe, so gar nicht imstande bin zu sagen“" (Platon, Laches 194b).

Woher kommt dieses Versagen? Sokrates hat recht mit seiner Vermutung, dass der Tapfere ein Wissen darum hat, was es heißt tapfer zu sein. Aber dieses Wissen ist verschieden von dem Wissen um rein-diskursive oder theoretische Gegenstände. Man kann nicht auf den Gegenstand zeigen, prädikative Aussagen sammeln, deren definitorischer Identitätspol dann die Tapferkeit ist.

Das Wissen, welches gesucht wird, ist an die individuelle Erfahrung des Tapferen gebunden. Es ist ein Wissen darum, wie es ist, ein Tapferer zu sein und über dieses Wissen lässt sich sprechen. Aber der Tapfere kann es nicht in der - von Sokrates gesuchten Weise tun. Eben an dieser Stelle kommt dann die evozierende Rede ins Spiel. Wir suchen also nicht nur nach der Bedeutung der Worte, nicht nur nach dem, was das Wort ,Heimat bedeutet, sondern danach was Heimat ist. Nach der Bedeutsamkeit, die sich im Vollzug des Lebens und in den individuellen Erfahrungen ergibt. Diese Bedeutsamkeit ist weiter angelegt und, das ist das Spannende bei Misch, ist weder auf Worte, noch Sprache, ja selbst auf eine menschliche Lebensform beschränkt, weshalb im Folgenden noch einmal argumentativ tiefer angesetzt werden muss. Um die Bedeutsamkeit im Sinne Mischs zu verstehen, muss nun zumindest kursorisch in das elementare und das Erlebniswissen eingeführt werden. Heimat, das sei hier voran gestellt, findet sich vornehmlich in eben jener Wissensschicht.

Misch entwickelt im ersten Teil seiner Vorlesungen einen Boden universeller ausdrucksförmiger Bedeutsamkeit und Sinnhaftigkeit, welchen er als elementares Lebensverhalten und Wissen bezeichnet. Elementares Wissen liegt vor der sprachlichen Lebensform des Menschen und kann beispielsweise auch Tieren zugeschrieben werden. Elementares Verstehen ist umwelt- und situationsbezogen. Es ist an leibliche Vollzüge gebunden und unterscheidet noch nicht zwischen Ich und Objekt. Solches Verstehen vollzieht sich unbewusst und rein instinktiv; es bezieht sich schlicht auf leiblich und wortlos erfolgte Vorgänge, die auf elementare Weise etwas bedeuten.

Interessant ist nun, dass Misch davon ausgeht, dass solche vordiskursiven Weisen zu verstehen auch beim Menschen wirksam ist, auch wenn sie in methodischer Hinsicht nicht anders als aus einer bewussten Perspektive zugänglich sind. Ein sehr einsichtiges Beispiel ist die Analyse dessen was passiert, wenn wir uns erschrecken. Erschrickt man, so hat man etwas Begegnendes als bedrohlich verstanden, aber niemand erschrickt, indem er oder sie etwas als etwas Bestimmtes erkennt, es einordnet und anschließend beschließt, dass man erschrecken sollte. Vielmehr hat man etwas verstanden, bedeutet und wahrgenommen. Die Reflexion darüber, was es ist, das uns erschrocken hat, setzt nachträglich ein. 
Zwischen dieses elementare Wissen und einer bewussten Sprachlichkeit schaltet Misch nun in seinem schrittweisen Aufbau die Erlebnisse. Er entnimmt den Erlebnisbegriff dem Gedankengut seines Lehrers Dilthey. Erlebnis, das ist nicht die Bedeutung der Worte, sondern die Bedeutsamkeit der Gegenstände und Dinge für uns. Ein Erlebnis steht uns nicht als Objekt und anderes gegenüber. Es geht aus dem elementaren Wissen insofern hervor, als dass ein Erlebnis für mich noch nicht unterschieden ist von dem, was es für mich ist. Erlebnis meint das, wo man darinnen ist, nicht gegenständlich von ihm wissend, sondern nur unbestimmt wissend um es (Misch 1994, 344). ,Wissen um' ist ein Wissen, welches nur im Vollzug der gemachten Erfahrungen entsteht (Weingarten 2003, 44). Indem ich mich auf Erlebnisse beziehe, beziehe ich mich nicht meinend auf Gegenstände außerhalb meiner selbst, sondern auf mich, der ich den Gegenstand dessen, was ich weiß, zugleich erfahre und so in der Artikulation erfasse. Misch schreibt: „Dem Erlebnis steht nichts gegenüber in freier Ferne, sondern es erfüllt uns, wir besitzen es in Fülle, während das gegenständlich gerichtete, begreifende Denken das eben nicht besitzt, worauf es meinend gerichtet ist" (Misch 1994, 572). Die Erlebnisse, die wir in der Welt machen, lassen ihre Gegenstände bedeutsam sein und zwar auf andere als rein-diskursive Weise; auf eine leibliche Weise, die sich in und aus den individuellen Erfahrungen speist.

Es scheint, als wenn Heimat sich vorwiegend in dieser Schicht des elementaren Erlebniswissens verorten lässt, indem die leiblich-sinnlichen Gefühle vergangener Erlebnisse und Erfahrungen zum Klingen gebracht werden. Schuberts Lindenbaum rauscht von ersehnter Heimatruhe und auch der Heimatminister Horst Seehofer sagt, wenn er 2019 versucht, den Gegenstand seines politischen Tuns in einer Rede zu fassen: „Dort sagt mir jeder Baum eine Geschichte" (Seehofer 2019). Ein weiterer Auslöser für heimatliche Gefühle kann auch der Geruch sein. Christian Graf von Krockow fasst dies zusammen, wenn er sagt: „Heimat riecht nach Harz und nach Heu, nach Kartoffelfeuern, Leder, Kuchenbacken, gebrannten Mandeln, [...] Oder sei's Schweinemist, Ruß und Rauch: sie riecht jedenfalls“ (Krockow 1984). Wir hatten diese Beobachtung auch schon zuvor angesprochen, als wir den Geburtsort Hamburg von der Heimat unterschieden haben. Das heimatliche Hamburg, welches zu solchem erklärt wird, weil wir von dort kommen und dort ein persönlicher Erfahrungs- und Erlebnissschatz den zunächst nüchternen Ort zum Ort für uns macht. Ein Ort, der durch die Erlebnisse die wir in ihm gemacht haben, zur Heimat und auf elementar-leibliche Weise mit unserem jetzigen Ich verknüpft wird.

An dieser Stelle stellt sich die Frage, wo eigentlich das Problem liegt? Warum wird Heimat zum utopischen Sehnsuchtsort erklärt und wir gehen nicht einfach zurück zur heimatlichen Scholle? Es lassen sich zwei Probleme anführen:

(a) Sprechen wir von Erlebnissen, so müssen wir über die konstitutionellen Eigenschaften dessen nachdenken, was wir Erlebnis nennen. Hans-Georg Gadamer arbeitet 
treffend heraus, dass jedes Erlebnis aus der Kontinuität des Lebens herausgehoben ist und zugleich auf das Ganze des Lebens bezogen ist (vgl. Gadamer 1960, 75). Er schreibt: „Wenn etwas ein Erlebnis genannt oder als Erlebnis gewertet wird, so ist es durch seine Bedeutung zur Einheit eines Sinnganzen zusammengeschlossen." (Gadamer 1960, 729) Diejenigen, die etwas aus dem Fluss des Lebens heraussondern, indem sie ihm Bedeutung auf beispielsweise seine Heimatlichkeit zusprechen, sind selbst die Träger der erinnerten Erlebnisse, aber wenn sie das Erlebnis auf diese Weise herausstellen, so ist es notwendig vergangen. „Was Erlebnis genannt werden kann, konstituiert sich in der Erinnerung“, stellt Gadamer $(1969,72)$ fest, und auch Bollnow formuliert: „Die Bedeutung, die ein Ereignis in unserem Leben hat, ist nicht im Augenblick des Erlebens selbst zu erfassen, sondern ergibt sich erst nachträglich in dem rückwärts in die Vergangenheit gerichteten Blick der Erinnerung." (Bollnow 1980, 10) Erkennen wir etwas Erfahrenes als Heimat, so ist es vergangen.

(b) Wie erinnern wir uns? Die Form, in der Erlebnisse aus dem Fluss mannigfaltiger Lebensvollzüge zu eigener Gegenständlichkeit werden, muss nun thematisiert werden. Erlebnisse und erst recht das elementare Wissen sind nicht unmittelbar verfügbar. ${ }^{1}$ Sie sind ja gerade durch ihr unbewusstes Darinsein gekennzeichnet. Misch hatte seinen Aufbau der Logik mit der Feststellung begonnen, dass gewisse Ausdrucks-, Bedeutungs- und Sinnformen universell sind und sich in vordiskursiven Wissensformen finden und von dort bis in die menschliche Rede ziehen. Die evozierende Rede ist strukturell analog zu der Form des Erlebniswissens, insofern auch die evozierende Rede erfahrungsgebunden und vollzugsgebunden ist. Aber nicht nur formell sind diese beiden Formen des Wissens analog. Sie sind aufeinander bezogen, da das elementare Leibeswissen und das erfahrungsgebundene Erlebniswissen den Gegenstand stellen, der in evozierender Rede ausgedrückt wird. Wir hatten anfangs festgestellt, dass Misch zwischen einer schrittweise aufbauenden Perspektive und einer solchen Perspektive hin und her geht, die die sprachliche Artikulation an den methodischen Anfang stellt. Die Gegenstände des Elementaren und leiblich Erfahrenen sind gewissermaßen unverfügbar und können erst in sprachlicher Artikulation objektiviert, d.h. zu Gegenständen werden, auf die man sich beziehen kann. Damit ist zwar davon auszugehen, dass sie auf gewisse Weise vorsprachlich zuhanden sind, aber zugleich sind sie erst nachträglich überhaupt fassbar. Das Erlebnis steht uns nicht als Anderes gegenüber, sondern es erfüllt uns. Wir besitzen es bereits in Fülle und wissen von dem, was wir haben, indem das Wissen sich reflexiv auf sich selbst rückwendet. Diese vergegenständliche Objektivierung der erfahrenen Erlebnisse vollzieht sich im Medium der Sprache. Hier stellt sich die Macht des Wortes ein, und zwar so, dass durch die

\footnotetext{
1 Misch fasst dies bündig, wenn er gegen Dilthey einwendet: „[W]ir bewegen uns in einer Ausdruckswelt und nicht in einer Erlebniswelt." (Misch 1994, 78)
} 
Kraft des treffenden Ausdrucks die Bewusstwerdung des Erlebnisses erfolgt (Misch 1994, 512f.). Es handelt sich um einen ursprünglichen primären Zugang zu den uns umweltlich begegnenden Dingen, einem so etwas, das uns begegnet und welches sich im treffenden Ausdruck der Evokation einfangen lässt, bewusst wird, gegenständlich wird, vermitteln lässt und so objektiviert.

Ein evozierender Ausdruck ist nicht an die klassische Satzform gebunden, sondern kann auch größeren Umfang haben, ein Gedicht oder das Ganze eines Romans betreffen, oder sich in einem einzigen treffenden Wort erschöpfen. Auch wenn etwas immer in Sprache ausgedrückt ist, ist der Gegenstand des Sprechens nicht aus einer korrekten Sprachanwendung ableitbar, sondern geht von dem ausgedrückten Gedanken selbst aus, der in einem intuitiven, sprachlichen Erfassen produktiv den treffenden Ausdruck findet, um eben jenes individuelle Gefühl des Wissens darum, wie es ist, etwas lebensweltlich zu erfahren, zu treffen. Die Dynamik der evozierenden Ausdrücke unterscheidet sich von den rein-diskursiven Aussagen dadurch, dass sie nur durch den Vollzug der in ihnen ausgedrückten Bewegung fassbar sind und immer neu vergegenwärtigt und vollzogen werden müssen, um verstanden zu werden (Misch 1994, 37). Hermeneutische Gegenstände sind so an den Vollzug der einzelnen Rede und die in ihr zur Sprache kommenden Gegenstände gebunden. Erst im Zur-Sprache-kommen selbst entstehen die Gegenstände als solche. Misch stellt fest, dass „[w]ährend für die Naturwissenschaften also noch galt, dass Naturwissenschaftliche Begriffe, einmal gewonnen, bestehen und als feste Größe genommen werden können“, evozierende Ausdrücke, gerade an Ausdruckskraft verlieren, wenn sie in terminologischen Gebrauch genommen werden, und „dieses schnelle Sichverbrauchen der Ausdruckskraft eines ursprünglich treffenden Wortes kommt aber daher, weil die Ausdruckskraft an den Vollzug des darin ausgedrückten Wissens gebunden ist“" (Misch 1994, 551).

Auch Heimat ist ebenso eine hermeneutische Gestaltung, die im Vollzug der evozierenden Rede zu ihrem Ausdruck kommt. Wir haben es hier mit keinem Randphänomen der Sprache zu tun, sondern mit einer umfassenden Weise des Menschen, sich selbst zu verstehen. Auch Misch ist eine Untersuchung der spezifischen Form der Versprachlichung der Erlebnisse und deren Bedeutung ein spezielles Anliegen. Das zeigt sich schon daran, dass er einen großen Teil seiner Produktivität darauf verwendet hat, die Resultate eben solcher Selbstäußerungen zu untersuchen. Er versteht Autobiographie als eine Äußerung des Wissens des Menschen von sich selbst (vgl. Misch 1949, 10).

Die menschliche Lebensform unterscheidet sich von allen anderen Lebensformen dadurch, dass sie grundlegend sprachlich strukturiert ist. Mit dem gemeinschaftlichen Vollzug des Sprechens von Sprache - das entwickelt Misch eindringlich im Aufbau der Logik, ohne dass es hier en détail ausgeführt werden kann - entsteht die Möglichkeit von Selbst- 
wie Gegenstandsbewusstsein. Es ist also nicht nur so, dass wir die Möglichkeit haben, einen wie auch immer gearteten mentalen Zustand des Gefühls oder der Wahrnehmung in Sprache auszudrücken und auf die Welt zu beziehen, sondern vielmehr vorhergehend so, dass eben jene Welt in einem ursprünglich zu denkenden Akt sich selbst im Wort objektiviert und so mentale Zustände als bewusste Zustände allererst ermöglicht. Das bedeutet aber auch, dass wir keinen anderen als einen sprachlichen Zugriff auf unsere Erlebnisse haben.

Mischs Schüler Josef König formuliert das in dem Aufsatz Georg Misch als Philosoph:

[D]as primäre Wissen vom Erwirken und von den Erlebnissen überhaupt ist für uns nur in der Gestalt eines im Spiegel des Ausdruck Erblickten da.

Daß die Vergegenständlichung die Erlebnisse in einem gewissen Sinne hervorbringt, korrespondiert dem, daß es Erlebnisse nur in der Gestalt von Zurückgespiegelten gibt. (König 1967, 231)

Das ursprüngliche Eingebundensein und Erleben sind damit in ihrer Unmittelbarkeit nicht mehr zu erreichen. Gadamer formuliert diesen Gedanken: „Erhebung über die Umwelt dagegen ist für den Menschen Erhebung zur Welt und bedeutet nicht verlassen der Umwelt, sondern eine andere Stellung zu ihr, ein freies, distanziertes Verhalten, dessen Vollzug jeweils ein sprachlicher ist." (Gadamer 1960, 448f) Die bewusste Freiheit schafft aber zugleich eine Distanz. Wir versuchen sprechend in einem „zweiten Gang“ in der Redeform des Evozierens die Unmittelbarkeit wieder herzustellen, indem wir uns erzählen, erzählen wie es ist, zu sein. Und da wir eine Lebensform und eine Sprache teilen, so kann es passieren, dass ein Ausdruck trifft und verstanden wird, weil er eine grundlegende Erfahrung evoziert.

\section{Fazit}

Vielleicht ist Heimat ein solcher Ausdruck, der eben jene Unmöglichkeit der Rückkehr in einen kindlich-utopischen Zustand der Selbstverständlichkeit nostalgisch trifft. Nostalgisch, weil wir an der Unmöglichkeit der Rückkehr leiden, denn auch wenn die Orte der gemachten Erfahrungen bestehen bleiben mögen, so sind die Lebensvollzüge in ihnen längst vergangen, und nicht mehr erreichbar, oder eher nie anders als sprachlich distanziert zu erreichen. Spricht der Mensch über Heimat, dann ist anzunehmen, dass sie nicht mehr selbstverständlich ist. Dann befindet sich der Mensch im Exil, sieht seine Lebensweise von Fremden oder Anderem bedroht, oder wendet sich gegen eine fortschreitende Modernisierung, Technisierung oder Globalisierung, die ihn vom locus amoenus seiner selbstverständlichen Zugehörigkeit entfernt. Am Anfang war Heimat heißt ein 2016 erschienenes Buch von Eberhard Rathgeb und der Autor hat recht und unrecht mit dem 
Titel. Heimat muss anfänglich gedacht werden, da sich die Erzählung von Heimat immer auf ein zuvor Gewesenes bezieht, doch zugleich kann Heimat als solche überhaupt erst im Akt der Versprachlichung, im Vollzug ihres Sprechens gedacht werden und entsteht erst, wenn ein Ausdruck es schafft, dass Gefühl des Erlebten zu fassen. Am methodischen Anfang steht das Wort. ${ }^{2}$

Eine Beschäftigung mit Heimat, die diese begrifflichen Eigenschaften nicht bedenkt, ist gefährlich. Denkt man Heimat als real zu errichtenden Ort mit klar umgrenzbaren Eigenschaften, dann wird Heimat problematisch. Ein solcher unreflektierter Heimatforderer versucht, Heimat zu fixieren, ohne zu verstehen, dass ein jeder seine Heimat selbst erzählen muss, weil jede Erfahrung als solche individuell ist. Ein solcher Heimatforderer vergisst, dass Heimat zugeschrieben werden kann und erst recht nicht an nationalen Grenzen und Abstammung fixiert sein muss, sondern, dass man in einem Akt der Anerkennung seine heimatliche Verortung selbst vollziehen muss. Er bemerkt nicht, dass Heimat in dem Moment, in dem er beginnt sie zu fordern, nicht mehr selbstverständlich und einfach erreichbar ist.

Und trotzdem dürfen wir nicht aufhören, über Heimat zu sprechen. Heimat vollzieht sich doch gerade im Erzählen von ihr; eine Erzählung von uns selbst, die davon erzählt, wer wir sind, indem wir erzählen, woher wir kommen. In der Rede von Heimat kann man finden, woher man kommt, woran man krankt, was fehlt, und wohin man will. Beheimatung ist ein identitätsbildender Akt von Individuen wie Gruppen, eine geistige Bewegung, die ihr Ziel in sich selber trägt und die sich im sprechenden Vollzug immer wieder neu hervorbringen muss. Ein in diesem Sinne aufgeklärtes Sprechen über Heimat ist wichtig, wenn das Selbstverständnis angesichts immer weniger Selbstverständlichkeiten neu stabilisiert werden muss.

\section{Literatur}

Bastian, Andrea. 1995. Der Heimat-Begriff. Eine begriffsgeschichtliche Untersuchung in verschiedenen Funktionsbereichen der deutschen Sprache. Berlin: De Gruyter.

\footnotetext{
2 Maja Soboleva kommt in ihrem jüngst erschienenen Aufsatz Ist, Heimat' ein Mythos? Der Heimatbegriff zwischen Bezeichnung und Bedeutung (2020) zu dem Schluss, dass Heimat atopisch und achronisch verstanden werden könne (vgl. Soboleva 2020, 520). Da eine örtliche Bindung nicht notwendig sei und Heimat „nur im Moment des Sprechens (Denkens und Vorstellens) vorhanden ist“ (ibid., 522), deutet sie Heimat letztlich als Mythos, der lediglich "reine" Bedeutung und „ideellen Charakter" enthalte (ibid., 527). Hier wird hingegen behauptet, das Sprechen über Heimat stehe am methodischen Anfang, verweise aber zugleich auf ein zuvor Erlebtes, welches durchaus örtlich gebunden sein kann. Heimat ist nicht konstruktivistisch zu denken, sondern die Aufgabe besteht vielmehr darin, die Verweisstruktur der Heimatrede ernst zu nehmen, aber zugleich als Akt sprachlicher Anerkennung zu verstehen. Damit hat die Rede über Heimat die eigenwillige zeitliche Struktur einer gleichzeitigen Vorzeitigkeit.
} 
Bollnow, Otto Friedrich. 1980. „Lebensphilosophie und Logik. Georg Misch und der Göttinger Kreis“, Zeitschrift für philosophische Forschung, Bd. 34, Heft 3, 423-440.

Bollnow, Friedrich Otto. 1983. Studien zur Hermeneutik. Band II: Zur hermeneutischen Logik von Georg Misch und Hans Lipps. Freiburg und München: Alber Verlag.

Gadamer, Hans-Georg. 1960. Wahrheit und Methode. Grundzüge einer philosophischen Hermeneutik. Tübingen: J. C. B. Mohr (Paul Siebeck).

Heidegger, Martin. 1983. „Sprache und Heimat“. In Martin Heidegger: Aus der Erfahrung des Denkens 1910-1976, Bd. 13, 155-180. Frankfurt am Main: Vittorio Klostermann.

Heinrich Becker, Hans-Joachim Dahms, Cornelia Wegeler (Hg.). 1998. Die Universität Göttingen unter dem Nationalsozialismus. München: K. G. Saur.

König, Josef. 1967. „Georg Misch als Philosoph“, Nachrichten der Akademie der Wissenschaften in Göttingen, Nr. 7, 152-243.

Krockow, Christian Graf von. „Heimat.“ Die Zeit, 05.10.1984.

Misch, Georg. 1949. Geschichte der Autobiographie, Bd. 1. Frankfurt am Main: Schulte-Bulmke.

Misch, Georg. 1994. Der Aufbau der Logik auf dem Boden der Philosophie des Lebens. Göttinger Vorlesungen über Logik und Einleitung in die Theorie des Wissens. München: Alber Verlag.

Platon. 1977. Laches. In Platon. Werke in acht Bänden. Griech. u. dt., Bd. 1, herausgegeben von Gunter Eigler. Darmstadt: Wissenschaftliche Buchgesellschaft.

Rathgeb, Eberhard. 2016. Am Anfang war Heimat. Auf den Spuren eines deutschen Gefühls. München: Karl Blessing.

Weingarten, Michael. 2003. „Leben (bio-ethisch).“ In Bibliothek dialektischer Grundbegriffe, Bd. 2, herausgegeben von Andreas Hüllinghorst. Bielefeld: transcript.

Seehofer, Horst. „Dort sagt mir jeder Baum eine Geschichte. Horst Seehofer im Gespräch mit Tina Hildebrand und Andreas Lebert." Die Zeit, 16.03.2019.

Soboleva, Maja. 2020. „Ist „Heimat‘ ein Mythos? Der Heimatbegriff zwischen Bezeichnung und Bedeutung “. Deutsche Zeitschrift für Philosophie: Zweimonatsschrift der internationalen philosophischen Forschung, 68(4), 514-531. 


\title{
At Home, at Mine (chez moi). Return to Oneself
}

\author{
Petar Bojanić \\ University of Belgrade (Serbia) \\ University of Rijeka (Croatia)
}

\begin{abstract}
My intention is to reconstruct three "relational notions" (Popper) - house, homeland, and nostalgia - in order to show the violent strategies that determine them and on which they depend. Nostalgia and the idea of returning

to "oneself", along with various protocols of affirmation of identity, birth, and dwelling, imply interruption of
\end{abstract}

war and violence while also allowing for their possibility and renewal. The text affirms Clausewitz's notion of friction and reveals its potential for any possible theory of peace.

Keywords: nostalgia, house, homeland, friction, war

(c)Petar Bojanić; bojanic@instifdt.bg.ac.rs,bojanic@cas.uniri.hr

Colloquium: New Philologies, Volume 6, Issue 1 (2021)

doi: 10.23963/cnp.2021.6.1.9

Stable URL: https://colloquium.aau.at/index.php/Colloquium/article/view/155

This work is licensed under a Creative Commons Attribution 4.0 International License (CC BY 4.0). 


\section{Ich will heim, Ich will heim}

To reach the title and that which interests me most - the word "Heimat" - I would first like to take a roundabout way to also look at a few moments, perhaps crucial for a deconstructive or detective methodology.

First, I am interested in whether the house is an institution (an institution usually concerns a group of people - a minimum of three) and in the moment when it becomes an institution (which would be, for example, when it is defended or hosts an outsider, a guest, or is destroyed and exists only in the memory of a group of people, or serves as quarantine and protection against a virus). The house I mention is tied to the citizen returning (a citizen is by definition one who has exited the interior of the house and is affirmed by being in the spaces between houses), returning to a house that still in some way belongs to them. It is certainly not merely a house which one leaves or from which everything begins. ${ }^{1}$

Second, the homeland (the Serbo-Croatian words "dom" and "domovina" follow the English or German relation of home and homeland) implies a house that is not temporary or transient, and thus always more than a house as such: It is the surrounding landscape, the environment, homestead, and hearth tied to land and village, a city neighborhood, a territory ('territorial imperative' is Robert Ardrey's 1966 phrase).

Third, I would like to consider the action or activity that best describes what we call 'homeland' (Heimat). What action or engagement is crucial to confirm Heimat? In other words, in a paradox that perhaps explains this complicated construction better than anything, what protocol affirms the homeland by negating it?

I am certain that the discussion of Heimat must always begin anew with words that ought never to be ignored in the complicated histories of the phenomenon or figure or Mythos of "Heimat".

\section{Ich will heim, Ich will heim}

In paragraph 4 of his thesis Nostalgia oder Heimwehe, defended June $22^{\text {nd }} 1688$ at the Medical Faculty of the University of Basel, Johannes Hofer describes the grave injury and agony of a young peasant woman from a village near Basel. After falling from a certain height, she lay unconscious for several days and came to only after the application of various remedies and surgeries conducted in improvised conditions. Awaking and seeing unknown women taking care of her, she is overcome by nostalgia [Nostalgia statim corrept], says Hofer, after which she refuses all food, answering all questions with a single

1 "Home is where one starts from." (Eliot 1941, 26) 
phrase: "I want to go home. I want to go home." Her parents ultimately accept that she return home, even in her weak state [Tandem ergo a parentibus licet maxime imbecillis domum est delata] (Hofer 1688, 8; English translation 1934, 376-391), after which her condition improves suddenly and without any medication whatsoever. Hofer presents another case in the same paragraph: that of a young student from a wealthy family who travels to Basel for his studies but falls gravely ill. His condition improves rapidly after being sent home. These two cases allow Hofer to construct his argument about the appearance of an entirely new and unusual illness, explaining why Swiss soldiers were getting sick in large numbers.

What do I/we mean when I/we say, "I want to go home?"

The 'study' of nostalgia is tied to a vehement love for one's homeland, ${ }^{2}$ and as such nostalgia is a condition of interruption of war, as well as the condition for new war and violence. To begin with, or even before any beginning, in a preamble to any true study of nostalgia [die Heimweh-Lehre] (Ernst 1949, 57), let me offer two explanations or justifications that might support the framework of this text, or an introduction of the magical simulation of returning home, to oneself, to one's mother.

1. Hofer is the first to use the word "nostalgia" to indicate something well-known before him. He attempts to compile various cases defending the existence of an illness, as well as indicate treatments. The Swiss doctor's effort is only the beginning of a very long history of reconstruction of this phenomenon. Note that he arrives at a diagnosis of "nostalgia" by investigation or a "talking cure" with a patient. (Often, the therapist discovers entirely by accident that the patient's "state" is altered when either mentions the word "home", "childhood", "home region". This means that the therapy consists of recalling the patient's past, making the process of recollection overlap with the process and time of "recovery" in didactic form.) It is also interesting that this illness is "discovered" in conjunction with other problems (a fall from great height and a grave wound of the above-mentioned young woman; difficult course of study in a foreign land; great exertion on the part of the soldiers, etc.). All these other difficulties instigate a kind of retreat, regression or retardation, a desire to return, a going back ('to oneself', 'home', 'one's own', 'the before', 'to one's mother,' 'into coziness', 'indoors', 'inside,' 'the womb', ...). They cause a general state of insecurity, instability, and loss of solid ground under one's feet. The presentation of "nostalgia" could arouse violent behavior towards oneself or others since it requires a backwards move. The illness, paradoxically uniting women and soldiers, those committed to institutions and those expelled, those locked up and those lost, the

2 "Si cui verò magis arrideat Nostomanias aut Filopatridomanias appelatio, perturbatum animum ob impeditum in Patriam à qualicunque causa reditum denotans, per me omninó licebit." (Hofer, in Ernst $1949,62)$ 
displaced and renegades (the "illness" was noted in Switzerland across several languages, borders, and regions), assumes the existence of some obscure obstacles and presumes that it has to be "resolved" and be "liberated from" by someone else. The illness (which today has been relegated to "feeling" or "mood") is an expression of quiet or passive resistance in the form of disobedience, blindness, and rejection of authority. For example, there is rejecting the authority of parents who press their daughter into work and then have to accept her return from a far-away place; or rejecting the authority of the homeland, authority of a country's army over an individual, which yields before the illness to allow the recruit to return home. As a resistance to a higher or more powerful instance or force, nostalgia acquires the status of "alleged" illness that serves to malinger (avoid war, duty, work, service, discipline, community), while therapy for this supposed illness would only simulate - and thus confirm - its existence. Various quack doctors, from Hofer to Freud testify that it is enough for the patient to merely think, or utter, that they want to go home in order to feel better. In the same vein, it is also enough to convincingly malinger and simulate this illness to obtain "leave" from the authoritative body. In order to return home, it is enough to write, incessantly write.

2. Still, why is the construction or symptom of this alleged illness ("illness") present as the statement "I want to go home" [Ich will heim]? Why does nostalgia assume a register of speech turned to oneself, one not necessarily 'from oneself', 'from I', from speech in scare quotes, and why does it indicate a will to return? Once again, what do I/we mean when I/we say "I want to go home?"

And of course, what does "being at home" (chez moi) even mean? ${ }^{3}$

Presently, I would like to present a few ways in which nostalgia (or an "epidemic of nostalgia" ${ }^{4}$ ) is "paradoxical". I would like to describe its contentious nature, and explain the connection between nostalgia and the word "frictions" (which I write in italics and

3 Let us look at the way Paul Celan thematizes this 'chez moi. On the last page of Jean Améry's book Jenseits von Schuld und Sühne. Bewältigungsversuche eines Überwältigten (1966), Paul Celan notes "Heimat, Und Ich ? Ich war nicht einmal zuhause, als ich daheim (zuhause) war" (in Badiou’s translation: "Pays natal... Et moi ? Je nétais même pas à la maison, quand j’étais chez moi (à la maison)" (Celan 2004, 451, 459). Here we have Celan reading Améry's essay "Wieviel Heimat braucht der Mensch?" in this book, encountering the sentence "Ich war kein Ich mehr und lebte nicht in einem Wir." Heimat implies the existence of something more intimate than community as such - the existence of "Wir" and the belonging to that "Wir". Such a "Wir" is a fictitious first entity that implies any future thematization of Heimat or loss of Heimat. Heimat, entirely different for all members of a community, becomes the integrative factor for all of us, making us closer and more equal as members of the community. We are connected if and only if each belongs to their own native land, that is to say everyone is at home. The condition that we are all together is satisfied if each of us is in their own (real) placeand belongs to their original "Wir". One without a native land, paradoxically, is not part of the community or not part of us all. One without their "Wir" does not exist or will soon cease to exist.

4 In Greek, epidemos designates the awareness of a Greek man belonging to his homeland; it stands in contrast to the word apodemos, which describes a state of suffering due to being far away from one's homeland. 
plural). Clausewitz was the first to "produce" this word into a notion and used it exclusively in the singular. In German and in Serbo-Croatian, nostalgia is feminine and designates friction. For Clausewitz, nostalgia (mal du pays or "mocka nо pодине" as Vladimir Jankélévitch [1974, 276 $]^{5}$ reminds us) is indeed another element that leads to friction, obstructs military operation, invites desertion, interrupts war and brings peace. And vice versa: the return home is a return to a new war. Histories of return, from Homer, Virgil, and Dante, assume a certain conduct of violence (on his way home, Odysseus constantly uses cunning, cheating, murder; or elsewhere, fleeing violence does not prevent Aeneas from also committing it). Remaining in one's birthplace, in the province, introduces us all too easily to sundry visions of protection and safety, that is, it incites us to search for the guardian of the house, the sovereign and master.

When I say paradox I mean that nostalgia is always surrounded by some kind of violent strategy (which is, after all, the nature of any knot, riddle, or aporia). Tarkovsky further explicates this "paradox" ${ }^{6}$ He adds the Cyrillic letter " $\mathrm{H}$ " (Nostalghia) to the title of his film to prevent Italian viewers from reading it as if it were their word, and while Andrei speaks Italian in the film, his inner monologues are in Russian. The film is "soaked" with water constantly leaking (gathering, running off, seeping through), and Andrei's dialogues are in Italian while his inner monologues are in Russian. Between minutes 15 and 17, Andrei insists that poetry, like music, cannot be translated; that is that no one (in this case, the Italian woman) has any idea about Russia. When his own translator Eugenia attempts to soften these words, mentioning that the translator of the Russian poet Tarkovsky into Italian is himself a poet and that translation is necessary for people to interact, Andrei first notes how miserable (we) Russians are in not being able to understand Dante, Petrarch, and Machiavelli, and offers his maximalist recipe of communal life and mutual understanding: "Borders should be destroyed [distruggere le frontiere]", "state borders should be destroyed [dello stato]."

Should we immediately forget these two last sentences ("borders" in the plural, "state" in the singular; "destruction" as a surprisingly brutal word), as these words are arbitrary and seemingly uttered without any additional motivation? How can we connect and hold together two positions: that there is something in me (such as something "Russian") which is entirely "my own" and obscured from others, and at the same time a demand for states and borders to be destroyed? If the state (singular) did not exist, would we really be together, would we have a single language, and would individual memories thus

5 Jankélévitch's text on nostalgia is the sixth chapter, 276-313.

6 "I wanted to make a film about Russian nostalgia - about the particular state of mind which assails Russians who are far from their native land. I wanted the film to be about the fatal attachment of Russians to their national roots, their past, their culture, their native places, their families and friend." (Tarkovsky 1989, 202) 
disappear, and with them nostalgia? Or conversely, is nostalgia awoken by the thwarted return (for example, I have run away and now no longer possess papers allowing me to return)? Or, in order to arrive in the first place, do I have to destroy all obstacles on my way? A solution to this confusion in Tarkovsky's dialogue could be found in the histories of construction discourses on nostalgia. From Johannes Hofer and Rousseau to Jaspers, Heidegger, Popper or Freud, it is perhaps possible to eke out a few moments that determine the figure of nostalgia.

a) Nostalgia (just like allergy, homoeopathy, etc.) is an invented Greek word and a great etymological construction (das Heim-weh is also a new German word) created by Hofer in his late seventeenth-century dissertation, and which he juxtaposes with the French phrase Maladie du Pays (cf. Dodman 2018, 22). Hofer (although by no means he alone) lived in the Alps, was in touch with the Italian, German and French languages, wrote his thesis in Latin, and constructed the word for "his own" illness in Greek: nostos is Reditum in Patriam (the 1779 German translation renders this as "die Rückkehr ins Vaterland"), while algios is dolorem aut tristitiam in Latin [and Schmerz oder Betrübnis in German], and weh from das Heim-weh (Ernst 1949, 62-63).7 “'Homeland', 'return to the homeland' and 'pain' are the first and basic elements of nostalgia.

b) Nostalgia was first an illness, then a feeling (Bernet 2006, 87), then a state or mood [Heimwehverstimmung] for Jaspers, and finally, a linguistic or discursive product [DiskursProdukt] (cf. Bunke 2009, 25). Nostalgia first referred to the homeland or fatherland (Zwinger and Hofer came up with Pothopatridalgija and Filopatridomanija ${ }^{8}$ ), and quickly becomes a cry for a return to one's home (Ich will heim), to one's parents, loved ones, childhood, etc. Finally, Freud speaks of prenatal separation: the fact that the female sex organ [das weibliche Genitale] has something Unheimliches for "neurotic persons", reveals the entrance to one's ancient homeland [alte Heimat], towards which all humanity turns. Liebe ist Heimweh (2001, 112-113), Freud continues in the same passage, quoting a traditional saying that explains the nature of the unconscious as an encounter with the unbeimlich. ${ }^{9}$

\footnotetext{
7 The most detailed etymological analysis of the word nostalgia and the German Heimweh can be found in Nostalgie in der Geschichte der Medizin by Klaus Brunnert (1984, 29-43). In the introduction, Brunnert finds that prior to Hofer there were two traces of nostalgia being recognized as an illness or a medical phenomenon: Six Spanish soldiers between 1634 and 1644 during the Thirty Years' War were declared to be suffering from el mal de corazón or estar roto, while the word Heimweh was used for the first time in 1569 by Ludwig Pfyffer von Altishofen.

8 Hofer, writing De Hydrope uteri [uterine water], joins filia with patria and mania, while Zwinger reprints Hofer's dissertation in 1710 under a different title, De Pothopatridalgia, vom Heimwehe, systematically replacing the word nostalgia with pothopatridalgia (potos, patris, algos) (Prete 1992, 60).

9 Freud prefers Schelling's explanation of this untranslatable word: "this word designates what ought to remain a secret, hidden [im Verborgenen] ... and yet has appeared [hervorgetreten]." (Freud 2001)
} 
c) The illness first affected Swiss soldiers serving in the French or some other foreign army. Later, even toward the late nineteenth century (Jaspers' dissertation is the last great systematic attempt to examine nostalgia in the context of crime and violence), ${ }^{10}$ the paradigmatic patients are girls sent by their parents to boarding schools or to work in other family homes, as au-pairs and maids. They murder the children they care for or set fire to the houses in which they work, all with the aim of being sent home .

d) Music or various patriotic songs rouse epidemics of great nostalgia among soldiers, as witnessed by military doctors and generals. Jean-Baptiste Du Bos, writing in 1719, says that in less than three months, more than six thousand people died in a single city. Rousseau, in a letter to Marshal de Montmorency-Luxembourg of January $20^{\text {th }} 1763$, writes about the song ranz-des-vaches, mentioning the illness this song causes, called Hemvé (Rousseau 1972, 52). Dukes and commanders passed the death sentence on those singing such songs.

e) "Nostalgia is a form of melancholy caused by the ennui of being with foreigners who do not like us. It seemed to me that I had discovered", writes Albrecht von Haller in the Dictionnaires des Sciences, des Arts et des Métiers in 1777, "that one of the reasons for nostalgia lies in the political order of Switzerland. Very few foreigners frequent there and nearly none is able to remain since the right to live there is tied to birth and blood. [...] families from the same place (in the Alps) marry amongst each other, almost never mixing with outside blood."11

The always assumed but never sufficiently elaborated connection between nostalgia and melancholy is usually bridged with a "third" element that both have in common: "the loss of a loved person, or to the loss of some abstraction which has taken the place of one, such as one's country, liberty" (Freud 1964, 243), "loss of object" (Agamben 2006), "awareness of something distant, consciousness of something far away (conscience d'un ailleurs), the awareness of contrast between the past and present, between the past and future" (Jankélévitch 1974, 280-281), hypochondria or hysteria. ${ }^{12}$

${ }^{10}$ In his thesis, Jaspers (1963 [1909], 1-84) analyzes twenty case of serious crimes rooted in the desire to end exile and forcibly return to one's parental home.

11 "I have seen this malady several times and can speak of it with certainty. It is melancholy caused by a strong desire to see one's parents..." (Ernst 1949, 116-117).

${ }^{12}$ A medical report on the state of some freshmen cadets of the Naval Academy in Annapolis states that "melancholy and nostalgia are the most common symptoms of the hysterical state of these young boys" (cf. Bunke 2009, 240). 
f) The only remedy for this illness is a return to one's homeland and home. Various cases from the eighteenth and nineteenth century show that just thinking about returning (or just departing for home) is sufficient to improve the mood or even recuperate. ${ }^{13}$

g) The history of nostalgia is a history of "cases", testimonies, but also confessions. In $\$ 30$ of Anthropology, Kant says that an experienced general told him about the nostalgia of the Swiss. When they finally do return to their mostly poor regions, their homeland, they still do not find the time of their childhood.

h) Nostalgia is pure fiction (Nostalgie feinte [nostalgia simulate] (Bunke 2009, 116117), ${ }^{14}$ in the words of Meyserey or de Sauvages in 1763, and later Starobinski) and exclusively a symptom of the presence of another illness. It is malingering and "contagious" in so far as it is transmitted by talking (discourse, discussion, conversation, in words). ${ }^{15}$

Now, the last two examples that construct the great history of the figure of nostalgia should be thought first and always together. As soon as Andrei (Tarkovsky) utters the words "No one understands me (us)", or "Borders should be destroyed", there is something prearranged and pathetic, something "hypocritical" in nostalgic protocols. Still, it will certainly not be sufficient to simply displace nostalgia, as some kind of fantasy, into literature or pure fantasy. Kant attempted to liberate nostalgia from its spatial dimension, to determine it economically and ascribe it to the poor. He sought to remove it entirely from the homeland (because the return to homeland leads to death, Qui Patriam quarit, Mortem invenit ${ }^{16}$, but also because the homeland is where all is well [patria ubi bene]. In this way, Kant opposed the nineteenth-century notion of the European hungry for gold, digging for it on another continent, anxiously awaiting his return home ${ }^{17}$ - all of which is dealt a death blow by Martin Heidegger and the hermeneutics of old texts. It is not only a matter of Heidegger's reduction of everything to nostalgia and discovery of hidden nostalgia [verborgene Heimweh], or a return to linking Heimweh with

\footnotetext{
13 "The source of this despair was not difficult to reveal. I say reveal, for it was nearly impossible to pry a confession from this type of patient, none would admit what he suffered. They were all, so to speak, ashamed about the pain they felt, although they were betrayed by the joy that would sparkle in their eyes at the mention of promised leave." From the report of Denis Guerbois, army surgeon and first person to defend a thesis on nostalgia in French (1803). The quote is from A. Bolzinger $(2003,101)$.

${ }^{14}$ F. B. de Sauvages differentiates between three types of nostalgia: simple [simple], which is common among soldiers and can be repressed on the condition that soldiers find ways to have fun, can be dissuaded, or are on occasion given what they want (i.e. a return home?); complex [compliqué], which cannot be cured by any medicine but only if the soldiers actually run away or go home; and feigned [feinte], that is, simulated and imagined in order to avoid service (cf. Ernst 1949, 96-100).

15 Two famous texts by Starobinski attempt to show the fictitious nature of nostalgia: J. Starobinski, "The Idea of Nostalgia" (1966) and "Sur la nostalgie. La mémoire tourmentée" (2003).

${ }^{16}$ In his most detailed analysis of nostalgia to date, Simon Bunke interprets this position by Bernandino Ramazzini from 1700 on pages 90-92 (cf. Bunke 2009).

${ }^{17}$ P. Pinel, “Encyclopédie méthodique. Médicine” (1821) (Prete 1992, 740).
} 
Heimat (soil, house, or roots) but there is also an insistence on the importance of 'proximity', 'one's own', and then a hysterical repetition of a never fully deconstructed idea taken from Humboldt about the inseparability of language [Sprache] and homeland [Heimat]. It seems to me that Humboldt's famous sentence from his 1827 letter to Charlotte Diede, "Die wahre Heimat ist eigentlich die Sprache" (Von Humboldt 1848, 322) - with all its various incarnations and repetitions from Fritz Mauthner, Else Lasker-Schueler and Hannah Arendt to Derrida and Gadamer - still fits well in Heidegger's speech on the occasion of the $700^{\text {th }}$ anniversary of his hometown of Messkirch: "Unsere Sprache nennt den Zug zur Heimat das Heimweh" (Heidegger 2000, 578). What we should recognize in the strength of language - the strength of our language to name our own aspiration with the word "nostalgia" ( $Z u g$ is a sudden, fierce, and abrupt tug) - is the passion towards the homeland with which Tarkovsky at once excludes other languages and protects his own interior Russian language. It is the same force that calls for the destruction of borders.

I would like to insist on the point that Heidegger's 'return' from the Alps to the Alps, to Schwarzwald (such as in Hoelderlin's poem "Heimkunft", analyzed in detail by Heidegger, in which the poet returns in 1801 from Switzerland to his home region). Namely, this always assumes a return to traditional characteristics and uniforms: Nostalgia, in a word, revives nausea and war-time uncertainty. Further, it seems that several of Heidegger's most important inversions regarding Heimat still remain in the registers of nostalgia and thus produce or assume violence. Heidegger's (or Andrei's) insistence on the untranslatability of language, as well as on "private language", nurtured regional dialects, the power of the idiomatic (which is to say one's own region) all fit within the various theories of the 'unrepeatability' of the other, which we see in the theories about the foreigner or the Other in Lyotard, Levinas, or Deleuze. In demonstrating that no author feels at home in their language and that all language, even one's mother tongue, is completely foreign, Deleuze paradoxically reiterates Heidegger's and Andrei's position that there is something within us that is exclusively "ours" (untranslatable, unrepeatable, indivisible with others, incomprehensible to others, uncommunicable, and unpresentable). To be a foreigner or the Other assumes the existence of a homeland (such as Israel in Levinas, or some imaginary territory outside a given state's territory) even when it is claimed that the time of the house has irretrievably passed (Adorno 1951, $₫ 18^{18}$ ). The sentence "No one understands me (us)" (a position that includes the sentence "I want to go home") produces irreducible difference and foreigners, that is to say, a foreigner who necessarily

\footnotetext{
${ }^{18}$ One of the available English translations is rather infelicitous: "not to be at home in one's home." "Es gehört selbst zu meinem Glücke, kein Hausbesitzer zu sein', schrieb Nietzsche bereits in der Fröhlichen Wissenschaft. Dem müßte man heute hinzufügen: es gehört zur Moral, nicht bei sich selber zu Hause zu sein." (Adorno 1951, 58)
} 
produces foreigners around them. In that same way, the sentence "Borders should be destroyed" (which can also assume the line "I want to go home" if understood as "I do not wish to have any obstacles on the way home") assumes that the world ought to be one big house, and we always be at home. Learned people and philosophers (socalled intellectuals) - this is always the warrant and preliminary conclusion - ought to turn the world into a home because "philosophy is true nostalgia, desire to be at home anywhere" [Die Philosophie ist eigentlich Heimweh, ein Trieb, überall zu Hause zu sein] - a title by Novalis that Heidegger analyzes in $₫ 2$, at the beginning of the 1929 winter semester (Heidegger $1983, \S 2 b, 7-10){ }^{19}$

It seems to me that if the institution of philosophy would like in the future to free itself from such monstrous constructions - to find its own space once again between the houses, in the streets ${ }^{20}$ - it is not enough to merely follow and re-actualize Kant's sobering positions on true philosophizing that protects us from illnesses of the mind, from longing [Sehnsucht] for other worlds, and also from nostalgia [Heimweh]. ${ }^{21}$ It is imperative for the institution of philosophy to continuously uncover and acknowledge its explicit and implicit responsibilities for sundry wars and violence in history. ${ }^{22}$

Why then do I need von Clausewitz's "friction" [Friktion] to describe how nostalgia functions? Clausewitz first mentions the word Friktion in a letter (September 29th 1806) to his future wife. He writes of difficulties that one of the commanders, Scharnhorst, had in running the Prussian army; Clausewitz considered him as very talented, but says he

${ }^{19}$ We certainly need an analysis of the later interpretations and transformations of this "saying" by Novalis in Lukacs (in The Theory of the Novel) and Adorno and Horkheimer (in Dialectic of the Enlightenment).

20 This project actually requires the reconstruction and revalorization of one of Karl Popper's first texts, "Zur Philosophie des Heimatgedankens" (1927). Popper is very precise in defining Heimat and the house as relational notions, insisting on the importance of education that 'demystifies' the dogmatism of the house and the closure of the homeland. Here are Popper's opening lines: "The notion of homeland is certainly a prime example (Musterbeispiel) for what is, in contrast to the clear logical concept, called a 'psychological notion:' a collection of more or less vague notions, memory images, joined by a few elements of terminological nature ('place of birth')" (Popper 2006 [1927], 10).

21 “Der Kritik der reinen Vernunft ist ein Präservativ für eine Krankheit der Vernunft, welche ihren Keim in unserer Natur hat. Sie [diese Krankheit; Erdmanna's addition] ist das Gegenteil von der Neigung, die uns an unser Vaterland fesselt (Heimweh). Eine Sehnsucht, uns ausser unserm Kreise zu verlieren und andere Welten zu beziehen.” Note 5073, written between 1776 and 1778 (Kant 1928, 80).

${ }^{22}$ It is also imperative to revive and analyze some complicated and entirely forgotten positions. One such is recalled in 1952 by Erich Auerbach towards the end of "Philologie und Weltliteratur" (translated into English by Maire and Edward Said). Auerbach mentions a passage from Hugh of Saint Victor (from Didascalicon III, 20), a twelfth-century Saxon monk, on exile as a mode of life preferred by the man of learning: "It is, therefore, a great source of virtue for the practiced mind to learn, bit by bit, first to change about in visible and transitory things, so that afterwards it may be able to leave them behind altogether. The man who finds his homeland sweet is still a tender beginner (delicatus); he to whom every soil is as his native one is already strong (fortis); but he is perfect to whom the entire world is as a foreign land (perfectus vero, cui mundus totus exsilium est). The tender soul has fixed his love on one spot in the world; the strong man has extended his love to all places; the perfect man has extinguished." (Auerbach 1969, 17) 
would become completely paralyzed and pacified in the face of constant friction of other, different opinions. Scharnhorst cannot resist the friction 'emitted' by various advisors in the headquarters or in his offices and cannot make the decision to start up the 'war machine.' This example allows Clausewitz to imagine a grandiose military leader who would use his force of will to defeat anything in his way, that is, the myriad frictions of various elements. Anything that slows down the "movement" of war, all the obstacles and problems that obstruct military activity, paradoxically bother the commander, interrupt fighting, and probably bring peace. In Chapter Seven, "Friction in War" [Friktion im Kriege], of his book on war, Clausewitz writes:

Friction is the only concept that more or less corresponds to the factors that distinguish real war from war on paper [was den wirklichen Krieg von dem aufdem Papier unterscheidet]. The military machine [militärische Maschine] - the army and everything related to it - is basically very simple and therefore seems easy to manage. But we should bear in mind that none of its components is of one piece: each part is composed of individuals [Individuen], every one of whom retains his potential of friction. (Von Clausewitz 2007 [1832], 66)

Contrary to Clausewitz, but thanks to him, we know that if we wish to somehow interrupt war or foil it, it would appear that we must make things more, not less complex, always introducing new elements into play, onto the stage, into the open. We should also pay particular attention to what Clausewitz calls the "war on paper". Nostalgia is certainly one of the most important frictions; it obstructs and temporarily interrupts aggressive war, opening space for defense. Soldiers daydream of their homes; let us imagine them slowly returning to their homelands and houses. Yet, does the existence of one's house not already assume the readiness to protect it - protect and secure the idea of ownership, hide the path towards it, destroy (for oneself) the obstacles and borders on that path, to defend (with others, certainly) the "principle of the house" from less nostalgic intruders? Consider, as an illustration of this paradox, the Serbo-Croatian verb "braniti": it is the root verb of both odbrana, defense, but also zabrana, prohibition. The phrases braniti kucu and braniti princip kuce could be translated as defending the house, that is, defending the principle of the house; but they also mean banning or barring (the other) from the house, thus denying (to others) the house, denying them the principle of the house. The existence of one's own house, always a latent "nostalgia on paper", implies the existence of a house that is no longer a house, holding continuous conflict [stasis] of ideas, sex, gender, engendering, generations... a house in whose name it is impossible to go to war and for which it is impossible to fight. For this reason, Clausewitz's phrase, "war on 
paper", can, paradoxically, as both a fantasy and fiction of pure war - as friction - stop war and bring about peace. Still, I do not think war can be prevented if it is idealized, continuously constructed and planned, or incessantly written about. "War on paper" is above all supposed to evoke the origin of nostalgia in melancholy and in the misery of (learned) scholars [mysery of schollers] (Burton 1927 [1621],259-261), and means that there is an indestructible connection between nostalgic soldiers and experts for justifying the right to war and killing.

\section{Literatur}

Adorno, Theodor W. 1951. Minima Moralia. Reflexionen aud dem beschädigten Leben. Frankfurt am Main: Suhrkamp.

Auerbach, Erich. 1969. “Philology and Weltliteratur.” The Centennial Review 13 (1): 1-17.

Agamben, Giorgio. 2006. Stanze. La parola e il fantasma nella cultura occidentale. Torino: Einaudi.

Bernet, Rudolf. 2006. "Heimweh und Nostalgie." In Utopie. Heimat, herausgegeben von Martin Heinze, Dirk Quadflieg und Martin Bührig. 103-118. Berlin: Parodos Verlag.

Bolzinger, André. 2003. "Il y a deux cents ans, premières thèses parisienne sur la nostalgie." L'évolution psychiatrique 68 (1): 97-107.

Brunnert, Klaus. 1984. Nostalgie in der Geschichte der Medizin. Düsseldorf: Triltsch Druck und Verlag.

Bunke, Simon. 2009. Heimweh. Studien zur Kultur-und Literaturgeschichte einer tödlichen Krankheit. Freiburg: Rombach Verlag.

Burton, Robert. 1927 [1621]. The Anathomy of Melancholy, edited by Floyd Dell and Paul Jordan-Smith. New York: Tudor Publishing Co.

Celan, Paul. 2004. La bibliothéquephilosophique, ed. Alexandra Richter, Patrick Alac and Bertrand Badiou. Paris: Editions Rue d'Ulm.

Dodman, Thomas. 2018. What Nostalgia Was. War, Empire and the Time of a Deadly Emotion. Chicago: University of Chicago Press.

Eliot, Thomas S. 1941. Four Quartets, Part II, “East Coker”. London: Harcourt.

Ernst, Fritz. 1949. Vom Heimweh. Zürich: Fretz \& Wasmuth Verlag.

Freud, Sigmund. 1957. "Mourning and Melancholia." In The Standard Edition of the Complete Psychological Works of Sigmund Freud, Volume XIV (1914-1916): On the History of the PsychoAnalytic Movement, Papers on Metapsychology and Other Works, edited by James Strachey, 237258. London: The Hogarth Press and The Institute of Psycho-analysis.

Freud, Sigmund. 2001. Das Unheimliche und andere Texte: L'inquiétante étrangeté et autres textes. Paris: Gallimard.

Goddard, Jean-Christophe. 2006. "Schelling ou Fichte. L'être comme angoisse ou l'être comme Bonheur." In Le Bonheur, ed. Alexander Schnell. Paris: Vrin. 
Hofer, Johannes. 1934 [1688]. Dissertatio medica de Nostalgia, oder Heimwehe. Basel. English translation by Carolyn Riser Anspach. "Medical Dissertation on Nostalgia by Johannes Hofer, 1688." Bulletin of the Institute of the History of Medicine 2 (6): 376-391.

Heidegger, Martin. 1983. Die Grundbegriffe der Metaphysik. Welt-Endlichkeit-Einsamkeit, GA 29/30, herausgegeben von Friedrich-Wilhelm von Herrmann. Frankfurt am Main: Vittorio Klostermann.

Heidegger, Martin. 2000. “700 Jahre Messkirch.” In Reden und andere Zeugnisse eines Lebensweges 1910-1976, GA 16, herausgegeben von Hermann Heidegger, 574-582. Frankfurt am Main: Vittorio Klostermann.

Jankélévitch, Vladimir. 1974. L'irréversible et la nostalgie. Paris: Flammarion.

Jaspers, Karl. 1963 [1909]. Heimweh und Verbrechen. (Diss. Med). In Gesammelte Schriften zur Psychopathologie, 1-84. Berlin; Göttingen; Heildelberg: Springer Verlag.

Kant, Immanuel. 1928. Kants gesammelte Schriften, Vol. 18, Kants handschriftlicher Nachlass 3 , 5. Berlin: Walter de Grunter \& Co.

Popper, Karl. 2006 [1927]. "Zur Philosophie des Heimatgedankens.” In Frühe Schriften, (Gesammelte Werke in deutscher Sprache, Bd. 1.), herausgegeben von Troels E. Hansen, 10-26. Tübingen: Mohr Siebeck.

Prete Antonio, Ed. 1992. Nostalgia. Storia di un sentimento. Milano: Raffaello Cortina Editore.

Rousseau, Jean-Jacques. 1972. "Lettre à Charles-François-Frédéric de Montmorency-Luxembourg, maréchal-duc de Luxembourg," in Correnspondance complète de J. J. Rousseau, ed. by Ralph A. Leigh. Vol. 15, (letter no. 2440). Banbury: Voltaire Foundation.

Starobinski, Jean, and William S. Kemp. 1966. “The Idea of Nostalgia.” Diogenes 14 (54): 81103.

Starobinski, Jean. 2003. “Sur la nostalgie. La mémoire tourmentée." Cliniques méditerrainéenes 67 (1): 191-202.

Tarkovsky, Andrei. 1989. Sculpting in Time: Reflections on the Cinema. English translation K. Hunter-Blair. Texas: University of Texas Press.

Von Clausewitz, Carlvon. 2007 [1832]. On War. English translation B. Heuser. Oxford: Oxford University Press.

Von Humboldt, Wilhelm von. 1848. "Brief an Charlotte vom 21. August 1827." In Briefe von Wilhelm von Humboldt an eine Freundin, Teil 1, Leipzig. 